HENRIQUE TAKASHI ADATI TOMOMITSU

A RELAÇÃO ENTRE AS CAPACIDADES DE TECNOLOGIA DA INFORMAÇÃO E A GESTÃO DO CONHECIMENTO: UMA VISÃO SOB A PERSPECTIVA DA RESOURCE-BASED VIEW 


\title{
A RELAÇÃO ENTRE AS CAPACIDADES DE TECNOLOGIA DA INFORMAÇÃO E A GESTÃO DO CONHECIMENTO: UMA VISÃO SOB
} A PERSPECTIVA DA RESOURCE-BASED VIEW

\author{
Dissertação apresentada à Escola \\ Politécnica da Universidade de São Paulo \\ para obtenção do título de Mestre em \\ Ciências.
}

São Paulo 


\title{
A RELAÇÃO ENTRE AS CAPACIDADES DE TECNOLOGIA DA INFORMAÇÃO E A GESTÃO DO CONHECIMENTO: UMA VISÃO SOB
} A PERSPECTIVA DA RESOURCE-BASED VIEW

\author{
Dissertação apresentada à Escola \\ Politécnica da Universidade de São Paulo \\ para obtenção do título de Mestre em \\ Ciências. \\ Área de Concentração: Engenharia de \\ Produção \\ Orientador: Prof. Dr. Renato de Oliveira \\ Moraes
}

São Paulo 
Catalogação-na-publicação

Tomomitsu, Henrique Takashi Adati

A relação das capacidades de tecnologia da informação e a gestão do conhecimento: uma visão sob a perspectiva da resource-based view / H. T. A. Tomomitsu -- São Paulo, 2017.

$190 \mathrm{p}$.

Dissertação (Mestrado) - Escola Politécnica da Universidade de São Paulo. Departamento de Engenharia de Produção.

1.TECNOLOGIA DA INFORMAÇÃO 2.GESTÃO DO CONHECIMENTO 3.ESTRATÉGIA ORGANIZACIONAL 4.MODELAGEM DE EQUAÇÕES ESTRUTURAIS I.Universidade de São Paulo. Escola Politécnica. Departamento de Engenharia de Produção ll.t. 
À minha família por todo o apoio durante minha trajetória. 


\section{AGRADECIMENTOS}

Primeiramente agradeço meus pais por todo apoio e orientação ao longo da minha trajetória acadêmica e profissional, sem dúvida ambos são a referência que busco me espelhar.

Agradeço meu orientador, Professor Doutor Renato de Oliveira Moraes, por ter me concedido essa oportunidade e por todo o apoio na construção deste trabalho. Sua dedicação durante o desenvolvimento deste trabalho foi fundamental para que os resultados fossem alcançados.

Ao Professor Doutor Fernando Laurindo por todas suas críticas construtivas para que eu pudesse me desenvolver cada vez mais ao logo do curso.

Aos professores do Departamento de Engenharia de Produção, principalmente aqueles com os quais tive a oportunidade de cursar suas disciplinas, e consequentemente me proporcionaram muitas horas de estudo e aprendizado, que certamente aplicarei no meu dia a dia.

A todos funcionários do Departamento de Engenharia de Produção que sempre que necessário deram todo o apoio que precisei durante o curso.

Aos meus colegas de trabalho, em especial ao meu ex-gestor Armando Ghetti e excoordenadora Thais Cristina, que permitiram que eu pudesse conciliar meu lado acadêmico com meu lado profissional. E aos meus pares Victor Araújo e Marlos Melo por todo o apoio e conselhos, além de darem sequencia as minhas atividades na minha ausência em alguns períodos em que estive em aulas ou eventos.

Aos professores Cláudio Oliveira e Jorge Muniz Junior por todo o apoio e orientação durante a etapa de qualificação para que o trabalho fosse entregue com a melhor qualidade possível. Todos as sugestões feitas foram discutidas e levadas em consideração para incrementar o estudo desenvolvido. 
A menos que modifiquemos a nossa maneira de pensar, não seremos capazes de resolver os problemas causados pela forma como nos acostumamos a ver o mundo. Albert Einstein 


\section{RESUMO}

No contexto da resource-based view, que é uma das principais abordagens estratégicas associada com os fatores internos de uma organização, a tecnologia da informação aparece como um recurso que pode ter impactos positivos sobre a performance de uma organização. Diante de algumas tipologias identificadas na literatura, alguns autores dividem os recursos de tecnologia da informação em três grupos: recursos tangíveis de $\mathrm{TI}$, recursos humanos de $\mathrm{Tl}$ e recursos intangíveis habilitados pela TI. Nesse último grupo é destacado que o conhecimento pode ser viabilizado por meio da $\mathrm{Tl}$, e deve ser considerado um ativo que a empresa poderia usufruir por meio da TI para se diferenciar de seus concorrentes. Dessa forma podese afirmar que existe uma influência das capacidades de $\mathrm{TI}$ (infraestrutura de $\mathrm{TI}$, operação de $\mathrm{TI}$ e recursos humanos de $\mathrm{TI}$ ) sobre a de gestão do conhecimento, uma vez que elas podem viabilizar uma melhor eficiência sobre os processos de gestão do conhecimento. $O$ objetivo deste trabalho é analisar a relação das capacidades de tecnologia da informação sobre a gestão do conhecimento, levando em consideração os seguintes fatores: o impacto estratégico da TI no presente e no futuro, e o estilo de gestão de conhecimento voltado pra o conhecimento explícito, com o intuito de verificar se esses fatores afetam a intensidade da relação principal foco do estudo. Para alcançar os objetivos propostos foi realizada uma pesquisa seguindo uma abordagem quantitativa, por meio de um levantamento survey. Foram identificadas evidências empíricas de que a capacidade de TI tem um impacto positivo sobre a gestão do conhecimento conforme já destacado na literatura, além desse resultado foi constatado que os fatores moderadores influenciam positivamente essa relação. As grandes contribuições para a teoria foram o incremento de mais três novos processos compondo as dimensões da gestão do conhecimento, e a inclusão dos efeitos moderadores (o estilo de gestão do conhecimento voltado para o conhecimento explícito, o impacto estratégico da TI no presente e no futuro) no modelo de pesquisa proposto.

Palavras-chaves: Tecnologia da Informação; Gestão do Conhecimento; Visão Baseada em Recursos. 


\begin{abstract}
In the context of resource-based view, which is one of the key strategic approaches associated with an organization's internal factors, information technology appears as a resource that can have positive impacts on an organization's performance. Faced with some typologies identified in the literature, some authors divide information technology resources into three groups: tangible IT resources, IT human resources, and IT-enabled intangible resources. In the latter group it is highlighted that knowledge can be made via IT and should be considered an asset that the company could use through IT to differentiate itself from its competitors. In this way, it can be said that there is an influence of IT capacities (IT infrastructure, IT operation and IT human resources) over knowledge management, since they can enable a better efficiency in the management processes of the knowledge. The objective of this work is to analyze the relationship of information technology capacities on knowledge management, taking into account the following factors: the strategic impact of IT in the present and in the future, and the style of knowledge management aimed at explicit knowledge, in order to verify if these factors affect the intensity of the relationship main focus of the study. In order to reach the proposed objectives, a research was carried out following a quantitative approach, through a survey survey. Empirical evidence has been found that IT capacity has a positive impact on knowledge management as already highlighted in the literature, besides this result it was found that the moderating factors positively influence this relationship. The major contributions to the theory were the increase of three new processes composing the dimensions of knowledge management, and the inclusion of the moderating effects (the style of knowledge management focused on explicit knowledge, the strategic impact of IT in the present and in the future) in the proposed research model.
\end{abstract}

Keywords: Information Technology; Knowledge Management; Resource-Based View. 


\section{LISTA DE FIGURAS}

Figura 1 - Forças mercadológicas para geração de valor .......................................36

Figura 2 - Recursos, capacidades e competências .................................................

Figura 3 - Grid do impacto estratégico de $\mathrm{TI}$..................................................42

Figura 4 - Principais palavras-chaves envolvidas com a TI e RBV..........................56

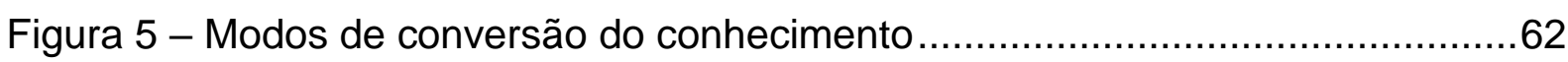

Figura 6 - Estilos de métodos de gestão do conhecimento .....................................65

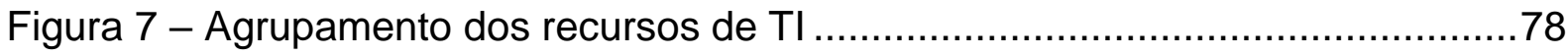

Figura 8 - Modelo de Pérez-López e Alegre (2012) ............................................

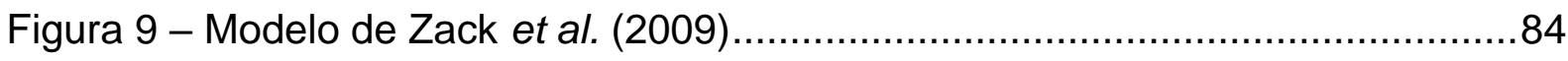

Figura 10 - Framework conceitual de Meso e Smith (2000) ..................................86

Figura 11 - Framework conceitual de Alavi e Leidner (2001) ................................ 86

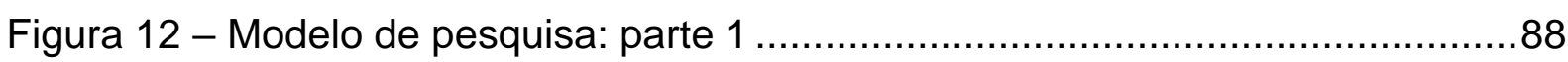

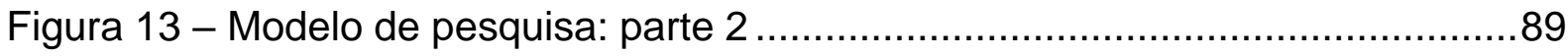

Figura 14 - Estrutura Lógica da Abordagem Quantitativa.....................................93

Figura 15 - Etapas de execução de uma pesquisa do tipo survey ............................95

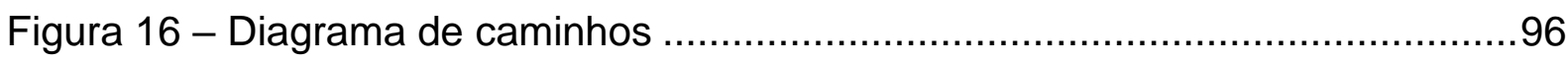

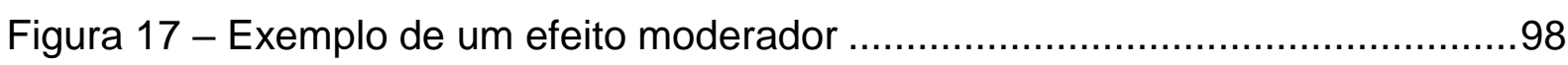

Figura 18 - Interação com efeito moderador...................................................... 99

Figura 19 - Relações reflexivas entre uma HOC e as LOCs .................................100

Figura 20 - Relações formativas entre uma HOC e as LOCs ...............................100

Figura 21 - Modelo de pesquisa: diagrama de caminhos ...................................109

Figura 22 - Cálculo do tamanho da amostra no software G*Power.......................111

Figura 23 - Modelo (A): Diagrama de Caminhos ……….................................124

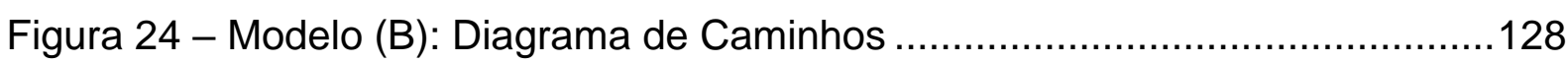

Figura 25 - Modelo (C): Diagrama de Caminhos …….......................................135

Figura 26 - Modelo (D): Diagrama de Caminhos …….....................................141

Figura 27 - Modelo (E): Diagrama de Caminhos ……......................................147 


\section{LISTA DE GRÁFICOS}

Gráfico 1 - Publicações sobre o tema ao longo dos últimos 20 anos .......................53

Gráfico 2 - Distribuição das publicações por autores ..........................................54

Gráfico 3 - Distribuição das publicações por países .............................................54

Gráfico 4 - Distribuição das publicações por periódico e fator de impacto ................55

Gráfico 5 - Distribuição de genêro dos respondentes...........................................119 


\section{LISTA DE QUADROS}

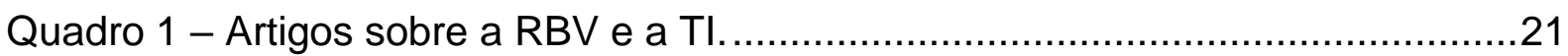

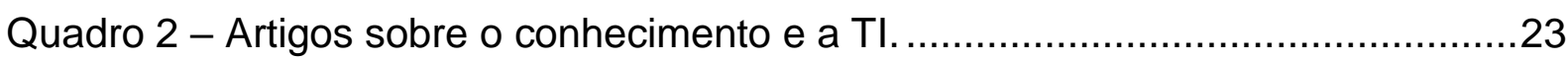

Quadro 3 - Abordagens da gestão estratégica ................................................28

Quadro 4 - Conceitualização da resource-based view …………….......................30

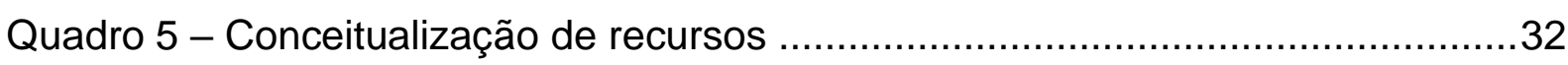

Quadro 6 - Escala de benefícios de Farbey et al. (1995) ......................................4 44

Quadro 7 - Variáveis referentes à dimensão infraestrutura de TI............................50

Quadro 8 - Variáveis referentes à dimensão RH de TI .......................................51

Quadro 9 - Variáveis referentes à dimensão operação de TI .................................51

Quadro 10 - Definições dos conceitos: Dados, Informação e Conhecimento............58

Quadro 11 - Conhecimento Explícito e Conhecimento Tácito ………………..........59

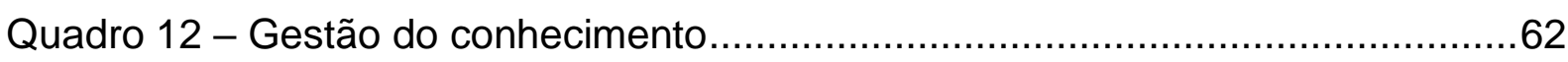

Quadro 13 - Perspectivas da Gestão do Conhecimento .......................................64

Quadro 14 - Variáveis referentes à criação do conhecimento ..................................69

Quadro 15 - Variáveis referentes à aquisição do conhecimento ............................70

Quadro 16 - Variáveis referentes ao armazenamento do conhecimento ...................71

Quadro 17 - Variáveis referentes ao compartilhamento do conhecimento ................71

Quadro 18 - Variáveis referentes à aplicação do conhecimento ............................72

Quadro 19 - Variáveis referentes à proteção do conhecimento...............................72

Quadro 20 - Recursos de TI e os processos de GC afetados ...............................75

Quadro 21 - Indicadores da dimensão: Infraestrutura de TI ................................... 80

Quadro 22 - Indicadores da dimensão: Conhecimento da TI ...............................80

Quadro 23 - Indicadores da dimensão: Operação da TI....................................... 81

Quadro 24 - Indicadores da dimensão: Aquisição do conhecimento ........................82

Quadro 25 - Indicadores da dimensão: Compartilhamento do conhecimento ..........82

Quadro 26 - Indicadores da dimensão: Aplicação do conhecimento ........................83

Quadro 27 - Grau de confiabilidade composta calculada .....................................83

Quadro 28 - Literaturas de referência para cada hipótese ...................................91

Quadro 29 - Medições para o construto Capacidade de Tecnologia da Informação.

Quadro 30 - Medições para o construto Capacidade de Gestão do conhecimento (Parte 1) 
Quadro 31 - Medições para o construto Capacidade de Gestão do conhecimento (Parte 2) ......

Quadro 32 - Estrutura do questionário ……………..................................112

Quadro 33 - Códigos para as variáveis latentes ..............................................122 


\section{LISTA DE TABELAS}

Tabela 1 - Publicações com mais citações na amostra (continua) ...........................56

Tabela 2 - Publicações com mais citações na amostra (conclusão) ........................57

Tabela 3 - Resultado matriz de rotação das variáveis ........................................108

Tabela 4 - Base de dados para coleta dos dados ………................................118

Tabela 5 - Base de dados para coleta dos dados ...............................................118

Tabela 6 - Tempo de casa dos respondentes (continua) ....................................119

Tabela 7 - Nível hierárquico dos respondentes ................................................120

Tabela 8 - Área de atuação dos respondentes ...................................................121

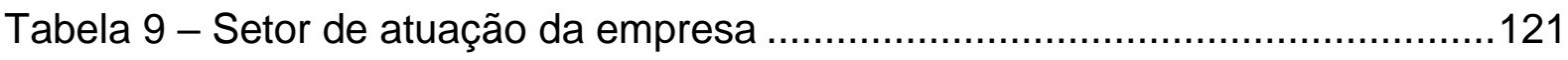

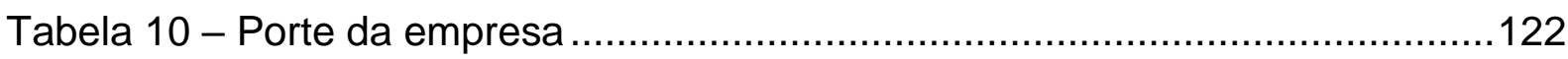

Tabela 11 - Modelo (A): Métricas do modelo de mensuração ...............................124

Tabela 12 - Modelo (A): Cargas externas associadas a TI..................................125

Tabela 13 - Modelo (A): Cargas externas associadas a GC ...............................126

Tabela 14 - Modelo (A): Critério de Fornell-Lacker variáveis de 1 ordem ..............127

Tabela 15 - Modelo (A): Critério de Fornell-Lacker variáveis de 2 ordem ..............127

Tabela 16 - Modelo (B): Métricas do modelo de mensuração ...............................129

Tabela 17 - Modelo (B): Cargas externas associadas a TI...................................129

Tabela 18 - Modelo (B): Cargas externas associadas a GC ….........................130

Tabela 19 - Modelo (B): Critério de Fornell-Lacker variáveis de 1 ordem ..............131

Tabela 20 - Modelo (B): Critério de Fornell-Lacker variáveis de 2 ordem ..............131

Tabela 21 - Modelo (B): Coeficientes de caminho ............................................132

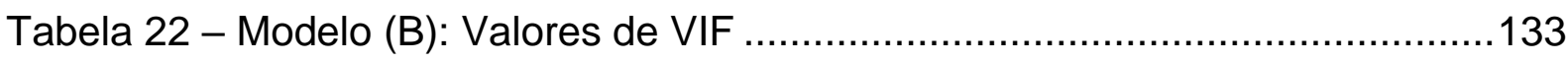

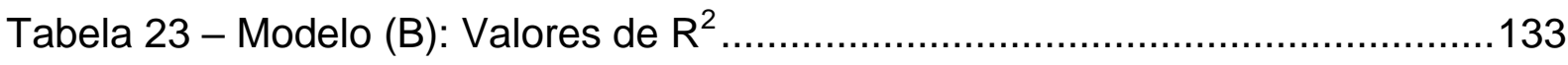

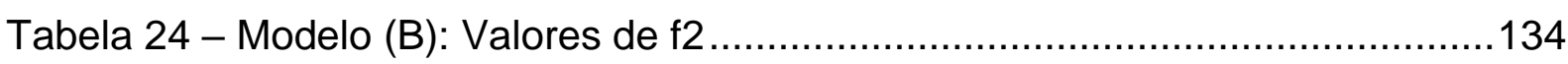

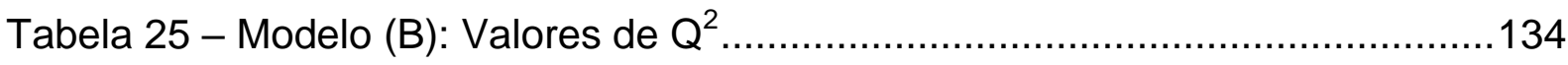

Tabela 26 - Modelo (C): Métricas do modelo de mensuração ………………........136

Tabela 27 - Modelo (C): Cargas externas associadas a $\mathrm{TI}$.................................136

Tabela 28 - Modelo (C): Cargas externas associadas a GC …..........................137

Tabela 29 - Modelo (C): Critério de Fornell-Lacker variáveis de 1 ordem ..............137

Tabela 30 - Modelo (C): Critério de Fornell-Lacker variáveis de 2 ordem ..............138

Tabela 31 - Modelo (C): Coeficientes de caminho..............................................138

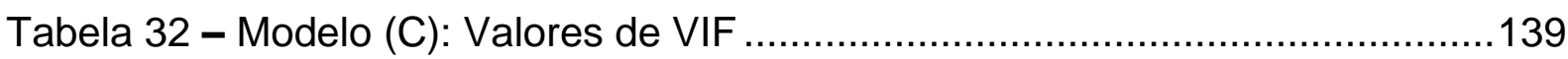


Tabela 33 - Modelo (C): Valores de $\mathrm{R}^{2}$ 139

Tabela 34 - Modelo (C): Valores de $\mathrm{f}^{2}$ 140

Tabela 35 - Modelo (C): Valores de $\mathrm{Q}^{2}$ 140

Tabela 36 - Modelo (D): Métricas do modelo de mensuração 142

Tabela 37 - Modelo (D): Cargas externas associadas a TI 142

Tabela 38 - Modelo (D): Cargas externas associadas a GC 143

Tabela 39 - Modelo (D): Critério de Fornell-Lacker variáveis de 1 ordem 144

Tabela 40 - Modelo (D): Critério de Fornell-Lacker variáveis de 2 ordem 144

Tabela 41 - Modelo (D): Coeficientes de caminho 145

Tabela 42 - Modelo (D): Valores de VIF 145

Tabela 43 - Modelo (D): Valores de $\mathrm{R}^{2}$ 146

Tabela 44 - Modelo (D): Valores de $\mathrm{f}^{2}$ 146

Tabela 45 - Modelo (D): Valores de $\mathrm{Q}^{2}$. 147

Tabela 46 - Modelo (E): Métricas do modelo de mensuração 148

Tabela 47 - Modelo (E): Cargas externas associadas a TI 148

Tabela 48 - Modelo (E): Cargas externas associadas a GC 149

Tabela 49 - Modelo (E): Critério de Fornell-Lacker variáveis de 1 ordem 150

Tabela 50 - Modelo (E): Critério de Fornell-Lacker variáveis de 2 ordem 150

Tabela 51 - Modelo (E): Coeficientes de caminho 151

Tabela 52 - Modelo (E): Valores de VIF 151

Tabela 53 - Modelo (E): Valores de $\mathrm{R}^{2}$ 152

Tabela 54 - Modelo (E): Valores de $\mathrm{f}^{2}$ 152

Tabela 55 - Modelo (E): Valores de $Q^{2}$. 153

Tabela 56 - Validação das hipóteses propostas 154 


\section{LISTA DE ABREVIATURAS}

$\begin{array}{ll}\text { AVE } & \text { Average variance extracted } \\ \text { CFA } & \text { Confirmatory Factorial Analysis } \\ \text { GC } & \text { Gestão do conhecimento } \\ \text { GTI } & \text { Gestão da tecnologia da informação } \\ \text { PLS } & \text { Partial least square } \\ \text { RBV } & \text { Resource-based view } \\ \text { SCP } & \text { Structural-Conduct-Performance } \\ \text { SEM } & \text { Structural equation modeling } \\ \text { SIG } & \text { Sistemas de informações gerenciais } \\ \text { SAD } & \text { Sistemas de apoio à decisão } \\ \text { TI } & \text { Tecnologia da informação } \\ \text { USP } & \text { Universidade de São Paulo }\end{array}$




\section{SUMÁRIO}

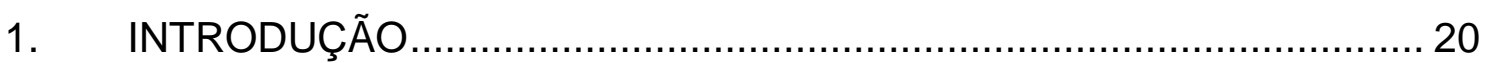

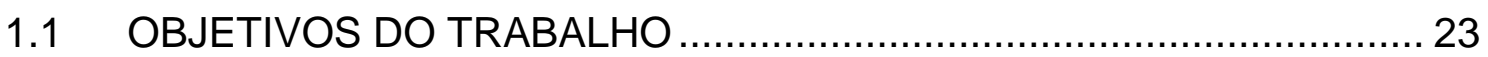

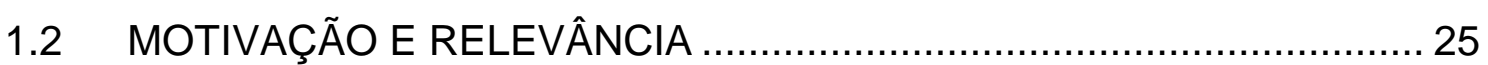

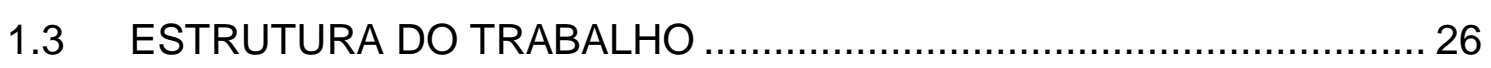

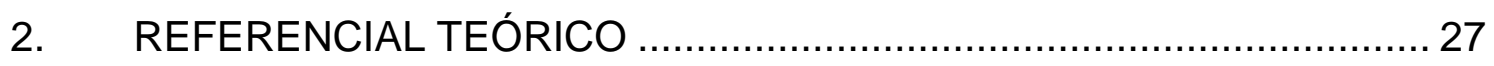

2.1 ESTRATÉGIA E RESOURCE-BASED VIEW THEORY ........................ 27

2.2 A TECNOLOGIA DA INFORMAÇÃO .................................................. 40

2.3 A CAPACIDADE DE TECNOLOGIA DA INFORMAÇÃO........................ 45

2.4 PANORAMA ATUAL DA RBV NO CAMPO DA TI .............................. 52

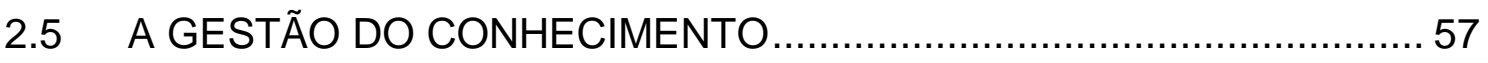

2.6 AS CAPACIDADES DE TI E A GESTÃO DO CONHECIMENTO ........... 74

2.7 MODELOS E FRAMEWORKS ENCONTRADOS NA LITERATURA .... 79

2.7.1 MODELO DE PÉREZ-LÓPEZ E ALEGRE (2012) …............................ 79

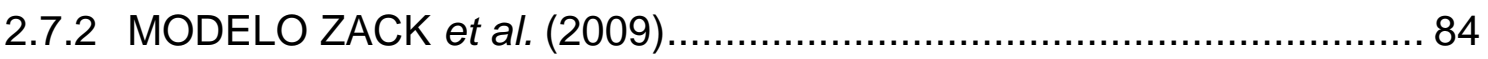

2.7.3 FRAMEWORK CONCEITUAL DE MESO E SMITH (2000).................. 85

2.7.4 FRAMEWORK CONCEITUAL DE ALAVI E LEIDNER (2001) ............... 86

2.8 CONSIDERAÇÕES SOBRE O REFERENCIAL TEÓRICO DE PESQUISA 87

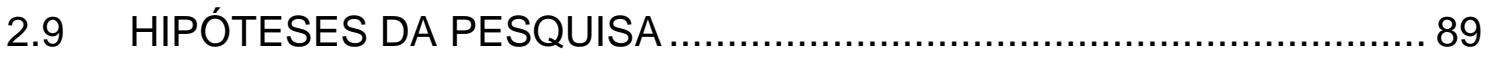

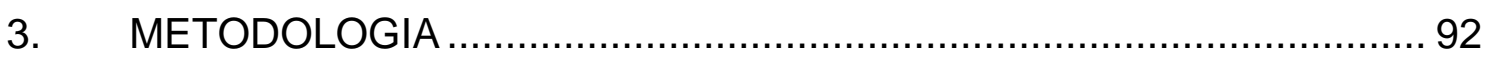

3.1 ABORDAGEM DA PESQUISA E MÉTODOS DE PESQUISA............... 92

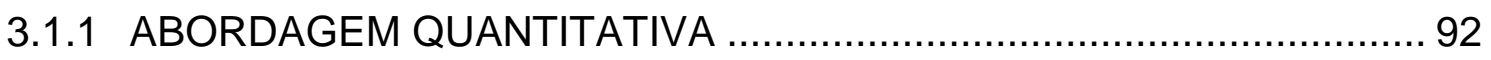

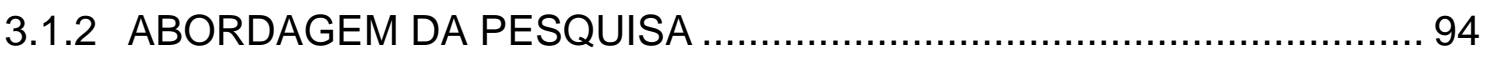

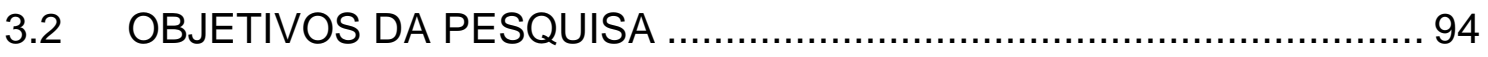

3.3 PROCEDIMENTOS DA PESQUISA QUANTITATIVA: SURVEY .......... 94

3.3.1 MODELAGEM DE EQUAÇÕES ESTRUTURAIS .................................. 95 
3.3.2 MODELO DE PESQUISA 101

3.3.3 UNIDADES DE ANÁLISE E AMOSTRAGEM .................................... 110

3.3.4 INSTRUMENTO DE PESQUISA E COLETA DE DADOS ................... 112

3.3.5 PROCEDIMENTO DE ANÁLISE DO MODELO DE PESQUISA ..........112

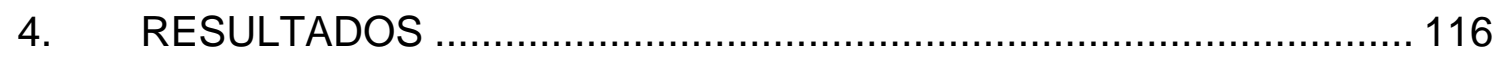

4.1 PROCESSO DE COLETA E CARACTERÍSTICAS DA AMOSTRA..... 117

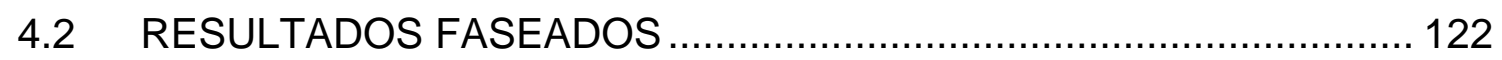

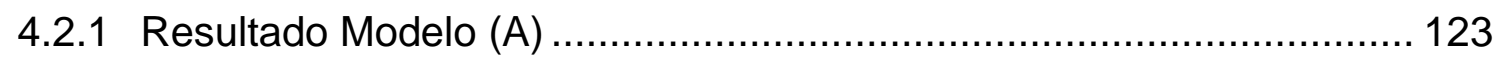

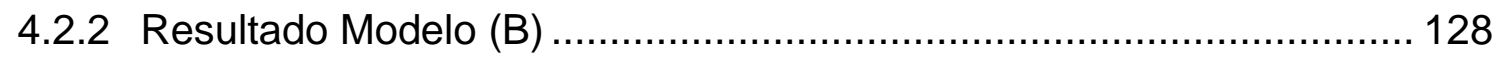

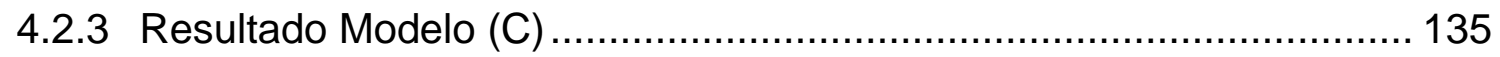

4.2.4 Resultado Modelo (D) .............................................................. 141

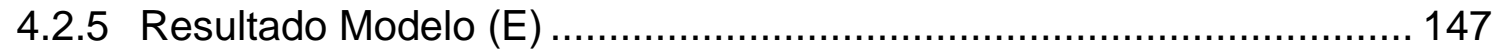

4.3 CONCLUSÃO DAS AVALIAÇÕES REALIZADAS …........................... 153

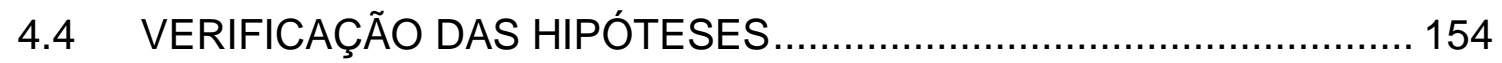

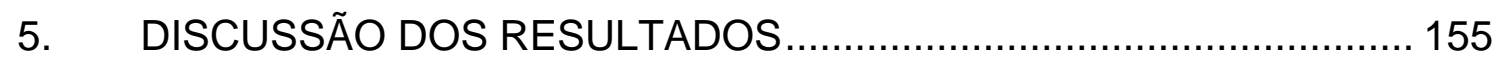

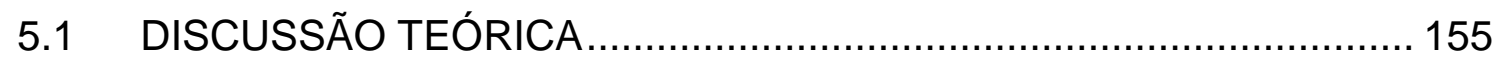

5.2 CONTRIBUIÇÃO PARA A TEORIA ………….................................. 161

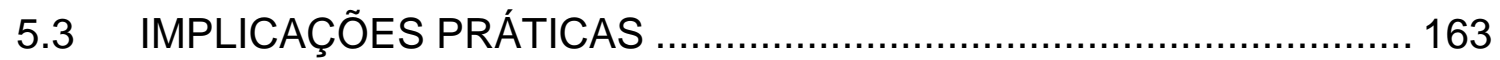

5.4 LIMITAÇÕES E OPORTUNIDADES PARA ESTUDOS FUTUROS .... 165

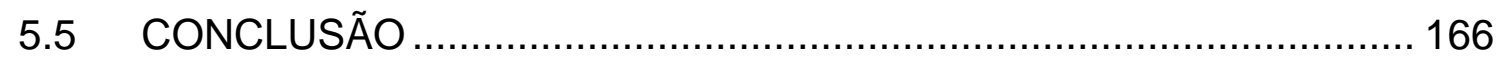

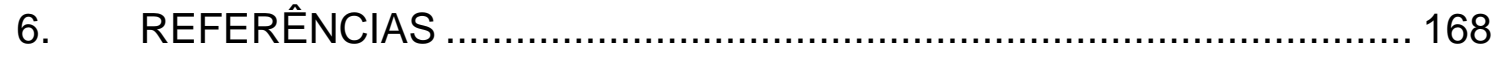

APÊNDICE 1 - CARTA-CONVITE DA COLETA DE DADOS PRELIMINAR . 176 APÊNDICE 2 - QUESTIONÁRIO PRELIMINAR ........................................... 177

APÊNDICE 3 - CARTA-CONVITE PARA COLETA DE DADOS …................ 180

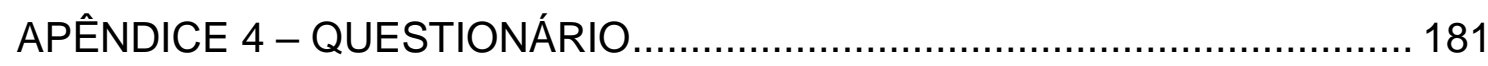

APÊNDICE 5 - CARGAS CRUZADAS MODELO A ..................................... 186

APÊNDICE 6 - CARGAS CRUZADAS MODELO B .................................. 187 
APÊNDICE 7 - CARGAS CRUZADAS MODELO C …................................... 188

APÊNDICE 8 - CARGAS CRUZADAS MODELO D .................................... 189

APÊNDICE 9 - CARGAS CRUZADAS MODELO E ................................... 190 


\section{INTRODUÇÃO}

As decisões estratégicas adotadas pelas organizações devem considerar, prioritariamente, a possibilidade de geração da vantagem competitiva para que a empresa consiga se diferenciar dos seus concorrentes (ANSOFF e McDONNELL, 1984).

Existem diversas escolas relacionadas com a gestão estratégica - design, planejamento, posicionamento, empreendedora, cognitiva, aprendizado, poder, cultural, ambiental e configuração (MINTZBERG et al., 2010) - sobre a perspectiva de se obter uma vantagem competitiva sustentável.

Uma abordagem que se enquadra na escola cultural - na qual a formulação da estratégia é vista como um processo coletivo, ou seja, a formulação estratégica é vista como um processo enraizado na força social da cultura -, que têm ganhado uma importância cada vez maior nas últimas décadas é a resource-based theory of competitive advantage.

Essa abordagem é frequentemente chamada de resource-based view (RBV) e mantêm um olhar para os fatores internos às organizações, diferentemente de outras abordagens que analisam os fatores externos às organização.

A seguir são apresentados a visão geral das três principais abordagens voltadas para analisar os fatores internos à organização.

- Resource-based view: a organização é vista como um feixe de recursos e capacidades, que são heterogeneamente distribuídos pelas organizações. A gestão eficiente desses recursos e capacidades são considerados fundamentais para proporcionar um maior valor ao negócio. Isso consequentemente pode contribuir para que a organização alcance uma vantagem competitiva sustentável. (GRANT, 1996; EISENHARDT e MARTIN, 2000; FURRER et al., 2008)

- Knowledge-based view: além de se preocupar com as questões tradicionais da gestão estratégica, se preocupa também com questões que envolvem a teoria das organizações e a teoria da inovação. Essa abordagem considera o conhecimento como um input crítico e uma fonte primária de valor, principalmente no que diz respeito da sua aplicação para a produção de bens e de serviços. (GRANT, 1996; SPENDER, 1996) 
- Dynamics Capabilities: mantém o foco sobre as fontes e os métodos de criação e captura de valor por organizações que operam em ambientes de rápidas mudanças tecnológicas. As capacidades dinâmicas são caracterizadas pela forma com que as organizações integram, constroem e reconfiguram suas competências internas e externas para se adaptar às mudanças do ambiente. (STUART e PODOLONY, 1996; TEECE, et al., 1997; EISENHARDT e MARTIN, 2000)

Furrer et al. (2008) entendem que a RBV é uma abordagem estratégica sobre o uso dos recursos para se atingir a vantagem competitiva, ou seja, mantém o foco sobre a relação entre os recursos e a performance das empresas. Nesse contexto a estratégia pode ser definida segundo Grant (1991) como a combinação entre recursos e habilidades internas e as oportunidades e riscos criados pelo ambiente externo.

A RBV aparece com frequência na literatura fazendo um par importante com a Tecnologia da Informação ( $\mathrm{TI}$ ), e alguns estudos apresentam uma perspectiva de que os recursos de $\mathrm{TI}$ podem ter um papel importante para as organizações, uma vez que podem impactar positivamente o desempenho das mesmas, permitindo que elas consigam alcançar um diferencial competitivo. Stoel e Muhanna (2009) destacam que o entendimento da associação entre a $\mathrm{Tl}$ e o desempenho da organização tornou-se um assunto de interesse considerável entre pesquisadores. $O$ Quadro 1 apresenta um conjunto de estudos identificados na literatura que abordam a TI com a RBV e no qual pode-se notar que o tema ainda é foco de estudo nos últimos anos.

Quadro 1 - Artigos sobre a RBV e a TI.

\begin{tabular}{|l|l|}
\hline \multicolumn{1}{|c|}{ Autores } & \multicolumn{1}{c|}{ Título Artigo } \\
\hline Mata et al. (1995) & $\begin{array}{l}\text { Information technology and sustained competitive advantage: a } \\
\text { resource-based analysis }\end{array}$ \\
\hline Bharadwaj (2000) & $\begin{array}{l}\text { A Resource-Based Perspective on Information Technology Capability } \\
\text { and Firm Performance: An Empirical Investigation. }\end{array}$ \\
\hline Wade e Hulland (2011) & $\begin{array}{l}\text { Review: the resource-based view and information systems research: } \\
\text { review, extension, and suggestions for future research }\end{array}$ \\
\hline
\end{tabular}




\begin{tabular}{|l|l|}
\hline Mithas et al. (2011) & How information management capability influences firm performance \\
\hline Seddon (2015) & $\begin{array}{l}\text { Implications for strategic IS research of the resource-based theory of } \\
\text { the firm: A reflection }\end{array}$ \\
\hline Wu et al. (2015) & $\begin{array}{l}\text { How information technology governance mechanisms and strategic } \\
\text { alignment influence organizational performance: insights from a } \\
\text { matched survey business and IT managers }\end{array}$ \\
\hline Wu e Chiu (2015) & $\begin{array}{l}\text { Organizational applications of IT innovation and firm's competitive } \\
\text { performance: } \text { A resource-based view and the innovation diffusion } \\
\text { approach }\end{array}$ \\
\hline
\end{tabular}

Fonte: Elaborado pelo autor.

Segundo Porter e Millar (1985) a intensidade do valor estratégico da tecnologia da informação para as organizações varia de acordo com a sua implicação sobre os produtos e serviços ofertados pela empresa, e com a dependência dos processos de negócio e dos processos de apoio em relação ao uso de tecnologias da informação.

Mithas et al. (2011) realizaram um estudo com o objetivo de entender como a capacidade de gestão da informação por meio de recursos de TI impacta as capacidades organizacionais que estão relacionadas com os resultados em diferentes contextos obtidos por uma organização. Dessa forma os recursos de $\mathrm{TI}$ podem ser vistos como um fator importante para que a empresa possa ter um desempenho superior aos seus concorrentes, sendo que a importância estratégica de TI pode variar de uma empresa para outra segundo Laurindo (2008).

A RBV em conjunto com a Tl também está associada com a outro recurso primordial para qualquer organização: o conhecimento. Halawi et al. (2006) destacam que o conhecimento pode ser considerado um ativo estratégico valioso para as organizações em termos de competitividade.

A aliança da gestão do conhecimento e da TI pode gerar impactos positivos no desempenho de uma organização, sendo um aspecto estratégico para as organizações, e é foco de diversos pesquisadores, como Alavi e Leidner (2001), os quais apresentam um estudo destacando o papel da TI na gestão do conhecimento, que passa a ser considerada uma capacidade importante para as organizações. Além disso, Cepeda e Veera (2007) destacam que os processos de gestão de 
conhecimento podem estar associados com a capacidade dinâmica da organização aprimorar ou desenvolver novas capacidades por meio desse processo. O Quadro 2 apresenta alguns estudos identificados na literatura que abordam a TI em conjunto com o conhecimento.

Quadro 2 - Artigos sobre o conhecimento e a TI.

\begin{tabular}{|l|l|}
\hline \multicolumn{1}{|c|}{ Autores } & \multicolumn{1}{c|}{ Título Artigo } \\
\hline Alavi e Leidner (2001) & $\begin{array}{l}\text { Review: knowledge management and knowledge management } \\
\text { systems: conceptual foundations and research issues }\end{array}$ \\
\hline Mohamed et al. (2006) & $\begin{array}{l}\text { Knowledge management and information technology: can they } \\
\text { work in perfect harmony? }\end{array}$ \\
\hline Wild e Griggs (2008) & $\begin{array}{l}\text { A model of information technology opportunities for facilitating the } \\
\text { practice of knowledge management }\end{array}$ \\
\hline Peréz-López e Alegre (2012) & $\begin{array}{l}\text { Information technology competency, knowledge processes and } \\
\text { firm performance }\end{array}$ \\
\hline Wagner et al. (2014) & $\begin{array}{l}\text { The impact of information technology on knowledge creation: an } \\
\text { affordance approach to social media }\end{array}$ \\
\hline
\end{tabular}

Fonte: Elaborado pelo autor.

\subsection{OBJETIVOS DO TRABALHO}

O estudo tem como objetivo geral é analisar a relação das capacidades de TI sobre a gestão do conhecimento. Para tanto o estudo levou em consideração alguns fatores moderadores: o grau de importância da TI no presente e no futuro, com base nos indicadores identificados em um estudo preliminar realizado que partiu dos questionamentos apresentados no grid de impacto estratégico da TI de Nolan e McFarlan (2005), e o estilo de gestão de conhecimento voltado para o conhecimento explícito baseado no estudo dos autores Choi e Lee (2003), Stankosky (2005) e Wild e Griggs (2008).

O estudo realizado por Nolan e McFarlan (2005) é referência na literatura no que diz respeito ao impacto estratégico da tecnologia da informação para uma organização, demonstrando o papel da $\mathrm{Tl}$ e sua importância para a organização. Os autores apresentam um grid de impacto estratégico da Tl composto por quatro quadrantes, que permite identificar o tipo de abordagem estratégica em relação a $\mathrm{Tl}$ adotada por uma organização. Existem dois tipos de abordagens: defensiva - quadrantes: 
Fábrica e Suporte - ou ofensiva - Transição e Estratégico. Esse grid possui dois eixos, um que representa o impacto estratégico da $\mathrm{TI}$ no presente, e um segundo que representa o impacto estratégico da TI no futuro.

Wild e Griggs (2008) destacam que a gestão do conhecimento está associada com sistemas e ferramentas de $\mathrm{TI}$ que apoiam esse processo em relação ao armazenamento e uso do conhecimetno pela organização. No modelo apresentado por Choi e Lee (2003) é descado que quando uma empresa possui um estilo de gestão do conhecimento orientado para o conhecimento explícito, a TI tem um papel fundamental, visto que esse tipo de conhecimento é mais fácil de ser codificado, armazenado e compartilhado. Os autores apresentam um modelo no qual é possível classificar as empresas com base na intensidade da orientação delas em relação ao estilo de gestão voltado para o conhecimento tácito e/ou explícito, o que permite identificar o estilo de gestão do conhecimento adotado pela organização, o qual pode ser: passivo, orientação sistêmica, orientação humana e dinâmica.

Corroborando para a visão dos autores Wild e Griggs (2008) e Choi e Lee (2003), Stankosky (2005) destacam a tecnologia da informação como um pilar que sustenta a gestão do conhecimento, visto que essa apoia a codificação do conhecimento explícito e seu compatilhamento.

Os objetivos específicos do estudo estão voltados para o efeito de fatores moderadores sobre a relação principal do estudo:

1. Analisar o efeito do impacto estratégico da TI no presente e no futuro, baseado no grid estratégico de Nolan e McFarlan (2005), na relação das capacidades de tecnologia da informação sobre a gestão do conhecimento;

2. Analisar o efeito do estilo do método de gestão do conhecimento voltado para o conhecimento explícito baseado nos estudos Choi e Lee (2003), Stankosky (2005) e Wild e Griggs (2008) na relação das capacidades de gestão do conhecimento sobre a capacidade de tecnologia da informação.

Para atender os objetivos de pesquisa propostos foi realizada uma pesquisa baseada em uma abordagem quantitativa, aplicada por meio do método de pesquisa do tipo survey. 


\subsection{MOTIVAÇÃO E RELEVÂNCIA}

$\mathrm{Na}$ literatura, a abordagem resource-based view aparece em conjunto com a $\mathrm{Tl}$, com o intuito de entender os impactos dessa relação sobre a performance de uma organização. Um dos estudos de referência nesse contexto foi o estudo de Bharadwaj (2000) que buscou examinar a relação da capacidade de TI com o desempenho das organizações. Nesse estudo a autora cria uma tipologia em relação aos recursos de $\mathrm{TI}$, dividindo-os em recursos tangíveis de $\mathrm{Tl}$, recursos humanos de TI e recursos intangíveis habilitados pela TI.

No contexto dos recursos intangíveis habilitados pela $\mathrm{TI}$, surge o conhecimento como um ativo que a empresa pode usufruir por meio da TI. Dessa forma pode-se afirmar que existe um impacto das capacidades de $\mathrm{TI}$ - viabiliza uma melhor eficiência sobre os processos de gestão do conhecimento -, no contexto da resource-based view, sobre a de gestão do conhecimento. Isso possibilitou a criação de uma visão mais robusta, a perspectiva da organização baseada no conhecimento, que também está relacionada com a literatura sobre a gestão estratégica nas organizações. (NONAKA e TAKEUCHI, 1995; ALAVI e LEIDNER, 2001)

"A abordagem baseada no conhecimento postula que serviços compostos de recursos tangíveis dependem de como estes são combinados e aplicados, o que, por sua vez, é dependente do conhecimento da organização. Como os recursos baseados no conhecimento são usualmente difíceis de serem imitados e socialmente complexos, eles podem proporcionar uma vantagem competitiva a longo prazo." (ALAVI e LEIDNER, 2001).

Diante desse cenário, no qual os recursos baseados no conhecimento podem proporcionar vantagens competitivas para as organizações, e que a tecnologia da informação é um elemento que pode contribuir para a gestão desses recursos, é interessante complementar a literatura abordando de que forma as capacidades de TI afetam a gestão do conhecimento de acordo com o impacto estratégico da TI no presente e no futuro, baseado em conceitos apresentados no grid estratégico de Nolan e McFarlan (2005), e com o estilo de gestão do conhecimento voltado para o conhecimento explícito, que é apresentado nos estudos de Choi e Lee (2003), Stankosky (2005) e Wild e Griggs (2008). 


\subsection{ESTRUTURA DO TRABALHO}

Este trabalho está organizado em 5 capítulos.

No capítulo 1é apresentado o contexto, o problema, os objetivos e a estrutura da pesquisa realizada.

O capítulo 2 busca apresentar uma revisão sobre todos os construtos envolvidos no estudo. Em um primeiro momento é apresentado um quadro teórico sobre a literatura relacionada com a questão da estratégia e da RBV, com o objetivo de apresentar um contexto sobre a importância dos dois recursos analisados no estudo: a tecnologia da informação e o conhecimento. Em seguida, é apresentado o conceito de $\mathrm{Tl}$ e a taxonomia do construto capacidade de $\mathrm{Tl}$ que deve ser levado em consideração no estudo, visto as diversas taxonomias identificadas na literatura.

Na sequência, é abordada a gestão do conhecimento, com o obejtivo de apresentar as dimensões dos seus processos que serão considerados no estudo. Ambos os construtos, a capacidades de $\mathrm{TI}$ e a gestão do conhecimento, são impressindíveis para o estudo, visto que fazem parte do modelo de pesquisa. Em seguida, é abordada a relação entre esses dois construtos e são discutidos modelos de pesquisas identificados na literatura envolvendo esses construtos. Por fim é apresentada uma breve consideração final sobre o referencial de pesquisa adotado, além das hipóteses de pesquisa.

No capítulo 3 são descritos os procedimentos metodológicos adotados para realizar a pesquisa, desde a escolha da metodologia empregada até os métodos empregados ao longo do estudo.

O capítulo 4 apresenta os resultados após a execução da análise estatística.

Por fim, o capítulo 5 descreve as principais considerações do estudo, limitações e recomendações para estudos futuros, e as contribuições para teoria e para a prática. 


\section{REFERENCIAL TEÓRICO}

Esse capítulo tem como objetivo apresentar os principais construtos que estão vinculados com a proposta de pesquisa. Além disso, o referencial teórico é importante para o norteamento do estudo, principalmente na definição de proposições ou hipóteses da pesquisa. Esse capítulo foi dividido em 9 seções:

1. Estratégia e resource-based view theory;

2. A tecnologia da informação;

3. A capacidade de tecnologia da informação;

4. Panorama da RBV no campo da Tl;

5. A gestão do conhecimento;

6. As capacidades de $\mathrm{Tl}$ e a gestão do conhecimento;

7. Modelos com a associação de capacidades de TI sobre a gestão do conhecimento;

8. Considerações finais do referencial de pesquisa;

9. Hipóteses de pesquisa;

\subsection{ESTRATÉGIA E RESOURCE-BASED VIEW THEORY}

Segundo Vasconcelos e Cyrino (2000) as abordagens sobre a gestão estratégica podem ser classificadas em duas vertentes principais de acordo com o foco que a mesma mantem sobre os aspectos externos ou internos que envolvem as organizações.

O Quadro 3 apresenta a divisão das abordagens sobre a gestão estratégica entre os fatores externos e os fatores internos, e em cada uma é apresentado os modelos para cada abordagem e seus precursores na literatura.

Quando se trata da gestão estratégica relacionada com os fatores externos a literatura destaca a análise estrutural da indústria que traz dois grandes modelos: a organização industrial - modelo Structure-Conduct-Performance (SCP) - e a análise de posicionamento.

Já em relação a gestão estratégica relacionada com fatores internos a literatura destaca a abordagem baseada em recursos que contém as seguintes "correntes": resource-based view, dynamic capabilities e knowledge-based view. 
Quadro 3 - Abordagens da gestão estratégica

\begin{tabular}{|c|c|}
\hline \multicolumn{2}{|c|}{ Gestão Estratégica } \\
\hline $\begin{array}{l}\text { Fatores Externos } \\
\text { Análise estrutural da indústria: } \\
\text { - Organização Industrial: modelo SCP } \\
\text { (Edward Mason e Joe Bain) } \\
\text { - Análise de posicionamento (Michael Porter) }\end{array}$ & $\begin{array}{l}\text { Fatores Internos } \\
\text { Abordagem baseada em recursos: } \\
\text { - Resource-based view (Edith Penrose; } \\
\text { Birger Wernefelt; e Robert Morris Grant) } \\
\text { - Dynamic capabilities (David J. Teece et al.; } \\
\text { Toby E, Stuart e Joel M. Podolny) } \\
\text { - Knowledge-based view (Robert Morris } \\
\text { Grant; Thomas C. Powell e Anne Dent- } \\
\text { Micallef; JC Spenser) }\end{array}$ \\
\hline
\end{tabular}

Fonte: adaptado de Vasconcelos e Cyrino, 2000.

Na visão de Porter (1996) a estratégia pode ser conceituada como sendo a criação de uma posição única e de valor no mercado, que envolve um conjunto diferente de atividades. Ela pode ser dividida em três tipos de estratégias competitivas genéricas, que são: liderança em custo total, diferenciação e enfoque. Vasconcelos e Cyrino (2000) resumem o modelo SCP como um framework que supõe que a performance econômica das organizações é resultado direto de seu comportamento (estratégia) concorrencial em termos de fixação de preços e custos e que esse comportamento depende da estrutura da indústria na qual as firmas estão inseridas.

"A estratégia empresarial é o curso de ação que uma empresa adota para assegurar seus objetivos de desempenho - como sua sobrevivência, o tamanho que pretende alcançar, os concorrentes que deseja enfrentar e a posição que pretende ter no mercado. As estratégias também são chamadas de políticas de negócio" (MAXIMIANO, 2008)

Enquanto isso Grant (1991) define a estratégia como a combinação entre recursos e habilidades internas e as oportunidades e riscos criados pelo ambiente externo, que tem total sinergia com o que é defendido pela resource-based view, a qual é considerada uma abordagem voltada para gestão estratégica com um olhar mais crítico sobre os recursos internos à uma organização.

A resource-based view, segundo Miller e Shamsie, (1996) fornece um útil complemento à conhecida perspectiva estrutural de estratégia desenvolvida por Michael Porter, uma vez que essa perspectiva desloca a ênfase do ambiente 
competitivo empresarial para os recursos que as empresas formaram visando a concorrer umas com as outras naquele mesmo ambiente.

Essa será a abordagem base para essa pesquisa. A resource-based view theory, apresenta ser uma abordagem utilizada frequentemente pelos pesquisadores nos últimos anos, tais como Tippins e Sohi (2003), Ray et al. (2005), Stoel e Muhanna (2009), Wade e Hulland (2011), e Todorovic et al. (2015). Priem e Butler (2001) destacam que a popularidade da resource-based view theory no campo da gestão estratégica teve um aumento expressivo por volta da década de 90 devido à sua rápida difusão na literatura sobre estratégia.

Conforme citado anteriormente, Mintzberg et al. (2010) apresentam diversas escolas associadas ao campo de estudo da gestão estratégica e uma delas é a escola cultural que está associada com a formulação de estratégia como um processo coletivo. Os autores definem a cultura como um significado compartilhado criado por um grupo de pessoas ao longo do tempo, sendo esse processo feito por atividades puramente sociais envolvendo a interação de pessoas com os recursos empregados na organização.

Segundo Hoskisson et al. (1999), a ênfase sobre os recursos competitivos internos já era tema de alguns clássicos da literatura como As funções dos executivos, de Chester Banard (1938), A Liderança na Administração: uma Interpretação Sociológica, de Philip Selznick (1957) ou A teoria do crescimento da firma, de Edith Penrose (1959). Esses pesquisadores, assim como outros da mesma corrente, têm um interesse sobre a ponderação dos motores de crescimento interno e argumentam que o sucesso continuado de uma empresa ocorre principalmente em função dos seus recursos competitivos internos e singulares.

A resource-based view theory, segundo Ray et al. (2005), surgiu inicialmente com o objetivo de se entender as condições sob as quais determinadas organizações são capazes de obter e sustentar uma vantagem competitiva. Porém outros estudos se apropriaram dessa teoria para entender por que a performance dos processos dentro das organizações varia entre um conjunto de concorrentes.

Kor e Mahoney (2004) fizeram um estudo para identificar as contribuições para a gestão estratégica sob a perspectiva da RBV geradas pelo trabalho de Edith 
Penrose em 1959, que foi a precursora, segundo diversos autores para a RBV. As principais contribuições comentadas pelos autores são:

- apresentação de uma explicação lógica para desvendar relações causais entre os recursos, capacidades e vantagens competitivas; e

- apresentação de pelo menos três argumentos centrais relativos as ligações entre os recursos da empresa, oportunidades produtivas e crescimento das empresas rentáveis:

a) as empresas podem criar valor econômico não devido a mera posse de recursos, mas devido a uma gestão eficaz e inovadora de recursos;

b) destaca as relações causais entre recursos e geração de oportunidades produtivas para o crescimento e a inovação; e

c) explica os condutores da taxa e direção de crescimento da firma.

No contexto de que a autora foi a precursora dessa abordagem voltada para os recursos internos de uma organização, o Quadro 4 contém o detalhe da visão dos principais autores identificados na literatura que trata da resource-based view.

Quadro 4 - Conceitualização da resource-based view

\begin{tabular}{|l|l|}
\hline \multicolumn{1}{|c|}{ Autores } & \multicolumn{1}{|c|}{ Conceituação da Resource-based view } \\
\hline Wernerfelt (1984) & $\begin{array}{l}\text { Entende que essa abordagem apresenta uma relação entre recursos e } \\
\text { lucratividade de uma organização. Além de trazer à tona a importância } \\
\text { do tópico associado com a gestão do posicionamento da organização } \\
\text { baseado nos recursos que ela possui. }\end{array}$ \\
\hline Peteraf (1993) & $\begin{array}{l}\text { No contexto de negócio essa abordagem pode auxiliar os gestores a } \\
\text { entenderem que os recursos podem ser uma base importante para a } \\
\text { vantagem competitiva. }\end{array}$ \\
\hline $\begin{array}{l}\text { Collis e Montgomery } \\
(1995)\end{array}$ & $\begin{array}{l}\text { A resource-based view combina uma análise interna dos fenômenos } \\
\text { que ocorrem dentro das empresas com uma análise externa do setor e } \\
\text { do ambiente competitivo. }\end{array}$ \\
\hline Grant (1996) & $\begin{array}{l}\text { Essa abordagem apresenta a organização como um feixe único de } \\
\text { recursos e capacidades individuais na qual a tarefa primária de gestão } \\
\text { é maximizar o valor por meio do desenvolvimento otimizado de } \\
\text { recursos e capacidades existentes, para posteriormente ocorrer um }\end{array}$ \\
\hline
\end{tabular}




\begin{tabular}{|c|c|}
\hline & desenvolvimento dos recursos base da organização para o futuro. \\
\hline Teece et al. (1997) & $\begin{array}{l}\text { Essa abordagem se baseia em recursos e mantém o foco sobre as } \\
\text { rendas provenientes de recursos específicos e escassos de } \\
\text { organizações do que o foco sobre os lucros de um posicionamento do } \\
\text { produto que a organização oferece seguido por outras abordagens. }\end{array}$ \\
\hline $\begin{array}{l}\text { Eisenhardt e Martin } \\
(2000)\end{array}$ & $\begin{array}{l}\text { É uma perspectiva que mantém o foco sobre a organização interna de } \\
\text { uma empresa, sendo então considerada um complemento para ênfase } \\
\text { tradicional da estratégia sobre a estrutura da indústria e o } \\
\text { posicionamento estratégico que são determinantes para a vantagem } \\
\text { competitiva. }\end{array}$ \\
\hline Zott (2003) & $\begin{array}{l}\text { As empresas em um mesmo setor tem desempenhos diferentes uma } \\
\text { vez que mesmo no equilíbrio de mercado, as empresas se diferem em } \\
\text { termos de recursos e capacidades controladas pelas organizações. }\end{array}$ \\
\hline Helfat e Peteraf (2003) & $\begin{array}{l}\text { A visão baseada em recursos fornece uma explicação de } \\
\text { heterogeneidade competitiva baseada na premissa de que } \\
\text { concorrentes próximos diferem nos seus recursos e capacidades de } \\
\text { maneiras importantes e duráveis. Essas diferenças afetam a vantagem } \\
\text { e a desvantagem competitiva. }\end{array}$ \\
\hline $\begin{array}{l}\text { Ray et al. (2004) } \\
\text { Ray et al. (2005) }\end{array}$ & $\begin{array}{l}\text { Essa abordagem está associada com o fato das empresas ganharem e } \\
\text { sustentarem uma vantagem competitiva pela integração de recursos } \\
\text { valiosos e capacidades. Essa teoria sugere que os recursos que estão } \\
\text { em posse de uma ampla quantidade de organizações que competem } \\
\text { entre si podem não explicar a variância sobre o desempenho dessas } \\
\text { empresas. }\end{array}$ \\
\hline $\begin{array}{l}\text { Amstrong e Shimizu } \\
(2007)\end{array}$ & $\begin{array}{l}\text { Abordam a RBV como um modelo para explicar as condições } \\
\text { subjacentes que podem fazer uma empresa alcançar uma vantagem } \\
\text { competitiva sustentável por meio dos recursos que elas possuem. }\end{array}$ \\
\hline Wang e Ahmed (2007) & $\begin{array}{l}\text { A RBV mantém sua ênfase sobre recursos e capacidades como a } \\
\text { origem de vantagem competitiva. Os recursos são heterogeneamente } \\
\text { distribuídos entre empresas concorrentes e são imperfeitamente } \\
\text { móveis, o que faz com que essa heterogeneidade persista ao longo do } \\
\text { tempo. }\end{array}$ \\
\hline
\end{tabular}


Furrer et al. (2008)

Essa abordagem conceitualiza uma organização como um feixe de recursos produtivos, no qual o ambiente é composto por diferentes organizações processando feixes únicos desses recursos. É uma abordagem estratégica a respeito do uso dos recursos para se atingir a vantagem competitiva, que tem foco na relação entre os recursos e a performance das empresas

Fonte: elaborado pelo autor.

Sucintamente a partir desse levantamento pode-se notar que a RBV apresenta argumentos de que uma empresa pode ter um desempenho superior que seus concorrentes por meio de uma melhor gestão dos seus recursos estratégicos, ou seja, mantém seu foco sobre o ambiente interno das organizações

Essa abordagem é considerada um modelo teórico associado com a gestão estratégica para entender como as organizações conseguem alcançar uma vantagem competitiva sustentável por meio dos recursos estratégicos que elas possuem. Alguns autores, como Collis e Montgomery (1995) e Andersén (2011), destacam a importância de se levar em consideração fatores externos nesse modelo para que seja possível explicar de forma mais plausível a diferença de desempenho entre organizações

A resource-based view será o framework a ser seguido nesse estudo visto sua crescente presença na literatura e por se encaixar no contexto do problema de pesquisa que é entender o impacto da tecnologia de informação sobre a gestão do conhecimento de modo que ambos possam ser considerados recursos estratégicos para uma organização.

A seguir é apresentado o Quadro 5, que contém a definição de recursos de acordo com a visão dos principais autores encontrados na literatura sobre a resource-based view.

Quadro 5 - Conceitualização de recursos

\begin{tabular}{|c|l|}
\hline \multicolumn{1}{|c|}{ Autores } & \multicolumn{1}{c|}{ Conceito de recurso } \\
\hline Wernerfelt (1984) & $\begin{array}{l}\text { Qualquer coisa que possa ser pensada como ponto forte ou ponto } \\
\text { fraco de uma organização. Mais formalmente considera os recursos } \\
\text { como sendo todo ativo (tangível ou intangível) que está vinculado } \\
\text { semi-permanentemente com a organização. }\end{array}$ \\
\hline
\end{tabular}




\begin{tabular}{|c|c|}
\hline Barney (1991) & $\begin{array}{l}\text { Todos ativos, capacidades, processos organizacionais, atributos da } \\
\text { firma, informação e conhecimento que são controlados pelas } \\
\text { organizações, que podem permitir que elas implementem estratégias } \\
\text { para melhorar o desempenho das mesmas. Em seu estudo o autor } \\
\text { propõe que os recursos são heterogeneamente distribuídos entre as } \\
\text { organizações e que eles podem não ser perfeitamente móveis entre as } \\
\text { organizações. }\end{array}$ \\
\hline Grant (1991) & $\begin{array}{l}\text { Inputs do processo produtivo. Os recursos individuais de uma } \\
\text { organização incluem equipamentos, habilidades individuais de } \\
\text { funcionários, patentes, marcas, dentre outros. }\end{array}$ \\
\hline $\begin{array}{l}\text { Eisenhardt e Martin } \\
(2000)\end{array}$ & $\begin{array}{l}\text { Todos ativos físicos, humanos e organizacionais que podem ser } \\
\text { usados para implementar uma estratégia de criação de valor por uma } \\
\text { organização. Os recursos incluem habilidades e competências que } \\
\text { são fundamentais para a vantagem competitiva de uma organização }\end{array}$ \\
\hline Helfat e Peteraf (2003) & $\begin{array}{l}\text { Um ativo ou entrada para produção (tangível ou intangível) que uma } \\
\text { organização possui. }\end{array}$ \\
\hline Wade e Hulland (2004) & $\begin{array}{l}\text { Ativos e capacidade que estão disponíveis e são usáveis na detecção } \\
\text { e resposta a oportunidade e ameaças de mercado. }\end{array}$ \\
\hline
\end{tabular}

Fonte: elaborado pelo autor.

Com base no Quadro 5, os recursos podem ser entendidos como qualquer ativo tangível ou intangível que uma organização possui. Dois conceitos chaves do estudo, que serão abordados abordados são a tecnologia da informação e o conhecimento. A forma como a organização utiliza os seus recursos de forma a integrá-los ou mesmo a forma de gestão dos recursos deve ser entendido como uma capacidade. Segundo Sirmon et al. (2007), a gestão de recursos é um amplo processo de estruturação do portfólio de recursos de uma empresa, agrupando os recursos de modo a construir as capacidades que tem um propósito de gerar e sustentar valor para os consumidores. Dessa forma, Grant (1991) afirma que as capacidades de uma empresa representam o que ela pode fazer como resultado de grupos de recursos trabalhados juntos. Para Helfat e Peteraf (2003) uma capacidade organizacional está associada com a habilidade de uma organização coordenar um conjunto de tarefas, por meio do uso dos recursos organizacionais para o propósito de alcançar um determinado resultado. Wang e Ahmed (2007) definem capacidades 
de uma firma como a habilidade de implantar recursos, geralmente em combinação e encapsular tanto processos explícitos quanto elementos tácitos incorporando-os sobre os processos.

Existem diversas taxonomias na literatura em relação aos recursos:

- Recursos de capital físico, recursos de capital humano e recursos de capital organizacional (BARNEY, 1991);

- Recursos financeiros, recursos físicos, recursos humanos, recursos tecnológicos, reputação e recursos organizacionais (GRANT, 1991);

- Recursos tangíveis, recursos humanos e recursos intangíveis (BHARADWAJ, 2000);

Para que os recursos possam realmente gerar uma contribuição efetiva para a diferenciação da empresa no mercado em que atua é preciso que os recursos sejam segundo Barney (1991):

- Valiosos, permitindo que a empresa explore as oportunidades do ambiente e neutralize suas ameaças.

- Raros, os concorrentes não podem ter facilidade de acesso aos mesmos.

- Difíceis de imitar ou substituir, para evitar que outras empresas utilizem recursos que possam produzir o mesmo efeito.

No cenário de um mercado competitivo, Barney (1991) entende que os recursos são heterogeneamente distribuídos entre as organizações e que eles podem não ser perfeitamente móveis entre as organizações, e dessa forma é possível que eles proporcionem benefícios apenas para algumas organizações. O estudo realizado por Peteraf (1993) apresenta quatro condições que são consideradas elementos chaves para transformar os recursos considerados valiosos, raros e difíceis de imitar em uma vantagem competitiva sustentável:

- Heterogeneidade: uma suposição da resource-based view é que feixes de recursos e de capacidades são heterogêneos entre diferentes organizações, isso significa que os pacotes de recursos e capacidades variam entre firmas, o que pode aumentar a chance de se criar uma vantagem competitiva sustentável (PETERAF, 1993; MINTZBERG et al., 2010);

- Limites ex ante à competição: antes de qualquer firma estabelecer uma posição de recurso superior, deve haver uma competição limitada a essa 
posição. Dessa forma é preciso ter um pacote de recursos que seja diferente dos pacotes dos concorrentes para que a conquista de uma vantagem competitiva sustentável possa ser alcançada, ou seja, é preciso criar barreiras para impedir que outras empresas criem o mesmo pacote de recursos (PETERAF, 1993; MINTZBERG et al., 2010);

- Limites ex post à competição: para uma empresa ganhar uma posição superior e ganhar rendas, devem existir forças que limitam a concorrência no alcance dessas rendas. Esses limites então se referem a uma barreira que dificulta que os concorrentes imitem com eficácia o que a empresa pioneira está fazendo (PETERAF, 1993; MINTZBERG et al., 2010);

- Imobilidade de recursos: os recursos são considerados perfeitamente imóveis se eles não podem ser barganhados; em contrapartida, os recursos são considerados imperfeitamente imóveis quando eles são especializados para necessidades específicas de uma empresa. Dessa forma, um pacote de recursos oferecerá uma vantagem competitiva sustentável se não depender de apoio contínuo de fornecedores de recursos externos (PETERAF, 1993; MINTZBERG et al., 2010).

Complementando as características supracitadas que os recursos devem possuir, os autores Collis e Montgomery (1995) destacam que é possível verificar se um recurso tem valor para uma organização por meio da análise de três forças de mercado conforme a Figura 1:

- a demanda: as necessidades dos consumidores são atendidas e há superioridade em termos competitivos?; e

- a escassez: as capacidades e os recursos são duráveis e passíveis de imitação e de substituição?; e

- a adequação: quem é o dono dos lucros?. 
Figura 1 - Forças mercadológicas para geração de valor

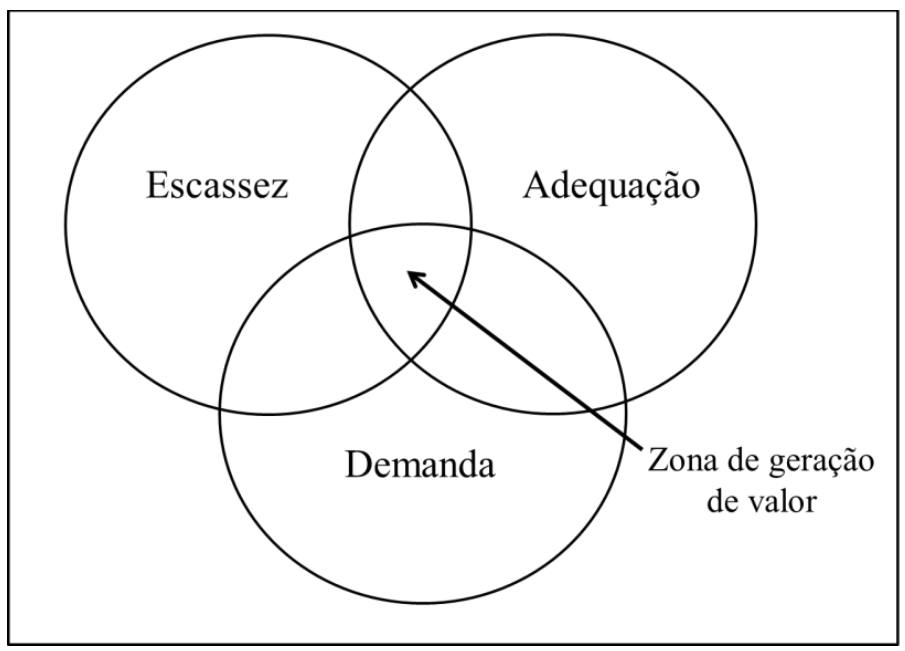

Fonte: Adaptado de Collis e Montgomery, 1995.

Wade e Hulland (2004) destacam que existem fortes evidências de que os recursos de TI podem impactar o desempenho da organização, porém para que o estudo dessa relação seja mais efetivo é preciso levar em consideração aspectos contingenciais (organizacionais e ambientais) e a complementariedade entre recursos.

"A complementariedade representa um aprimoramento do valor do recurso, que surge quando um recurso produz um retorno melhor na presença de outros recursos.

" (POWELL e DENT-MICALLEF, 1997)

Dessa forma os recursos que possuem essas características estabelecidas por Barney (1991), Collis e Montgomery (1995) e Wade e Hulland (2004) podem ser considerados recursos estratégicos. Segundo Grant (1991), a chave da abordagem baseada em recursos para a formulação estratégica das organizações é entender a relação entre recursos, capacidades, vantagem competitiva e lucratividade, e em particular, é preciso ter um entendimento sobre os mecanismos para que a vantagem competitiva possa ser sustentável ao longo do tempo.

Stoel e Muhanna (2009) destacam que as diferenças no desempenho das empresas são explicadas em termos dos tipos de recursos e capacidades que empresas diferentes controlam. Já Andersén (2011) complementa que o processamento de um recurso estratégico de modo a fazer com que ele tenha um impacto sobre o desempenho da firma é muito complexo, o que sugere que seja levado em consideração outros fatores - encaixe dos recursos estratégicos a configuração já existente, capacidade gerencial dos recursos, capacidade de marketing, apropriação 
de rendas e desvantagens competitivas - que podem afetar a relação entre recursos estratégicos e o desempenho da organização além das características supracitadas.

Em mercados caracterizados pela mudança constante, a vantagem competitiva não necessariamente é originada pelos recursos ou capacidades, mas sim pela forma que a organização gerencia seus recursos a fim de gerar novas capacidades que a destaquem no mercado na qual está inserida. (TEECE et al., 1997; CEPEDA E VERA, 2007)

Nesse cenário surge a abordagem denominada dynamic capabilities, que foi objeto de estudo de diversos autores a partir de Teece et al. (1997), os quais analisaram as fontes e os métodos de criação e captura de valor por organizações que operam em um ambiente de rápidas mudanças tecnológicas. Essa abordagem é vista como uma nova abordagem que permite o entendimento de novas fontes de vantagem competitiva para as organizações.

Os autores definiram as capacidades dinâmicas como a habilidade para alcançar novas formas de vantagem competitiva, na qual o termo dinâmico se refere à capacidade de renovar competências assim como alcançar a harmonia com a mudança do ambiente de negócio, ou seja, a capacidade da empresa se adaptar as mudanças no ambiente no qual ela está inserida. O termo capacidade, por sua vez, enfatiza o papel da gestão estratégica no processo de adaptação, integração, reconfiguração de habilidades organizacionais, recursos e competências funcionais para atender os requisitos de uma mudança no ambiente.

A abordagem da capacidade dinâmica tem grande importância para complementar a abordagem baseada em recursos, uma vez que a RBV, segundo Eisenhardt e Martin (2000), não explica adequadamente como e por quê certas firmas têm vantagem competitiva em situações de mudanças rápidas e imprevisíveis.

Nesse tipo de ambiente as capacidades dinâmicas, que são caracterizadas pela forma com que as empresas integram, constroem e reconfiguram competências internas e externas para se adequar rapidamente as mudanças no ambiente, tornam-se a fonte de vantagem competitiva sustentável para uma organização. Os autores entendem que as capacidades dinâmicas são rotinas organizacionais e estratégicas que permitem que as organizações alcancem novas configurações 
(criação, integração, reconfiguração) de recursos de acordo com os acontecimentos que envolvem o ambiente no qual essa organização está inserida.

Helfat e Peteraf (2003) apresentam uma visão muito semelhante, e entendem que as capacidades dinâmicas envolvem questões relacionadas com a adaptação e a mudança, uma vez que eles constroem, integram ou reconfiguram outros recursos ou capacidades. Zott (2003) entende que as capacidades de uma organização são indiretamente ligadas com o desempenho da empresa, uma vez que podem mudar o pacote de recursos, as rotinas operacionais e as competências que uma organização possui. Isso, consequentemente, pode afetar o desempenho econômico das empresas, ou seja, as capacidades dinâmicas são incorporadas em processos organizacionais que orientam a evolução da configuração de recursos e rotinas operacionais de uma organização.

Segundo Wang e Ahmed (2007), as capacidades dinâmicas podem ser entendidas como uma orientação comportamental de uma empresa para integrar, reconfigurar, renovar e recriar seus recursos e capacidades, e o mais importante, aprimorar e reconstruir outras capacidades essenciais em reposta à mudança no ambiente para alcançar uma vantagem competitiva sustentável. Os autores entendem que existem três fatores importantes associados as capacidades dinâmicas, são eles:

- Capacidade de adaptação: habilidade de uma organização identificar e capitalizar oportunidades de mercado emergentes (WANG E AHMED, 2007);

- Capacidade de absorção: habilidade de uma organização reconhecer o valor de informações externas a organização, assimilando essas informações e aplicando-as para fins comerciais, ou seja, é a habilidade de avaliar e utilizar conhecimento externo (COHEN e LEVINTHAL, 1990 apud WANG E AHMED, 2007);

- Capacidade de inovação: habilidade de desenvolver novos produtos e/ou mercados, por meio do alinhamento da orientação estratégica inovadora com os comportamentos e processos inovadores (WANG E AHMED, 2007).

Dentro do contexto de alta incerteza devido à altas mudanças no mercado é preciso que a empresa aprimore suas capacidades de absorção, de adaptação e de inovação para conseguir gerir seus recursos mais eficientemente. Para isso, a gestão do conhecimento junto com a tecnologia da informação pode ser um foco das 
empresas para que elas consigam melhorar esses três aspectos e consequentemente sua gestão de recursos estratégicos.

Conforme supracitado, diversas visões dos autores apresentam o conceito de competências, que na literatura está muito associado com o conceito de capacidade, sendo muitas vezes considerados a mesma coisa por alguns autores. No presente estudo os dois conceitos devem ser tratados de forma diferentes. A capacidade deve ser entendida como a habilidade da organização em reunir, integrar e gerar recursos valiosos, geralmente em combinação ou co-presença. (AMIT e SCHIENAJER, 1993; BHARADWAJ, 2000)

Já a competência deve ser entendida conforme visão apresentada por Hamel e Prahalad (1995), na qual quando os recursos e as capacidades são bem explorados e aliados às oportunidades do mercado, tornam-se competências essenciais (core competences) que proporcionarão o diferencial competitivo da empresa.

A Figura 2 mostra de forma estruturada como os conceitos (recursos, capacidades e competências) devem ser entendidos no presente estudo. Os recursos devem ser entendidos como qualquer ativo tangível ou intangível que uma organização possui. Já as capacidades estão associadas com a forma que a empresa gere esses recursos para atender um determinado fim, porém quando essas capacidades geram benefícios que permitam que a empresa se diferencie em relação aos seus concorrentes de maneira sustentável, devemos entender que elas geram competências para a organização.

Figura 2 - Recursos, capacidades e competências

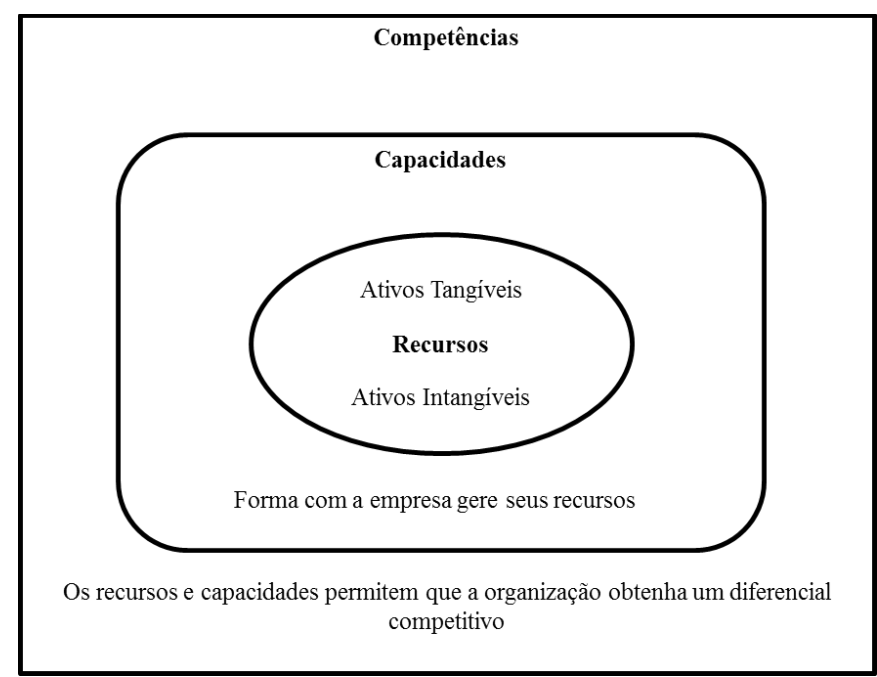

Fonte: Elaborado pelo autor. 


\subsection{A TECNOLOGIA DA INFORMAÇÃO}

O papel estratégico da TI

Segundo Keen (1993) apud Laurindo et al. (2001), o conceito de tecnologia da informação é mais abrangente do que o de processamento de dados, sistemas de informação, engenharia de software, informática ou o conjunto de hardware e software, pois também envolve aspectos humanos, administrativos e organizacionais.

"A $\mathrm{TI}$ é composta pelos seguintes componentes: hardware e seus dispositivos periféricos, software e seus recursos, sistemas de telecomunicações, e sistemas de gestão de dados e informações. Além disso, todos esses componentes necessitam do componente fundamental que é o recurso humano, sem ele a tecnologia não tem funcionalidade. " (REZENDE e ABREU, 2006)

Santhanam e Hartono (2003) entendem que as empresas alocam recursos de capital para adquirir tecnologias de informação assumindo que esse investimento irá prover retornos econômicos para a organização.

"As organizações olham para os investimentos em tecnologias da informação como um caminho para combater seus concorrentes por meio do aumento da produtividade, lucratividade, e da qualidade das suas operações. " (DEVARAJ e KOHLI, 2003)

Segundo Clemons (1991) a tecnologia da informação pode ser uma parte essencial da estratégia corporativa. A TI é mencionada constantemente na literatura como um elemento que pode contribuir para que a organização consiga criar uma vantagem competitiva sustentável (BARNEY, 1991; DEVARAJ e KOHLI, 2003; SAUVE E MEDEIROS, 2003).

Nesse contexto, a tecnologia da informação pode ter tem um papel fundamental na estratégia de uma empresa de acordo com o impacto que a mesma pode ocasionar no desempenho de uma organização.

As empresas podem ser classificadas com base na forma que elas escolhem seus recursos de TI. Schein (1989) classifica as organizações com base nas formas de decisões que são tomadas para escolher a tecnologia da informação. $O$ autor apresenta quatro classificações:

- Céticas: demonstram incertezas quanto aos benefícios de TI e tomam decisões baseadas nos custos de TI. 
- Dependentes: apoiam as decisões de TI, favoráveis à automação, delegam as decisões para os especialistas.

- Envolvidas: acreditam que devam estar envolvidas nas decisões de TI, especialmente as mais estratégicas

- Positivas: postura positiva, entusiasmada e idealista sobre TI, apoiam e participam das decisões de TI.

A classificação supracitada tem um olhar sobre a forma que as empresas se posicionam para a escolha de um determinado recurso de tecnologia da informação. Outra maneira de se classificar uma organização é baseada nos impactos que os recursos podem proporcionar para ela, como é apresentado por Nolan e McFarlan (2005) no "Grid do impacto estratégico da Tl", no qual são apresentadas duas abordagens estratégicas em relação a Tl:

- Tl defensiva: manter os sistemas funcionando é mais importante na configuração atual da empresa do que competir usando tecnologias emergentes; e

- TI ofensiva: a visão estratégica de TI está acima ou no mesmo nível da segurança.

Para realizar essa classificação os autores apresentam um modelo que trabalha com dois eixos importantes que são levados em consideração: o grau associado com a necessidade da organização possuir tecnologias confiáveis - com o intuito de que o negócio não pode parar, e caso isso ocorra a empresa corre grandes riscos de prejuízos para o negócio - e o outro associado com a necessidade da organização possuir novas tecnologias - com o intuito de melhorar seus processos e serviços para atender os seus consumidores da melhor forma possível.

A partir dos dados sobre esses dois eixos, uma organização pode ser classificada no "Grid do impacto estratégico da Tl" de Nolan e McFarlan (2005) apresentado na Figura 3, que é uma forma interessante de se analisar o impacto das aplicações de TI para as organizações. 
Figura 3 - Grid do impacto estratégico de TI

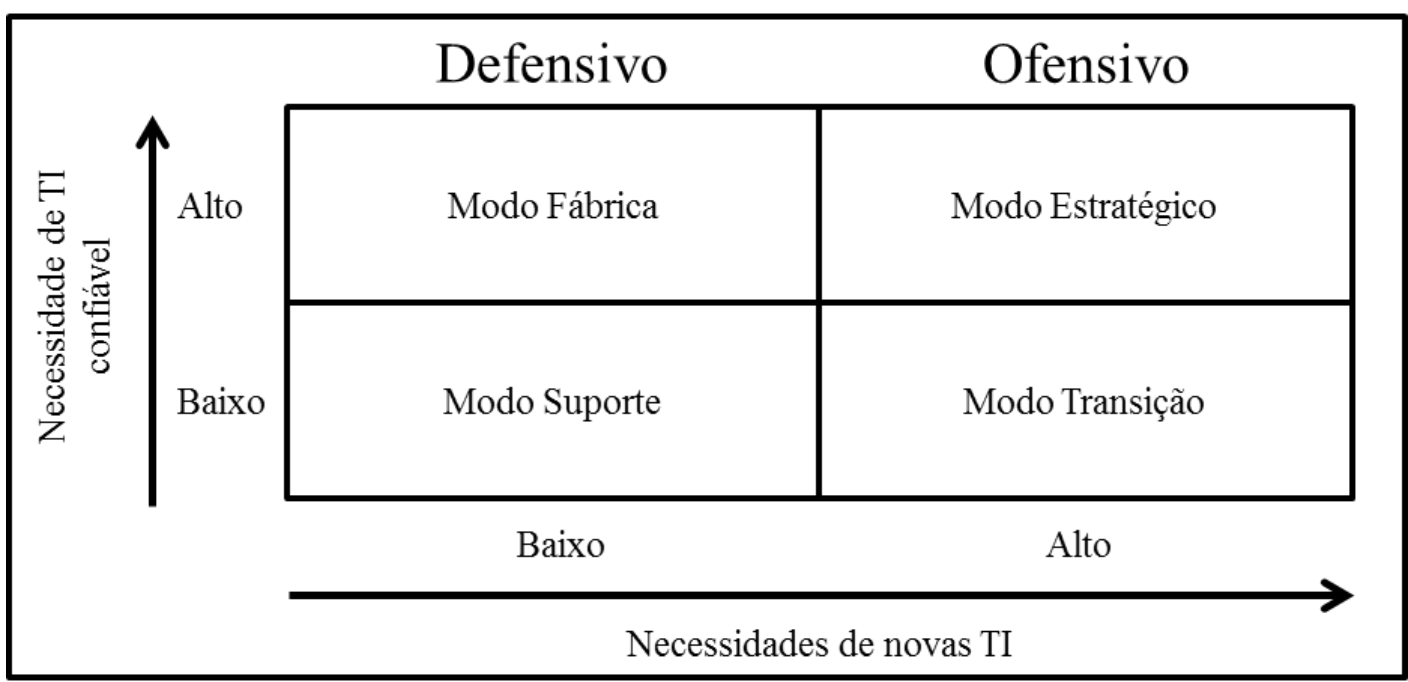

Fonte: Adaptado de Nolan e McFarlan, 2005.

Nolan e McFarlan (2005) destacam as seguintes características para cada quadrante desse grid:

- Modo Fábrica:

- se os sistemas falharem por um minuto ou mais, há pouca perda imediata para o negócio;

- a queda no tempo de resposta além de um segundo, apresenta sérias consequências tanto para usuários internos, quanto para usuários externos;

- a maioria das atividades de negócio importantes são online;

- o trabalho dos sistemas é basicamente manutenção;

- os sistemas provêm uma pequena diferenciação estratégica ou uma redução de custos.

- Modo Suporte:

- mesmo que hajam repetidas interrupções de até 12 horas nos serviços, não gera nenhuma consequência séria para o negócio;

- o tempo de resposta do usuário pode levar até 5 segundos para transações online;

- os sistemas internos são praticamente invisíveis para clientes e fornecedores. Existe uma baixa necessidade de extranet;

- a empresa pode reverter rapidamente para procedimentos manuais para $80 \%$ das transações importantes; 
○ o trabalho dos sistemas é basicamente manutenção.

- Modo Transição:

- novos sistemas indicam transformações significativas em processos e serviços;

- novos sistemas indicam significativas reduções de custo;

- novos sistemas eliminam disparidades significativas de custo, serviço e desempenho com competidores;

- TI representa mais de $50 \%$ do patrimônio investido pela organização;

- TI compõe mais de $15 \%$ das despesas totais da corporação.

- Modo Estratégico:

- se os sistemas falham por um ou mais minutos haverá uma perda imediata para o negócio;

- a queda no tempo de resposta além de um segundo, apresenta sérias consequências tanto para usuários internos, quanto para usuários externos;

- novos sistemas indicam transformações significativas em processos e serviços;

- novos sistemas indicam significativas reduções de custo;

- novos sistemas eliminam disparidades significativas de custo, serviço e desempenho com os competidores.

Segundo Porter e Millar (1985), a intensidade do valor estratégico da tecnologia da informação para as organizações varia de acordo com a sua implicação sobre os produtos e serviços ofertados pela empresa, e com a dependência dos processos de negócio e dos processos de apoio em relação ao uso de tecnologias da informação. Os autores demostram essa relação por meio da matriz de intensidade de informação, dessa forma se uma organização tem uma alta intensidade de informação nos produtos e nos processos então a tecnologia da informação tem uma grande importância.

Barney e Hesterly (2007) argumentam que as organizações que fazem um investimento cedo em uma determinada tecnologia, estão implementando uma estratégia de liderança tecnológica, que pode gerar duas vantagens competitivas: atingir uma posição baixo custo e aumentar o desempenho da organização $A$ 
tecnologia da informação pode ser vista como vantagem competitiva sob perspectivas diferentes:

- recursos de TI entendidos como uma tecnologia avançada: ser uma tecnologia inovadora, o que possibilita que organização atinja a diferenciação em relação aos seus concorrentes (OLIVEIRA, 1998 apud ANDREASI e GAMBARATO, 2010); e

- recursos de TI proporcionando a redução de custo: atingir a liderança no custo (OLIVEIRA, 1998 apud ANDREASI e GAMBARATO, 2010); e

- recursos de TI simplificando os processos: automatização dos processos melhorando a eficiência dos mesmos (OLIVEIRA, 1998 apud ANDREASI e GAMBARATO, 2010); e

- recursos de TI enriquecem a tomada de decisão: melhorar a eficiência e eficácia do intercâmbio de dados, por meio de uma melhor integração entre as áreas das organizações; facilitar a análise de dados, o que contribui para uma tomada de decisão mais rápida e efetiva (PORTO et al., 2000).

Outra visão em relação aos benefícios que as aplicações de TI podem prover é a apresentada por Farbey et al. (1995) que apresenta uma escala de avaliação dos benefícios da TI na organização, no qual conforme se avança na escala, mais aumenta sua complexidade, riscos e incertezas, porém indicam benefícios potenciais maiores. Conforme o Quadro 6 os autores apresentam um modelo composto por oito degraus, e cada degrau corresponde a um tipo de mudança, e consequentemente um tipo de aplicação.

Quadro 6 - Escala de benefícios de Farbey et al. (1995)

\begin{tabular}{|c|l|l|}
\hline Degrau & \multicolumn{1}{|c|}{ Tipo de mudança na aplicação } & \multicolumn{1}{c|}{ Objetivo } \\
\hline Degrau 1 & Mudanças obrigatórias & $\begin{array}{l}\text { A organização tem que fazer a mudança de TI } \\
\text { a fim de sobreviver ou adequar-se a normas e } \\
\text { leis }\end{array}$ \\
\hline Degrau 2 & Automação & $\begin{array}{l}\text { Uso da TI para substituir processos visando a } \\
\text { redução de custos e/ou aumento da } \\
\text { produtividade. }\end{array}$ \\
\hline
\end{tabular}




\begin{tabular}{|l|l|l|} 
Degrau 3 & Sistemas de Valor Agregado Direto & $\begin{array}{l}\text { A aplicação de TI vai além da automação, } \\
\text { permitindo melhorar a forma de se fazer o } \\
\text { negócio }\end{array}$ \\
\hline Degrau 4 & $\begin{array}{l}\text { Sistemas de Informações Gerenciais } \\
\text { SIG) }\end{array}$ & $\begin{array}{l}\text { Uso da TI para a planejamento, controle e } \\
\text { tomada de decisão. }\end{array}$ \\
\hline Degrau 5 & Infraestrutura & $\begin{array}{l}\text { Provêm a infraestrutura fundamental que } \\
\text { permite a realização negócio da organização, } \\
\text { embora não produza nenhum benefício direto }\end{array}$ \\
\hline Degrau 6 & Sistemas inter-organizacionais & $\begin{array}{l}\text { Sistemas que transpõem as fronteiras } \\
\text { organizacionais, permitindo diferentes níveis } \\
\text { de colaboração e troca de informações. }\end{array}$ \\
\hline Degrau 7 & Sistemas estratégicos & $\begin{array}{l}\text { Permitem a obtenção de vantagem } \\
\text { competitiva, melhoram a produtividade e } \\
\text { performance, permitem novas formas de } \\
\text { gestão e organização e permitem o } \\
\text { desenvolvimento de novas formas de negócio. }\end{array}$ \\
\hline Degrau 8 & Transformação do negócio & $\begin{array}{l}\text { Aplicações de TI que permitem mudanças que } \\
\text { transformam a organização }\end{array}$ \\
\hline
\end{tabular}

Fonte: Farbey et al., 1995.

O envolvimento da tecnologia da informação no campo estratégico é algo presente na literatura desde antes da década de 90. Segundo Powell e Dent-Micallef (1997), o campo da gestão estratégica se expandiu na literatura visto o aumento do interesse das organizações no papel da TI na formulação e implementação das estratégias corporativas, que consequentemente poderiam afetar o desempenho financeiro dessas empresas.

\subsection{A CAPACIDADE DE TECNOLOGIA DA INFORMAÇÃO}

Mata et al. (1995) defendem que a RBV é uma forma de entender a relação entre a TI e a vantagem competitiva sustentável. Os autores destacam que essa é uma perspectiva na qual a capacidade de uma organização usar a TI para alavancar os seus recursos que trazem vantagens permite que a TI seja uma fonte potencial para alcançar uma vantagem competitiva sustentável. 
Powell e Dent-Micallef (1997) entendem que diante do contexto da resource-based view, a TI tem um papel importante sobre essa abordagem, uma vez que ela pode criar vantagens por meio da alavancagem de outros recursos humanos e de negócio. Essa associação com outros tipos de recursos é denominada pelos autores como complementariedade.

Bharadwaj (2000) realizou um estudo empírico para examinar a associação entre a capacidade de $\mathrm{Tl}$ e a performance da firma, e classifica os recursos de $\mathrm{Tl}$ em três grupos:

- Infraestrutura de TI: entendida como ativos físicos, que compreendem os computadores, as tecnologias de informação e comunicação, as plataformas técnicas de compartilhamento e banco de dados, por exemplo.

- Recursos humanos de TI: compreendem experiências, relacionamentos, percepções e treinamentos dos colaboradores.

- Recursos intangíveis habilitados pela TI:

- Orientação voltada para o cliente: capacidade de rastrear e prever mudanças nas preferências do consumidor. A TI permite que as empresas rastreiem mudanças no perfil de consumo dos clientes mais rapidamente;

- Ativos de conhecimento e capital intelectual: a tecnologia da informação é crítica para a gestão de conhecimento como sistemas de groupware e multimídia que ajudam a esclarecer pressupostos, acelerar a comunicação, incitar o conhecimento tácito, e construir um histórico de ideias e depois catalogá-las;

- Sinergia: as tecnologias de informação voltadas para criação de sinergias organizacionais podem ajudar na entrega de recursos necessários, removendo limitações física, espacial e temporal para comunicação.

Tippins e Sohi (2003) definem capacidades de Tl como a forma que as empresas gerem as informações que possuem, e as divide em três dimensões:

- Conhecimento da TI: conhecimento técnico sobre objetos que compõem os sistemas baseados em computação; 
- Operação da TI: processos que viabilizam um determinado fim, como melhores serviços e reduções de custo;

- Objetos de TI: artefatos que auxiliam a aquisição, processamento, armazenamento e disseminação e uso de informação, como hardware, software e suporte.

Baseado no modelo de Tippins e Sohi (2003), Pérez-López e Alegre (2012) apresentam as seguintes definições em relação às capacidades de TI:

- Conhecimento da TI: grau com que a organização entende as capacidades existentes e emergentes a partir da $\mathrm{TI}$, por meio das experiências, interpretações e reflexões de seus colaboradores; $\mathrm{e}$

- Operação da TI: métodos, processos e técnicas associadas com a TI necessários para criar valor ao negócio; e

- Infraestrutura de TI: artefatos, ferramentas e recursos que contribuem para aquisição, processamento, armazenamento e disseminação e uso da informação.

Em um contexto similar, Lu e Ramamurthy (2011) definem a capacidade da TI como um construto que envolve três dimensões:

- capacidade de infraestrutura de TI: capacidade da organização implantar e estender plataformas compartilháveis; e

- capacidade de abranger o negócio por meio da TI: a capacidade de gestão da empresa para prever e explorar os recursos de TI para apoiar e reforçar os objetivos de negócios; e

- capacidade de manter uma postura proativa: capacidade de uma empresa procurar proativamente maneiras de compreender as tecnologias de informação inovadoras ou explorar Tl's existentes para criar oportunidades de negócio para a organização.

Stoel e Muhanna (2009) definem as capacidades de TI como um feixe complexo de recursos de TI relacionados, habilidades e conhecimento usados por meio de processos de negócio, que permitem que as organizações coordenem atividades e façam uso de ativos de TI para alcançar os resultados desejados. Os autores dividem a capacidade de TI em dois grupos: 
- capacidades de TI focadas no ambiente externo: recursos de TI relacionados, habilidades e conhecimento que ajudam a empresa a entender e responder de forma mais ágil às mudanças no mercado e às necessidades dos seus clientes.

- capacidades de TI focadas no ambiente interno: recursos de TI relacionados, habilidades e conhecimento acumulado que ajudam as organizações na oferta de produtos e serviços confiáveis, e na redução de custos indiretos.

Wade e Hulland (2004) entendem que os recursos de sistemas de informação (SI) raramente contribuem diretamente para uma vantagem competitiva sustentável, porém eles são parte de um conjunto complexo de recursos e capacidades, que juntos podem conduzir para um desempenho sustentável, ou seja, os sistemas de informação exercem sua influência em uma organização por meio dos relacionamentos complementares com outros ativos e capacidades da empresa. Os autores entendem que as capacidades proporcionadas por meio dos recursos de $\mathrm{TI}$ podem seguir a taxonomia apresentada no estudo de Day (1994), que é composta por três tipos:

- inside-out: capacidades que são implementadas dentro da organização em resposta aos requisitos e oportunidades de mercado e tendem a ser focado internamento;

- outside-in: capacidades que são orientadas externamente, colocação e ênfase sobre a antecipação dos requisitos de mercado, criando relações duradouras com clientes, e entendimento dos concorrentes;

- spanning: capacidade que envolvem ambas análises internas e externas, uma vez que precisam integrar os outros dois tipos de capacidades.

O estudo realizado pelos autores Powel e Dent-Micallef (1997) apresenta descobertas que demonstram a importância do uso da TI para alavancar outros recursos intangíveis, recursos humanos complementares e recursos de negócio como a flexibilização da cultura organizacional, o planejamento estratégico integrado e o relacionamento com fornecedores, que possibilitam que as organizações obtenham vantagens em relação aos seus concorrentes.

Adamides e Karacapilidis (2006) destacam que o papel da tecnologia da informação não é somente organizar dados em informações úteis, mas também suportar a 
transformação da informação em um conhecimento organizacional. Nesse contexto o olhar a respeito dos impactos da tecnologia da informação sobre a gestão de ativos intangíveis tem sido alvo de alguns estudos como Bharadwaj (2000) que entende que a TI tem um papel fundamental para a gestão do conhecimento de uma organização conforme supracitado.

Nessa pesquisa será levado em consideração que a capacidade de TI é composta por três dimensões: Infraestrutura de TI, Recursos Humanos de TI e Operação da TI, integrando o modelo apresentado por Pérez-López e Alegre (2012) com a perspectiva de outros autores como Bharadwaj (2000), que apresentam o conceito de Recursos Humanos de TI muito semelhante com o conceito de Conhecimento de TI apresentado também por Tippins e Sohi (2003).

A escolha de seguir o modelo de Pérez-López e Alegre (2012) se deve ao fato dos autores apresentarem um modelo robusto dentro do contexto fato para o estudo em questão que é abordagem baseada em recursos, além de conter dois construtos que se deseja avaliar. A seguir uma breve descrição sobre cada dimensão supracitadas.

A capacidade de infraestrutura da TI no modelo de Alavi e Leidner (2001) é a base que sustenta os diversos processos de gestão do conhecimento - criação do conhecimento, armazenamento do conhecimento, compartilhamento do conhecimento e aplicação do conhecimento. Essa base é, segundo os autores, composta por uma rede interna (intranet) e tecnologias da informação como groupwares. Para Bharadwaj (2000) a infraestrutura de TI pode ser entendida como ativos físicos, que compreendem os computadores, as tecnologias de informação e comunicação, as plataformas técnicas de compartilhamento e banco de dados, por exemplo.

A segunda dimensão, recursos humanos de TI, na visão apresentada por PérezLópez e Alegre (2012) está associada com o conhecimento da TI - grau com que a organização entende as capacidades existentes e emergentes a partir da TI. O conhecimento da $\mathrm{TI}$ depende principalmente das experiências, relacionamentos, percepções e treinamento dos colaboradores. Esse conjunto de fatores segundo Bharadwaj (2000) correspondem à capacidade de recursos humanos de TI.

Por fim a capacidade de operação de TI pode ser entendida de acordo por PérezLópez Alegre (2012), como métodos, processos e técnicas associadas com a TI e 
necessárias para criar valor ao negócio. Dessa forma é preciso que a empresa mantenha uma postura proativa - identificar maneiras de compreender as tecnologias de informação inovadoras ou explorar as tecnologias de informação existentes para criar oportunidades para a organização - e abranger o negócio por meio das tecnologias da informação - prever e explorar os recursos de TI para apoiar e reforçar os objetivos do negócio (LU e RAMAMURTHY, 2011).

A operação da TI pode viabilizar diversos resultados positivos que criam valor ao negócio e um exemplo dessa situação é a viabilização de recursos intangíveis por meio da TI.

Bharadwaj (2000) apresenta alguns recursos intangíveis viabilizados pela operação da TI, são eles: a orientação voltada para o cliente - rastrear e prever mudanças nas preferências do consumidor -, a sinergia - eliminação de limitações físicas, espaciais e temporais de comunicação - e a gestão do conhecimento - esclarecer pressupostos, acelerar a comunicação, incitar o conhecimento tácito, e construir um histórico de ideias e depois catalogá-las.

Essa dimensão envolve um olhar sobre o ambiente interno de uma organização ou então sobre o ambiente externo. Para Stoel e Muhanna (2009) as capacidades de TI focadas no ambiente externo como habilidades que ajudam a empresa a responder de forma mais ágil às mudanças no mercado e às necessidades dos seus clientes, enquanto as capacidades de TI focadas no ambiente interno ajudam a organização na oferta de produtos e serviços confiáveis, e na redução de custos indiretos.

Baseado na literatura supracitada, o Quadro 7 apresenta as variáveis que serão utilizadas no estudo com o objetivo de mensurar a capacidade de infraestrutura de TI.

Quadro 7 - Variáveis referentes à dimensão infraestrutura de TI

\begin{tabular}{|l|l|l|}
\hline \multicolumn{1}{|c|}{ Dimensão } & \multicolumn{1}{|c|}{ Variáveis } & \multicolumn{1}{c|}{ Autores } \\
\hline $\begin{array}{l}\text { Infraestrutura de TI } \\
\text { Alpha de Cronbach: } \\
0,920 \text { (Pérez-López, 2012) }\end{array}$ & $\begin{array}{l}\text { A empresa possui um departamento formal } \\
\text { de gestão de tecnologias da informação? }\end{array}$ & $\begin{array}{l}\text { Tippins e Sohi (2003) } \\
\text { Pérez-López (2012) }\end{array}$ \\
\cline { 2 - 3 } $\begin{array}{l}\text { 0,811 (Tippins e Sohi, } \\
\text { 2003) }\end{array}$ & $\begin{array}{l}\text { A empresa possui um cargo de gestão cuja } \\
\text { principal responsabilidade é o } \\
\text { gerenciamento do uso das tecnologias da } \\
\text { informação? }\end{array}$ & $\begin{array}{l}\text { Tippins e Sohi (2003) } \\
\text { Pérez-López (2012) }\end{array}$ \\
\hline
\end{tabular}




\begin{tabular}{|l|l|l|}
\hline & $\begin{array}{l}\text { A empresa reserva um orçamento anual } \\
\text { para investir em novas tecnologias da } \\
\text { informação? }\end{array}$ & $\begin{array}{l}\text { Tippins e Sohi (2003) } \\
\text { Pérez-López (2012) }\end{array}$ \\
\cline { 2 - 3 } & $\begin{array}{l}\text { A empresa cria aplicações customizadas } \\
\text { de softwares quando surge uma } \\
\text { necessidade? }\end{array}$ & Tippins e Sohi (2003) \\
\cline { 2 - 3 } & $\begin{array}{l}\text { Os colaboradores da organização são } \\
\text { conectados por uma rede de } \\
\text { computadores? }\end{array}$ & $\begin{array}{l}\text { Tippins e Sohi (2003) } \\
\text { Pérez-López (2012) }\end{array}$ \\
\hline
\end{tabular}

Fonte: elaborado pelo autor.

Já o Quadro 8 apresenta as variáveis que serão utilizadas no estudo com o objetivo de mensurar a capacidade de recursos humanos de $\mathrm{TI}$.

Quadro 8 - Variáveis referentes à dimensão RH de TI

\begin{tabular}{|l|l|l|}
\hline \multicolumn{1}{|c|}{ Dimensão } & \multicolumn{1}{|c|}{ Variáveis } & \multicolumn{1}{c|}{ Autores } \\
\hline Recursos humanos de TI & $\begin{array}{l}\text { No geral, o staff de apoio técnico é bem } \\
\text { informado quando se trata de tecnologias } \\
\text { da informação? }\end{array}$ & $\begin{array}{l}\text { Tippins e Sohi (2003) } \\
\text { Pérez-López (2012) }\end{array}$ \\
\cline { 2 - 3 } $\begin{array}{l}\text { 0,803 (Pérez-López, 2012) } \\
0,912 \text { (Tippins e Sohi, } \\
2003)\end{array}$ & $\begin{array}{l}\text { A empresa possui um elevado grau de } \\
\text { expertise em tecnologias da informação? }\end{array}$ & $\begin{array}{l}\text { Tippins e Sohi (2003) } \\
\text { Pérez-López (2012) }\end{array}$ \\
\cline { 2 - 3 } & $\begin{array}{l}\text { A empresa busca atualizar seus } \\
\text { colaboradores em relações as novas } \\
\text { inovações das tecnologias da } \\
\text { informação? }\end{array}$ & $\begin{array}{l}\text { Tippins e Sohi (2003) } \\
\text { Pérez-López (2012) }\end{array}$ \\
\hline & $\begin{array}{l}\text { A empresa possui conhecimento para } \\
\text { desenvolver e sustentar um } \\
\text { relacionamento com seus consumidores } \\
\text { por meio de tecnologias da informação? }\end{array}$ & Tippins e Sohi (2003) \\
\hline
\end{tabular}

Fonte: elaborado pelo autor.

Por fim o Quadro 9 apresenta as variáveis que serão utilizadas no estudo com o objetivo de mensurar a capacidade de recursos humanos de $\mathrm{TI}$.

Quadro 9 - Variáveis referentes à dimensão operação de TI

\begin{tabular}{|c|c|c|}
\hline Dimensão & Variáveis & Autores \\
\hline $\begin{array}{l}\text { Operação da TI } \\
\text { Alpha de Cronbach: } \\
\text { 0,877 (Pérez-López, 2012) }\end{array}$ & $\begin{array}{l}\text { A empresa possui experiência para } \\
\text { coletar e analisar informações de } \\
\text { mercado sobre seus clientes por meio } \\
\text { de tecnologias da informação? }\end{array}$ & $\begin{array}{l}\text { Tippins e Sohi (2003) } \\
\text { Pérez-López (2012) }\end{array}$ \\
\hline 0,891 (Tippins e Sohi, 2003) & A empresa busca utilizar rotineiramente & Tippins e Sohi (2003) \\
\hline
\end{tabular}




\begin{tabular}{|l|l|l|}
\hline & $\begin{array}{l}\text { tecnologias da informação para acessar } \\
\text { informações de mercado a partir de } \\
\text { bases de dados externas à } \\
\text { organização? }\end{array}$ & Pérez-López (2012) \\
\hline $\begin{array}{l}\text { A empresa possui um conjunto de } \\
\text { procedimentos para coletar informações } \\
\text { de clientes a partir de fontes online? }\end{array}$ & $\begin{array}{l}\text { Tippins e Sohi (2003) } \\
\text { Pérez-López (2012) }\end{array}$ \\
\hline $\begin{array}{l}\text { A empresa utiliza tecnologias da } \\
\text { informação frequentemente quando se } \\
\text { trata de questões que envolvem o } \\
\text { gerenciamento de informações de } \\
\text { clientes }\end{array}$ & $\begin{array}{l}\text { Tippins e Sohi (2003) } \\
\text { Pérez-López (2012) }\end{array}$ \\
\hline $\begin{array}{l}\text { A empresa usa tecnologias da } \\
\text { informação para analisar informações } \\
\text { de clientes e do mercado? }\end{array}$ & Tippins e Sohi (2003) \\
\cline { 2 - 3 } & $\begin{array}{l}\text { A empres-López (2012) } \\
\text { informação para adquirir, armazenar e } \\
\text { processar informação sobre seus } \\
\text { clientes? }\end{array}$ & Pérez-López (2012) \\
\hline
\end{tabular}

Fonte: elaborado pelo autor.

\subsection{PANORAMA ATUAL DA RBV NO CAMPO DA TI}

Para demonstrar uma visão abrangente do panorama da RBV no campo da tecnologia da informação, foi realizado uma busca na base de dados Web of Science buscando o seguinte conjunto de palavras-chaves e filtro por artigos e revisões: ("Resource-Based View" and "Information Technology") OR ("ResourceBased View" and "IT capability") OR ("RBV" and "Information Technology") OR ("RBV" and "IT capability") OR ("Information Technology Capability" and "ResourceBased View”) OR (“Information Technology Capability").

Conforme o Gráfico 1, foi possível notar que o tema ainda vem sendo foco de estudos pelos pesquisadores desse campo de estudo, visto o cresimento expressivo de estudos relacionados a esse tema. 
Gráfico 1 - Publicações sobre o tema ao longo dos últimos 20 anos

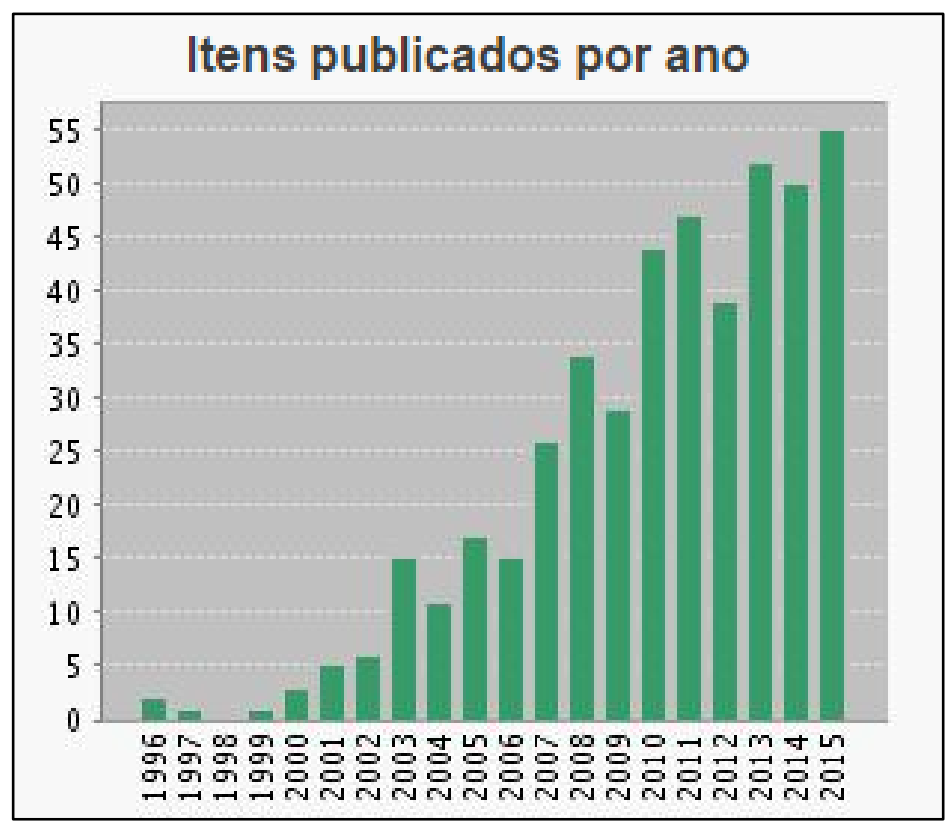

Fonte: Web of Science

Nos últimos anos, é possível notar que o número de publicações apresenta uma tendência de crescimento, ou seja, esse campo de estudo ainda não se encontra saturado, o que indica que ainda existe temas que estão sendo foco dos pesquisadores para que seja alcançado uma estabilização sobre esse tema de pesquisa.

Com o objetivo de se ter uma visão mais abrangente dos estudos que compõem essa amostra identificada foi feito uma análise para entender como os artigos estão distribuídos por autores, por polos de pesquisas, e por periódicos. Os resultados dessa análise são apresentados nos Gráfico 2, Gráfico 3 e Gráfico 4, respectivamente.

A distribuição das publicações por autores é apresentada no Gráfico 2, onde é possível notar que existe um conjunto relevante de autores que publicaram uma quantidade representativa de artigos nesse campo de estudo: os 11 autores apresentados correspondem a $12,94 \%$ de todas as publicações, o que demonstra um nível representativo de centralização das publicações sobre esses autores. 
Gráfico 2 - Distribuição das publicações por autores

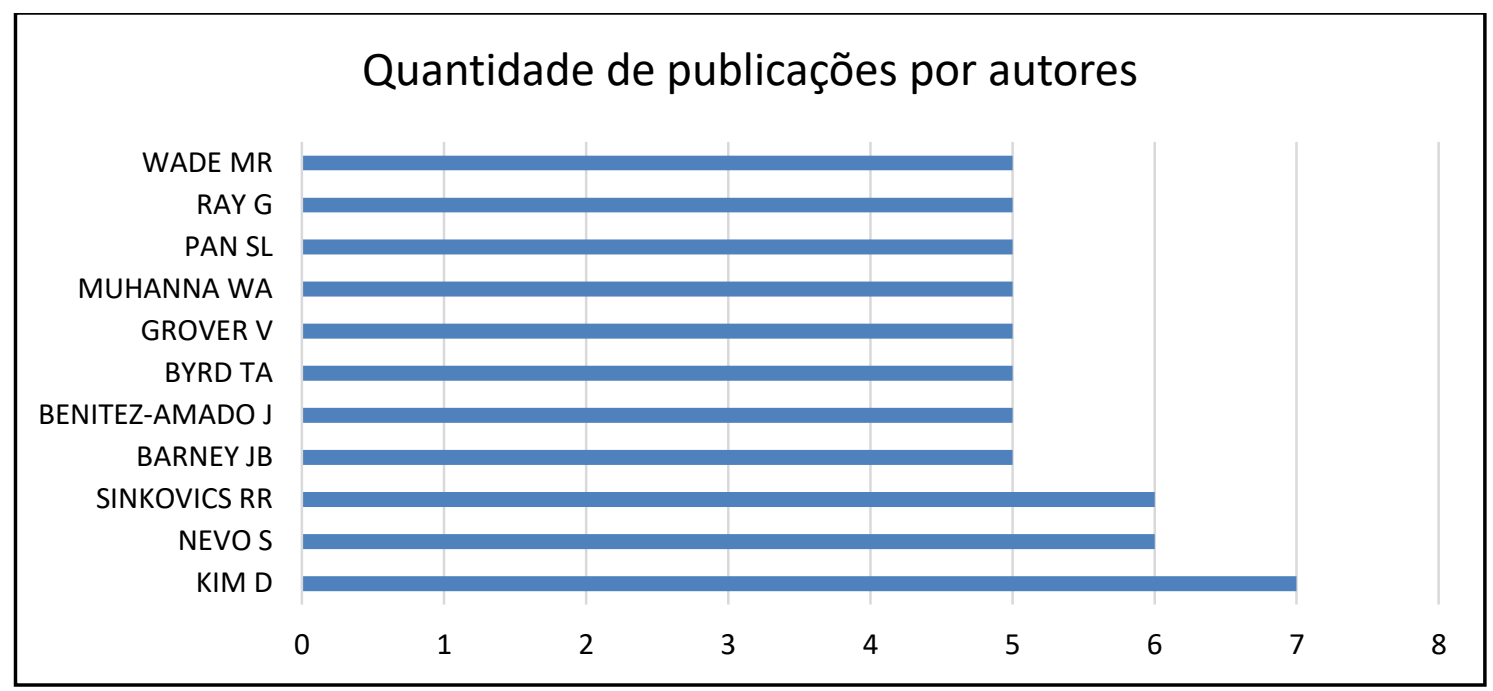

Fonte: elaborado pelo autor.

Porém é importante ressaltar que um número elevado de publicações não garante que a relevância dos seus trabalhos seja alta para o campo de estudo, para chegar a essa conclusão é preciso verificar os periódicos nos quais os artigos foram publicados e a quantidade de vezes que ele foi citado.

O principal pólo de desenvolvimento de estudos sobre o assunto do presente artigo são países desenvolvidos como os Estados Unidos, seguido da China, Inglaterra, Espanha e Taiwan, conforme o Gráfico 3.

O Estados Unidos é o principal pólo de publicações nesse campo de estudo com uma média estável de 22,4 publicações por ano. E a China vem cada vez mais aumentando a quantidade de estudos nesse campo.

Gráfico 3 - Distribuição das publicações por países

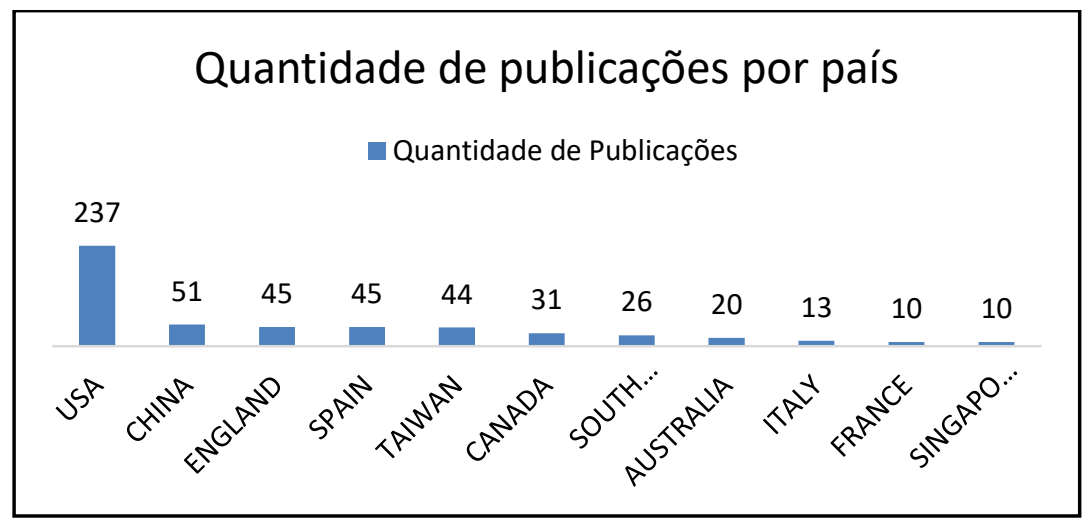

Fonte: elaborado pelo autor. 
Por meio do Gráfico 4, é possível notar que grande parte das publicações dentro desse campo de pesquisa são publicados em periódicos relacionados com a gestão, estratégia e sistemas de informação.

Gráfico 4 - Distribuição das publicações por periódico e fator de impacto

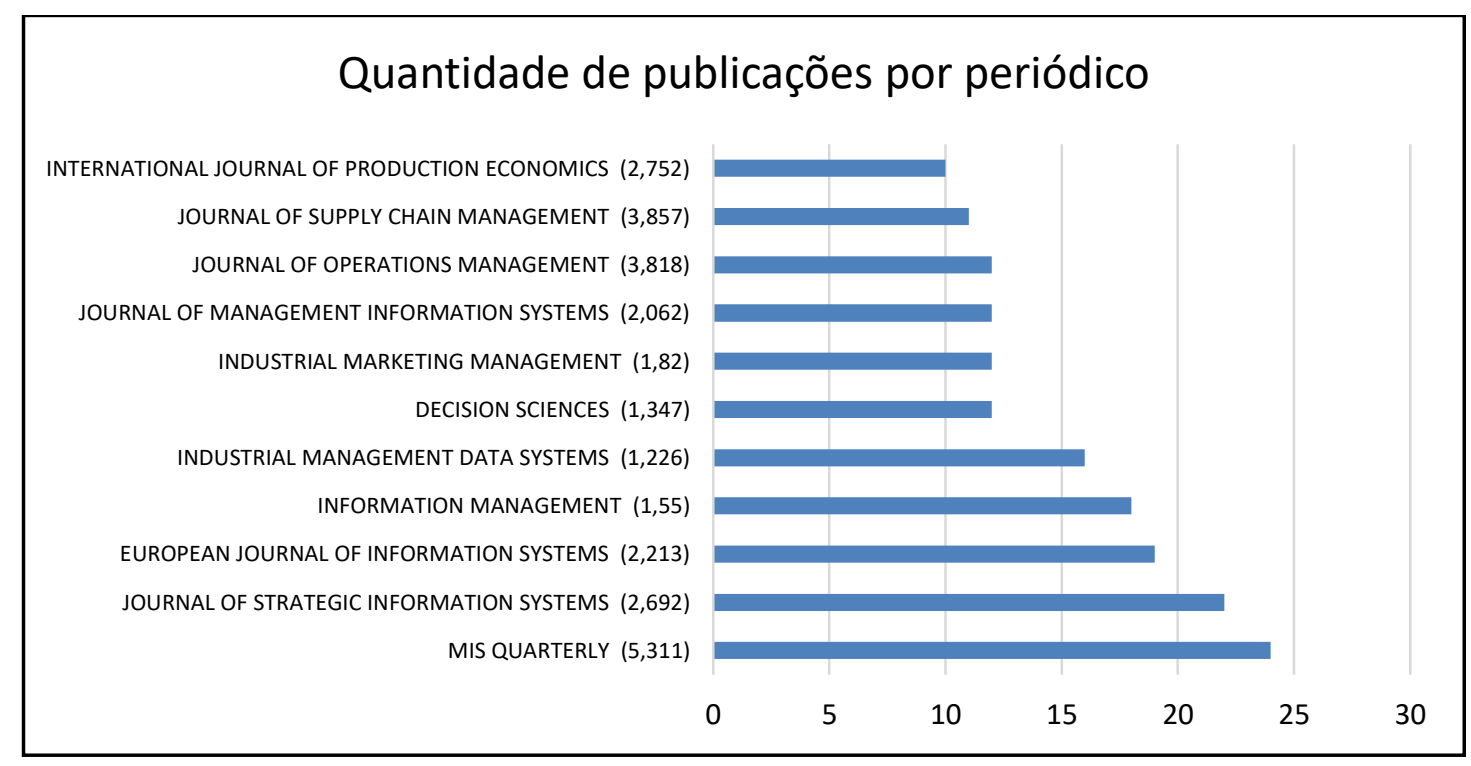

Fonte: elaborado pelo autor.

Para se ter uma visão da concentração das principais temáticas associadas com o campo de pesquisa foi realizada uma análise de key-words. Foi identificada uma alta concentração de estudos envolvendo aspectos relacionandos com a performance da organização, capacidades, capacidades dinâmicas, capacidades de TI, vantagem competitiva, e-business, valor de negócio pela TI, gestão do conhecimento, gestão da cadeia de suprimento, gestão estratégica, gestão do relacionamento com o cliente, inovação e recursos de TI.

A Figura 4 apresenta a consolidação das principais key-words identificadas na amostra inicial e classificadas nos seguintes campos: processos, gestão, capacidades, segmento e performance. 
Figura 4 - Principais palavras-chaves envolvidas com a TI e RBV

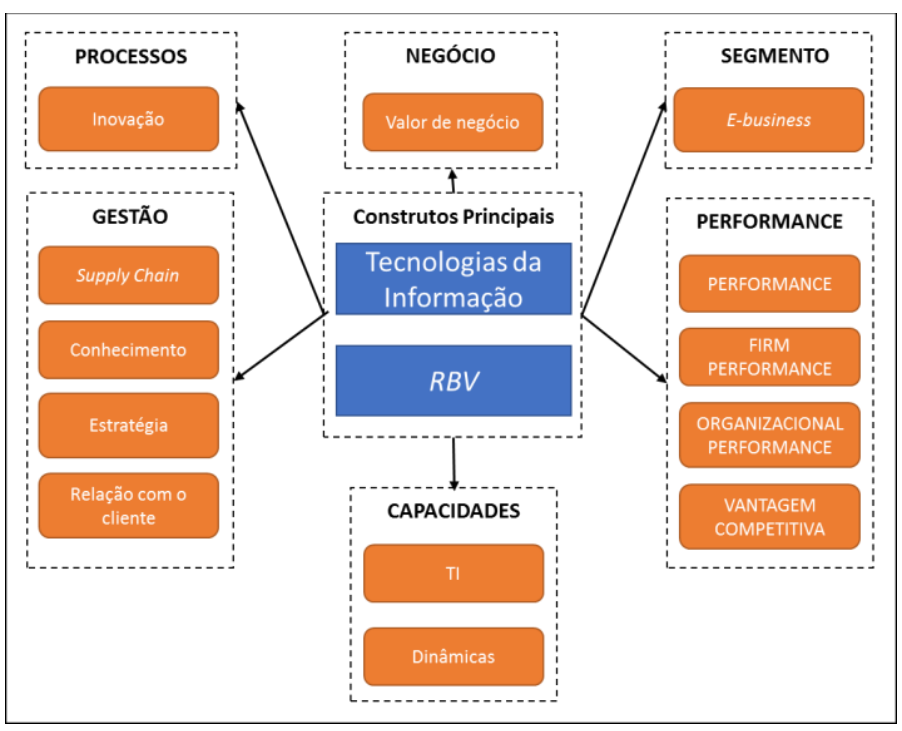

Fonte: elaborado pelo autor.

A Tabela 1 apresenta os artigos com mais de 200 citações na amostra coletada, é possível notar que grande parte dos artigos foram publicados em periódicos relacionados com a gestão estratégica e com sistemas de informação.

Após a leitura dos abstracts dos estudos identificados foi possível identificar que a maioria dos estudos trazem o construto tecnologia da informação/sistemas de informação associado as seguintes temáticas: competência, capacidade, e-business, processos de negócio, valor de negócio, performance organizacional, vantagem competitiva. Em relação aos tipos de métodos de pesquisa utilizados é possível notar uma certa variedade desde revisões da literatura, até a proposição de modelos que são validados por meio de pesquisas do tipo survey.

Tabela 1 - Publicações com mais citações na amostra (continua)

\begin{tabular}{llcc}
\hline \multicolumn{1}{c}{ Autores } & \multicolumn{1}{c}{ Periódico } & Ano & Total de citações \\
\hline DAY, G. S. & JOURNAL OF MARKETING & 1994 & 1514 \\
BHARADWAJ, A. S. & MIS QUARTERLY & 2000 & 867 \\
MELVILLE, N.; & MIS QUARTERLY & 2004 & 590 \\
$\begin{array}{l}\text { RAEMER, K.; } \\
\text { GURBAXANI, V. }\end{array}$ & & \\
MATA, F. J.; & MIS QUARTERLY & 1995 & 582 \\
$\begin{array}{l}\text { FUERST, W. L.; } \\
\text { BARNEY, J. B. }\end{array}$ & & \\
$\begin{array}{l}\text { POWELL, T. C.; } \\
\text { DENTMICALLEF, A. }\end{array}$ & STRATEGIC MANAGEMENT JOURNAL & 1997 & 561 \\
$\begin{array}{l}\text { RAY, G.; } \\
\text { BARNEY, J. B.; }\end{array}$ & STRATEGIC MANAGEMENT JOURNAL & 2004 & 393 \\
MUHANNA, W. A. & & & \\
TIPPINS, M. J.; & STRATEGIC MANAGEMENT JOURNAL & 2003 & 361 \\
SOHI, R. S. & & &
\end{tabular}


Tabela 2 - Publicações com mais citações na amostra (conclusão)

\begin{tabular}{llcc}
\hline \multicolumn{1}{c}{ Autores } & \multicolumn{1}{c}{ Periódico } & Ano & Total de citações \\
\hline NEWBERT, S. L. & STRATEGIC MANAGEMENT JOURNAL & 2007 & 319 \\
$\begin{array}{l}\text { PRIEM, R. L.; } \\
\text { BUTLER, J. E. }\end{array}$ & ACADEMY OF MANAGEMENT REVIEW & 2001 & 281 \\
$\begin{array}{l}\text { ZHU, K.; } \\
\text { KRAEMER, K. L. }\end{array}$ & INFORMATION SYSTEMS RESEARCH & 2005 & 267 \\
$\begin{array}{l}\text { BARUA, A.; } \\
\text { KONANA, P.; } \\
\text { WHINSTON, A.B.; }\end{array}$ & MIS QUARTERLY & 2004 & 234 \\
$\begin{array}{l}\text { YIN, F. } \\
\begin{array}{l}\text { SANTHANAM, R.; } \\
\text { HARTONO, E. }\end{array}\end{array}$ & & \\
$\begin{array}{l}\text { ZHU, K.; } \\
\text { KRAEMER, K. L. }\end{array}$ & MIS QUARTERLY & 2003 & \\
$\begin{array}{l}\text { RAY, G.; } \\
\text { MUHANNA, W. A.; } \\
\text { BARNEY, J. B. }\end{array}$ & MIS QUARTERLY & 224 \\
\hline
\end{tabular}

Fonte: elaborado pelo autor.

\subsection{A GESTÃO DO CONHECIMENTO}

O ativo intangível conhecimento tem um papel fundamental para as organizações, dessa forma antes de ser abordado a gestão do conhecimento, será realizada uma breve análise sobre o que é o conhecimento.

O Quadro 10 apresenta a definição de conhecimento segundo a perspectiva de alguns autores, e pode-se notar que esse conceito na literatura está associado a outros dois conceitos - o dado e a informação. Esse, por sua vez, tem uma importância muito grande na literatura que envolve a tecnologia da informação e comunicação, principalmente devido a presença de sistemas de informação que estão relacionados com cada um desses conceitos.

No presente estudo, o conhecimento deve ser entendido como uma transformação da informação em instruções que podem direcionar a tomada de decisão em um nível executivo ou então auxiliar as tarefas no nível tático e operacional. Isso, consequentemente, pode contribuir para que a empresa alcance a vantagem competitiva, porém esse processo pode depender de um processo humano quando se trata de um conhecimento tácito ou da tecnologia da informação quando se trata de um conhecimento explícito que é mais fácil de codificar, estruturar e comunicar (ACKOFF, 1989; NONAKA e TAKEUCHI, 1997, DAVENPORT, 1998; BRAGANZA, 2004) 
Quadro 10 - Definições dos conceitos: Dados, Informação e Conhecimento

\begin{tabular}{|c|c|c|c|}
\hline Autor & Dados & Informação & Conhecimento \\
\hline $\begin{array}{l}\text { ACKOFF } \\
(1989)\end{array}$ & $\begin{array}{l}\text { Dados são símbolos que } \\
\text { representam as } \\
\text { propriedades de objetos e } \\
\text { eventos. }\end{array}$ & $\begin{array}{l}\text { A informação consiste em } \\
\text { dados processados, e o } \\
\text { processamento tem o intuito } \\
\text { de aumentar sua utilidade. }\end{array}$ & $\begin{array}{l}\text { O conhecimento é a } \\
\text { transformação da } \\
\text { informação em } \\
\text { instruções. }\end{array}$ \\
\hline $\begin{array}{l}\text { NONAKA e } \\
\text { TAKEUCHI } \\
(1997)\end{array}$ & & $\begin{array}{l}\text { A informação é um meio ou } \\
\text { material necessário para } \\
\text { extrair e construir o } \\
\text { conhecimento. }\end{array}$ & $\begin{array}{l}\text { O conhecimento é } \\
\text { considerado um } \\
\text { processo humano } \\
\text { dinâmico de justificar a } \\
\text { crença pessoal com } \\
\text { relação à "verdade". }\end{array}$ \\
\hline $\begin{array}{l}\text { DAVENPORT } \\
\text { (1998) }\end{array}$ & $\begin{array}{l}\text { Simples observações sobre } \\
\text { o estado do mundo. } \\
\text { - Facilmente estruturado } \\
\text { - Facilmente obtido por } \\
\text { máquinas } \\
\text { - Frequentemente } \\
\text { - } \text { quantificado }\end{array}$ & $\begin{array}{l}\text { Dados dotados de relevância } \\
\text { e propósito. } \\
\text { - Requer unidade de } \\
\text { Análise } \\
\text { - Exige consenso em } \\
\text { relação ao significado } \\
\text { - Exige necessariamente a } \\
\text { mediação humana }\end{array}$ & $\begin{array}{l}\text { Informação valiosa da } \\
\text { mente humana. Inclui } \\
\text { reflexão, síntese, } \\
\text { contexto. } \\
\text { - De difícil } \\
\text { estruturação } \\
\text { - De difícil captura em } \\
\text { - } \text { máquinas } \\
\text { Frequentemente } \\
\text { - } \text { tácito } \\
\text { De difícil } \\
\text { transferência }\end{array}$ \\
\hline $\begin{array}{l}\text { BRAGANZA } \\
(2004)\end{array}$ & $\begin{array}{l}\text { Os dados são elementos } \\
\text { que constituem uma } \\
\text { informação. }\end{array}$ & $\begin{array}{l}\text { A informação é o que as } \\
\text { pessoas ou sistemas } \\
\text { precisam para serem } \\
\text { capazes de realizar suas } \\
\text { atividades. }\end{array}$ & $\begin{array}{l}\text { O conhecimento } \\
\text { segundo o modelo } \\
\text { Knowledge-Information- } \\
\text { Data (KID) apresentado } \\
\text { pelo autor é explícito, ou } \\
\text { seja, pode ser } \\
\text { codificado, estruturado e } \\
\text { comunicado facilmente. }\end{array}$ \\
\hline
\end{tabular}

Fonte: elaborado pelo autor. 
Dentro do contexto da gestão estratégica existe a knowledge-based theory que de acordo com Grant (1996) vai além das questões tradicionais de gestão estratégica (escolha estratégica e vantagem competitiva), se preocupando com questões fundamentais sobre a teoria das organizações, notavelmente a natureza da coordenação dentro das organizações, a estrutura organizacional, o papel da gestão e da atribuição de tomadas de decisão corretas, fronteiras determinantes da organização, e a teoria da inovação. Para o autor, um dos conceitos importantes é que um input crítico na produção e uma fonte primária de valor é o conhecimento. A criação desse conhecimento é uma atividade individual, e o papel primário da organização deve ser a aplicação de conhecimento existente na produção de bens e de serviços, essas são as principais ênfases da knowledge-based theory. Além disso, uma característica dessa abordagem é que ela oferece uma base teórica para entender inovações e tendências organizacionais.

Segundo Nonaka e Takeuchi (1997), a criação do conhecimento organizacional corresponde à capacidade de uma organização criar e difundir um novo conhecimento pela empresa, assim como incorporá-lo a produtos, serviços e sistemas. Além disso, os autores destacam que a criação do conhecimento organizacional deve ser entendida em dois componentes principais: as formas de interação do conhecimento (tácito e explícito) e os níveis de criação de conhecimento (individual, grupo e organizacional).

Como foi supracitado, o conhecimento pode ser classificado em dois tipos: o conhecimento explícito e o conhecimento tácito. O Quadro 11 apresenta as principais definições em relação a essa classificação. O conhecimento explícito tem uma característica de ser mais fácil de ser entendido e codificado e consequentemente utilizado pela organização como um todo para alcançar uma vantagem competitiva. Já o conhecimento tácito geralmente está em posse dos seus recursos humanos que uma organização possui e é preciso que esse conhecimento individual seja entendido para que possa ser compartilhado dentro da organização.

Quadro 11 - Conhecimento Explícito e Conhecimento Tácito

\begin{tabular}{|l|l|l|}
\hline \multicolumn{1}{|c|}{ Autores } & \multicolumn{1}{|c|}{ Conhecimento Explícito } & \multicolumn{1}{c|}{ Conhecimento Tácito } \\
\hline $\begin{array}{l}\text { POLANYI (1996) } \\
\text { apud AKUDE (2014) }\end{array}$ & $\begin{array}{l}\text { O conhecimento explícito é aquele } \\
\text { que pode ser abertamente }\end{array}$ & $\begin{array}{l}\text { O conhecimento tácito é aquele } \\
\text { mantido na mente humana, uma }\end{array}$ \\
\hline
\end{tabular}




\begin{tabular}{|c|c|c|}
\hline & expressado e comunicado. & $\begin{array}{l}\text { vez que a mente humana tem um } \\
\text { poder "tácito" de descobrir e } \\
\text { guardar a informação. }\end{array}$ \\
\hline $\begin{array}{l}\text { NONAKA e } \\
\text { TAKEUCHI (1997) }\end{array}$ & $\begin{array}{l}\text { Pode ser expresso em palavras e } \\
\text { números, é facilmente comunicado e } \\
\text { compartilhado sob a forma de dados } \\
\text { brutos, fórmulas científicas, } \\
\text { procedimentos codificados ou } \\
\text { princípios universais. }\end{array}$ & $\begin{array}{l}\text { É pessoal e difícil de formalizar } \\
\text { dentro de um contexto, o que } \\
\text { dificulta sua transmissão e } \\
\text { compartilhamento com outros. Além } \\
\text { disso, esse tipo de conhecimento } \\
\text { está enraizado nas ações e } \\
\text { experiências de um indivíduo ou } \\
\text { uma equipe, bem como em suas } \\
\text { emoções, valores ou ideais. }\end{array}$ \\
\hline HARLOW (2008) & & $\begin{array}{l}\text { O conhecimento tácito é } \\
\text { naturalmente interno e } \\
\text { relativamente difícil de codificar e } \\
\text { extrair. }\end{array}$ \\
\hline $\begin{array}{l}\text { WILD e GRIGGS } \\
(2008)\end{array}$ & $\begin{array}{l}\text { Conhecimento explícito como o } \\
\text { conhecimento sobre mercados, } \\
\text { clientes, fornecedores, } \\
\text { características de produtos, bem } \\
\text { como características de processos e } \\
\text { tecnologias que ajudam no } \\
\text { desempenho dos funcionários em } \\
\text { suas atividades para melhorar } \\
\text { produtos e serviços oferecidos para } \\
\text { os clientes. }\end{array}$ & \\
\hline MOHAMED (2008) & $\begin{array}{l}\text { O conhecimento explícito pode ser } \\
\text { armazenado em bases de dados e } \\
\text { em manuais. }\end{array}$ & $\begin{array}{l}\text { O conhecimento tácito é o } \\
\text { conhecimento pessoal usado por } \\
\text { indivíduos para melhorar seu } \\
\text { trabalho. }\end{array}$ \\
\hline $\begin{array}{l}\text { HOLSTE e FIELDS } \\
(2010)\end{array}$ & $\begin{array}{l}\text { É frequentemente impessoal e } \\
\text { formal por natureza, e } \\
\text { frequentemente toma a forma de } \\
\text { documentos, relatórios, catálogos, } \\
\text { apresentações, fórmulas, patentes, } \\
\text { etc. }\end{array}$ & $\begin{array}{l}\text { É altamente pessoal e difícil de ser } \\
\text { traduzido para uma forma escrita. }\end{array}$ \\
\hline
\end{tabular}




\begin{tabular}{|l|l|l|}
\hline WANG et al. (2014) & $\begin{array}{l}\text { É um conhecimento que pode existir } \\
\text { em uma forma simbólica ou } \\
\text { registrada. }\end{array}$ & $\begin{array}{l}\text { É um conhecimento que não pode } \\
\text { ser expressado verbalmente, } \\
\text { simbolicamente ou registrado. }\end{array}$ \\
\hline $\begin{array}{l}\text { WAGNER et al. } \\
(2014)\end{array}$ & $\begin{array}{l}\text { O conhecimento explícito é } \\
\text { codificável, sistemático, formal e } \\
\text { mais fácil de ser disseminado. }\end{array}$ & $\begin{array}{l}\text { O conhecimento tácito é pessoal, } \\
\text { tem um contexto específico e é um } \\
\text { conhecimento subjetivo. }\end{array}$ \\
\hline
\end{tabular}

Fonte: elaborado pelo autor.

Nonaka e Takeuchi (1997) destacam quatro modos diferentes de conversão do conhecimento, conforme Figura 5 e detalhados a seguir baseado na visão dos autores:

- Socialização: conversão do conhecimento tácito em conhecimento explícito. É um processo de compartilhamento de experiências. Essa conversão ocorre por meio de interações sociais e troca de experiência entre membros da organização. Exemplos de métodos empregados: sessões de brainstorming reuniões formais para discussões detalhadas destinadas a resolver problemas difíceis nos projetos em desenvolvimento; observação, imitação e prática; e interação com clientes (NOKANA e TAKEUCHI, 1997; ALAVI e LEIDNER, 2001)

- Externalização: conversão do conhecimento tácito em conhecimento explícito. É um processo de criação do conhecimento, na medida em que o conhecimento tácito se torna explícito, expresso na forma de metáforas, analogias, conceitos, hipóteses ou modelos. Exemplos de métodos empregados: combinação da dedução e indução (NOKANA e TAKEUCHI, 1997; ALAVI e LEIDNER, 2001)

- Combinação: conversão do conhecimento explícito em conhecimento explícito. É um processo de sistematização de conceitos em um sistema de conhecimento. Se refere a criação de novos conhecimentos explícitos por meio da combinação, categorização, e sintetização do conhecimento explícito existente. Os indivíduos trocam e combinam conhecimentos através de meios como documentos, reuniões, conversas ao telefone ou redes de comunicação computadorizadas (NOKANA e TAKEUCHI, 1997; ALAVI e LEIDNER, 2001)

- Internalização: conversão do conhecimento explícito em conhecimento tácito. É um processo de incorporação do conhecimento explícito no conhecimento 
tácito. Quando são internalizadas nas bases do conhecimento tácito dos indivíduos sob a forma de modelos mentais ou know-how técnico compartilhado, as experiências através da socialização, externalização e combinação tornam-se ativos valiosos (NOKANA e TAKEUCHI, 1997; ALAVI e LEIDNER, 2001)

Figura 5 - Modos de conversão do conhecimento

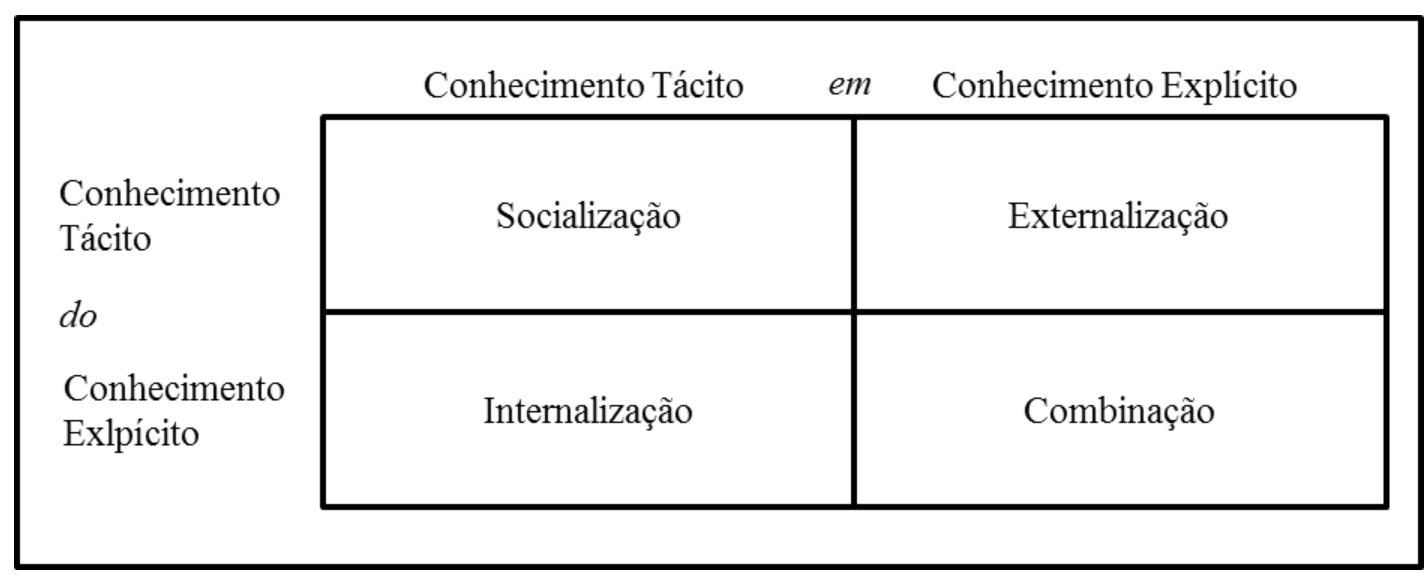

Fonte: Nonaka e Takeuchi, 1997.

A forma como a empresa utiliza seus recursos para gerir o conhecimento tácito e o conhecimento explícito pode ser denominado gestão do conhecimento.

Choi e Lee (2002), destacam que os métodos de gestão voltados para o conhecimento explícito enfatizam a capacidade de criação, armazenamento, compartilhamento e uso do conhecimento documentado, enquanto os métodos voltados para o conhecimento tácito enfatizam o compartilhamento do conhecimento pela interação interpessoal. O Quadro 12 apresenta as definições da gestão do conhecimento sob a perspectiva de alguns autores identificados na literatura.

Quadro 12 - Gestão do conhecimento

\begin{tabular}{|l|l|}
\hline \multicolumn{1}{|c|}{ Autores } & \multicolumn{1}{|c|}{ Gestão do Conhecimento } \\
\hline Meso e Smith (2000) & $\begin{array}{l}\text { É o processo de captura da expertise e inteligência coletiva em } \\
\text { uma organização e uso deles para criar inovação por meio de } \\
\text { um aprendizado organizacional contínuo. }\end{array}$ \\
\hline Martensson (2000) & $\begin{array}{l}\text { Aquisição e armazenamento do conhecimento dos } \\
\text { colaboradores e viabilizar o acesso à informação aos outros } \\
\text { colaboradores por toda a organização. }\end{array}$ \\
\hline
\end{tabular}




\begin{tabular}{|l|l|}
\hline Chuang (2004) & $\begin{array}{l}\text { Habilidade de reunir e integrar recursos ligados a gestão do } \\
\text { conhecimento em combinação com recursos e capacidades de } \\
\text { outras áreas. }\end{array}$ \\
\hline Halawi et al. (2006) & $\begin{array}{l}\text { Desenvolvimento de abordagens para obter o conhecimento } \\
\text { certo para o indivíduo certo na hora certa e no formato certo, de } \\
\text { forma que seja possível desenvolver novas capacidades o que } \\
\text { permitiria um melhor desempenho da organização. }\end{array}$ \\
\hline Greiner et al. (2007) & $\begin{array}{l}\text { Inclui todas as atividades que utilizam o conhecimento para } \\
\text { realizar os objetivos da organização para enfrentar os desafios } \\
\text { do ambiente e se manter competitiva no mercado. }\end{array}$ \\
\hline Muniz et al. (2009) & $\begin{array}{l}\text { A gestão do conhecimento pode ser entendida como uma } \\
\text { atuação "orquestrada" de capturar, preservar, compartilhar e } \\
\text { utilizar/reutilizar os conhecimentos tácitos e explícitos criados } \\
\text { por seus colaboradores, de modo a gerar resultados } \\
\text { mensuráveis para a organizaçãoe para as pessoas }\end{array}$ \\
\hline Andreeva e Kianto (2012) & $\begin{array}{l}\text { Conjunto de atividades de gestão que viabilizam a entrega de } \\
\text { valor por meio de ativos do conhecimento. }\end{array}$ \\
\hline
\end{tabular}

Fonte: elaborador pelo autor.

A gestão do conhecimento é composta por processos de conhecimento, que podem ser empregados em determinadas práticas gerenciais. Essas práticas de gestão do conhecimento são aspectos da organização que são manipuláveis e controláveis por atividades concisas e intencionais de gestão.

Wild e Griggs (2008) dividem a gestão do conhecimento em três perspectivas: a informacional, a tecnológica e a cultural. Em relação à perspectiva informacional os autores destacam que os gestores veem a gestão do conhecimento como um meio de manter controle não só sobre o próprio conhecimento, mas também sobre quem detém o conhecimento e como localizá-lo. Na perspectiva tecnológica, os gestores geralmente associam a gestão do conhecimento com vários sistemas e ferramentas. Por fim a perspectiva cultural envolve os aspectos de aprendizado, comunicação e propriedade intelectual. O Quadro 13 apresenta de forma sucinta os principais aspectos e questões envolvidas sobre cada perspectiva em relação à gestão do conhecimento. 
Quadro 13 - Perspectivas da Gestão do Conhecimento

\begin{tabular}{|c|c|c|}
\hline Cultura & Informação & Tecnologia \\
\hline $\begin{array}{l}\text { - } \text { Aprendizado } \\
\text { - } \text { organizacional } \\
\text { - } \text { Comunicação } \\
\text { - Propriedade Intelectual } \\
\text { Processos de negócio }\end{array}$ & $\begin{array}{ll}\text { - } & \text { Acesso rápido } \\
\text { - } & \text { Real-time } \\
\text { - } & \text { Quem detém o } \\
\text { conhecimento? } \\
\text { - Como localizar o } \\
\text { conhecimento? }\end{array}$ & $\begin{array}{ll}\text { - } & \text { Data warehouse } \\
\text { - } & \text { Intranet } \\
\text { - } & \text { Expert Systems } \\
\text { - } & \text { Ferramentas de apoio a } \\
& \text { decisão }\end{array}$ \\
\hline
\end{tabular}

Fonte: adaptado de Wild e Griggs, 2008.

Stankosky (2005) apresenta um modelo composto por quatro pilares que sustentam a gestão do conhecimento, ou seja, são a base o sucesso da gestão do conhecimento e, consequentemente, dos sistemas de gestão de conhecimento. Os quatros pilares são apresentados a seguir segundo a visão de Stankosky (2005):

- Liderança/Gestão: associado com os processos de tomada de decisões ambientais, estratégicos e de nível empresarial envolvendo os valores, objetivos, requisitos de conhecimento, fontes de conhecimento, priorização e alocação de recursos de ativos de conhecimento da organização. Ele salienta a necessidade de princípios de gestão integrada e técnicas, principalmente com base em sistemas de pensamento e abordagens.

- Organização: associado com os aspectos operacionais de ativos de conhecimento, incluindo funções, processos formais e estruturas organizacionais informais, medidas de controle e métricas, melhoria de processos e reengenharia de processos. Subjacente a este pilar são princípios e técnicas de engenharia de sistemas para garantir um fluxo baixo, rastreamento e utilização ótima de todos os ativos de conhecimento da organização.

- Aprendizagem: o pilar de aprendizagem incide sobre os princípios e práticas para garantir que os indivíduos colaborarem e compartilhem conhecimento ao máximo. É dada ênfase à identificação e aplicação dos atributos necessários para estruturar uma "organização que aprende".

- Tecnologia: associado com as diversas tecnologias de informação peculiares de apoio que permitem estratégias e operações de gestão do conhecimento. 
Uma taxonomia relacionada com tecnologias de informação que suportam a colaboração e codificação das estratégias e funções de gestão do conhecimento.

Choi e Lee (2003) classificam os métodos de gestão de conhecimento em quatro estilos: dinâmico, orientado a aspectos sistêmicos, orientado a aspectos humanos e passivo, conforme Figura 6. A identificação do estilo de cada empresa em relação aos métodos de gestão do conhecimento empregados leva em consideração os níveis de orientação para o âmbito explícito ou tácito.

No caso, os autores definem a orientação explícita como o grau de codificação e armazenamento de um conhecimento organizacional para acesso e uso fácil por uma pessoa. Em contrapartida, definem a orientação tácita como o grau de aquisição e compartilhamento de conhecimento organizacional por meio de interações pessoais.

Figura 6 - Estilos de métodos de gestão do conhecimento

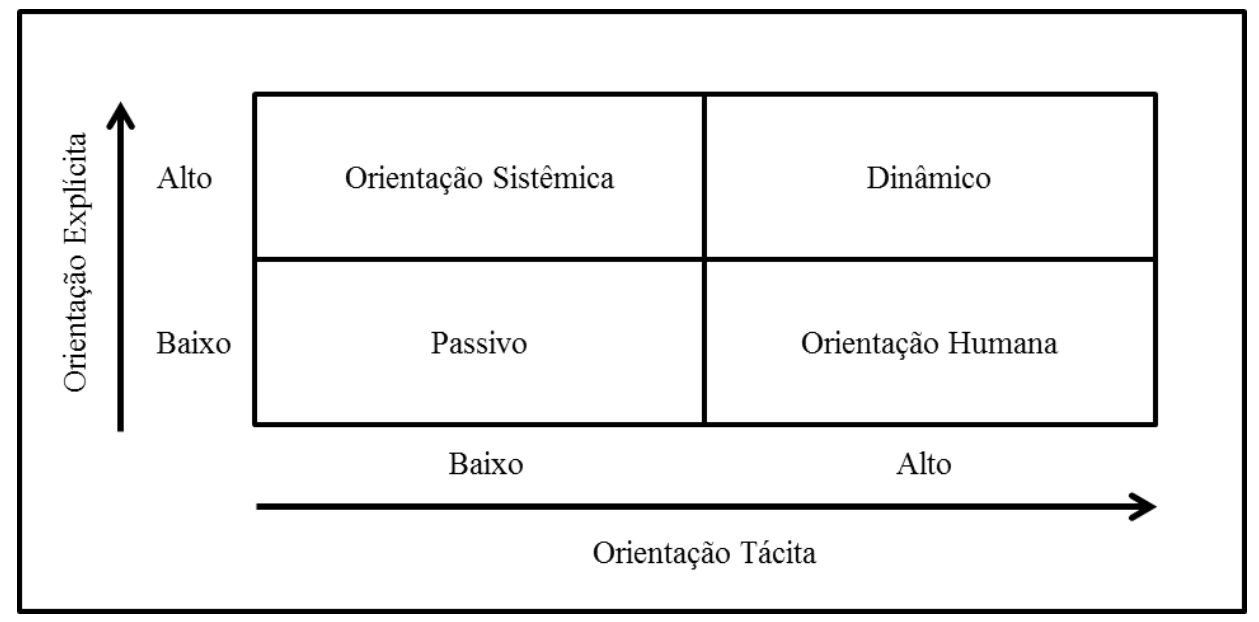

Fonte: Choi e Lee, 2003.

A seguir é apresentada a definição de cada estilo, segundo Choi e Lee (2003):

- Passivo: empresas que apresentam pouco interesse sobre a gestão do conhecimento. A estrutura organizacional, cultura organizacional ou tecnologias da informação não são usadas para o gerenciamento do conhecimento. Dessa forma, empresas que atuam em ambientes turbulentos e se enquadram nesse estilo tendem a ser menos eficientes e eficazes em relação aos concorrentes. 
- Orientação Sistêmica: empresas que mantém o foco sobre a codificação e reutilização do conhecimento. A TI tem um papel importante para esse estilo, devido ao aumento da confiabilidade que proporcionou e a diminuição da complexidade de acesso e uso do conhecimento.

- Orientação Humana: empresas que mantém o foco sobre a aquisição e o compartilhamento do conhecimento tácito e experiências interpessoais. Nessas firmas, o conhecimento surge a partir de redes sociais de trabalho informais e os procedimentos padrão podem ser ignorados para a descoberta de novas formas de operação.

- Dinâmico: empresas que mantém o foco sobre métodos orientados para o âmbito explícito e tácito, o que faz com que sejam mais agressivas e integrativas. Esse estilo dinâmico explora o conhecimento comprovado e explora novos potenciais.

A literatura apresenta com grande frequência os seguintes processos de conhecimento: (i) a criação ou construção ou transformação (NONAKA e TAKEUCHI, 1997; MESO e SMITH, 2000; ALAVI E LEIDNER, 2001; KAKABADSE et al., 2003; HARLOW, 2008; ZACK et al. 2009; JOSHI et al., 2010), (ii) a aquisição ou localização (Meso e Smith, 2000; ZACK et al. 2009; JOSHI et al., 2010; PÉREZLÓPEZ e ALEGRE, 2012), (iii) o armazenamento (MESO e SMITH, 2000; ALAVI E LEIDNER, 2001), (iv) o compartilhamento ou transferência (ALAVI E LEIDNER, 2001; KAKABADSE et al., 2003; RAY et al., 2005; MOHAMED et al., 2006; HARLOW, 2008; HOSTE e FIELDS, 2010), (v) a aplicação ou utilização (MESO e SMITH, 2000; ALAVI E LEIDNER, 2001; HARLOW, 2008; ZACK et al. 2009; PÉREZLÓPEZ e ALEGRE, 2012) e (vi) a proteção (ZACK et al. 2009).

A seguir é apresentado uma descrição de cada processo citado. Esses são os processos que serão levados em consideração no estudo em questão, como sendo a base para a gestão do conhecimento de uma organização.

O processo de criação do conhecimeto pode ser entendido como a capacidade de uma organização criar um novo conhecimento ou substituir um conhecimento, para incorporá-los a produtos, serviços e sistemas. (NONAKA e TAKEUCHI, 1997; ALAVI e LEIDNER, 2001) 
Nonaka e Takeuchi (1997) apresentam um questionamento em seu estudo em relação a esse processo: "Quem é o responsável pela criação do novo conhecimento? ". A resposta dos autores é que a criação do novo conhecimento é produto de uma interação dinâmica entre diversos agentes dentro de uma organização, independentemente da hierarquia em que a pessoa se encontra, mas cada um com uma determinada responsabilidade. Nesse contexto, os autores apresentam um olhar sobre o ambiente interno da organização, porém conforme Alavi e Leidner (2001), a empresa também pode criar conhecimento a partir da obtenção de informações do ambiente externo, que processadas de forma correta podem gerar um conhecimento útil para uma organização.

O processo de aquisição do conhecimento pode ser entendido como a capacidade de a organização identificar e obter o conhecimento, interno ou externo à organização. As empresas devem sempre buscar novos e melhores conhecimentos para aumentar sua competitividade, e para isso é preciso manter o foco sobre os conhecimentos que são críticos para a sua operação. A habilidade da aquisição do conhecimento interno e externo é denominada de integração e, segundo Nonaka e Takeuchi (1997), o sucesso das empresas japonesas se deve à preocupação das mesmas em integrar mundo externo e interno, e esse comportamento seria o que abastece a inovação contínua dentro das organizações. (NONAKA e TAKEUCHI, 1997; JOSHI et al., 2010; PÉREZ-LÓPEZ e ALEGRE, 2012)

Diferentemente do processo de criação do conhecimento, o processo de aquisição busca um conhecimento que já existe, seja ele externo à organização - experiências e necessidades dos clientes e/ou fornecedores, relatórios econômicos e práticas de sucesso em outras organizações, por exemplo - ou então um conhecimento interno à organização - experiências dos próprios colaboradores nos afazeres do dia-a-dia de forma a sempre buscar melhorar o formato do trabalho, por exemplo. (ALAVI e LEIDNER, 2001; ZACK et al., 2009; PÉREZ-LÓPEZ e ALEGRE, 2012)

O processo de armazenamento do conhecimento está associado com a memória organizacional, que inclui os conhecimentos que residem em várias formas de componentes: documentos, bases de dados, sistemas baseados em inteligência artificial, procedimentos e processos organizacionais, e o conhecimento adquirido por indivíduos ou comunidades. Esse processo, de forma sucinta, consiste no processo de uma organização codificar o conhecimento interno e externo à 
organização e armazená-lo de forma que possa ser recuperado com facilidade para que seja tomada algum tipo de decisão (ALAVI e LEIDNER, 2001).

O processo de compartilhamento do conhecimento pode ser entendido como a capacidade de a organização disseminar o conhecimento por toda a organização. Essa capacidade é considerada rara e tem um custo elevado para ser imitada por concorrentes. Esse processo pode ocorrer em diversos níveis: entre indivíduos, de indivíduos para comunidades, entre comunidades, dentro de comunidades, e de uma comunidade para a organização (ALAVI e LEIDNER, 2001; RAY et al., 2005; PÉREZ-LÓPEZ e ALEGRE, 2012).

Esse processo é um dos mais desafiadores, pois depende de diversos fatores como, por exemplo, a cultura da organização. Oliveira et al. (2008) destacam a importância de uma cultura voltada para a contribuição para a GC mais eficaz, pois nesse contexto as capacidades de tecnologia da informação têm o papel de facilitar a busca e a localização do conhecimento, e auxiliar na sua disseminação por meio de múltiplos canais e ferramentas. Segundo King e Marks Junior (2008), o indivíduo é um potencial participante do compartilhamento do conhecimento.

Os processos de gestão do conhecimento supracitados são a base para que uma organização possa aplicar o conhecimento. Segundo Alavi e Leidner (2001), os processos de criação, armazenamento e compartilhamento não necessariamente aumentam o desempenho organizacional, mas a aplicação do conhecimento que uma organização possui sim. O desempenho organizacional frequentemente depende mais da habilidade da organização converter o conhecimento em ações efetivas.

O processo de aplicação do conhecimento sobre os produtos e serviços é considerado um dos aspectos mais desafiadores na gestão do conhecimento, e tem um papel importante para que as organizações alcancem as vantagens competitivas. Além disso, esse processo está totalmente associado com questões que envolvem a tomada de decisão. Dessa forma, o conhecimento pode ser aplicado tanto para melhorar os processos internos como para buscar novas maneiras da empresa se posicionar em relação aos seus concorrentes, o que retrata uma aplicação mais estratégica por meio do uso do conhecimento que a empresa 
possui (ALAVI e LEIDNER, 2001; HARLOW, 2008; PÉREZ-LÓPEZ e ALEGRE, 2012).

Por fim, um processo que ainda não tem sido grande foco de pesquisadores na literatura, visto os poucos estudos identificados sobre esse assunto, é o processo de proteção de todo o conhecimento que a empresa possui, principalmente quando se trata de um conhecimento crítico que posiciona a empresa a frente de seus concorrentes.

O processo de proteção do conhecimento é importante para que a empresa evite perder conhecimento ou então evitar que o conhecimento que ela possui seja adquirido por outras organizações, o que pode contribuir para que a organização perca a sua competitividade, caso o conhecimento seja crítico para a sua diferenciação. Pode ser entendido como a capacidade de a empresa reter o seu capital humano, evitando que o ocorra um êxodo de conhecimento para outras empresas concorrentes. Além disso, também engloba a questão de controle de acessos a determinados conhecimentos que podem ser restritos a um determinado público (ZACK et al., 2009).

A partir da revisão da literatura, foram identificados diversos processos de gestão do conhecimento que foram incluídos no modelo de pesquisa com o intuito de incrementar o modelo apresentado por Pérez-López e Alegre (2012), no qual foram utilizados apenas os processos de gestão do conhecimento: aquisição do conhecimento, compartilhamento do conhecimento e aplicação do conhecimento. Os outros três processos que foram incluídos no presente modelo de pesquisa foram a criação do conhecimento, o armazenamento do conhecimento e a proteção do conhecimento.

Baseado na literatura supracitada o Quadro 14 apresenta as variáveis que serão utilizadas no estudo com o objetivo de mensurar o processo de criação do conhecimento.

Quadro 14 - Variáveis referentes à criação do conhecimento

\begin{tabular}{|l|l|l|}
\hline \multicolumn{1}{|c|}{ Processo de GC } & \multicolumn{1}{|c|}{ Variáveis } & \multicolumn{1}{c|}{ Autores } \\
\hline $\begin{array}{l}\text { Criação do } \\
\text { conhecimento }\end{array}$ & $\begin{array}{l}\text { A empresa possui processos bem } \\
\text { definidos para obter informações do seu } \\
\text { ambiente externo para gerar } \\
\text { conhecimentos para uso interno? }\end{array}$ & Alavi e Leidner (2001) \\
\hline
\end{tabular}




\begin{tabular}{|l|l|l|}
\hline 0,810 pelo estudo & $\begin{array}{l}\text { A empresa possui processos bem } \\
\text { definidos que permitem um trabalho } \\
\text { colaborativo entre os seus funcionários? }\end{array}$ & Meso e Smith (2000) \\
\cline { 2 - 3 } & $\begin{array}{l}\text { A empresa incentiva a formação de } \\
\text { comunidades de práticas para } \\
\text { desenvolver o conhecimento da } \\
\text { organização em um determinado } \\
\text { assunto? }\end{array}$ & Alavi e Leidner (2001) \\
\hline
\end{tabular}

Fonte: elaborado pelo autor.

O Quadro 15 apresenta as variáveis que serão utilizadas no estudo com o objetivo de mensurar o processo de aquisição do conhecimento.

Quadro 15 - Variáveis referentes à aquisição do conhecimento

\begin{tabular}{|c|c|c|}
\hline Processo de GC & Variáveis & Autores \\
\hline \multirow{7}{*}{$\begin{array}{l}\text { Aquisição do } \\
\text { conhecimento } \\
\text { Alpha de Cronbach: } \\
\text { 0,818 (Pérez-López, } \\
\text { 2012) }\end{array}$} & $\begin{array}{l}\text { A empresa procura se reunir com seus } \\
\text { clientes com o objetivo de identificar } \\
\text { suas necessidades? }\end{array}$ & $\begin{array}{l}\text { Zack et al. (2009) } \\
\text { Pérez-López e Alegre (2012) }\end{array}$ \\
\hline & $\begin{array}{l}\text { A empresa tem processos para } \\
\text { aquisição do conhecimento sobre seus } \\
\text { fornecedores? }\end{array}$ & Pérez-López e Alegre (2012) \\
\hline & $\begin{array}{l}\text { A empresa tem processos para } \\
\text { aquisição do conhecimento sobre o } \\
\text { mercado em que atua? }\end{array}$ & Zack et al. (2009) \\
\hline & $\begin{array}{l}\text { A empresa tem processos que } \\
\text { permitem que seja capitalizado } \\
\text { práticas de sucesso de outras } \\
\text { organizações? }\end{array}$ & $\begin{array}{l}\text { Zack et al. (2009) } \\
\text { Pérez-López e Alegre (2012) }\end{array}$ \\
\hline & $\begin{array}{l}\text { A empresa tem processos para gerar } \\
\text { novos conhecimentos a partir do } \\
\text { conhecimento existente? }\end{array}$ & Pérez-López e Alegre (2012) \\
\hline & $\begin{array}{l}\text { Novas abordagens e ideias sobre o } \\
\text { desempenho do trabalho são } \\
\text { experimentadas continuamente? }\end{array}$ & Pérez-López e Alegre (2012) \\
\hline & $\begin{array}{l}\text { A empresa tem mecanismos para } \\
\text { identificar o conhecimento dos seus } \\
\text { colaboradores possuem? }\end{array}$ & Alavi e Leidner (2001) \\
\hline
\end{tabular}

Fonte: elaborado pelo autor.

O Quadro 16 apresenta as variáveis que serão utilizadas no estudo com o objetivo de mensurar o processo de armazenamento do conhecimento 
Quadro 16 - Variáveis referentes ao armazenamento do conhecimento

\begin{tabular}{|c|c|c|}
\hline Processo de GC & Variáveis & Autores \\
\hline \multirow{4}{*}{$\begin{array}{l}\text { Armazenamento do } \\
\text { conhecimento } \\
\text { Alpha de Cronbach: } \\
0,936 \text { pelo estudo }\end{array}$} & $\begin{array}{l}\text { A empresa tem mecanismos para } \\
\text { armazenar o conhecimento criado ou } \\
\text { adquirido? }\end{array}$ & Alavi e Leidner (2001) \\
\hline & $\begin{array}{l}\text { A empresa tem mecanismos para } \\
\text { codificar o conhecimento de forma que } \\
\text { esse possa ser armazenado? }\end{array}$ & Alavi e Leidner (2001) \\
\hline & $\begin{array}{l}\text { O conhecimento armazenado é acessado } \\
\text { e utilizado por indivíduos que não tem } \\
\text { conhecimento do originador do } \\
\text { conhecimento? }\end{array}$ & Alavi e Leidner (2001) \\
\hline & $\begin{array}{l}\text { A empresa tem mecanismos que } \\
\text { permitem a recuperação do conhecimento } \\
\text { de forma eficaz e eficiente? }\end{array}$ & Alavi e Leidner (2001) \\
\hline
\end{tabular}

Fonte: elaborado pelo autor.

O Quadro 17 apresenta as variáveis que serão utilizadas no estudo com o objetivo de mensurar o processo de compartilhamento do conhecimento

Quadro 17 - Variáveis referentes ao compartilhamento do conhecimento

\begin{tabular}{|c|c|c|}
\hline Processo de GC & Variáveis & Autores \\
\hline \multirow{6}{*}{$\begin{array}{l}\text { Compartilhamento do } \\
\text { conhecimento } \\
\text { Alpha de Cronbach: } \\
0,880 \text { (Zack et al., } \\
2009 \text { ) } \\
0,836 \text { (Pérez-López, } \\
2012 \text { ) }\end{array}$} & $\begin{array}{l}\text { Reuniões são periodicamente } \\
\text { agendadas para informa todos os } \\
\text { colaboradores sobre as últimas } \\
\text { inovações da empresa? }\end{array}$ & Pérez-López e Alegre (2012) \\
\hline & $\begin{array}{l}\text { A empresa tem mecanismos formais } \\
\text { para garantir o compartilhamento de } \\
\text { boas práticas de diferentes campos de } \\
\text { atividades? }\end{array}$ & $\begin{array}{l}\text { Zack et al. (2009) } \\
\text { Pérez-López e Alegre (2012) }\end{array}$ \\
\hline & $\begin{array}{l}\text { Existem pessoas que são pontos } \\
\text { focais de determinados assuntos e } \\
\text { que são responsáveis por disseminar } \\
\text { o conhecimento para o restante da } \\
\text { equipe? }\end{array}$ & Pérez-López e Alegre (2012) \\
\hline & $\begin{array}{l}\text { Existem indivíduos responsáveis por } \\
\text { coletar, juntar e distribuir internamente } \\
\text { sugestões dos colaboradores? }\end{array}$ & Pérez-López e Alegre (2012) \\
\hline & $\begin{array}{l}\text { A empresa possui mecanismos que } \\
\text { permitem que o conhecimento seja } \\
\text { compartilhado entre unidades } \\
\text { distribuídas? }\end{array}$ & Alavi e Leidner (2001) \\
\hline & $\begin{array}{l}\text { A empresa tem mecanismos para } \\
\text { disseminar o conhecimento com }\end{array}$ & Andreeva e Kianto (2012) \\
\hline
\end{tabular}




\begin{tabular}{|l|l|l|}
\hline & stakeholders externos à organização? & \\
\cline { 1 - 3 } & $\begin{array}{l}\text { A empresa possui mecanismos que } \\
\text { facilitam a interação e colaboração } \\
\text { entre seus colaboradores? }\end{array}$ & $\begin{array}{l}\text { Adamides e Karacapilidis } \\
\text { (2006) }\end{array}$ \\
\hline
\end{tabular}

Fonte: elaborado pelo autor.

O Quadro 18 apresenta as variáveis que serão utilizadas no estudo com o objetivo de mensurar o processo de aplicação do conhecimento

Quadro 18 - Variáveis referentes à aplicação do conhecimento

\begin{tabular}{|c|c|c|}
\hline Processo de GC & Variáveis & Autores \\
\hline \multirow{4}{*}{$\begin{array}{l}\text { Aplicação do } \\
\text { conhecimento } \\
\text { Alpha de Cronbach: } \\
0,770 \text { (Pérez-López, } \\
2012 \text { ) }\end{array}$} & $\begin{array}{l}\text { A empresa possui processos para } \\
\text { aplicar o conhecimento aprendido a } \\
\text { partir de experiências nas atividades } \\
\text { do dia-a-dia? }\end{array}$ & $\begin{array}{l}\text { Andreeva e Kianto (2012) } \\
\text { Pérez-López e Alegre (2012) }\end{array}$ \\
\hline & $\begin{array}{l}\text { A empresa facilita o acesso ao } \\
\text { conhecimento para aqueles que } \\
\text { precisam dele? }\end{array}$ & Pérez-López e Alegre (2012) \\
\hline & $\begin{array}{l}\text { A empresa possui processos para } \\
\text { utilizar o conhecimento no } \\
\text { desenvolvimento de novos produtos } \\
\text { e/ou serviços? }\end{array}$ & Pérez-López e Alegre (2012) \\
\hline & $\begin{array}{l}\text { A empresa tem capacidade de } \\
\text { identificar e aplicar o conhecimento } \\
\text { para mudar as condições de } \\
\text { concorrência por meio de novas } \\
\text { capacidades de TI? }\end{array}$ & Pérez-López e Alegre (2012) \\
\hline
\end{tabular}

Fonte: elaborado pelo autor.

Por fim o Quadro 19 apresenta as variáveis que serão utilizadas no estudo com o objetivo de mensurar o processo de armazenamento do conhecimento.

Quadro 19 - Variáveis referentes à proteção do conhecimento

\begin{tabular}{|l|l|l|}
\hline \multicolumn{1}{|c|}{ Processo de GC } & \multicolumn{1}{|c|}{ Variáveis } & \multicolumn{1}{c|}{ Autores } \\
\hline $\begin{array}{l}\text { Proteção do } \\
\text { conhecimento }\end{array}$ & $\begin{array}{l}\text { A empresa possui mecanismos para } \\
\text { retenção de seus colaboradores? }\end{array}$ & Zack et al. (2009) \\
\cline { 2 - 3 } $\begin{array}{l}\text { Alpha de Cronbach: } \\
2009 \text { ) (Zack et al., }\end{array}$ & $\begin{array}{l}\text { A empresa valoriza os seus } \\
\text { colaboradores pelo conhecimento que } \\
\text { eles possuem? }\end{array}$ & Zack et al. (2009) \\
\cline { 2 - 3 } & $\begin{array}{l}\text { A empresa possui mecanismos para } \\
\text { controlar o acesso a bases de } \\
\text { conhecimento? }\end{array}$ & Zack et al. (2009) \\
\hline
\end{tabular}

Fonte: elaborado pelo autor. 
Alguns trabalhos, como Shaw et al. (2001), Sablah et al. (2004) e Mithas et al. (2011), destacam que alguns desses processos de gestão do conhecimento afetam determinadas práticas gerenciais. A seguir são apresentadas as práticas que podem ser impactadas pelos processos de conhecimento.

- Gestão de clientes: corresponde à habilidade da empresa determinar os requisitos, expectativas e preferência de seus consumidores, além de entender o mercado como um todo. Os processos de gestão de conhecimento são fundamentais para essa prática gerencial de forma que as empresas identifiquem oportunidades para criar novos produtos e serviços, atrair novos clientes, fidelizar clientes, e alcançar novos mercados. $O$ conhecimento sobre os clientes é um elemento crucial para a empresa promover seus produtos e/ou serviços, entender melhor o seu mercado em busca de novas oportunidades, com o objetivo de oferecer melhores experiências para seus consumidores; (SHAW et al., 2001; SABLAH et al., 2004; MITHAS et al., 2011)

- Gestão de capital humano: essa prática está relacionada com o gerenciamento de aspectos atrelados com os colaboradores de uma organização, desde a aspectos administrativos até a alocação dos funcionários. Essa prática exige, em determinados aspectos ,um recurso fundamental, o conhecimento, para guiar as decisões que são tomadas sobre um determinado colaborador ou então para criar redes internas que auxiliem a empresa a alcançar os seus objetivos; (ANDREEVA e KIANTO, 2012)

- Gestão de processos: essa prática gerencial permite que a empresa consiga uma flexibilidade, velocidade e redução de custos. O conhecimento tem um papel fundamental para melhorar os processos de uma empresa de forma eficaz e eficiente, e nesse cenário o mapeamento dos processos pode ser um elemento crucial para que possam ser identificados gaps com uma melhor facilidade; esse conhecimento permite a construção de processos de negócio mais robustos; (MITHAS et al., 2011; VIVAS et al., 2014)

- Gestão de projetos: a eficiência e a eficácia da execução dos projetos são impactadas pelo uso do conhecimento, como um recurso essencial para um melhor desempenho. Os processos do conhecimento permitem um melhor planejamento das equipes, uma resolução de problemas mais eficiente, 
execução de tarefas de forma mais ágil e permite um maior controle sobre as tarefas. É preciso que as organizações incentivem seus colaboradores sobre a importância do conhecimento para um melhor desempenho dos projetos executados; (AJMAL et al., 2010; REICH et al., 2013; TODOROVIC et al., 2015)

- Gestão da inovação: o conhecimento tem um papel crucial para o processo de inovação das organizações. É preciso que as empresas busquem novos conhecimento - capacidade de absorção - para que seja possível gerar novas ideias que promovam a inovação. (AJAX, 2005; ADAMS et al., 2006; HIDALGO e ALBORS, 2008)

\subsection{AS CAPACIDADES DE TI E A GESTÃO DO CONHECIMENTO}

A partir das capacidades de Tl destacadas na seção 2.3, essa seção tem como objetivo apresentar a forma como determinadas capacidades se relacionam com a gestão do conhecimento, que correspondem as práticas de GC de uma organização. Segundo Pérez-López e Alegre (2012), as capacidades de TI podem ter uma variedade de papéis para suportar os processos de gestão do conhecimento organizacional.

A principal capacidade de TI que viabiliza uma grande quantidade de práticas da gestão do conhecimento é a capacidade de infraestrutura de TI. Essa capacidade deve ser entendida como ativos físicos (artefatos, ferramentas e recursos) que contribuem para o processo de aquisição, processamento, armazenamento, disseminação e uso da informação (BHARADWAJ, 2000; LU e RAMAMURTHY, 2011; PÉREZ-LÓPEZ e ALEGRE, 2012).

Segundo Pérez-López e Alegre (2012), uma infraestrutura de TI altamente integrada fornece aos membros de uma organização um acesso rápido e efetivo sobre as informações corretas e facilita o processo de transferência do conhecimento. Além disso, ela fornece mecanismos para examinar processos e práticas e, consequentemente, pode aumentar a aplicação do conhecimento nos procedimentos diários de uma organização.

A capacidade de operação de TI pode ser entendida como métodos, processos e técnicas que criam valor ao negócio, ou seja, a empresa deve usufruir dos recursos de TI para apoiar e reforçar os objetivos de negócio. A empresa deve buscar 
proativamente formas de compreender as novas tecnologias da informação ou explorar as existentes para criar oportunidades de negócio e para tanto é preciso que a empresa mantenha uma visão sobre o ambiente interno e externo.

Em relação ao ambiente externo, deve manter o foco sobre o conhecimento proporcionado pela $\mathrm{TI}$ que permite que ela entenda e responda de forma mais ágil às mudanças do mercado e às necessidades dos seus clientes (orientação voltada para os clientes). Em contrapartida, com relação ao ambiente interno deve-se manter o foco sobre o conhecimento proporcionado pela TI que contribui para a oferta de produtos e serviços confiáveis, e na redução de custos indiretos. (BHARADWAJ, 2000; STOEL e MUHANNA, 2009; LU e RAMAMURTHY, 2011; PÉREZ-LÓPEZ e ALEGRE, 2012)

Segundo Pérez-López e Alegre (2012), a operação da TI envolve a aplicação dos componentes da $\mathrm{TI}$ nos processos de negócio. Essa capacidade viabiliza que as organizações gerenciem melhor suas bases de clientes, mantenham informações sobre clientes de uma forma mais organizada e que o conhecimento seja compartilhado por toda a organização com uma maior eficiência.

A capacidade de recursos humanos de $\mathrm{TI}$ compreende as experiências, relacionamentos, percepções e treinamentos dos colaboradores. (BHARADWAJ, 2000)

Nesse contexto Pérez-López e Alegre (2012) destacam que a TI pode auxiliar na catalogação das expertises dos colaboradores, e isso pode facilitar a localização das pessoas que detém um determinado conhecimento para que ele possa ser compartilhado.

A literatura apresenta diversos recursos $\mathrm{TI}$ que estão associados com as capacidades supracitadas, porém elas podem ter efeitos diferentes sobre os processos e práticas de gestão do conhecimento. O Quadro 20 apresenta uma perspectiva consolidada sobre os principais recursos de $\mathrm{TI}$ identificados na literatura e os processos de GC que podem ser viabilizados por meio deles.

Quadro 20 - Recursos de TI e os processos de GC afetados

\begin{tabular}{|l|l|l|}
\hline \multicolumn{1}{|c|}{ Recursos de TI } & \multicolumn{1}{|c|}{ Processos de GC } & \multicolumn{1}{c|}{ Autores } \\
\hline $\begin{array}{l}\text { Data Base Management } \\
\text { System (DBMS) }\end{array}$ & Aquisição ou localização; & $\begin{array}{l}\text { Bharadwaj (2000); Meso } \\
\text { e Smith (2000); Alavi e }\end{array}$ \\
\hline
\end{tabular}




\begin{tabular}{|c|c|c|}
\hline Data Warehouses (DW) & $\begin{array}{l}\text { Armazenamento; } \\
\text { Proteção; }\end{array}$ & $\begin{array}{l}\text { Leidner (2001); } \\
\text { Mohamed et al. (2006); } \\
\text { Holste e Fields (2010); } \\
\text { Andreeva e Kianto } \\
\text { (2012); }\end{array}$ \\
\hline $\begin{array}{l}\text { Business Intelligence (BI); } \\
\text { Customer Relationship } \\
\text { Manager (CRM); } \\
\text { Enterprise Resource } \\
\text { Planning (ERP) } \\
\text { Data Mining }\end{array}$ & $\begin{array}{l}\text { Criação ou construção ou } \\
\text { transformação; } \\
\text { Aquisição ou localização; } \\
\text { Compartilhamento ou transferência; } \\
\text { Armazenamento; } \\
\text { Aplicação ou utilização; }\end{array}$ & $\begin{array}{l}\text { Alavi e Leidner (2001); } \\
\text { Bharadwaj (2000); Meso } \\
\text { e Smith (2000); } \\
\text { Mohamed et al. (2006); } \\
\text { Carvalho (2012); }\end{array}$ \\
\hline $\begin{array}{l}\text { Comunidades virtuais } \\
\text { Intranet } \\
\text { Portais corporativo } \\
\text { Groupware }\end{array}$ & $\begin{array}{l}\text { Criação ou construção ou } \\
\text { transformação; } \\
\text { Aquisição ou localização; } \\
\text { Compartilhamento ou transferência; } \\
\text { Armazenamento; } \\
\text { Aplicação ou utilização; } \\
\text { Proteção; }\end{array}$ & $\begin{array}{l}\text { Bharadwaj (2000); } \\
\text { Martensson (2000); } \\
\text { Meso e Smith (2000); } \\
\text { Alavi e Leidner (2001); } \\
\text { Huysman (2006); Nevo } \\
\text { e Wade (2010); } \\
\text { Ransbotham e Kane } \\
\text { (2011); Pérez-López e } \\
\text { Alegre (2012); Andreeva } \\
\text { e Kianto (2012); } \\
\text { Carvalho (2012); Krogh } \\
\text { (2012); }\end{array}$ \\
\hline $\begin{array}{l}\text { Workflow Systems } \\
\text { Expert Systems }\end{array}$ & $\begin{array}{l}\text { Compartilhamento ou transferência; } \\
\text { Armazenamento; } \\
\text { Aplicação ou utilização; } \\
\text { Proteção; }\end{array}$ & $\begin{array}{l}\text { Alavi e Leidner (2001); } \\
\text { Cha et al. (2008); } \\
\text { Carvalho (2012); }\end{array}$ \\
\hline
\end{tabular}

Fonte: elaborado pelo autor.

Os recursos de $\mathrm{TI}$ voltados para o armazenamento de dados (DMNS e DW) permitem que as organizações armazenem dados, informações, conteúdos e conhecimento tanto relacionados com o ambiente interno (tais como dados de competências dos seus funcionários) como relacionados com o ambiente externo (tais como dados do mercado ou dados de clientes).

Consequentemente, esses recursos são importantes para que a organização mantenha sua memória organizacional. Essas bases de dados são insumos para processos de tratamento do seu conteúdo por outros recursos de TI no intuito de se criar algum tipo de conhecimento que a empresa possa usufruir para alcançar a vantagem competitiva. Além disso, é possível manter os dados protegidos uma vez que todo o acesso a essas bases são rastreáveis, e é possível conceder acesso apenas para determinados indivíduos (BHARADWAJ, 2000; MESO e SMITH, 2000; 
ALAVI e LEIDNER, 2001; MOHAMED et al., 2006; HOLSTE e FIELDS, 2010; ANDREEVA E KIANTO, 2012; PÉREZ-LÓPEZ e ALEGRE, 2012).

No contexto de sistemas que podem auxiliar no processamento dos conteúdos que são armazenados em base de dados para geração de novos conhecimentos, os quais permitem à organização tomar a melhor decisão, existem o $\mathrm{Bl}$, o CRM, o ERP e o Data Mining. Esses recursos de TI podem ser utilizados por uma empresa no processo de criação de novos conhecimentos, no compartilhamento desse conhecimento pela organização, e na aplicação desse conhecimento principalmente para as tomadas de decisão (ALAVI e LEIDNER, 2001; BHARADWAJ, 2000; MESO e SMITH, 2000; MOHAMED et al., 2006; CARVALHO, 2012).

Em uma perspectiva para o ambiente interno de uma organização, os recursos de $\mathrm{TI}$ também têm uma grande importância na gestão do conhecimento. Os principais recursos identificados na literatura são as comunidades virtuais, a Intranet, os portais corporativos e os sistemas de groupware. Esses recursos permitem que a organização crie novos conhecimentos, e mais do que isso, permitem que os seus colaboradores interajam entre si, o que contribui para o compartilhamento do conhecimento tácito que é mais difícil de ser disseminado pela organização. Além disso é possível criar rotas mais facilmente para determinados assuntos, o que traz um ganho na eficiência sobre o trabalho que é executado por esses colaboradores (BHARADWAJ, 2000; MARTENSSON, 2000; MESO e SMITH, 2000; ALAVI e LEIDNER, 2001; HUYSMAN, 2006; NEVO e WADE, 2010; RANSBOTHAM e KANE, 2011; PÉREZ-LÓPEZ e ALEGRE, 2012; ANDREEVA E KIANTO, 20120; CARVALHO, 2012; KROGH, 2012).

Conforme supracitado, o conhecimento sobre os processos de uma organização é fundamental para que ela possa obter um melhor desempenho. A literatura destaca os Workflow Systems, que são sistemas que permitem controlar várias atividades associadas com os processos de negócio, e os Expert Systems, que permitem que a organização tenha uma tomada de decisão mais rápida por meio da definição de processos que direcionam a melhor decisão que a empresa pode adotar. (ALAVI e LEIDNER, 2001; CHA et al., 2008; CARVALHO, 2012) 
Figura 7 - Agrupamento dos recursos de $\mathrm{TI}$

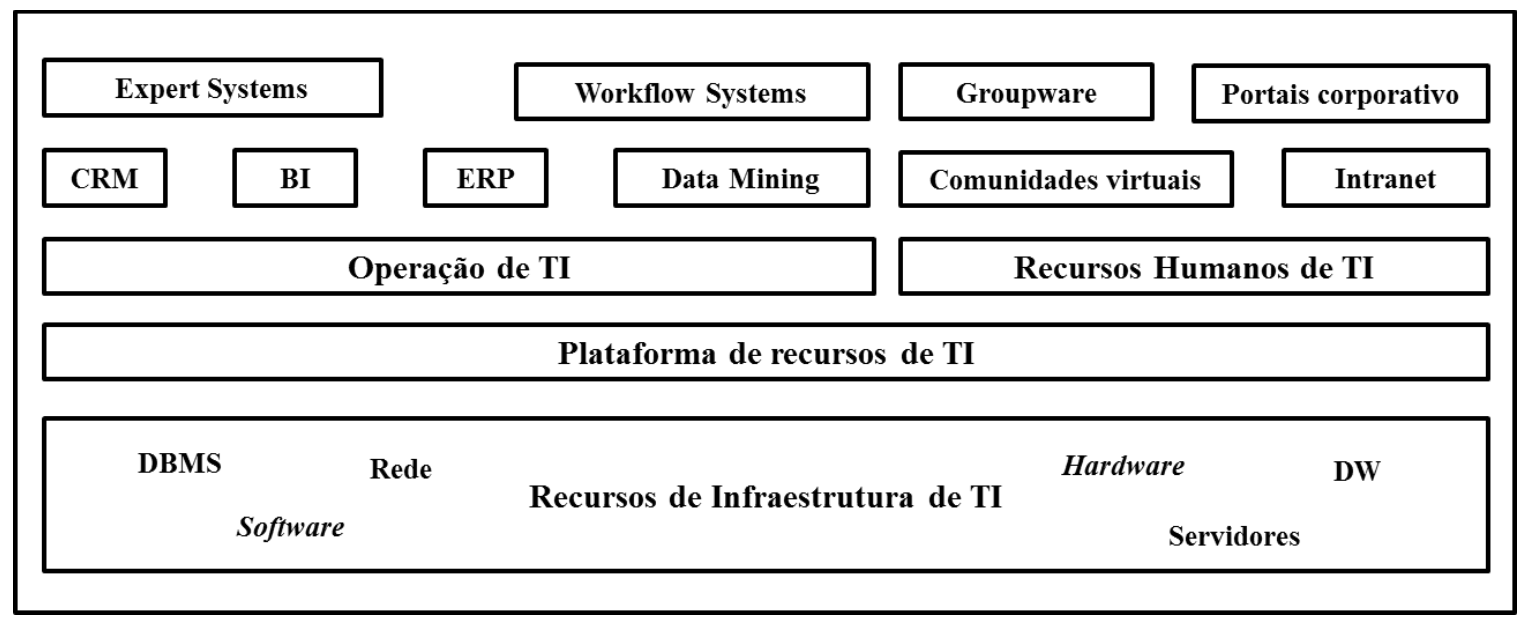

Fonte: elaborado pelo autor

A Figura 7 apresenta o agrupamento dos recursos de TI supracitados, no caso a base da estrutura é composta por recursos de infraestrutura de TI, ou seja, a empresa deve possuir a capacidade de infraestrutura de TI para suportar seu negócio, e a escolha desses recursos pode influenciar a eficiência e eficácia dos objetivos que uma organização pretende alcançar em relação aos aspectos voltados para a gestão do conhecimento. Esses recursos permitem que a organização crie uma plataforma, e a partir da sinergia desses recursos é possível que a organização trabalhe as outras duas capacidades: uma voltada para as operações de $\mathrm{Tl}$ e a outra voltada para os recursos humanos de $\mathrm{TI}$.

A capacidade de operação da TI correspondem em grande parte às aplicações que permitem que a empresa crie valor a partir do conhecimento que pode ser gerado. Essas aplicações de TI permitem que as empresas explorem novas oportunidades e identifiquem riscos ao negócio com uma maior eficiência.

Já em relação a capacidade de recursos humanos, é preciso que a organização tenha a rastreabilidade dos conhecimentos que seus colaboradores possuem, para permitir uma alocação de recursos mais eficientes e até mesmo identificar gaps para que sejam realizados os devidos treinamentos. Além disso, é preciso que ela facilite o acesso dos seus funcionários à conhecimentos por meio de portais corporativos, e até mesmo que sejam criadas comunidades de práticas para que o conhecimento possa ser disseminado pela organização, ou até mesmo que novos conhecimentos possam ser criados. 
Conforme supracitado, nessa seção, as capacidades de TI podem ter impactos sobre os processos e as práticas de gestão do conhecimento. A seguir são apresentados os principais modelos identificados na literatura que abordam a questão de como as capacidades de TI impactam a gestão do conhecimento.

\subsection{MODELOS E FRAMEWORKS ENCONTRADOS NA LITERATURA}

Essa seção tem como objetivo apresentar os modelos identificados na literatura que analisam a relação da gestão conhecimento com a TI. Esses estudos serviram como base para estruturar o modelo do estudo, voltado mais especificamente para a questão de entender a relação das capacidades de TI com a gestão do conhecimento.

\subsubsection{MODELO DE PÉREZ-LÓPEZ E ALEGRE (2012)}

O modelo de Pérez-López e Alegre (2012) analisa a relação das capacidades de TI com alguns processos de GC, que tem efeitos sobre o desempenho da empresa no mercado em que atua, o que pode impactar o desempenho financeiro de uma organização, conforme Figura 8. A pesquisa realizada pelos autores é de natureza quantitativa e do tipo survey, na qual foi elaborado um questionário para levantamento dos dados a serem analisados.

Figura 8 - Modelo de Pérez-López e Alegre (2012)

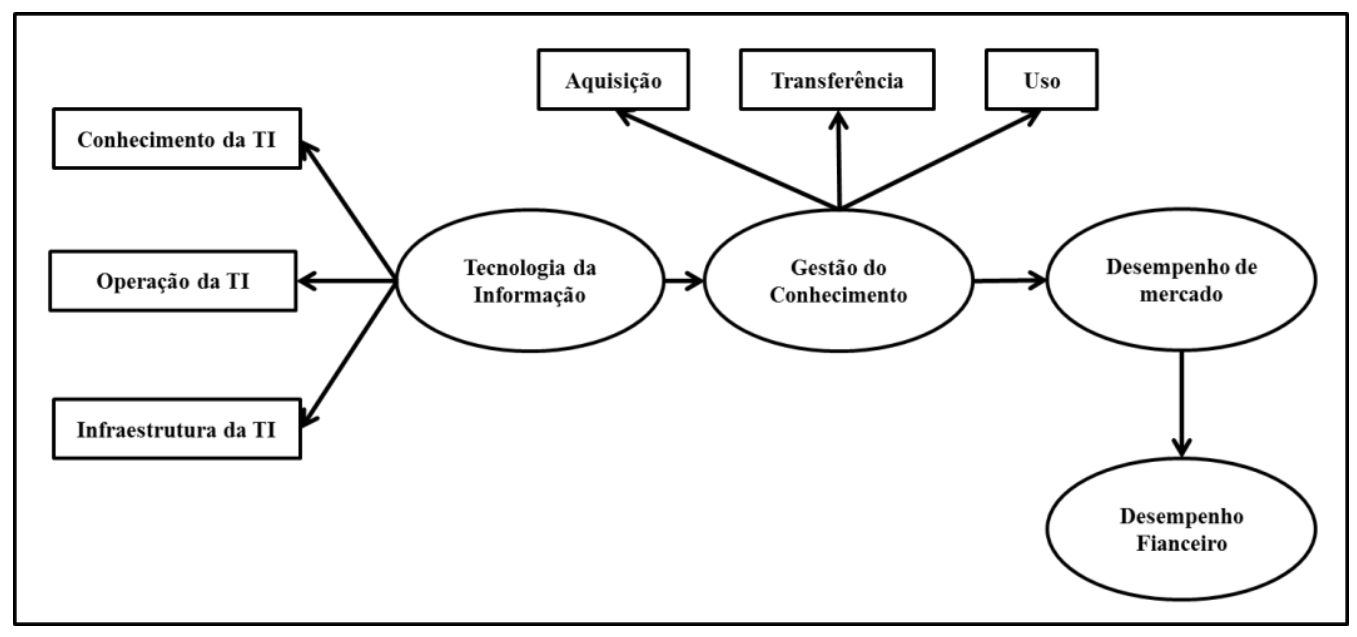

Fonte: Pérez-López e Alegre, 2012.

Os autores compõem a capacidade de TI por três dimensões:

- Conhecimento da TI: grau com que a organização entende as capacidades existentes e emergentes a partir da Tl; e 
- Operação da TI: métodos, processos e técnicas associadas com a TI necessárias para criar valor ao negócio; e

- Infraestrutura de TI: artefatos, ferramentas e recursos que contribuem para aquisição, processamento, armazenamento e disseminação e uso da informação.

Essas três dimensões foram mensuradas por meio de questionamentos seguindo uma escala Likert de cinco pontos, de 1 - discordo totalmente - até 5 - concordo totalmente.

O Quadro 21 apresenta os principais itens que foram mensurados pelos autores em relação a dimensão Infraestrutura de $\mathrm{TI}$.

Quadro 21 - Indicadores da dimensão: Infraestrutura de TI

\begin{tabular}{|l|l|}
\hline Infraestrutura de TI & Itens mensurados \\
\hline Item 1 & $\begin{array}{l}\text { A empresa possui um departamento formal de gestão de } \\
\text { tecnologias da informação? }\end{array}$ \\
\hline Item 2 & $\begin{array}{l}\text { A empresa possui um cargo de gestão cuja principal } \\
\text { responsabilidade é o gerenciamento do uso das tecnologias } \\
\text { da informação? }\end{array}$ \\
\hline Item 3 & $\begin{array}{l}\text { A empresa cria aplicações customizadas de softwares } \\
\text { quando surge uma necessidade? }\end{array}$ \\
\hline Item 4 & $\begin{array}{l}\text { Os colaboradores da organização são conectados por uma } \\
\text { rede de computadores? }\end{array}$ \\
\hline
\end{tabular}

Fonte: Pérez-López e Alegre, 2012.

O Quadro 22 apresenta os principais itens que foram mensurados pelos autores em relação a dimensão Conhecimento da $\mathrm{Tl}$.

Quadro 22 - Indicadores da dimensão: Conhecimento da TI

\begin{tabular}{|l|l|}
\hline Recursos humanos de TI & Itens mensurados \\
\hline Item 5 & $\begin{array}{l}\text { No geral, o staff de apoio técnico é bem informado quando } \\
\text { se trata de tecnologias da informação? }\end{array}$ \\
\hline Item 6 & $\begin{array}{l}\text { A empresa possui um elevado grau de expertise em } \\
\text { tecnologias da informação? }\end{array}$ \\
\hline Item 7 & $\begin{array}{l}\text { A empresa busca atualizar seus colaboradores em relações } \\
\text { as novas inovações das tecnologias da informação? }\end{array}$ \\
\hline
\end{tabular}

Fonte: Pérez-López e Alegre, 2012. 
O Quadro 23 apresenta os principais itens que foram mensurados pelos autores em relação a dimensão Operação da TI.

Quadro 23 - Indicadores da dimensão: Operação da TI

\begin{tabular}{|l|l|}
\hline Operação da TI & Itens mensurados \\
\hline Item 8 & $\begin{array}{l}\text { A empresa busca rotineiramente utilizar tecnologias da } \\
\text { informação para acessar informações de mercado de base } \\
\text { de dados externos? }\end{array}$ \\
\hline Item 9 & $\begin{array}{l}\text { A empresa possui um conjunto de procedimentos para } \\
\text { coletar informações de clientes a partir de fontes online? }\end{array}$ \\
\hline Item 10 & $\begin{array}{l}\text { A empresa usa tecnologias da informação para analisar } \\
\text { informações de clientes e do mercado? }\end{array}$ \\
\hline Item 11 & $\begin{array}{l}\text { A empresa conta com tecnologias da informação para } \\
\text { adquirir, armazenar e processar informação sobre seus } \\
\text { clientes? }\end{array}$ \\
\hline
\end{tabular}

Fonte: Pérez-López e Alegre, 2012.

A capacidade de TI, segundo os autores, tem uma variedade de papéis para suportar os processos de gestão do conhecimento organizacional destacados a seguir:

- Aquisição do conhecimento: processo pelo qual as empresas obtêm conhecimento a partir do ambiente externo ou gera o conhecimento internamente, ou seja, as empresas devem buscar novos e melhores conhecimentos que podem ajudar a organização a aumentar sua competitividade.

- Transferência do conhecimento: processo pelo qual a organização compartilha o conhecimento entre suas unidades e seus membros, promovendo novos entendimentos, para tanto é preciso que a organização desenvolva mecanismos que encorajem o diálogo e interação entre os indivíduos.

- Uso do conhecimento: o conhecimento deve ser aplicado aos produtos e serviços fornecidos pela organização, esse uso deve propiciar 0 desenvolvimento de capacidades dinâmicas.

Os três processos de conhecimento foram mensurados diante de alguns questionamentos seguindo uma escala Likert de cinco pontos, de 1 - discordo totalmente - até 5 - concordo totalmente. 
O Quadro 24 apresenta os principais itens que foram mensurados pelos autores em relação ao processo de aquisição do conhecimento.

Quadro 24 - Indicadores da dimensão: Aquisição do conhecimento

\begin{tabular}{|l|l|}
\hline $\begin{array}{l}\text { Aquisição do } \\
\text { conhecimento }\end{array}$ & Itens mensurados \\
\hline Item 12 & $\begin{array}{l}\text { A empresa procura se reunir com seus clientes com o objetivo de } \\
\text { identificar suas necessidades? }\end{array}$ \\
\hline Item 13 & $\begin{array}{l}\text { A empresa tem processos para aquisição do conhecimento sobre } \\
\text { seus fornecedores? }\end{array}$ \\
\hline Item 14 & $\begin{array}{l}\text { A empresa tem processos que permitem que seja capitalizado } \\
\text { práticas de sucesso de outras organizações? }\end{array}$ \\
\hline Item 15 & $\begin{array}{l}\text { A empresa tem processos para gerar novos conhecimentos a partir } \\
\text { do conhecimento existente? }\end{array}$ \\
\hline Item 16 & $\begin{array}{l}\text { Novas abordagens e ideias sobre o desempenho do trabalho são } \\
\text { experimentadas continuamente? }\end{array}$ \\
\hline
\end{tabular}

Fonte: Pérez-López e Alegre, 2012.

O Quadro 25 apresenta os principais itens que foram mensurados pelos autores em relação ao processo de compartilhamento do conhecimento.

Quadro 25 - Indicadores da dimensão: Compartilhamento do conhecimento

\begin{tabular}{|l|l|}
\hline $\begin{array}{l}\text { Compartilhamento } \\
\text { do conhecimento }\end{array}$ & Itens mensurados \\
\hline Item 17 & $\begin{array}{l}\text { Reuniões são periodicamente agendadas para informa todos os } \\
\text { colaboradores sobre as últimas inovações da empresa? }\end{array}$ \\
\hline Item 18 & $\begin{array}{l}\text { A empresa tem mecanismos formais para garantir o } \\
\text { compartilhamento de boas práticas de diferentes campos de } \\
\text { atividades? }\end{array}$ \\
\hline Item 19 & $\begin{array}{l}\text { Existem pessoas que são pontos focais de determinados assuntos } \\
\text { eque são responsáveis por disseminar o conhecimento para o } \\
\text { restante da equipe? }\end{array}$ \\
\hline Item 20 & $\begin{array}{l}\text { Existem indivíduos responsáveis por coletar, juntar e distribuir } \\
\text { internamente sugestões dos colaboradores? }\end{array}$ \\
\hline
\end{tabular}

Fonte: Pérez-López e Alegre, 2012.

$\mathrm{O}$

Quadro 26 apresenta os principais itens que foram mensurados pelos autores em relação ao processo de aplicação do conhecimento. 
Quadro 26 - Indicadores da dimensão: Aplicação do conhecimento

\begin{tabular}{|l|l|}
\hline $\begin{array}{l}\text { Aplicação do } \\
\text { conhecimento }\end{array}$ & Itens mensurados \\
\hline Item 21 & $\begin{array}{l}\text { A empresa possui processos para aplicar o conhecimento } \\
\text { aprendido a partir de experiências nas atividades do dia-a-dia? }\end{array}$ \\
\hline Item 22 & $\begin{array}{l}\text { A empresa facilita o acesso ao conhecimento para aqueles que } \\
\text { precisam dele? }\end{array}$ \\
\hline Item 23 & $\begin{array}{l}\text { A empresa possui processos para utilizar o conhecimento no } \\
\text { desenvolvimento de novos produtos e/ou serviços? }\end{array}$ \\
\hline Item 24 & $\begin{array}{l}\text { A empresa tem capacidade de identificar e aplicar o conhecimento } \\
\text { para mudar as condições de concorrência por meio de novas } \\
\text { capacidades de TI? }\end{array}$ \\
\hline
\end{tabular}

Fonte: Pérez-López e Alegre, 2012

Os autores realizaram uma avaliação da confiabilidade das escalas estipuladas para a mensuração dos itens supracitados, com base no estudo de Fornell e Larcker (1981), que está associado diretamente com o coeficiente alpha de Cronbach, os resultados obtidos são apresentados no Quadro 27.

Quadro 27 - Grau de confiabilidade composta calculada

\begin{tabular}{|l|c|}
\hline Capacidades de TI e Processos de conhecimento & alpha de Cronbach \\
\hline Conhecimento da TI & 0,920 \\
\hline Operação da TI & 0,803 \\
\hline Infraestrutura de TI & 0,877 \\
\hline Aquisição do conhecimento & 0,818 \\
\hline Disseminação do conhecimento & 0,836 \\
\hline Aplicação do conhecimento & 0,770 \\
\hline
\end{tabular}

Fonte: Pérez-López e Alegre, 2012

A validação dos construtos foi realizada por meio da aplicação de uma análise fatorial confirmatória usando um modelo de equações estruturais. Por meio desse modelo é possível destacar a importância de uma organização conhecer as capacidades que pode emergir por meio de uma boa gestão dos recursos de TI, principalmente a capacidade de gestão do conhecimento. Nesse contexto os 
recursos de TI têm um papel importante sobre os três processos apresentados: a aquisição, a transferência e a aplicação do conhecimento interno e externo à organização. A gestão do conhecimento segundo o modelo apresentado pode impactar o desempenho da organização no mercado e o desempenho financeiro.

\subsubsection{MODELO ZACK et al. (2009)}

A principal questão de pesquisa no estudo de Zack et al. (2009) foi identificar quais práticas de gestão do conhecimento estão relacionadas positivamente com o desempenho organizacional, e se esse desempenho organizacional está relacionado positivamente com o desempenho financeiro de uma organização, conforme modelo apresentado na Figura 9.

Figura 9 - Modelo de Zack et al. (2009)

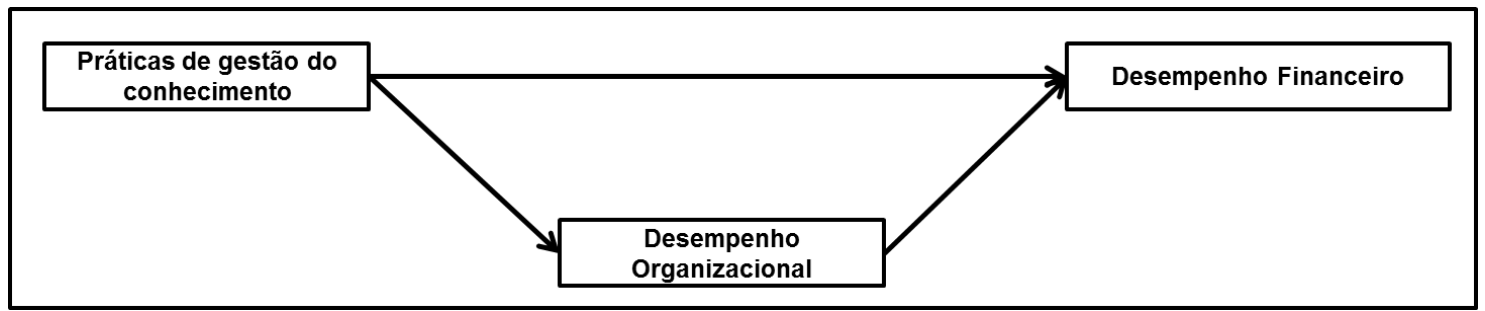

Fonte: Zack et al., 2009.

As práticas de gestão do conhecimento apresentadas pelos autores possuem um mesmo significado que os processos de gestão do conhecimento supracitados ao longo do referencial teórico sobre gestão do conhecimento supracitado. Entre os processos estão o processo de aquisição do conhecimento, compartilhamento do conhecimento e proteção do conhecimento.

Os autores utilizaram doze variáveis para compor o construto práticas de gestão do conhecimento: conhecimento faz parte do planejamento estratégico, os colaboradores são valorizados pelos conhecimentos que possuem, capacidade de identificar fontes internas de expertises, experiências e aprendizagem com consumidores e mercados, experiências e aprendizagem em relação a produtos e serviços, experiências e aprendizagem sobre operação e tecnologias, encoraja o compartilhamento de conhecimento, adquire conhecimento externo, busca realizar benchmarks em relação aos seus concorrente, possui grupos de gestão do conhecimento, boas práticas são disseminadas por toda organização e busca uma gestão estratégica do conhecimento para mapear o conhecimento que realmente 
pode criar valor ao negócio. As variáveis foram medidas com base em uma escala de 5 pontos no qual 1 indicava alta conformidade e 5 pouca conformidade. $O$ valor de confiabilidade (alpha de Cronbach) da escala para o construto práticas de gestão do conhecimento foi de 0,88 .

Esse estudo é importante para essa pesquisa, uma vez que, destaca o processo de proteção do conhecimento que ainda é escasso na literatura. Esse processo de gestão do conhecimento foi incluído no modelo de pesquisa, porém conforme visto será preciso realizar um estudo em relação a confiabilidade da escala utilizada, já que no estudo em questão a proteção do conhecimento é um dos itens que será mensurado.

\subsubsection{FRAMEWORK CONCEITUAL DE MESO E SMITH (2000)}

O modelo de Meso e Smith (2000) apresentado na Figura 10 tem um viés sobre a perspectiva técnica, na qual o sistema de gestão do conhecimento organizacional é um conjunto de softwares associados com uma infraestrutura de hardware que suporte os processos sobre o conhecimento e o aprendizado organizacional por meio do acesso e aumento do compartilhamento do conhecimento por toda a organização.

Os autores destacam que os softwares de groupware são ferramentas que proporcionam um aumento do trabalho colaborativo em grupo até mesmo com equipes que são dispersas geograficamente. As tecnologias Web também são destacadas pelos autores sob o ponto de vista de que elas são o caminho natural de comunicação entre indivíduos e na busca de conhecimento para execução de tarefas do dia a dia. Por meio desse modelo é possível destacar a importância dos recursos de TI que compõem uma infraestrutura sólida para a execução de sistemas de gestão do conhecimento organizacional, os quais buscam: aplicar o conhecimento adquirido por uma organização; descobrir novos conhecimentos por meio de uma busca de conhecimentos dispersos no ambiente externo ou por maio da mineração de dados de uma determinada base de dados que a empresa possui; criar novos conhecimentos que possam ser disseminados por toda a organização; documentação do conhecimento obtido ou criado pela organização, de forma que todos os colaboradores possam ter acesso a esse conhecimento com agilidade. 
Figura 10 - Framework conceitual de Meso e Smith (2000)

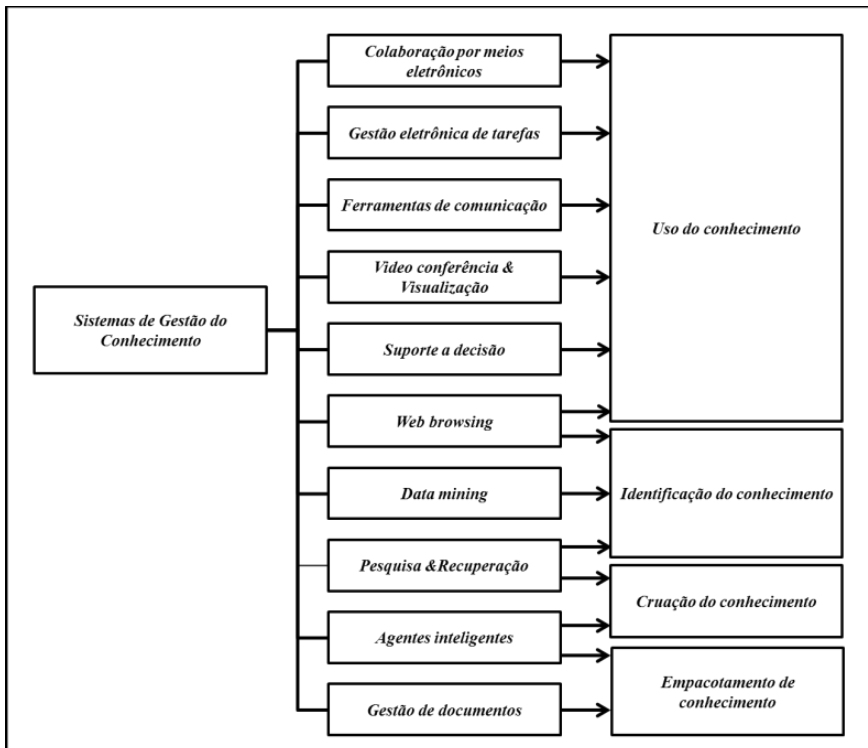

Fonte: Meso e Smith, 2000.

\subsubsection{FRAMEWORK CONCEITUAL DE ALAVI E LEIDNER (2001)}

O modelo elaborado por Alavi e Leidner (2001) destaca que a gestão do conhecimento consiste em um conjunto de processos e práticas dinâmicas incorporadas nos indivíduos, bem como em grupos. Além disso, os processos de criação, armazenamento, transferência e aplicação do conhecimento são essenciais para a uma gestão do conhecimento organizacional efetiva.

Figura 11 - Framework conceitual de Alavi e Leidner (2001)

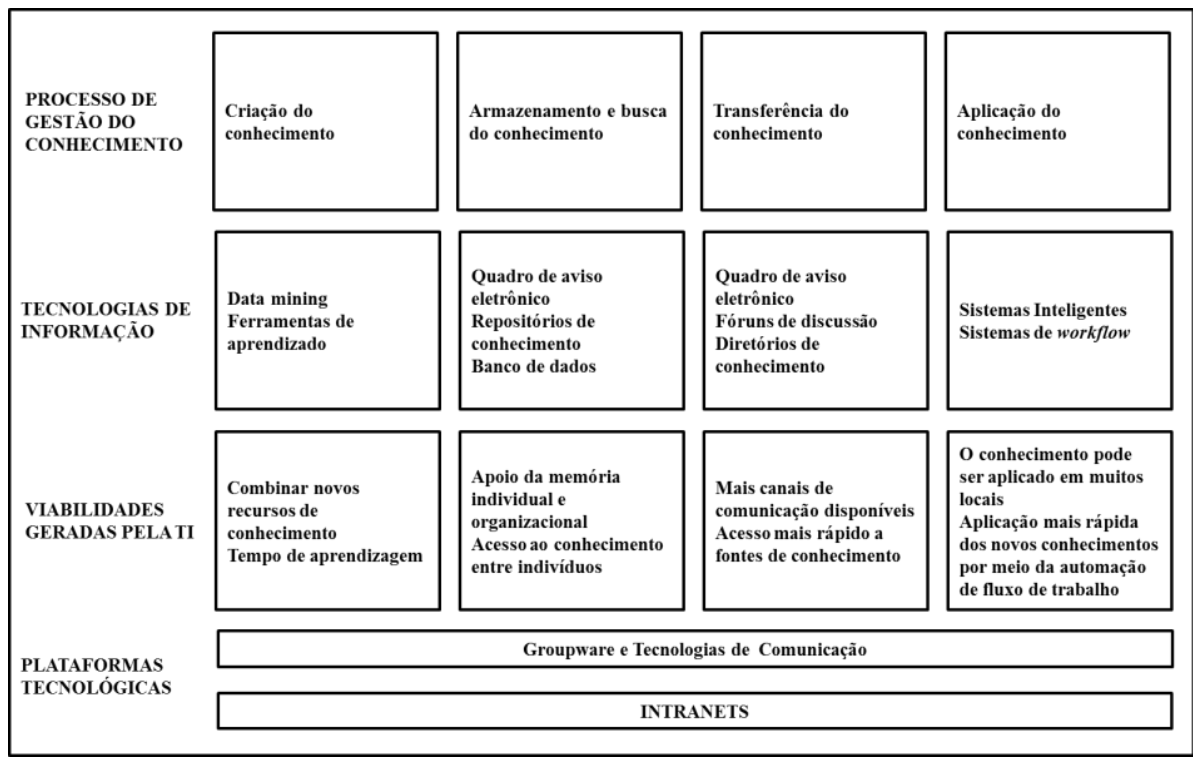

Fonte: Alavi e Leidner, 2001. 
Conforme mostra a Figura 11, os autores entendem que as aplicações de TI podem criar uma infraestrutura e um ambiente que contribui para a gestão do conhecimento organizacional por meio da atualização, suporte, aumento e reforço dos processos do conhecimento em um nível mais aprofundado. É possível notar uma grande variedade de tecnologias da informação que suportam diferentes processos de gestão do conhecimento em uma organização.

\subsection{CONSIDERAÇÕES SOBRE O REFERENCIAL TEÓRICO DE PESQUISA}

O presente estudo aborda a relação das capacidades de tecnologia da informação com a gestão do conhecimento. A partir da resource-based view, foram discutidos os conceitos relacionados com as capacidades de $\mathrm{Tl}$, a gestão do conhecimento e a relação entre os dois construtos.

A relação das capacidades de TI com a gestão do conhecimento parece justificável visto que, conforme Stankosky (2005), um dos pilares que compõem a gestão do conhecimento é a tecnologia da informação, a qual auxilia em questões estratégicas e operações envolvendo o uso do conhecimento. Além disso, alguns autores como Powel e Dent-Micallef (1997) e Bharadwaj (2000) entendem que as tecnologias da informação alavancam outros recursos intangíveis como, por exemplo, a própria gestão do conhecimento.

A presente pesquisa leva em consideração dois aspectos fundamentais, que são características das organizações e que podem afetar a relação entre os dois conceitos. O primeiro é o impacto estratégico da TI no presente e no futuro para a empresa, com base em conceitos apresentados no grid estratégico de Nolan e McFarlan (2005), que permite analisar o impacto das aplicações de TI para as organizações levando em consideração a necessidade de tecnologias da informação confiáveis ou novas. O segundo é o estilo do método de gestão do conhecimento voltado para o conhecimento explícito, visto que nesse cenário a tecnologia da informação tem uma grande importância para gestão desse tipo de conhecimento, conforme abordados pelos autores Choi e Lee (2003), Stankosky (2005) e Wild e Griggs (2008).

A pesquisa teve como base o modelo de Pérez-López e Alegre (2012), considerando as três capacidades de TI identificadas na revisão da literatura: capacidade de infraestrutura de TI, capacidade de operação de TI e capacidade de recursos 
humanos de TI. Em relação à gestão do conhecimento o estudo tem como objetivo analisar o impacto dessas capacidades de TI sobre a gestão do conhecimento composto pelos processos: aquisição do conhecimento compartilhamento do conhecimento e aplicação do conhecimento. Complementando os processos utilizados no estudo dos autores, o estudo em questão leva em consideração mais três processos de gestão do conhecimento, são eles: a criação do conhecimento, o armazenamento do conhecimento e a proteção do conhecimento. Essa parte do modelo de pesquisa pode ser observada na Figura 12.

Figura 12 - Modelo de pesquisa: parte 1

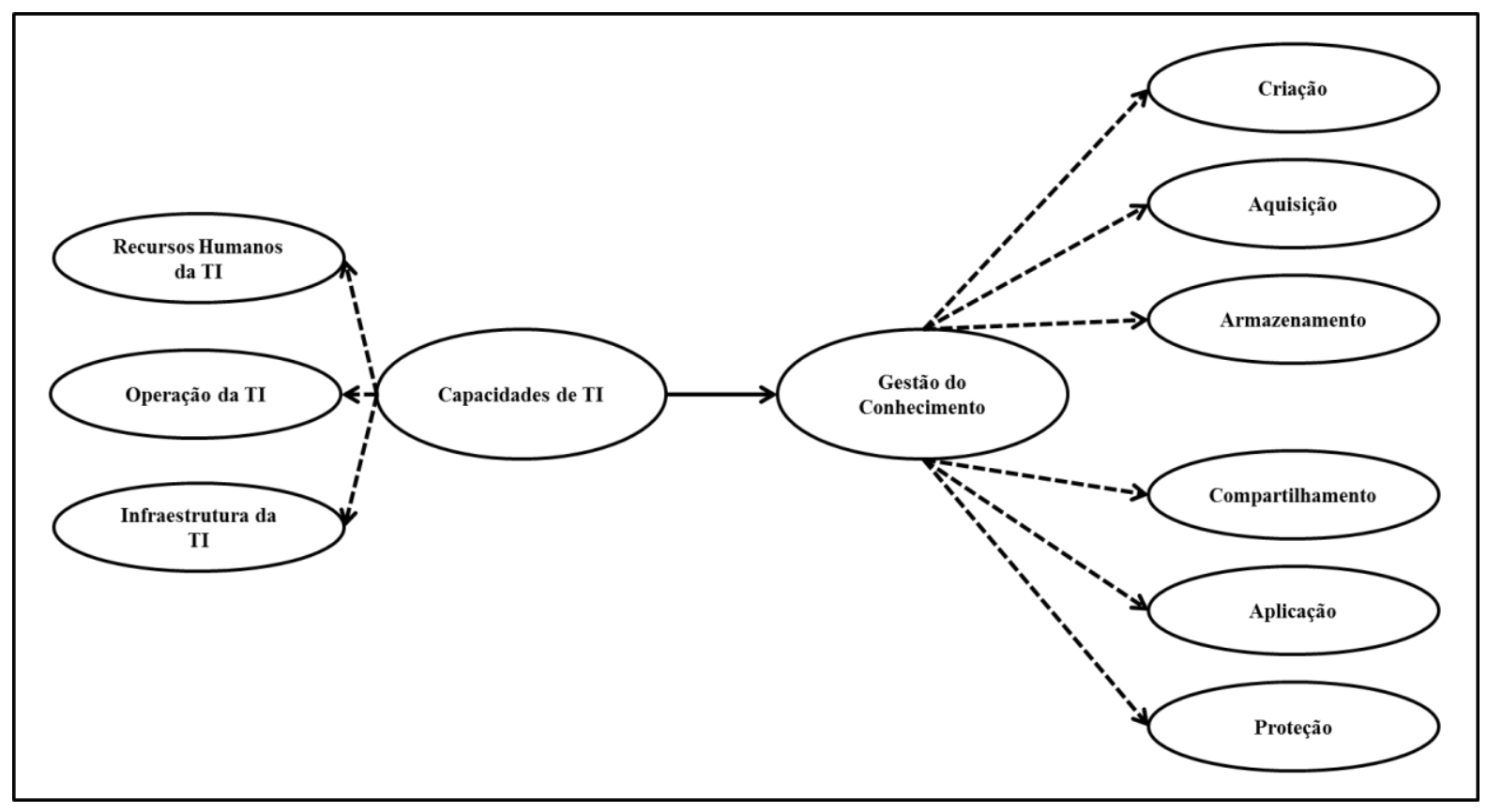

Fonte: elaborado pelo autor

Porém, como supracitado a relação das capacidades de tecnologia da informação com a gestão do conhecimento pode ser influenciada por diversos fatores moderadores. Será levado em consideração o impacto estratégico da TI no presente e no futuro, com base nos conceitos propostos pelo Grid Estratégico de Nolan e McFarlan (2005) e o estilo dos métodos de gestão do conhecimento voltado pra o conhecimento explícito com base nos estudos de Choi e Lee (2003), Stankosky (2005) e Wild e Griggs (2008), conforme Figura 13. 
Figura 13 - Modelo de pesquisa: parte 2

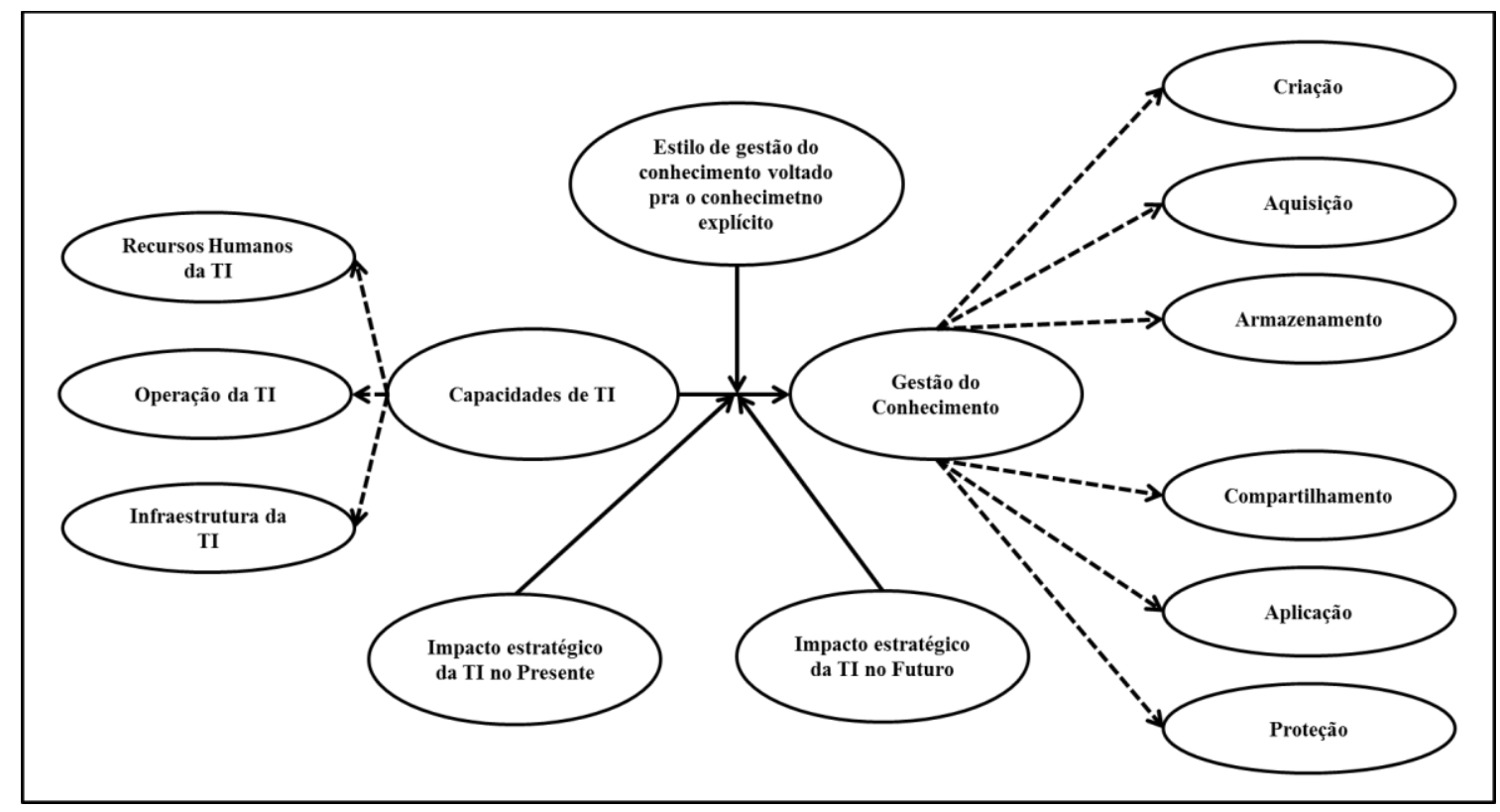

Fonte: elaborado pelo autor

\subsection{HIPÓTESES DA PESQUISA}

A etapa de elaboração de hipóteses da pesquisa, que retratam a relação das capacidades de $\mathrm{TI}$ com os processos de gestão do conhecimento, tiveram como base o modelo apresentado no estudo de Pérez-López e Alegre (2012), o "Grid do impacto estratégico de TI" de Nolan e McFarlan (2005) e o estilo de gestão do conhecimento voltado para o conhecimento explícito com base nos estudos de Choi e Lee (2003), Stankosky (2005) e Wild e Griggs (2008).

Com base nas seções anteriores foram elaboradas hipóteses sobre a relação entre as capacidades de $\mathrm{TI}$ com os processos de gestão do conhecimento. Conforme identificado as capacidades de TI podem ter uma variedade de papeis que viabilizam os processos organizacionais de gestão do conhecimento, conforme Bharadwaj (2000) e Pérez-López e Alegre (2012).

Pérez-López e Alegre (2012) destacam que uma infraestrutura de Tl altamente integrada fornece à organização um acesso rápido e eficiente sobre conjuntos de informações e facilita o processo de transferência do conhecimento. A capacidade de infraestrutura de TI também fornece os mecanismos necessários para otimizar processos e práticas organizacionais, e para aumentar aplicação do conhecimento nos procedimentos do dia-a-dia, que é denominado capacidade de operação das tecnologias da informação. Por fim a capacidade de recursos humanos de TI é 
encarada como o grau com que a organização entende as capacidades existentes e emergentes a partir da TI.

No estudo em questão essas serão as três capacidades que serão levadas em consideração. Pérez-Lopes e Alegre (2012) destacam que essas três capacidades fornecem um indício da habilidade das organizações entenderem e utilizarem as ferramentas e processos de TI que são necessários para gerenciar o conhecimento apropriadamente. Com isso a primeira hipótese do estudo é apresentada a seguir:

Hipótese 1: A capacidade de TI tem um efeito positivo sobre o processo de gestão do conhecimento.

A intensidade da relação das capacidades de TI sobre os processos de gestão do conhecimento pode ser influenciada pelo impacto estratégico da TI no presente e no futuro para uma organização. É esperado que as empresas ambos os fatores influenciem positivamente a relação das capacidades de $\mathrm{TI}$ com a gestão do conhecimento, visto que se a TI tem um impacto no presente deve-se ao fato de que as empresas dependem de que ela esteja operacional para que suprte o processo de gestão do conhecimento, assim como se a TI tem um impacto do futuro deve-se ao fato dela apoiar para transformações nos processos, como a gestão do conhecimento, podendo prover grandes diferenciações. Nesse contexto a segunda hipótese do estudo é apresentada a seguir:

Hipótese 2: O impacto estratégico da tecnologia da informação para a organização com base no grid estratégico de Nolan e McFarlan (2005) tem influência sobre a intensidade da relação das capacidades de TI com a gestão do conhecimento.

Hipótese 2a: O impacto da tecnologia da informação para a organização no presente tem influência sobre a intensidade da relação das capacidades de TI com a gestão do conhecimento.

Hipótese 2b: O impacto da tecnologia da informação para a organização no futuro tem influência sobre a intensidade da relação das capacidades de TI com a gestão do conhecimento.

Outro fator que deve ser levado em consideração e que pode ter um impacto na relação das capacidades de $\mathrm{Tl}$ e os processos de gestão do conhecimento é o estilo de gestão do conhecimento empregado pelas organizações. Segundo os autores Choi e Lee (2003), Stankosky (2005) e Wild e Griggs (2008) a tecnologia da 
informação tem um papel importante quando se trata de um estilo de gestão orientado para o conhecimento explícito.

Para mensurar esse fator moderador foi utilizado os indicadores que representam a orientação do estilo de gestão do conhecimento voltado para o conhecimento explícito presentes no estudo de Choi e Lee (2003), que classificam esses estilos em quatro tipos baseado na orientação para abordagem do conhecimento explícito ou tácito: passivo, orientação sistêmica, orientação humana e dinâmico. Dessa forma é esperado que as empresas que se enquadram nos quadrantes "Orientação Sistêmica" e "Dinâmico" apresentem uma intensidade da relação entre as capacidades de $\mathrm{TI}$ sobre os processos de gestão de conhecimento maior que as empresas que se enquadram no quadrante "Passivo" e "Orientação Humana", uma vez que conforme apresentado na literatura as tecnologias da informação podem ser empregadas mais facilmente sobre o conhecimento explícito, por isso a escolha de manter o foco da pesquisa sobre o estilo de gestão voltado para o conhecimento explícito. Com isso a terceira hipótese do estudo é apresentada a seguir:

Hipótese 3: O estilo do método da gestão do conhecimento orientado para o conhecimento explícito de uma organização, com base nos indicadores propostos por Choi e Lee (2003), tem influência sobre a intensidade da relação das capacidades de $\mathrm{TI}$ com os processos de gestão do conhecimento.

O Quadro 28 sumariza o relacionamento das hipóteses apresentadas com a literatura de referência apresentada durante o estudo.

Quadro 28 - Literaturas de referência para cada hipótese

\begin{tabular}{|l|l|}
\hline \multicolumn{1}{|c|}{ Hipóteses } & \multicolumn{1}{c|}{ Autores } \\
\hline Hipótese 1 & $\begin{array}{l}\text { Meso e Smith (2000); Alavi e Leidner (2001); Ray et al. } \\
\text { (2005); Adamides e Mohamed et al. (2006); Karacapilidis } \\
\text { (2006); Mohamed et al. (2006); Andreeva e Kianto (2012); } \\
\text { Pérez-López e Alegre (2012); }\end{array}$ \\
\cline { 2 - 3 } Hipótese 2 & Nolan e McFarlan (2005) \\
\hline Hipótese 3 & Choi e Lee (2003), Stankosky (2005) e Wild e Griggs (2008) \\
\hline
\end{tabular}

Fonte: elaborado pelo autor. 


\section{METODOLOGIA}

Nessa seção serão apresentados os aspectos metodológicos adotados na pesquisa, como a abordagem de pesquisa, o objetivo da pesquisa e os procedimentos adotados. As técnicas de coleta e análise dos dados também são apresentadas. Serão revisitadas questões associadas com as hipóteses da pesquisa diante do modelo que será seguido.

\subsection{ABORDAGEM DA PESQUISA E MÉTODOS DE PESQUISA}

As abordagens de pesquisa podem ser classificadas em três categorias: a abordagem qualitativa, a abordagem quantitativa e a abordagem mista. De acordo com a abordagem que se deseja seguir (quantitativa ou qualitativa) existem métodos de pesquisa adequados para se alcançar seus propósitos. Segundo Miguel (2010), a escolha da abordagem de pesquisa precede a escolha do método de pesquisa.

\subsubsection{ABORDAGEM QUANTITATIVA}

Segundo Creswell (2003), os estudos que possuem a abordagem quantitativa são aqueles nos quais o pesquisador avança o estudo sobre a relação entre variáveis por meio de questões ou hipóteses de pesquisa. A estrutura lógica das pesquisas que apresentam essa abordagem segundo Bryman (1989) é apresentada na Figura 14.

De acordo com o modelo apresentado por Bryman (1989) o ponto de início de um estudo é a teoria sobre algum aspecto de funcionamento organizacional, Miguel (2010) complementa que a teoria busca explicar e prever o problema estudado. A partir da teoria são deduzidas as hipóteses, que são soluções provisórias para o problema de pesquisa. $\mathrm{O}$ teste das hipóteses identificadas segundo o autor depende da operacionalização dos conceitos envolvidos em variáveis mensuráveis, da coleta dos dados e por fim análise dos dados com o uso da estatística. $O$ autor finaliza com a afirmação de que a interpretação dos resultados fornecerá uma base para a indução dos resultados, que se somará à base teórica existente, corroborando-a ou modificando-a. 
Figura 14 - Estrutura Lógica da Abordagem Quantitativa

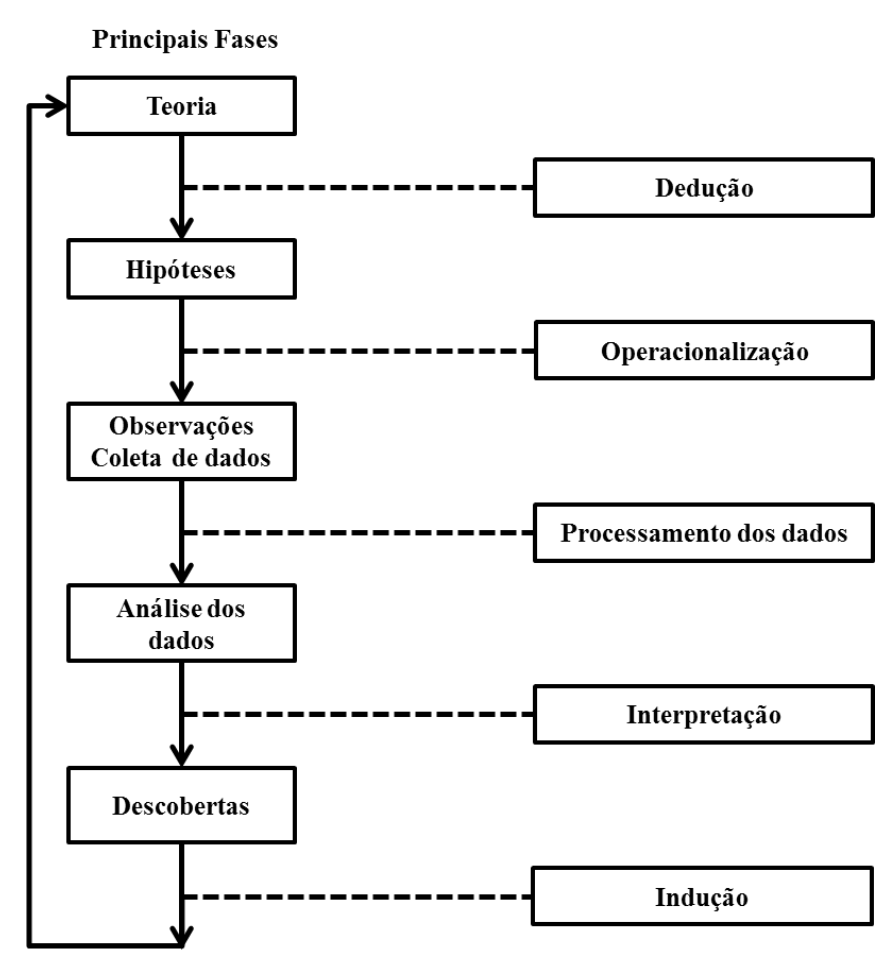

Fonte: Bryman, 1989.

Segundo Miguel (2010) os métodos de pesquisa mais apropriados para a condução de uma pesquisa quantitativa são:

- Pesquisa survey: o pesquisador não manipula os níveis das variáveis de pesquisa, podendo ter ou não proximidade com o objeto do estudo. As variáveis de pesquisa são avaliadas pelo respondente do questionário, que é o instrumento de pesquisa.

- Modelagem/simulação: o pesquisador manipula as variáveis e os seus níveis, mas não a realidade. Isso é feito no modelo de pesquisa, que é uma abstração da realidade. Pode haver ou não o uso de computadores para manipular as variáveis do modelo.

- Experimento ou Quase-Experimento: o pesquisador delineia um experimento de forma a testar o relacionamento entre as variáveis de pesquisa operacionalizada das hipóteses. Na realidade, o pesquisador manipula as variáveis independentes, estabelecendo níveis para elas, e observa o resultado na variável dependente. A diferença entre o experimento e o quaseexperimento é que, no primeiro, o pesquisador isola as variáveis que não fazem parte do experimento. 


\subsubsection{ABORDAGEM DA PESQUISA}

Optou-se por seguir uma abordagem quantitativa para realização da pesquisa, uma vez que o estudo visa analisar a intensidade das relações entre as capacidades de TI e a gestão do conhecimento, considerando os fatores moderadores associados com o impacto estratégico da $\mathrm{TI}$ e o estilo de gestão do conhecimento das organizações.

\subsection{OBJETIVOS DA PESQUISA}

Com o objetivo de alcançar os objetivos da pesquisa propostos, o presente estudo se caracteriza por uma pesquisa confirmatória sobre o assunto.

Segundo Waldemar et al. (2007), a pesquisa exploratória é apropriada para investigações em que o objeto de estudo apresenta uma escassez de conhecimento. Enquanto a pesquisa confirmatória segundo Forza (2002) é feita quando um fenômeno já foi articulado em uma forma de teoria utilizando conceitos, modelos e hipóteses bem definidas, que é o caso da pesquisa em questão.

No caso, conforme mostra a Figura 13, o modelo consiste em uma evolução do modelo apresentado por Pérez-López e Alegre (2012). O modelo do estudo que será avaliado possui similaridades em determinados aspectos com o modelo de PérezLópez e Alegre (2012) por isso justifica a questão de ser uma pesquisa confirmatória.

\subsection{PROCEDIMENTOS DA PESQUISA QUANTITATIVA: SURVEY}

Como na pesquisa não serão manipulados os níveis das variáveis de pesquisa, ou seja, não existe controle sobre as variáveis estudadas, o método de pesquisa quantitativa mais adequado para a condução do estudo é a pesquisa survey. Segundo Miguel (2007), a survey compreende o levantamento de dados de uma amostra significativa acerca do problema que se deseja estudar, seguida de uma análise quantitativa para obtenção de conclusões em relação aos dados coletados.

Miguel (2010) apresenta um guia contemplando as etapas para uma pesquisa do tipo survey, conforme Figura 15. 
Figura 15 - Etapas de execução de uma pesquisa do tipo survey
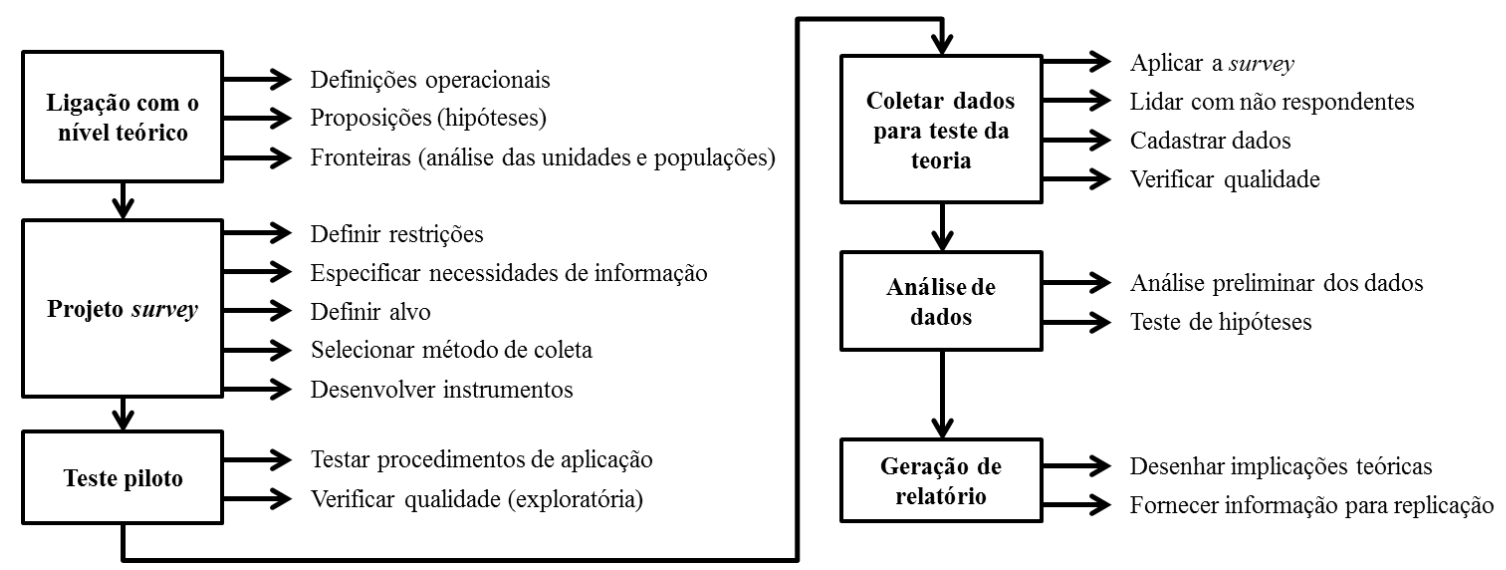

Fonte: Miguel, 2010.

Diante dos objetivos do estudo apresentados o capítulo 1, a pesquisa pode ser classificada como confirmatória, uma vez que está voltada para realizar uma análise da relação entre as capacidades de TI e os processos de gestão do conhecimento, respeitando um modelo teórico, ou seja, apoia-se em conceitos e modelos definidos na literatura que podem ser testados.

\subsubsection{MODELAGEM DE EQUAÇÕES ESTRUTURAIS}

A validação do modelo teórico proposto foi realizada com o uso da técnica de modelagem de equações estruturais (SEM - Structural Equation Modeling). Hair et al. (2009) destacam que essa é uma família de modelos estatísticos que buscam explicar as relações entre múltiplas variáveis. Dessa forma, essa técnica examina a estrutura de inter-relações expressas em uma série de equações, semelhante a uma série de equações de regressão múltipla. Essas equações descrevem as relações entre construtos (variáveis dependentes e independentes) envolvidos na análise, que são inobserváveis ou fatores latentes representados por múltiplas variáveis.

"A diferença mais óbvia entre SEM e outras técnicas multivariadas é o uso de relações separadas para cada conjunto de variáveis dependentes." (HAIR et al., 2009)

Hair et al. (2009) destacam que na SEM é feita uma distinção que se assemelha com o que é feito em outras técnicas, no que diz respeito a diferenciação das variáveis independentes e dependentes. A seguir é apresentado a definição dos dois 
tipos de construtos presentes em um modelo de equações estruturais, segundo Hair et al. (2009):

- Construtos exógenos: são os equivalentes latentes, multi-itens de variáveis independentes. Como tais, eles usam uma variável estatística de medidas para representar o construto, o qual atua como uma variável independente no modelo. Eles são determinados por fatores externos ao modelo, ou seja, não são explicados por qualquer outro construto ou variável do modelo, o que explica o termo independente;

- Construtos endógenos: são os equivalentes latentes, multi-itens de variáveis dependentes, ou seja, uma variável estatística de variáveis dependentes individuais. Tais construtos são teoricamente determinados por fatores dentro do modelo.

Hair et al. (2009) destacam que um modelo convencional em terminologia SEM consiste, na verdade, de dois modelos, o de mensuração (representando como variáveis medidas se unem para representar construtos) e o modelo estrutural (que mostra como construtos são associados entre si). Esse fato pode deixar o modelo bastante complexo e, dessa forma, muitos pesquisadores acham mais conveniente retratar um modelo de uma forma visual conhecida como diagrama de caminhos, que deve empregar convenções específicas tanto para construtos quanto para variáveis medidas e as relações entre elas, conforme Figura 16.

Figura 16 - Diagrama de caminhos

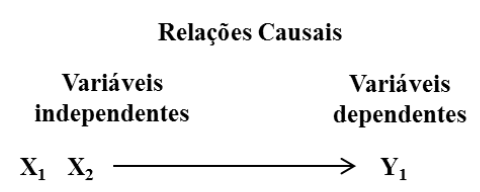

(a)

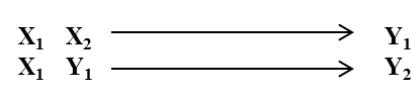

(b)

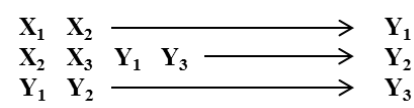

(c)
Diagrama de caminhos
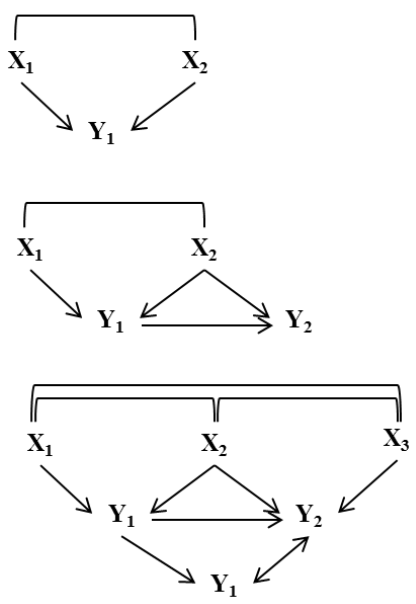

Fonte: Hair et al., 2009. 
Segundo Hair et al. (2009), a especificação de relações de dependência também determina se um construto é considerado exógeno ou endógeno. O construto endógeno atua como uma variável dependente, e qualquer construto com um caminho de dependência apontando para o mesmo é considerado endógeno. Enquanto um construto exógeno tem apenas relações correlacionais com outros construtos, ou seja, nenhum caminho de dependência chegando ao construto.

A SEM usa uma série de medidas que descrevem o quão bem a teoria de um pesquisador explica a matriz de covariância observada entre as variáveis medidas, se o modelo proposto estima propriamente todas as relações substantivas entre construtos, e se o modelo de mensuração define adequadamente os construtos, então deveria ser possível a estimação de uma matriz de covariância entre as variáveis que se aproxime bastante da matriz de covariância observada.

Outro fator que afeta o modelo de mensuração, segundo Hair et al. (2009), está associado com a questão de causalidade, que se refere à direção dos relacionamentos entre os construtos latentes e suas respectivas variáveis mensuráveis. A direção de causalidade conduz a abordagens constratantes de mensuração - modelos de mensuração reflexivos versus formativos. A teoria reflexiva de mensuração é baseada na ideia de que construtos latentes são a causa das variáveis medidas e que o erro resulta de uma incapacidade de explicar por completo essas medidas, enquanto a teoria formativa de mensuração é modelada com base na suposição de que as variáveis medidas são a causa do construto, e o erro nesses modelos é a incapacidade de explicar por completo o construto.

As técnicas de SEM podem ser divididas em dois grandes grupos, segundo Henseler et al. (2009): técnicas baseadas na covariância e técnicas baseadas na variância. As técnicas baseadas na variância buscam maximizar a variância explicada de todas as variáveis dependentes, enquanto as técnicas baseadas em covariância usam o modelo teórico para explicar a covariância de todos os indicadores.

Para a avaliação do modelo de mensuração, pode ser utilizado o método de análise fatorial confirmatória (CFA), que segundo Hair et al. (2009) é uma maneira de testar o quão bem variáveis medidas representam um número menor de construtos. A avaliação do modelo estrutural pode ser feita por meio do CFA alterado para 
representar um modelo estrutural, o qual mantém o foco, segundo Hair et al. (2009), no ajuste geral e relativo do modelo, e no tamanho, direção e significância das estimativas paramétricas estruturais, descritas com setas em um sentido no diagrama de caminhos.

Segundo Hair Jr et al. (2014), as relações de causa e efeito do modelo de caminho PLS implicam que uma variável latente exógena afeta diretamente uma variável latente endógena sem qualquer influência sistêmica de outras variáveis. Porém, é possível levar em consideração uma varável moderadora que pode afetar a força de uma relação específica entre duas variáveis latentes. A diferença entre 0 efeito moderador e o efeito mediador é que o primeiro é independente da variável preditora, e o segundo é dependente dessa variável.

A Figura 17 apresenta um esboço da relação de uma variável moderadora sobre uma relação entre uma variável exógena sobre uma variável endógena. Em um modelo sem efeito moderador existiria apenas o efeito principal $\mathrm{p} 1$. Hair $\mathrm{Jr}$ et al. (2014) destacam que os modelos que levam em consideração os fatores moderadores representam uma análise complementar às relações que são analisadas em um momento inicial na análise de modelos de equações estruturais. Isso é importante pois um efeito principal passa a ser considerado um efeito simples em um modelo moderador, fazendo com que esse efeito possa ter novos valores estimados e novos significados.

Figura 17 - Exemplo de um efeito moderador

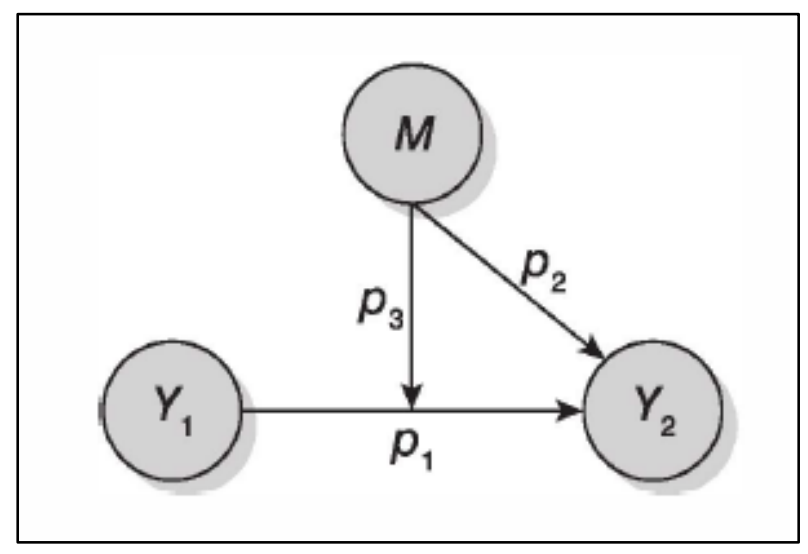

Fonte: Hair Jr et al., 2014.

A Figura 18 apresenta um esboço de como esse efeito moderador deve ser criado dentro da estrutura do software SmartPLS. No caso, é preciso que seja criado um 
construto que represente o efeito do fator moderador $(M)$ sobre a variável endógena da relação que se pretende avaliar. Além do termo de interação, que expressa com o efeito simples p1 muda de acordo com o efeito moderador (HAIR JR et al., 2014).

Figura 18 - Interação com efeito moderador

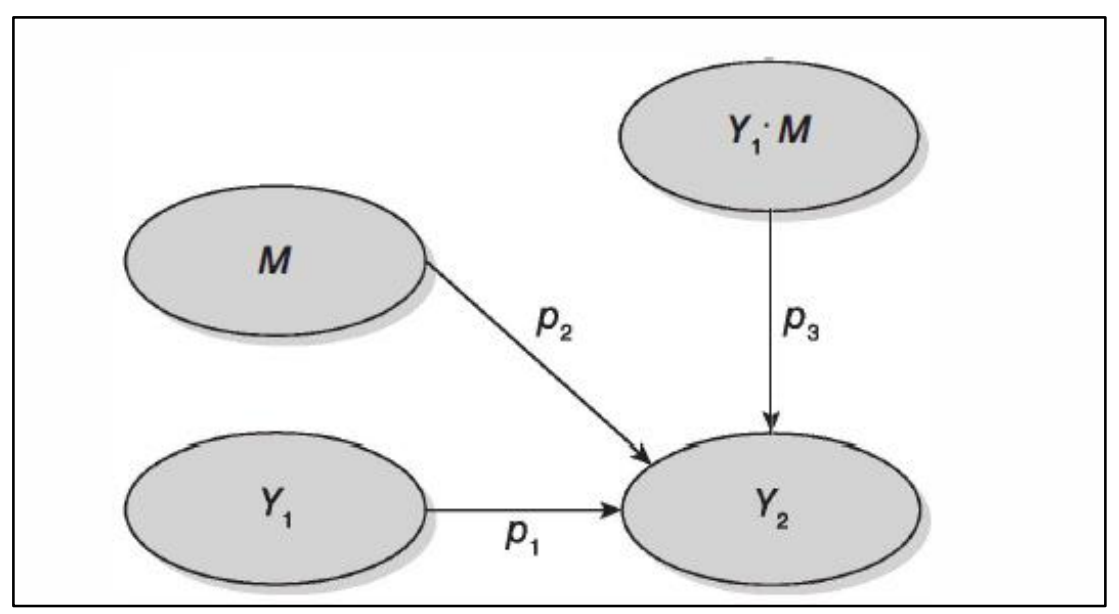

Fonte: Hair Jr et al., 2014.

Além do fator moderador, o modelo de pesquisa se apropria do conceito de modelo de alto nível - High Order Model (HOM) - ou Modelo de componentes hierárquicos Hierachical Component Model (HCM). Segundo Hair Jr et al. (2014), esse tipo de modelo envolve construtos de segunda ordem, ou seja, basicamente existe um conjunto de componentes de baixa ordem - lower-order components (LOCs) - que estão associados com um higher-order construct (HOCs), que é um multidimensional. $\mathrm{O}$ uso do HCMs na construção do modelo estrutural permite diminuir a quantidade de relações no modelo estrutural. Esse tipo de modelo pode ter duas abordagens: (1) bottom-up e (2) top-down. Na abordagem bottom-up um conjunto de variáveis latentes são combinadas em um construto mais genérico, ou seja, o construto mais genérico representa um conjunto de variáveis latentes. Enquanto na abordagem top-down um construto genérico é composto a partir de diversas dimensões.

Para estabelecer o modelo de mensuração do $\mathrm{HOC}$, é indicado pela literatura que os indicadores dos LOCs sejam repetidos como indicadores do HOC. Essa abordagem é simples de implementar, e o HOC deve ser avaliado seguindo os mesmos critérios de validação e confiabilidade que é feito sobre o modelo PLS. Hair Jr et al. (2014) destacam que um fator importante na relação entre as LOCs e a HOC é se a mesma é reflexiva ou formativa. A relação reflexiva deve ser selecionada no caso de existir 
um fator mais global que explique todas as correlações entre os fatores de primeira ordem, conforme exemplo da Figura 19. Enquanto a relação formativa pode ser selecionada quando na verdade cada LOC tem uma contribuição relativa para explicar a HOC. Além disso, espera-se que essa HOC faça a mediação da relação entre as LOCs e as variáveis dependentes no modelo PLS path, conforme Figura 20.

Figura 19 - Relações reflexivas entre uma HOC e as LOCs

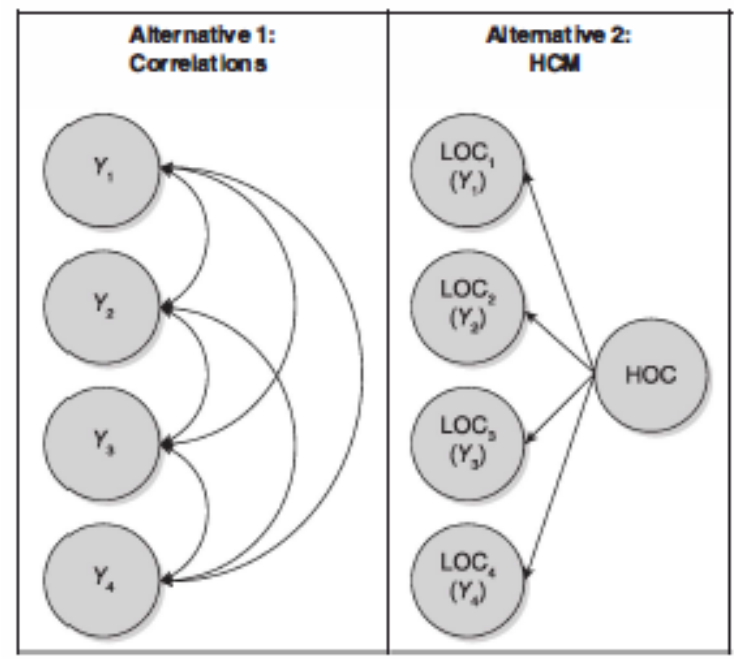

Fonte: Hair Jr et al., 2014.

Figura 20 - Relações formativas entre uma HOC e as LOCs

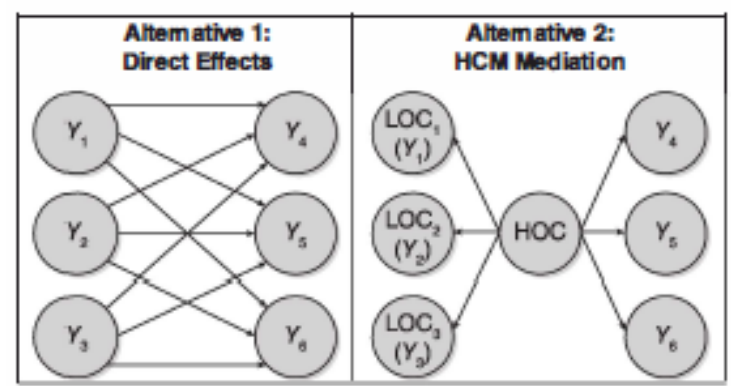

Fonte: Hair Jr et al., 2014.

No estudo, será levado em consideração uma técnica baseada em variância denominada modelagem de equações estruturais baseada na estimação de ajuste de mínimos quadrados (partial least square - PLS).

Henseler et al. (2009) destaca que o PLS tem como principal objetivo maximizar a explicação da variância em um modelo de equações estruturais baseado em seus construtos. Além disso, Ringle et al. (2014) destacam que essa técnica pode ser aplicada para modelos de mensuração constituídos tanto por variáveis formativas 
como reflexivas, e por fim ela tem uma menor exigência em relação ao tamanho mínimo da amostra em comparação aos métodos de covariância.

O modelo de pesquisa conta dois diferenciais dos modelos de equações estruturais que são: a presença de efeitos moderadores e o fato do modelo envolver componentes hierárquicos.

No que diz respeito à presença de efeitos moderadores no modelo está atrelado ao fato de analisar qual o impacto de determinados fatores (impacto estratégico da $\mathrm{TI}$ no presente e futuro, mais a orientação do estilo de gestão do conhecimento voltada para o conhecimento explícito) na relação das capacidades de TI sobre os processos de gestão do conhecimento. Já em relação à presença de componentes hierárquicos, o modelo destaca-se por dois cenários: no caso tem-se a Capacidade de $\mathrm{Tl}$ como uma HOC, no contexto de que essa HOC pode ser composta pelas LOCs - Capacidade de Infraestrutura de TI, Capacidade de Operação de TI e Capacidade de Recursos Humanos de TI -, e ser um mediador entre essas LOC's e a variável dependente Gestão do Conhecimento. Além disso, a Gestão do Conhecimento também pode ser uma HOC, porém no contexto de ser um fator mais global que explica as LOCs - Criação do Conhecimento, Aquisição do Conhecimento, Armazenamento do Conhecimento, Compartilhamento do Conhecimento, Aplicação do Conhecimento e Proteção do Conhecimento.

Na próxima seção são apresentados os procedimentos para análise do modelo de pesquisa.

\subsubsection{MODELO DE PESQUISA}

Para elaboração do modelo de pesquisa foi preciso definir as formas de medições dos construtos envolvidos na pesquisa. Em relação ao desenvolvimento das medições, Miguel (2010) entende que além da definição dos tipos e quantidades de questões, forma de apresentação, uso ou não de escalas numéricas, entre outros aspectos, sua elaboração deve estar estritamente relacionada ao modelo teórico, ou seja, à teoria vigente que originou os construtos. Assim, as questões devem ser um desdobramento dos construtos de tal modo que ao respondê-las se estará testando esses construtos. Conforme destacado por Bryman (1989), a mensurabilidade tem um papel central no processo de realização da pesquisa uma vez que permite testar as hipóteses identificadas. 
Todas as variáveis utilizadas para mensurar as capacidades de TI, os processos de gestão do conhecimento e os fatores moderadores foram mensuradas por meio da escala Likert de cinco pontos, variando de 1 (menor nível - discordo totalmente) a 5 (maior nível - concordo totalmente).

\subsubsection{Capacidades de tecnologia da informação}

Conforme supracitado ao longo da pesquisa a capacidade de TI foi dividida em três dimensões: Infraestrutura de TI, Recursos Humanos de TI e Operação de TI.

Dessa forma, o modelo é composto pela variável latente de segunda ordem denominada Capacidade de Tecnologia da Informação, associada com seus respectivos construtos de primeira ordem que correspondem as três dimensões citadas. Cada construto de primeira está associado com um conjunto de questões denominados indicadores, conforme Quadro 29.

Quadro 29 - Medições para o construto Capacidade de Tecnologia da Informação.

\begin{tabular}{|c|c|c|}
\hline $\begin{array}{l}\text { Variáveis } \\
\text { Latentes de } \\
\text { Segunda } \\
\text { Ordem }\end{array}$ & $\begin{array}{l}\text { Variáveis Latentes de } \\
\text { Primeira Ordem }\end{array}$ & Indicadores \\
\hline \multirow{8}{*}{$\begin{array}{l}\text { X - Capacidade } \\
\text { de tecnologia } \\
\text { da informação }\end{array}$} & \multirow{5}{*}{$\mathrm{X}_{1}$ - Infraestrutura de TI } & $\begin{array}{l}\mathrm{X}_{1.1} \text { - A empresa possui um departamento } \\
\text { responsável pela gestão de tecnologias da } \\
\text { informação? }\end{array}$ \\
\hline & & $\begin{array}{l}\mathrm{X}_{1.2} \text { - A empresa possui uma pessoa } \\
\text { responsável pela gestão de tecnologias da } \\
\text { informação? }\end{array}$ \\
\hline & & $\begin{array}{l}\mathrm{X}_{1.3} \text { - A empresa reserva um orçamento } \\
\text { anual para investir em novas tecnologias da } \\
\text { informação? }\end{array}$ \\
\hline & & $\begin{array}{l}\mathrm{X}_{1.4}-\mathrm{A} \text { empresa tem capacidade para criar } \\
\text { aplicações customizadas de softwares para } \\
\text { atender necessidades emergentes? }\end{array}$ \\
\hline & & $\begin{array}{l}X_{1.5} \text { - A empresa possui tecnologias da } \\
\text { informação que permitem a interação entre } \\
\text { seus colaboradores, tais como e-mails, } \\
\text { ferramentas de instant messaging, vídeo } \\
\text { conferência, entre outras? }\end{array}$ \\
\hline & \multirow{3}{*}{$\begin{array}{l}X_{2} \text { - Recursos Humanos de } \\
\text { TI }\end{array}$} & $\begin{array}{l}\mathrm{X}_{2.1} \text { - No geral, o corpo de apoio técnico da } \\
\text { empresa possui conhecimento em relação } \\
\text { as tecnologias da informação? }\end{array}$ \\
\hline & & $\begin{array}{l}\mathrm{X}_{2.2}-\mathrm{A} \text { empresa possui um elevado grau de } \\
\text { expertise em tecnologias da informação? }\end{array}$ \\
\hline & & $\begin{array}{lcccc}\mathrm{X}_{2.3}-\mathrm{A} & \text { empresa } & \text { busca } & \text { realizar } \\
\text { treinamentos, } & \text { para } & \text { manter } & \text { seus } \\
\text { colaboradores } & \text { atualizados } & \text { em relação as }\end{array}$ \\
\hline
\end{tabular}




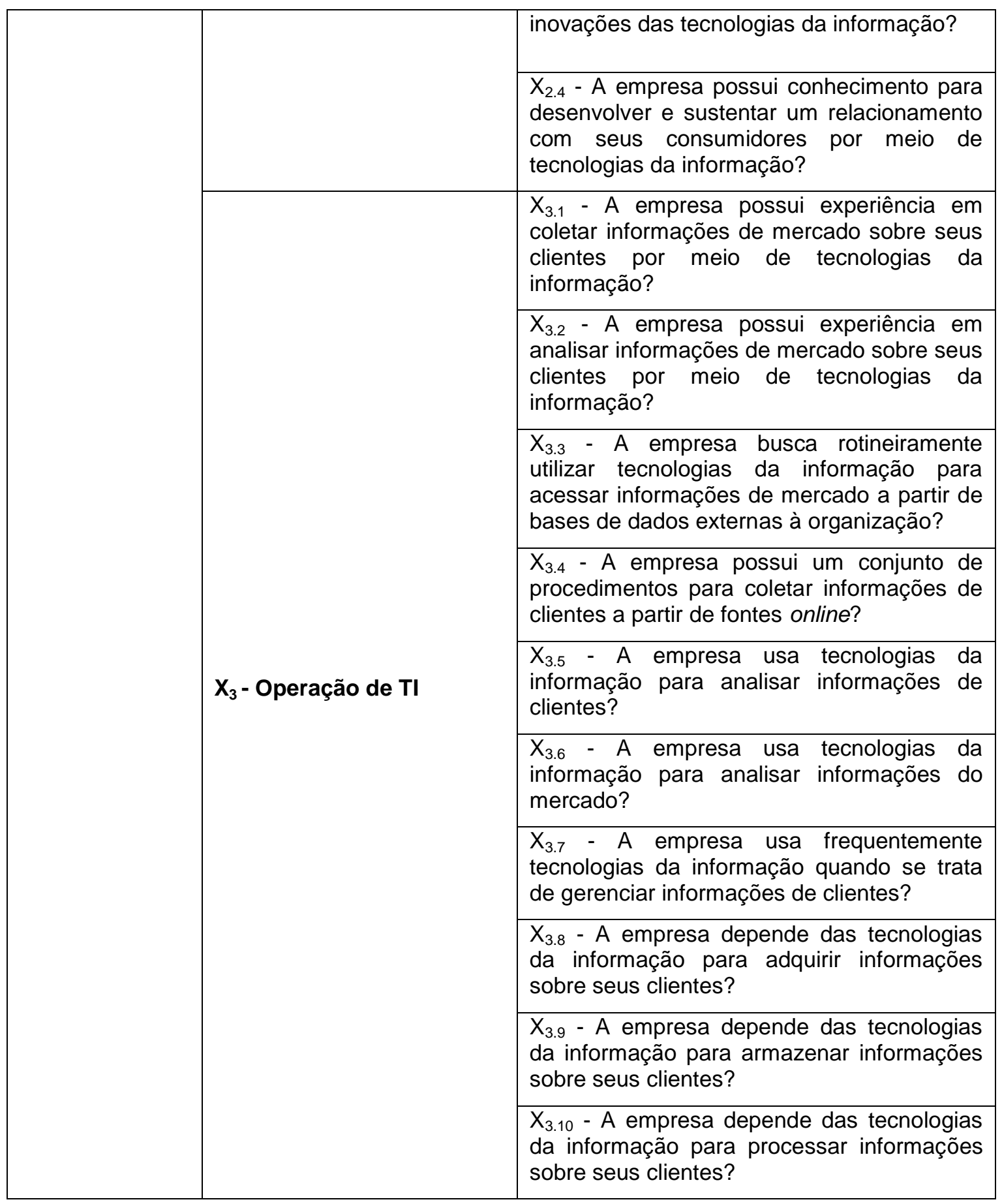

Fonte: elaborado pelo autor.

\subsubsection{Processos de gestão do conhecimento}

A partir da revisão da literatura, foram identificados diversos processos de gestão do conhecimento que foram incluídos no modelo de pesquisa com o intuito de incrementar o modelo apresentado por Pérez-López e Alegre (2012), no qual são utilizados os seguintes processos de gestão do conhecimento: aquisição do conhecimento, compartilhamento do conhecimento e aplicação do conhecimento. Os 
outros três processos que foram incluídos no presente modelo de pesquisa foram a criação do conhecimento, o armazenamento do conhecimento e a proteção do conhecimento.

Dessa forma o modelo é composto pelo construto de segunda ordem denominada Capacidade de Gestão do Conhecimento, associada com seus respectivos construtos de primeira ordem que correspondem aos 6 processos de gestão do conhecimento citados.

Cada construto de primeira ordem está associado com um conjunto de questões denominados indicadores, conforme Quadro 30 e Quadro 31.

Quadro 30 - Medições para o construto Capacidade de Gestão do conhecimento (Parte 1)

\begin{tabular}{|c|c|c|}
\hline $\begin{array}{c}\text { Variáveis } \\
\text { Latentes de } \\
\text { Segunda Ordem }\end{array}$ & $\begin{array}{l}\text { Variáveis Latentes } \\
\text { de Primeira Ordem }\end{array}$ & Indicadores \\
\hline \multirow{12}{*}{$\begin{array}{l}\text { Y - Capacidade } \\
\text { de gestão do } \\
\text { conhecimento }\end{array}$} & \multirow{3}{*}{$\begin{array}{l}Y_{1} \text { - Criação do } \\
\text { conhecimento }\end{array}$} & $\begin{array}{l}Y_{1.1} \text { - A empresa possui processos bem definidos } \\
\text { para obter informações do seu ambiente externo } \\
\text { para gerar conhecimentos para uso interno? }\end{array}$ \\
\hline & & $\begin{array}{l}Y_{1.2}-\text { A empresa possui processos bem definidos } \\
\text { que permitem um trabalho colaborativo entre os } \\
\text { seus colaboradores? }\end{array}$ \\
\hline & & $\begin{array}{l}Y_{1.3} \text { - A empresa incentiva a formação de } \\
\text { comunidades de práticas para desenvolver o } \\
\text { conhecimento da organização em um determinado } \\
\text { assunto? }\end{array}$ \\
\hline & \multirow{7}{*}{$\begin{array}{l}Y_{2}-\text { Aquisição do } \\
\text { conhecimento }\end{array}$} & $\begin{array}{l}Y_{2.1} \text { - A empresa procura se reunir com seus } \\
\text { clientes com o objetivo de identificar suas } \\
\text { necessidades? }\end{array}$ \\
\hline & & $\begin{array}{l}Y_{2.2} \text { - A empresa tem processos para aquisição do } \\
\text { conhecimento sobre seus fornecedores? }\end{array}$ \\
\hline & & $\begin{array}{l}Y_{2.3} \text { - A empresa tem processos para aquisição do } \\
\text { conhecimento sobre o mercado em que atua? }\end{array}$ \\
\hline & & $\begin{array}{l}Y_{2.4} \text { - A empresa tem processos que permitem que } \\
\text { seja capitalizado práticas de sucesso de outras } \\
\text { organizações? }\end{array}$ \\
\hline & & $\begin{array}{l}Y_{2.5}-\text { A empresa tem processos para adquirir novos } \\
\text { conhecimentos a partir do conhecimento existente? }\end{array}$ \\
\hline & & $\begin{array}{l}Y_{2.6}-\text { Novas abordagens } \mathrm{e} \text { ideias sobre } 0 \\
\text { desempenho do trabalho são experimentadas } \\
\text { continuamente? }\end{array}$ \\
\hline & & $\begin{array}{l}Y_{2.7}-A \text { empresa tem mecanismos para identificar o } \\
\text { conhecimento dos seus colaboradores possuem? }\end{array}$ \\
\hline & \multirow{2}{*}{$\begin{array}{l}Y_{3}- \\
\text { Armazenamento } \\
\text { do conhecimento }\end{array}$} & $\begin{array}{l}Y_{3.1}-A \text { empresa tem mecanismos para armazenar o } \\
\text { conhecimento criado? }\end{array}$ \\
\hline & & $\mathrm{Y}_{3.2}-\mathrm{A}$ empresa tem mecanismos para armazenar $\mathrm{o}$ \\
\hline
\end{tabular}




\begin{tabular}{|l|l|}
\hline \multirow{1}{|l|}{} & conhecimento adquirido? \\
\hline & $\begin{array}{l}Y_{3.3}-\text { A empresa tem mecanismos para codificar o } \\
\text { conhecimento de forma que esse possa ser } \\
\text { armazenado? }\end{array}$ \\
\hline & $\begin{array}{l}\text { Y3.4 - O conhecimento armazenado é acessado e } \\
\text { utilizado por indivíduos que não tem conhecimento } \\
\text { do originador do conhecimento? }\end{array}$ \\
\hline & $\begin{array}{l}\text { Y3.5 - A empresa tem mecanismos que permitem a } \\
\text { recuperação do conhecimento de forma eficaz e } \\
\text { eficiente? }\end{array}$ \\
\hline
\end{tabular}

Fonte: elaborado pelo autor.

Quadro 31 - Medições para o construto Capacidade de Gestão do conhecimento (Parte 2)

\begin{tabular}{|c|c|c|}
\hline $\begin{array}{l}\text { Variáveis } \\
\text { Latentes de } \\
\text { Segunda } \\
\text { Ordem }\end{array}$ & $\begin{array}{l}\text { Variáveis Latentes } \\
\text { de Primeira Ordem }\end{array}$ & Indicadores \\
\hline \multirow{13}{*}{$\begin{array}{l}\text { Y - Capacidade } \\
\text { de gestão do } \\
\text { conhecimento }\end{array}$} & \multirow{10}{*}{$\begin{array}{l}\mathrm{Y}_{4}- \\
\text { Compartilhamento } \\
\text { do conhecimento }\end{array}$} & $\begin{array}{l}Y_{4.1} \text { - Reuniões são periodicamente agendadas } \\
\text { para informar todos os colaboradores sobre as } \\
\text { últimas inovações da empresa? }\end{array}$ \\
\hline & & $\begin{array}{l}Y_{4.2} \text { - A empresa tem mecanismos formais para } \\
\text { garantir o compartilhamento de boas práticas? }\end{array}$ \\
\hline & & $\begin{array}{l}Y_{4.3} \text { - Existem especialistas que são responsáveis } \\
\text { por disseminar o conhecimento para o restante da } \\
\text { equipe? }\end{array}$ \\
\hline & & $\begin{array}{l}Y_{4.4} \text { - Existem indivíduos responsáveis por coletar } \\
\text { internamente sugestões dos colaboradores? }\end{array}$ \\
\hline & & $\begin{array}{l}Y_{4.5} \text { - Existem indivíduos responsáveis por juntar } \\
\text { internamente sugestões dos colaboradores? }\end{array}$ \\
\hline & & $\begin{array}{l}\text { Y4.6 - Existem indivíduos responsáveis por distribuir } \\
\text { internamente sugestões dos colaboradores? }\end{array}$ \\
\hline & & $\begin{array}{l}Y_{4.7} \text { - A empresa possui mecanismos que permitem } \\
\text { que o conhecimento seja compartilhado entre } \\
\text { unidades distribuídas? }\end{array}$ \\
\hline & & $\begin{array}{l}Y_{4.8} \text { - A empresa tem mecanismos para disseminar } \\
\text { o conhecimento com stakeholders externos à } \\
\text { organização? }\end{array}$ \\
\hline & & $\begin{array}{l}Y_{4.9} \text { - A empresa possui mecanismos que facilitam } \\
\text { a interação entre seus colaboradores? }\end{array}$ \\
\hline & & $\begin{array}{l}Y_{4.10}-\text { A empresa possui mecanismos que facilitam } \\
\text { a colaboração entre seus colaboradores? }\end{array}$ \\
\hline & \multirow{3}{*}{$\begin{array}{l}Y_{5}-\text { Aplicação do } \\
\text { conhecimento }\end{array}$} & $\begin{array}{l}Y_{5.1} \text { - A empresa possui processos para aplicar o } \\
\text { conhecimento aprendido a partir de experiências } \\
\text { nas atividades do dia-a-dia? }\end{array}$ \\
\hline & & $\begin{array}{l}Y_{5.2}-\text { A empresa facilita o acesso ao conhecimento } \\
\text { para aqueles que precisam dele? }\end{array}$ \\
\hline & & $\begin{array}{l}Y_{5.3} \text { - A empresa possui processos para utilizar o } \\
\text { conhecimento no desenvolvimento de novos } \\
\text { produtos e/ou serviços? }\end{array}$ \\
\hline
\end{tabular}




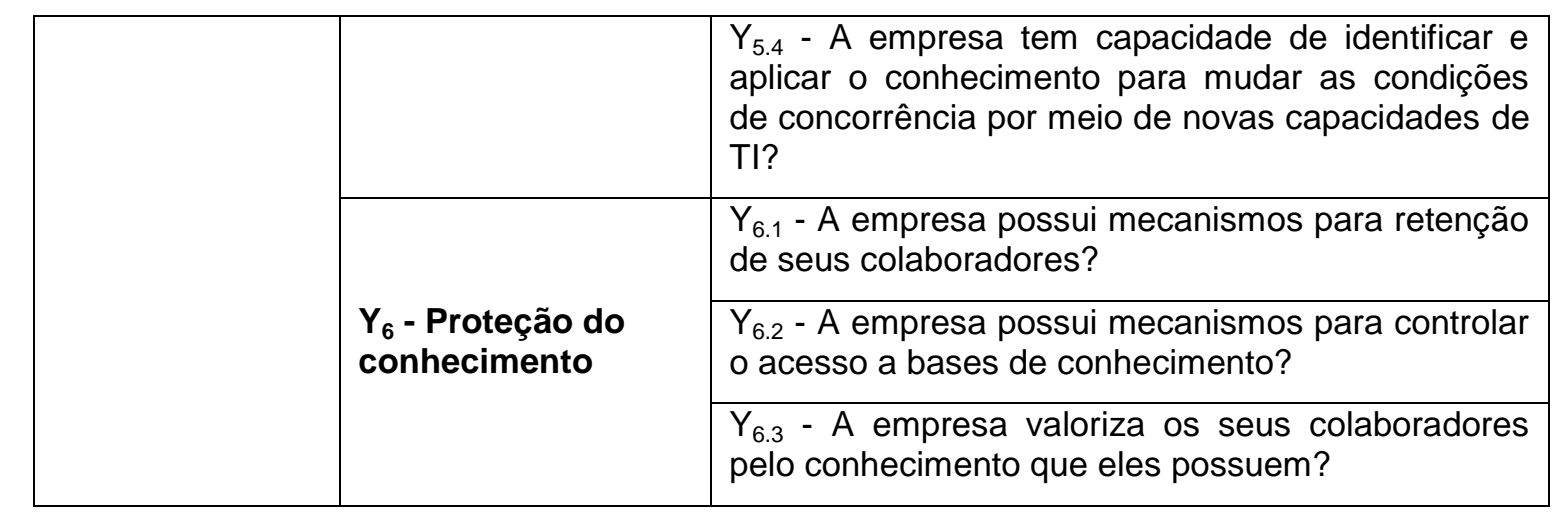

Fonte: elaborado pelo autor.

\subsubsection{Fatores Moderadores}

No modelo de pesquisa são apresentados os fatores moderadores que serão levados em consideração: o impacto estratégico da TI no presente e no futuro, com base nos conceitos apresentados no grid de Nolan e McFarlan (2005), e o estilo de gestão do conhecimento orientado para o conhecimento explícito segundo os autores Choi e Lee (2003), Stankosky (2005) e Wild e Griggs (2008).

A forma de mensuração dos fatores moderadores impacto estratégico da TI no presente e no futuri foi validada por meio de uma etapa preliminar, e a seguir é apresentado o conjunto de indicadores que foram utilizados para mensurar cada fator moderador.

\subsection{Impacto estratégico da TI}

Por meio das características de cada quadrante do "Grid estratégico do impacto da TI" apresentados por Nolan e McFarlan (2005), foram elencados alguns questionamentos para auxiliar a identificar em qual quadrante uma determinada empresa está posicionada.

a) A queda de um sistema por poucos minutos pode ocasionar perdas imediatas ao negócio?

b) O aumento no tempo de resposta pode ocasionar consequências graves para usuários internos e externos a organização?

c) A maioria das atividades essenciais são online?

d) Os sistemas fornecem pouca diferenciação estratégica ou redução de custo?

e) Os sistemas internos são invisíveis para fornecedores e consumidores? 
f) O trabalho dos sistemas é, principalmente, de apoio?

g) Novas tecnologias da informação propiciam um melhor processo e transformação nos serviços prestados?

h) Novas tecnologias propiciam principalmente uma redução de custos?

i) Novas tecnologias reduzem gaps com competidores no que diz respeito aos custos, serviços e processos?

Conforme já mencionado o grid do impacto estratégico da TI de Nolan e McFarlan (2005) apresentam dois eixos: o eixo das abscissas corresponde a necessidade de novas tecnologias da informação e nesse caso elas possuem um impacto futuro, enquanto o eixo das ordenadas corresponde a necessidade de tecnologias da informação confiáveis e nesse caso elas possuem um impacto presente.

Foi realizado um levantamento por meio de uma survey prelimiar, na qual foi obtido 105 respostas válidas. A análise dessa amostra teve como objetivo identificar os grupos de questões que pudessem representar cada eixo do grid estratégico de Nolan e McFarlan (2005).

Dessa forma, ao realizar uma análise fatorial esperava-se que fossem identificados dois fatores associados a cada eixo. A análise fatorial segundo Hair et al. (2009) permite identificar correlações entre variáveis, definindo um conjunto de variáveis que são fortemente inter-relacionadas, que é denominado fatores. Como espera-se que os fatores representem os dois eixos do modelo eles precisam ser ortogonais, ou seja, não-correlacionados, para essa validação foi realizado por meio da rotação varimax.

A Tabela 3 apresenta os resultados da análise fatorial realizada, no caso foram identificados um conjunto de três fatores ambos compostos por três variáveis. $\mathrm{O}$ Fator 2 está associado com o impacto das tecnologias da informação no presente e com a questão da necessidade de tecnologias da informação confiáveis. Já o Fator 1 está relacionado com o impacto das tecnologias da informação no futuro, e com a questão das novas tecnologias da informação. Por fim o Fator 3 está associado com questões associado ao estado atual da TI para a organização. 


\begin{tabular}{|c|c|c|c|}
\hline \multirow[b]{2}{*}{ Variáveis } & \multicolumn{3}{|c|}{ Componente } \\
\hline & 1 & 2 & 3 \\
\hline $\begin{array}{l}\text { A queda de um sistema por poucos minutos pode ocasionar perdas } \\
\text { imediatas ao negócio. }\end{array}$ & ,265 & ,845 &,- 033 \\
\hline $\begin{array}{l}\text { O aumento no tempo de resposta pode ocasionar consequências graves } \\
\text { para usuários internos e externos a organização. }\end{array}$ &, 165 & ,849 &,- 104 \\
\hline A maioria das atividades de negócio essenciais são online. &,- 006 & 830 &,- 044 \\
\hline $\begin{array}{l}\text { Os sistemas fornecem pouca diferenciação estratégica ou redução de } \\
\text { custos. }\end{array}$ &,- 078 & 079 & ,829 \\
\hline Os sistemas internos são invisíveis para fornecedores e consumidores. & ,094 &,- 076 &, 579 \\
\hline O trabalho dos sistemas é, principalmente, de apoio. & ,037 &,- 137 & ,747 \\
\hline $\begin{array}{l}\text { Novas tecnologias da informação propiciam um melhor processo e } \\
\text { transformação nos serviços prestados. }\end{array}$ & ,801 & ,115 & 131 \\
\hline Novas tecnologias propiciam principalmente uma redução de custos. & ,884 & ,081 & ,057, \\
\hline $\begin{array}{l}\text { Novas tecnologias reduzem gaps em relação aos concorrentes no que diz } \\
\text { respeito aos custos, serviços e processos. }\end{array}$ & 818, & 179, &,- 097 \\
\hline
\end{tabular}

Fonte: resultado gerado pelo software IBM SPPS.

Por meio dessa análise preliminar foram selecionadas as questões (a), (b), (c), (g), (h) e (i) que são as variáveis associadas a cada um dos eixos. O Fator 1, composto pelas variáveis (a), (b) e (c), está associado ao eixo as ordenadas, enquanto o Fator 2, composto pelas variáveis $(\mathrm{g}),(\mathrm{h})$, e (i), está associado com o eixo das abscissas.

É importante salientar os valores do alpha de cronbach que foram obtidos para cada um desses fatores que serão utilizados no estudo. O valor obtido para o Fator 1 foi igual a 0,802 e para o Fator 2 é igual a 0,817.

No estudo em questão esse fator moderador foi divivido em dois: o impacto estratégico da TI no presente e o impacto estratégico da TI no futuro.

\subsection{Estilo do método de gestão do conhecimento}

Para mensurar o estilo do método de gestão do conhecimento das empresas dos participantes da survey foram utilizadas as questões elaboradas por Choi e Lee (2003):

a) O conhecimento (know-how, habilidades técnicas ou métodos de solução de problemas) é bem codificado na empresa?

b) $O$ conhecimento pode ser adquirido facilmente por meio de documentos formais e manuais na empresa? 
c) Os resultados de projetos e reuniões devem ser documentados na empresa?

d) O conhecimento é compartilhado por meio de meios codificados, como manuais e documentos na organização?

Conforme já mencionado, o estilo de gestão do conhecimento apresentado por Choi e Lee (2003) apresentam dois eixos: o eixo das abscissas corresponde a orientação tácita, enquanto o eixo das ordenadas corresponde a orientação explícita. No estudo os autores obtiveram valores do alpha de cronbach relevantes para os dois conjuntos de variáveis utilizadas: o grau de orientação explícito e implícito. No caso para a orientação tácita os autores obtiveram um valor igual a 0,794 e para a orientação explícita um valor igual a 0,829.

Vale ressaltar que no estudo de Choi e Lee (2003) é destacado o fato de que quanto mais a orientação para a gestão do conhecimento é voltada para o conhecimento explícito existe uma ênfase maior na codificação e reuso do conhecimento, e nesse contexto a TI tem um papel fundamental para diminuir a complexidade ao acesso, compartilhamento e uso do conhecimento. Esse fato também é abordado nos estudos dos autores Stankosky (2005) e Wild e Griggs (2008).

Dessa forma o estudo em questão manteve o foco sobre o fator moderador estilo do método de gestão do conhecimento voltado para o conhecimento explícito.

\subsubsection{Modelo de pesquisa: Diagrama de caminhos}

O modelo de pesquisa contempla todos os aspectos supracitados. O modelo de pesquisa no formato de diagrama de caminhos de um modelo de equações estruturais, que contempla as variáveis latentes (construtos) e as variáveis observáveis (indicadores) associadas a cada variável latente, assim como as variáveis moderadoras que serão consideradas na pesquisa é apresentado na Figura 21.

Nessa figura, os construtos $M_{1}$ e $M_{2}$ correspondem aos construtos que envolvem o impacto estratégico da TI no presente e no futuro, enquanto o construto $M_{3}$ corresponde ao construto associado com o método de estilo de gestão do conhecimento voltado para o conhecimento explícito. E seus indicadores correspondem as questões que já foram supracitadas ao logo nas sub seções anteriores.

Figura 21 - Modelo de pesquisa: diagrama de caminhos 


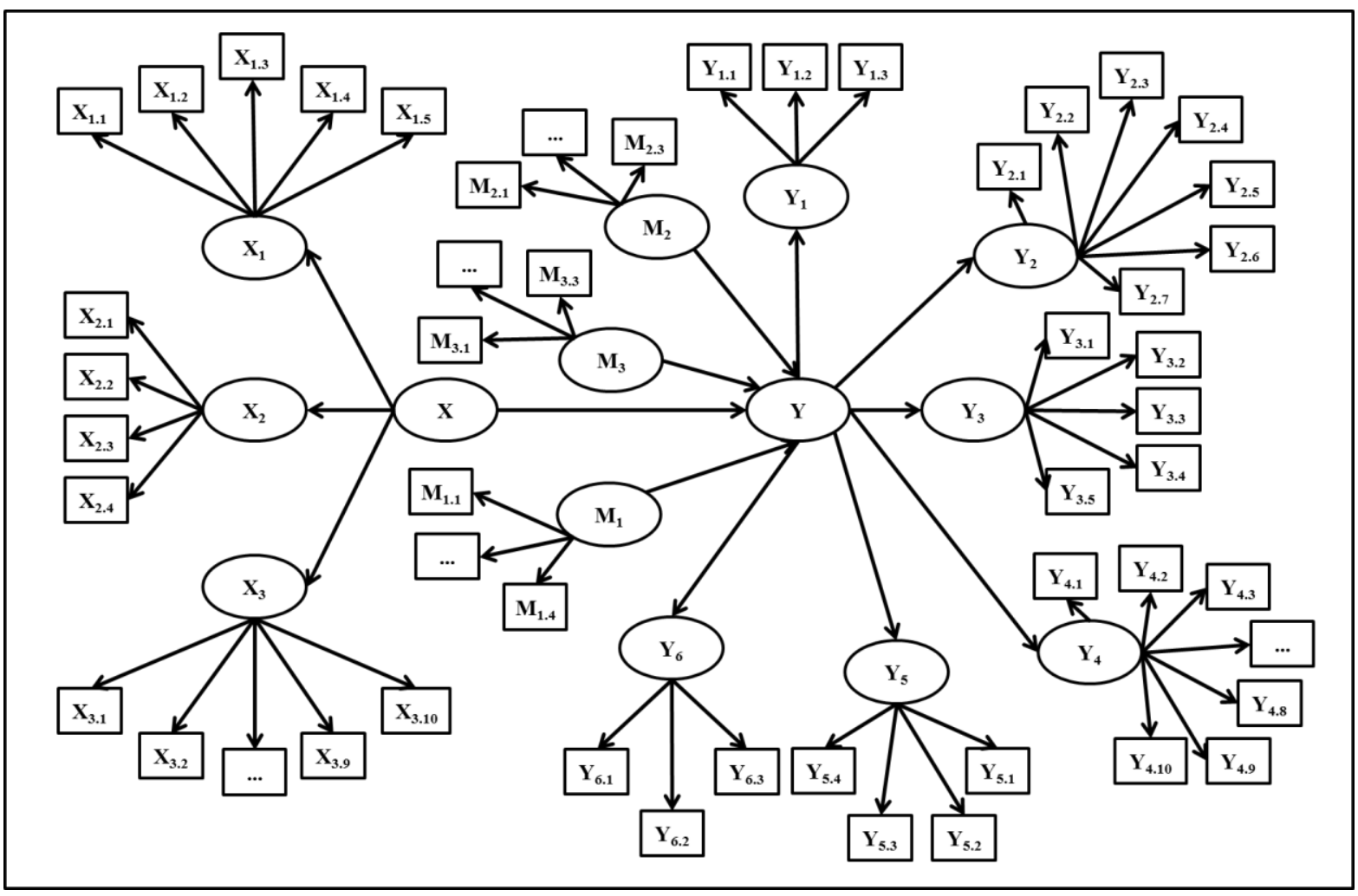

Fonte: elaborado pelo autor.

\subsubsection{UNIDADES DE ANÁLISE E AMOSTRAGEM}

Segundo Miguel (2010) a caracterização da população e da amostra é uma etapa importante para a condução de uma pesquisa do tipo survey. Dentre as diversas características delimitadoras de populações estão o porte da empresa e setor industrial, por exemplo. Complementando o autor destaca que a definição da amostra objetiva escolher de uma população um número suficiente de elementos, cujo estudo das características permita generalizar suas propriedades para a população de origem, no caso de amostras probabilísticas. Nesse contexto existem dois aspectos importantes relacionados com a definição da amostra: a aleatoriedade, ou seja, sua capacidade de representar a população, e o seu tamanho, considerando os requisitos dos procedimentos estatísticos para avaliação da qualidade da medição e para aplicação de testes de hipóteses.

Rasinski (2005) destaca que o design da amostra determina quem será mensurado. No geral as pesquisas do tipo survey buscam obter diferentes tipos de informação como valores, atitudes, opiniões, conhecimento, comportamentos, características e circunstâncias. 
A pesquisa em questão tem como objetivo buscar obter informações associadas com as características das organizações em relação aos processos de gestão do conhecimento e as tecnologias da informação.

Para determinar a amostra mínima ideal para o estudo foi utilizado o software G*Power 3.1.9.2, no estudo de Ringle et al. (2014) é destacado que esse software requer alguns parâmetros: o nível de confiança, o tamanho do efeito $\left(\mathrm{f}^{2}\right)$, o valor do erro probabilístico tipo I ( $\alpha$ ) e o número de preditores, ou seja, é preciso identificar o construto que recebe o maior número de setas. No modelo apresentado o número máximo de preditores de um construto é igual a 4.

A Figura 22 apresenta a tela do $G^{*}$ Power para a mensuração da amostra mínima. Segundo os cálculos realizados, o tamanho mínimo da amostra deve ser igual a 129. Segundo Ringle et al. (2014) para se ter um modelo mais consistente é interessante usar o dobro ou o triplo desse valor.

Figura 22 - Cálculo do tamanho da amostra no software $G^{\star} P o w e r$

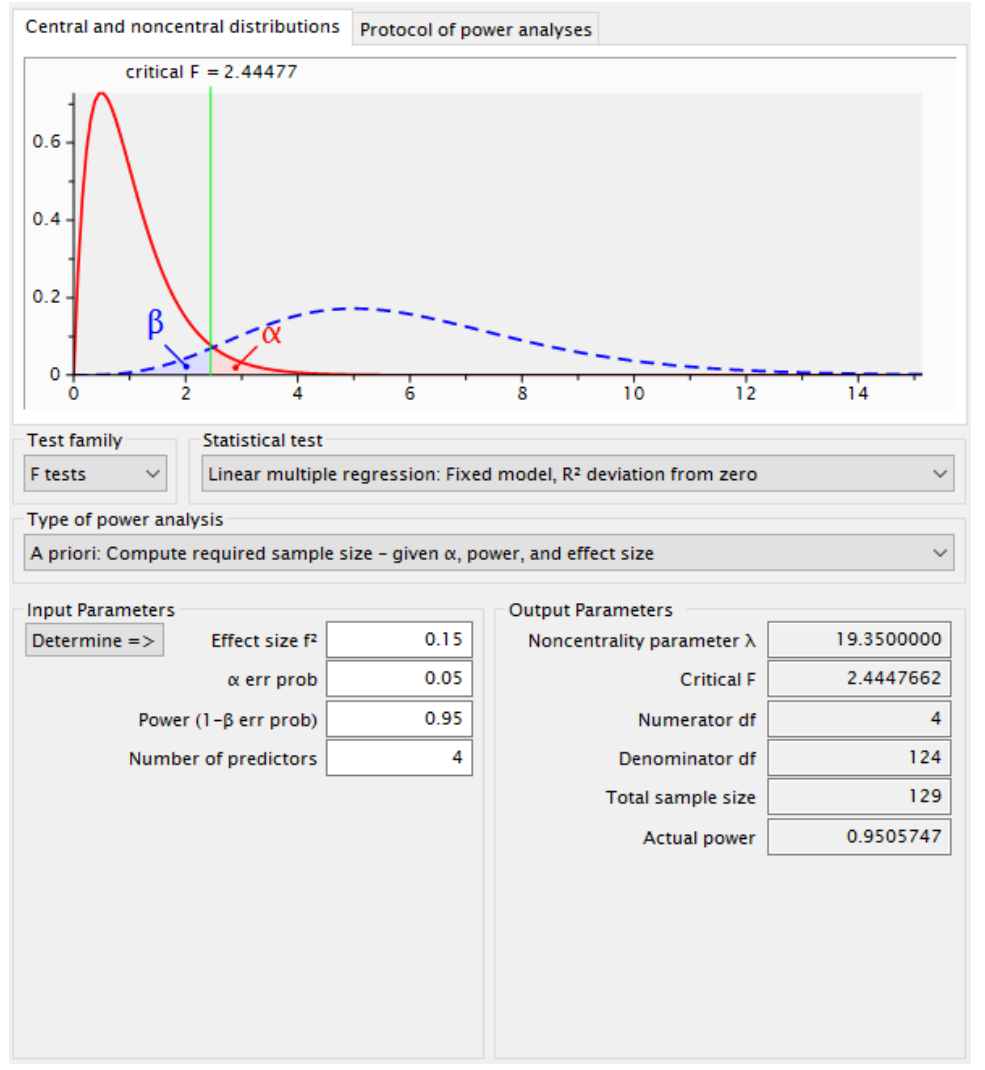

Fonte: software $G^{*}$ Power. 


\subsubsection{INSTRUMENTO DE PESQUISA E COLETA DE DADOS}

No presente estudo foi aplicado um questionário em português online por meio do uso da ferramenta de pesquisa "Survey Monkey", e a chamada para a pesquisa foi feita por meio da elaboração de cartas-convite. As cartas-convite foram enviadas para 10205 contatos.

O questionário elaborado e aplicado é apresentado no APÊNDICE 4 QUESTIONÁRIO. Ele é composto por 5 partes contemplando 33 questões, o Quadro 32 apresenta uma síntese de cada parte do questionário.

Quadro 32 - Estrutura do questionário

\begin{tabular}{|l|l|}
\hline \multicolumn{1}{|c|}{ Parte do questionário } & \multicolumn{1}{|c|}{ Objetivo } \\
\hline $\begin{array}{l}\text { Parte 1: Perfil da organização e do } \\
\text { respondente }\end{array}$ & $\begin{array}{l}\text { Busca obter as informações básicas sobre a } \\
\text { organização como seu porte, segmento de } \\
\text { atuação, se possui ou não departamentos de TI e } \\
\text { de gestão do conhecimento. }\end{array}$ \\
\hline $\begin{array}{l}\text { Parte 2: Grau de importância da TI } \\
\text { para organização }\end{array}$ & $\begin{array}{l}\text { Obter o perfil do respondente do questionário. } \\
\text { informação com base no seu impacto estratégico } \\
\text { no presente e no futuro, seguindo os princípios } \\
\text { apresentandos no grid de Nolan e McFarlan (2005). }\end{array}$ \\
\hline $\begin{array}{l}\text { Parte 3: Capacidades de Tecnologia } \\
\text { da Informação }\end{array}$ & $\begin{array}{l}\text { Entender as características da organização em } \\
\text { relação as capacidades de TI. }\end{array}$ \\
\hline $\begin{array}{l}\text { Parte 4: Estilo de gestão do } \\
\text { conhecimento }\end{array}$ & $\begin{array}{l}\text { Permitir avaliar o estilo de gestão do conhecimento } \\
\text { empregado na organizaçã, seguindo os princípios } \\
\text { apresentandos no grid de Choi e Lee (2003). }\end{array}$ \\
\hline $\begin{array}{l}\text { Parte 5: Processos de gestão do } \\
\text { conhecimento }\end{array}$ & $\begin{array}{l}\text { Entender as características da organização em } \\
\text { relação aos processos de gestão do conhecimento. }\end{array}$ \\
\hline
\end{tabular}

Fonte: elaborado pelo autor.

A população a que esse questionário se destina são pessoas que no momento atuam no mercado de trabalho sem restrição em relação à área em que atuam e do porte da organização.

\subsubsection{PROCEDIMENTO DE ANÁLISE DO MODELO DE PESQUISA}

A análise do modelo de pesquisa será realizada por meio da ferramenta SmartPLS, apresentada por Ringle et al. (2014). Segundo os autores para realizar uma análise 
que envolve a modelagem de equações estruturais por meio da ferramenta SmartPLS é preciso realizar as seguintes etapas:

- Preparação dos dados de entrada;

- Importação dos dados e estruturação do modelo a ser avaliado;

- Avaliação do modelo de mensuração;

- Avaliação do modelo estrutural; e

- Verificação das hipóteses de pesquisa.

\subsubsection{PREPARAÇÃO DOS DADOS DE ENTRADA}

Ringle et al. (2014) apresentam um conjunto de instruções em relação a preparação dos dados para posterior inclusão deles na ferramenta SmartPLS. No presente estudo os dados dos questionários respondidos foram exportados do Survey Monkey em um arquivo no formato .csv, que é o padrão de entrada para a ferramenta na qual o modelo foi analisado. Porém para realizar os tratamentos dos dados foi utilizada a ferramenta MS Excel, entre os tratamentos dos dados estão a renomeação de colunas e alguns ajustes de escala sempre que necessário.

\subsubsection{IMPORTAÇÃO DOS DADOS E ESTRUTURAÇÃO DO MODELO}

Após a preparação dos dados de entrada ser realizada, foi feito o processo de importação dos dados para o software SmartPLS. O passo seguinte é a estruturação do modelo estrutural por meio da construção de um diagrama de caminhos, que deve conter os construtos envolvidos na pesquisa, suas respectivas variáveis de medição e os devidos relacionamentos. Essa ferramenta permite que seja realizada uma avaliação tanto do modelo de mensuração como do modelo estrutural.

\subsubsection{IVALIAÇÃO DO MODELO DE MENSURAÇÃO}

Ringle et al. (2014) destacam que a avaliação do modelo de mensuração é composta por três etapas: validade convergente pelas observações das variâncias médias extraídas (average variance extracted - AVE), a validade da consistência interna por meio do alfa de cronbach e a confiabilidade composta, e por fim deve ser feita a avaliação da validade discriminante do modelo de equações estruturais. A primeira e a última etapa estão relacionadas com a validade dos construtos reflexivos enquanto a segunda etapa está relacionada com a confiabilidade dos construtos reflexivos. 


\section{Validade dos construtos reflexivos}

A validade convergente segundo Ringle et al. (2014) significa que o conjunto de variáveis analisado representa unicamente o mesmo construto, e é medida por meio da AVE, que indica a porção dos dados que é explicada por cada um dos construtos ou variáveis latentes, respectivos aos seus conjuntos de variáveis e o quanto, em média, as variáveis se correlacionam positivamente com os seus respectivos construtos ou variáveis latentes. Os autores destacam que quando o valor da AVE é superior a 0,50 admite-se que o modelo converge a um resultado satisfatório.

Já a validade discriminante segundo Ringle et al. (2014) pode ser entendida como um indicador de que os construtos ou variáveis latentes são independentes um dos outros. Essa validação pode ser feita segundo os autores de duas maneiras: pela observação das cargas cruzadas (cross loading) e pelo critério de Fornell-Larcker. O critério das cargas cruzadas analisa os indicadores com cargas fatoriais mais altas nas suas respectivas variáveis latentes ou construtos do que em outras. Já o critério de Fornell-Larcker compara as raízes quadradas dos valores das AVEs de cada construto com as correlações (de Pearson) entre os construtos ou variáveis latentes. As raízes quadradas das AVEs devem ser maiores que as correlações entre os dos construtos (RINGLE et al., 2014)

\section{Confiabilidade dos construtos reflexivos}

Ringle et al. (2014) destacam que o alfa de cronbach é o indicador tradicional para validação da consistência interna e esse indicador é baseado em intercorrelações das variáveis que medem o construto. Segundo os autores, a confiabilidade composta é mais adequada ao PLS-PM, pois prioriza as variáveis de acordo com as suas confiabilidades, enquanto o alfa de cronbach é muito sensível ao número de variáveis em cada construto. É destacado que para qualquer indicador um valor acima de 0,70 é satisfatório.

\subsubsection{AVALIAÇÃO DO MODELO ESTRUTURAL}

A primeira etapa da avaliação do modelo estrutural consiste principalmente na avaliação dos coeficientes de determinação de Pearson $\left(R^{2}\right)$, que avaliam a porção da variância das variáveis endógenas, que é explicada pelo modelo estrutural. A segunda consiste na avaliação das relações apontadas (coeficientes de caminho) por meio da técnica de amostragem bootstrapping (RINGLE et al., 2014) 
Outros indicadores auxiliam a explicar em mais detalhes o modelo estrutural estudado em uma determinada pesquisa são: o efeito do tamanho, que se refere a omissão de uma variável do modelo; o indicador da relevância preditiva do modelo, que avalia se um construto pode prever os demais construtos com que está relacionado; o fator de inflação da variância, para estudar a colinearidade entre os construtos estudados.

\subsubsection{VERIFICAÇÃO DAS HIPÓTESES DE PESQUISA}

As hipóteses do modelo de pesquisa serão avaliadas frente aos resultados obtidos por meio uso do software SmartPLS, com base nos coeficientes de caminho do modelo. 


\section{RESULTADOS}

Esta seção tem como objetivo apresentar o processo realizado para coleta da amostra, as características da amostra coletada e os resultados obtidos sobre o modelo de pesquisa elaborado.

Sobre a avaliação do modelo, vale ressaltar que foi feito uma análise faseada sobre o modelo de pesquisa, que consistiu na avaliação em cinco etapas. Conforme destacado por Hair et al. (2013), quando existe um suporte teórico em relação aos fatores moderadores estudados em um modelo, é recomendado analisar seus efeitos de forma individual, ou seja, considerando um modelo com cada fator moderador que será estudado.

Como foi supracitado ao longo do estudo, foi possível identificar um suporte teórico que direcionou o modelo de pesquisa a levar em consideração o impacto estratégico da TI no presente e no futuro, e a orientação do estilo de gestão do conhecimento voltado para o conhecimento explícito. No que diz respeito ao grid estratégico de Nolan e McFarlan (2005) é possível destacar que a TI permite: manter a empresa conectada com seus fornecedores e consumidores, o que pode estimular a criação e aquisição de conhecimento; suportar sistemas de gestão do conhecimento que permitem analisar os dados para gerar o conhecimento necessário para uma tomada de decisão mais rápida e efetiva; as novas tecnologias da informação podem melhorar processos de gestão do conhecimento, tornando-os mais eficientes e eficazes, o que pode melhorar o posicionamento da empresa no mercado.

Em relação ao estilo de gestão do conhecimento voltado para o conhecimento explícito, é ressaltado por Choi e Lee (2003) que quando a organização mantém o foco sobre esse tipo de conhecimento a TI tem um papel fundamental principalmente na questão de facilitar a codificação, o armazenamento e o reuso do conhecimento explícito que a organização possui.

Conforme foi destacado na revisão da literatura Modelo (A)

- Estrutura: modelo não leva em consideração as variáveis latentes associadas com os efeitos moderadores 
- Objetivo: realizar a validação prévia do modelo de mensuração

Modelo (B)

- Estrutura: modelo não leva em consideração as variáveis latentes associadas com os efeitos moderadores

- Objetivo: realizar a validação do modelo de mensuração ajustado após a validação realizada no Modelo $(A)$ e validar as relações de causalidades entre os construtos

Modelo (C)

- Estrutura: modelo que leva em consideração a variável latente moderadora associada ao estilo de gestão do conhecimento voltado para o conhecimento explícito

- Objetivo: avaliar o efeito da variável moderadora em questão sobre a relação de causalidade entre a capacidade de TI e a gestão do conhecimento

Modelo (D)

- Estrutura: modelo que leva em consideração a variável latente moderadora associada ao impacto estratégico da TI no presente

- Objetivo: avaliar o efeito da variável moderadora em questão sobre a relação de causalidade entre a capacidade de TI e a gestão do conhecimento

Modelo (E)

- Estrutura: modelo que leva em consideração a variável latente moderadora associada ao impacto estratégico da TI no futuro

- Objetivo: avaliar o efeito da variável moderadora em questão sobre a relação de causalidade entre a capacidade de TI e a gestão do conhecimento

\subsection{PROCESSO DE COLETA E CARACTERÍSTICAS DA AMOSTRA}

O primeiro estágio, antes de apresentar propriamente as características gerais da amostra, consiste na análise do processo de coleta de dados, as taxas de respostas e respostas válidas obtidas a fim de uso para evitar o uso de respostas incompletas ou com possível enviesamento.

A coleta de dados foi realizada em um período de 3 meses, de janeiro até março de 2017. Foram utilizadas três bases para realizar a coleta de dados: (1) base de dados 
do grupo de pesquisa de gestão de tecnologia da informação do Departamento de Engenharia de Produção (POLI-USP), (2) contatos da rede social Linkedin do autor e do seu orientador e (3) contato de profissionais de TI.

A Tabela 4 apresenta a quantidade de contatos em cada base utilizada. As primeiras bases foram as mais significativas em termos de quantidade de contatos, visto que a base de contatos de profissionais de TI corresponde a uma lista de indicações enviada por um dos respondentes do questionário, ou seja, foi obtido 191 novos contatos que foram convidados também via e-mail para participar da pesquisa.

Tabela 4 - Base de dados para coleta dos dados

\begin{tabular}{ll}
\hline \multicolumn{1}{c}{ Base de dados } & Número de contatos \\
\hline Base GTI & 6809 \\
Rede Social (Linkedin) & 3205 \\
Contatos de profissionais de TI & 191 \\
Total & 10205 \\
\hline
\end{tabular}

Fonte: Elaborado pelo autor

Durante esse período o autor enviou e-mails para os contatos presentes nas bases citadas. O e-mail enviado para convidar os possíveis respondentes se encontra no APÊNDICE 3 - CARTA-CONVITE PARA COLETA DE DADOS. No total foi recebido um retorno de 261 respondentes, porém 48 respostas estavam incompletas o que impediu seu uso para o processo de análise. Com isso a taxa de resposta foi igual a 2,09\%, conforme Tabela 5.

Tabela 5 - Base de dados para coleta dos dados

\begin{tabular}{lcc}
\hline Completude das respostas & Número de respostas & Taxa de resposta \\
\hline Respostas incompletas & 48 & $0,47 \%$ \\
Respostas completas & 213 & $2,09 \%$ \\
\hline
\end{tabular}

Fonte: Elaborado pelo autor

As respostas foram analisadas previamente para verificar se além das respostas incompletas existia alguma observação contemplando respostas somente com a mesma pontuação, o que permite evidenciar indícios de que o questionário foi preenchido de forma enviesada. Não foram identificadas nenhuma resposta que se enquadrou nesse segundo cenário. 
O segundo estágio consiste na caracterização dos respondentes. Essa etapa foi feita por meio de uma análise estatística descritiva de algumas características dos respondentes e das empresas em que eles atuam. A análise se inicia com o gênero dos respondentes, que é composto majoritariamente por pessoas do gênero masculino, correspondendo a $77 \%$ da amostra coletada.

Gráfico 5 - Distribuição de genêro dos respondentes

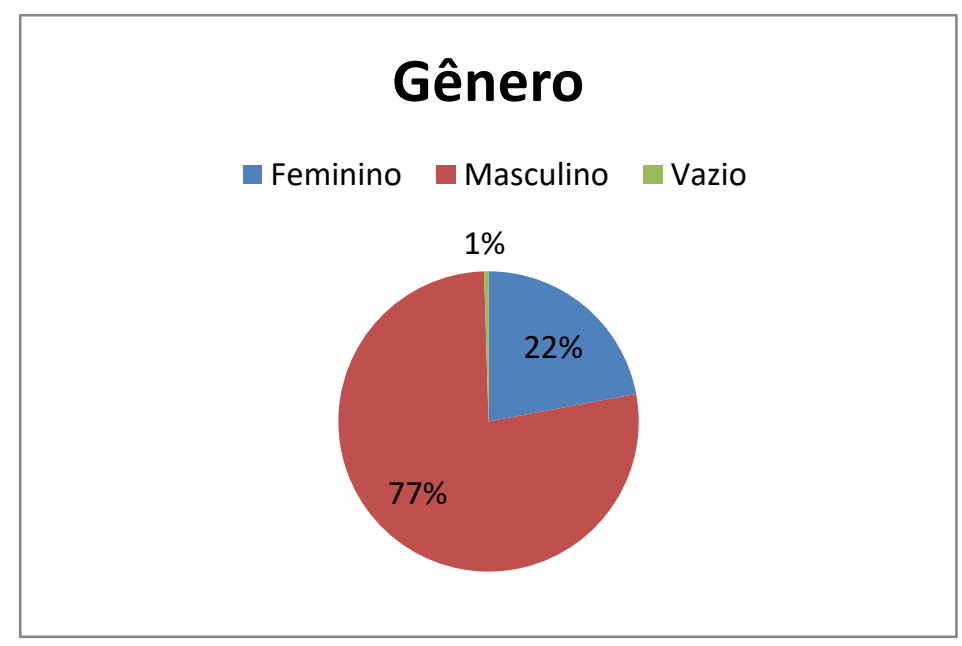

Fonte: Elaborado pelo autor

Outor fator interessante é o tempo de atuação atual dos respondentes na empresa em que estão trabalhando, conforme Tabela 6. Quando se aborda o tema gestão do conhecimento é interessante ter a percepção de pessoas que tem tempo de casa diferente, desde pessoas que entraram recentemente em uma organização até pessoas que já estão na organização a bastante tempo. Isso porque conforme foi levantado na literatura a gestão de conhecimento é composta por alguns processos que devem ocorrer continuamente para manter todos os colaboradores a par dos acontecimentos que ocorrem na área em que atuam, e também do conhecimento sobre a organização em que atuam.

Tabela 6 - Tempo de casa dos respondentes (continua)

\begin{tabular}{lc}
\hline \multicolumn{1}{c}{ Tempo de casa } & Quantidade \\
\hline Tempo de casa $<=5$ anos & 103 \\
5 anos $<$ Tempo de casa $<=10$ anos & 44 \\
10 anos $<$ Tempo de casa $<=15$ anos & 15 \\
15 anos $<$ Tempo de casa $<=20$ anos & 16 \\
20 anos $<$ Tempo de casa $<=25$ anos & 17 \\
25 anos $<$ Tempo de casa $<=30$ anos & 6 \\
30 anos $<$ Tempo de casa $<=35$ anos & 5 \\
35 anos $<$ Tempo de casa $<=40$ anos & 1
\end{tabular}


Tabela 6 - Tempo de casa dos respondentes (conclusão)

\begin{tabular}{lc}
40 anos $<$ Tempo de casa $<=45$ anos & 0 \\
45 anos $<$ Tempo de casa $<=50$ anos & 0 \\
50 anos $<$ Tempo de casa $<=55$ anos & 1 \\
Vazio & 5 \\
Total & 213 \\
\hline
\end{tabular}

Fonte: Elaborado pelo autor

Além disso a gestão do conhecimento não deveria se restringir ao nível hierárquico, visto que deveria existir uma comunicação tanto no sentido top-down quanto no bottom-up para que o conhecimento esteja sempre atualizado em todas as frentes, o que poderia auxiliar a manter 0 alinhamento entre todos envolvidos. A Tabela 7 demonstra que a amostra colhida contém uma diversidade em relação a esse quesito, visto que foram obtidas respostas desde analistas até diretores.

Tabela 7 - Nível hierárquico dos respondentes

\begin{tabular}{lcc}
\hline \multicolumn{1}{c}{ Cargo } & Quantidade & Taxa Proporcional \\
\hline Analista & 53 & $24,88 \%$ \\
Outro & 8 & $3,76 \%$ \\
Consultor & 19 & $8,92 \%$ \\
Presidente & 5 & $2,35 \%$ \\
Gerente & 26 & $12,21 \%$ \\
Diretor & 40 & $18,78 \%$ \\
Vazio & 2 & $0,94 \%$ \\
Coordenador & 34 & $15,96 \%$ \\
Estagiário & 3 & $1,41 \%$ \\
Docente & 23 & $10,80 \%$ \\
\hline
\end{tabular}

Fonte: Elaborado pelo autor

Em relação a área de atuação dos respondentes é possível notar, pela Tabela 8, uma alta concentração na área de Tecnologia, que é uma área que está em evolução contínua e nesse contexto exige uma Gestão do Conhecimento eficiente para entender essas mudanças que ocorrem de forma mais dinâmica. Além disso, é destacado a participação de integrantes que são parte de um Corpo Docente, para o trabalho é interessante destacar que a Gestão do Conhecimento é um processo que existe em qualquer tipo de organização, por isso não houve uma restrição em relação ao segmento de atuação das empresas nos quais os respondentes trabalham. 
Tabela 8 - Área de atuação dos respondentes

\begin{tabular}{lcc}
\hline \multicolumn{1}{c}{ Área de atuação dos respondentes } & Quantidade & Taxa Proporcional \\
\hline TI & 90 & $42,25 \%$ \\
Corpo docente & 38 & $17,84 \%$ \\
Planejamento & 16 & $7,51 \%$ \\
Outro & 8 & $3,76 \%$ \\
Financeiro & 8 & $3,76 \%$ \\
Administração & 7 & $3,29 \%$ \\
Comercial & 5 & $2,35 \%$ \\
Auditoria & 5 & $2,35 \%$ \\
Recursos Humanos & 4 & $1,88 \%$ \\
Pesquisa e Desenvolvimento & 4 & $1,88 \%$ \\
Marketing & 4 & $1,88 \%$ \\
Operações & 3 & $1,41 \%$ \\
Inovação & 3 & $1,41 \%$ \\
Vendas & 3 & $1,41 \%$ \\
Gestão de Projetos & 3 & $1,41 \%$ \\
Consultoria & 3 & $1,41 \%$ \\
Atendimento do cliente & 2 & $0,94 \%$ \\
Produção & 3 & $1,41 \%$ \\
Qualidade & 1 & $0,47 \%$ \\
Processos & 1 & $0,47 \%$ \\
Desenvolvimento de Produto & 1 & $0,47 \%$ \\
Vazio & 1 & $0,47 \%$ \\
\hline
\end{tabular}

Fonte: Elaborado pelo autor

Os principais segmentos de atuação das empresas foram Serviços, marcado pela especialidade no setor de educação, saúde e consultorias, seguido de empresas que atuam no segmento de tecnologia e industrial, conforme Tabela 9.

Tabela 9 - Setor de atuação da empresa

\begin{tabular}{lcc}
\hline \multicolumn{1}{c}{ Setor de atuação da sua empresa } & Quantidade & Taxa Proporcional \\
\hline Serviço & 101 & $47,42 \%$ \\
Tecnologia & 38 & $17,84 \%$ \\
Indústria & 24 & $11,27 \%$ \\
Financeiro & 19 & $8,92 \%$ \\
Público & 11 & $5,16 \%$ \\
Varejo & 7 & $3,29 \%$ \\
Construção Civil & 2 & $0,94 \%$ \\
Agronegócio & 1 & $0,47 \%$ \\
Outro & 10 & $4,69 \%$ \\
\hline
\end{tabular}

Fonte: Elaborado pelo autor

Em relação ao porte das empresas usou-se o critério divulgado pelo Sebrae baseado na quantidade de funcionários que a empresa possui. A maioria dos respondentes atuam em uma empresa de grande porte correspondendo a $62,91 \%$, 
enquanto respondentes que atuam em pequenas e médias empresas correspondem a $19,71 \%$, vide Tabela 10.

Tabela 10 - Porte da empresa

\begin{tabular}{lcc}
\hline \multicolumn{1}{c}{ Porte da empresa } & Quantidade & Taxa Proporcional \\
\hline Grande porte & 134 & $62,91 \%$ \\
Médio Porte & 11 & $5,16 \%$ \\
Pequeno porte & 31 & $14,55 \%$ \\
Microempresa & 37 & $17,37 \%$ \\
\hline
\end{tabular}

Fonte: Elaborado pelo autor

As principais considerações finais sobre a amostra que foi coletada são listadas a seguir.

1) O tamanho da amostra coletada é considerável para a análise do modelo, pois é superior ao valor esperado pela análise do $G^{*} P o w e r ;$

2) A amostra contempla a percepção de pessoas que ocupam diferentes níveis hierárquicos;

3) Existe uma diversidade em relação ao departamento de atuação dos respondentes;

4) Existe uma certa variedade de segmentos de empresas, além de existir empresas também de diferentes portes, apesar da concentração sobre empresas de grande porte.

\subsection{RESULTADOS FASEADOS}

Os diagramas de caminhos foram construídos com auxílio do software SmartPLS que foi utilizado para realizar toda avaliação do modelo estrutural elaborado para atender as hipótestes de pesquisa. Devido a existência de algumas limitações visuais para análise do modelo de pesquisa foi atribuído um código para cada variável latente do modelo conforme Quadro 33.

Quadro 33 - Códigos para as variáveis latentes

\begin{tabular}{|l|c|l|}
\hline \multicolumn{1}{|c|}{ Código } & Ordem & \multicolumn{1}{c|}{ Variável Latente } \\
\hline CP_INFRA_TI & 1 & Capacidade de Infraestrutura de TI \\
\hline CP_OPER_TI & 1 & Capacidade de Operação de TI \\
\hline CP_RH_TI & 1 & Capacidade de Recursos Humanos de TI \\
\hline CP_TI & 2 & Capacidade de TI \\
\hline PRE & 1 & Presente \\
\hline FUT & 1 & Futuro \\
\hline GC_CRIA & 1 & Criação do Conhecimento \\
\hline GC_AQUI & 1 & Aquisição do Conhecimento \\
\hline
\end{tabular}




\begin{tabular}{|l|c|l|} 
GC_ARMG & 1 & Armazenamento do Conhecimento \\
\hline GC_COMP & 1 & Compartilhamento do Conhecimento \\
\hline GC_APLI & 1 & Aplicação do Conhecimento \\
\hline GC_PROT & 1 & Proteção do Conhecimento \\
\hline GC & 2 & Gestão do Conhecimento \\
\hline ORIEN_EXPL & 1 & Estilo GC: orientação explícita \\
\hline MOD_EFCT_1 & - & Efeito moderador ORIEN_EXPL \\
\hline MOD_EFCT_2 & - & Efeito moderador PRE \\
\hline MOD_EFCT_3 & - & Efeito moderador FUT \\
\hline
\end{tabular}

Fonte: Elaborado pelo autor

Uma observação importante é que conforme supracitado o modelo de pesquisa em questão envolve construtos de segunda ordem. O SmartPLS permite realizar esse tipo de análise, porém foi identificado em discussões no fórum do SmartPLS que a medida AVE usada para validação convergente e validação discriminante deve ser calculada manualmente para as variáveis latentes de segunda ordem, visto que o cálculo feito pelo SmartPLS é errôneo quando se trata desse tipo.

Como já foi supracitado a estimação de um modelo de equações estruturais é composto por dois momentos: (1) validação do modelo de mensuração, que visa avaliar a capacidade dos indicadores representarem o construto latente, (2) validação do modelo estrutural, no qual são avaliadas as relações de causalidades entre os construtos latentes.

\subsubsection{Resultado Modelo (A)}

A primeira etapa realizada foi a validação do modelo (A) que não leva em consideração as variáveis latentes associadas aos efeitos moderadores, conforme Figura 23. 
Figura 23 - Modelo (A): Diagrama de Caminhos

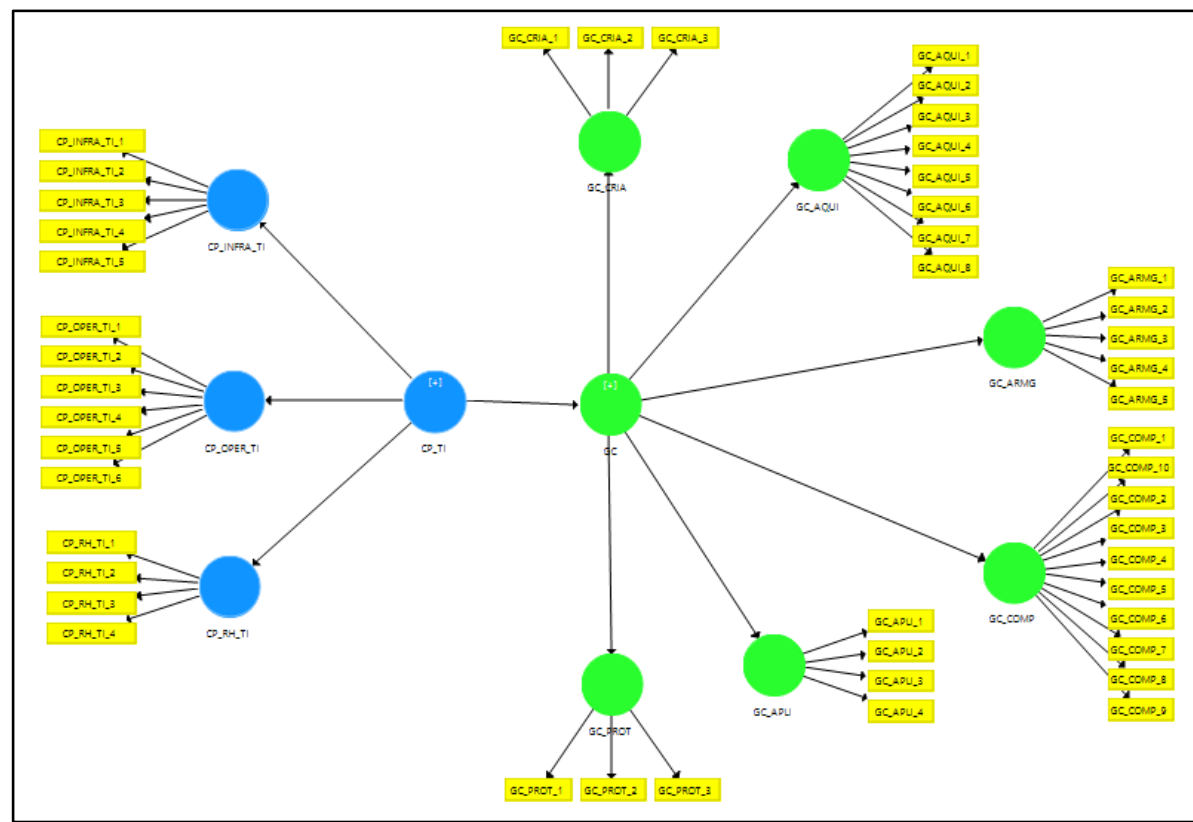

Fonte: Elaborado pelo autor

A avaliação do modelo de mensuração consiste na validação dos seguintes critérios:

(1) Consistência interna: Alpha de Cronbach e Confiabilidade Composta

(2) Validade convergente: Cargas externas e Average Variance Extracted (AVE)

(3) Validade discriminante: Cargas cruzadas e Critério de Fornell-Lacker

Os alpha de cronbach's identificados para cada variável latente estão em um nível aceitável, assim como os valores da confiabilidade composta. Além disso, a AVE de todos os construtos estão com níveis aceitáveis, ou seja, acima de 0,5. Isso pode ser avaliado na Tabela 11.

Tabela 11 - Modelo (A): Métricas do modelo de mensuração

\begin{tabular}{lccc}
\hline Variável Latente & Alpha de Cronbach's & Confiabilidade composta & AVE \\
\hline CP_INFRA_TI & 0,776 & 0,847 & 0,526 \\
CP_OPER_TI & 0,940 & 0,952 & 0,769 \\
CP_RH_TI & 0,855 & 0,902 & 0,697 \\
CP_TI & 0,906 & 0,921 & 0,653 \\
GC & 0,973 & 0,975 & 0,760 \\
GC_APLI & 0,886 & 0,922 & 0,746 \\
GC_AQUI & 0,925 & 0,939 & 0,660 \\
GC_ARMG & 0,936 & 0,951 & 0,796 \\
GC_COMP & 0,935 & 0,945 & 0,631 \\
GC_CRIA & 0,810 & 0,888 & 0,726 \\
GC_PROT & 0,722 & 0,844 & 0,644 \\
\hline
\end{tabular}

Fonte: Elaborado pelo autor 
Para complementar a análise da validade convergente é preciso avaliar as cargas externas de cada indicador associado a uma determinada variável latente. Hair (2009) destaca que a validade convergente indica o quanto os indicadores de um construto específico convergem ou compartilham uma elevada proporção de variância comum. $O$ indicado é que as cargas externas sejam superiores a 0,7 e que os indicadores com uma carga externa inferior a 0,4 sejam excluídas do modelo.

Como era esperado o construto Capacidade de TI possui indicadores com um valor abaixo de 0,7 e maior que 0,4 . Isso porque já se imaginava que as variáveis latentes capacidade de infraestrutura de TI, capacidade de operação de TI e capacidade de recursos humanos de $\mathrm{TI}$ podem ser consideradas independentes e compõem a variável mediadora capacidade de TI.

Tabela 12 - Modelo (A): Cargas externas associadas a TI

\begin{tabular}{ccccc}
\hline Indicadores & CP_INFRA_TI & CP_OPER_TI & CP_RH_TI & CP_TI \\
\hline CP_INFRA_TI_1 & 0,748 & & & 0,434 \\
CP_INFRA_TI_2 & 0,703 & & & 0,409 \\
CP_INFRA_TI_3 & 0,813 & & & 0,664 \\
CP_INFRA_TI_4 & 0,701 & & & 0,601 \\
CP_INFRA_TI_5 & 0,652 & & & 0,564 \\
CP_OPER_TI_1 & & 0,868 & & 0,726 \\
CP_OPER_TI_2 & & 0,899 & & 0,761 \\
CP_OPER_TI_3 & 0,912 & & 0,764 \\
CP_OPER_TI4 & & 0,880 & & 0,728 \\
CP_OPER_TI_5 & 0,864 & & 0,731 \\
CP_OPER_TI_6 & & 0,836 & & 0,774 \\
CP_RH_TI1 & & & 0,814 & 0,588 \\
CP_RH_TI_2 & & & 0,863 & 0,703 \\
CP_RH_TI_3 & & & 0,799 & 0,661 \\
CP_RH_TI_4 & & 0,862 & 0,733 \\
\hline
\end{tabular}

Fonte: Elaborado pelo autor

Apenas um indicador de todas as variáveis latentes de primeira ordem está com um valor abaixo do 0,7 indicado por Hair (2009), que é o indicador CP_INFRA_TI_5, que pertence a variável latente capacidade infraestrutura de TI, conforme Tabela 12. 
Tabela 13 - Modelo (A): Cargas externas associadas a GC

\begin{tabular}{|c|c|c|c|c|c|c|c|}
\hline Indicadores & GC_APLI & GC_AQUI & GC_ARMG & GC_COMP & GC_CRIA & GC_PROT & GC \\
\hline GC_APLI_1 & 0,830 & & & & & & 0,711 \\
\hline GC_APLI_2 & 0,882 & & & & & & 0,797 \\
\hline GC_APLI_3 & 0,903 & & & & & & 0,834 \\
\hline GC_APLI_4 & 0,839 & & & & & & 0,742 \\
\hline GC_AQUI_1 & & 0,641 & & & & & 0,551 \\
\hline GC_AQUI_2 & & 0,812 & & & & & 0,722 \\
\hline GC_AQUI_3 & & 0,824 & & & & & 0,710 \\
\hline GC_AQUI_4 & & 0,823 & & & & & 0,728 \\
\hline GC_AQUI_5 & & 0,863 & & & & & 0,787 \\
\hline GC_AQUI_6 & & 0,876 & & & & & 0,799 \\
\hline GC_AQUI_7 & & 0,822 & & & & & 0,789 \\
\hline GC_AQUI_8 & & 0,819 & & & & & 0,800 \\
\hline GC_ARMG_1 & & & 0,910 & & & & 0,744 \\
\hline GC_ARMG_2 & & & 0,911 & & & & 0,778 \\
\hline GC_ARMG_3 & & & 0,905 & & & & 0,781 \\
\hline GC_ARMG_4 & & & 0,873 & & & & 0,756 \\
\hline GC_ARMG_5 & & & 0,859 & & & & 0,748 \\
\hline GC_COMP_1 & & & & 0,742 & & & 0,703 \\
\hline GC_COMP_10 & & & & 0,757 & & & 0,724 \\
\hline GC_COMP_2 & & & & 0,813 & & & 0,807 \\
\hline GC_COMP_3 & & & & 0,801 & & & 0,770 \\
\hline GC_COMP_4 & & & & 0,842 & & & 0,750 \\
\hline GC_COMP_5 & & & & 0,848 & & & 0,754 \\
\hline GC_COMP_6 & & & & 0,841 & & & 0,744 \\
\hline GC_COMP_7 & & & & 0,772 & & & 0,690 \\
\hline GC_COMP_8 & & & & 0,781 & & & 0,725 \\
\hline GC_COMP_9 & & & & 0,738 & & & 0,685 \\
\hline GC_CRIA_1 & & & & & 0,841 & & 0,702 \\
\hline GC_CRIA_2 & & & & & 0,895 & & 0,770 \\
\hline GC_CRIA_3 & & & & & 0,817 & & 0,719 \\
\hline GC_PROT_1 & & & & & & 0,865 & 0,649 \\
\hline GC_PROT_2 & & & & & & 0,777 & 0,597 \\
\hline GC_PROT_3 & & & & & & 0,763 & 0,627 \\
\hline
\end{tabular}

Fonte: Elaborado pelo autor

Coforme Tabela 13, os indicadores de todas as variáveis latentes de primeira ordem estão majitoriamente superiores a 0,7 com exceção do indicador GC_AQUI_1 que pertence à variável latente Aquisição do Conhecimento. É possível notar também que os indicadores associadas a gestão do conhecimento estão a um nível aceitável, o que vai ao encontro do que foi supracitado anteriormente de que as variáveis de processos de conhecimento podem ser representadas por uma variável mais genérica. 
Após a análise referente a validade convergente, deve ser feito a análise da validade discriminante, que segundo Hair (2009) indica o quanto um construto é verdadeiramente distinto dos demais. Essa análise deve ser feita com base em duas medidas as cargas cruzadas e o critério de Fornell-Lacker.

Tabela 14 - Modelo (A): Critério de Fornell-Lacker variáveis de 1 ordem

\begin{tabular}{|c|c|c|c|c|c|c|c|c|c|}
\hline $\begin{array}{l}\text { Variável Latente de } \\
\text { Primeira Ordem }\end{array}$ & CP_INFRA_TI & CP_OPER_TI & CP_RH_TI & GC_APLI & GC_AQUI & GC_ARMG & GC_COMP & GC_CRIA & GC_PROT \\
\hline CP_INFRA_TI & 0,725 & & & & & & & & \\
\hline CP_OPER_TI & 0,416 & 0,877 & & & & & & & \\
\hline CP_RH_TI & 0,620 & 0,462 & 0,835 & & & & & & \\
\hline GC_APLI & 0,332 & 0,540 & 0,501 & 0,864 & & & & & \\
\hline GC_AQUI & 0,387 & 0,608 & 0,523 & 0,791 & 0,813 & & & & \\
\hline GC_ARMG & 0,378 & 0,435 & 0,556 & 0,743 & 0,692 & 0,892 & & & \\
\hline GC_COMP & 0,451 & 0,553 & 0,556 & 0,790 & 0,786 & 0,709 & 0,795 & & \\
\hline GC_CRIA & 0,412 & 0,529 & 0,530 & 0,729 & 0,791 & 0,685 & 0,763 & 0,852 & \\
\hline GC_PROT & 0,289 & 0,422 & 0,500 & 0,662 & 0,630 & 0,730 & 0,678 & 0,610 & 0,803 \\
\hline
\end{tabular}

Fonte: Elaborado pelo autor

Tabela 15 - Modelo (A): Critério de Fornell-Lacker variáveis de 2 ordem

\begin{tabular}{lll}
\hline $\begin{array}{l}\text { Variável Latente de } \\
\text { Segunda Ordem }\end{array}$ & CP_TI & GC \\
\hline CP_TI & 0,808 & \\
GC & 0,687 & 0,872 \\
\hline
\end{tabular}

Fonte: Elaborado pelo autor

Conforme pode-se notar na Tabela 14, sobre o critério de Fornell-Lacker, foram obtidos resultados aceitáveis visto que a raiz quadrada das AVEs de cada variável latente de primeira ordem é superior que a sua maior correlação com qualquer outro construto.

Vale ressaltar que os valores para esse critério referente as variáveis latentes de segunda ordem foram calculadas manuamente com base nos coeficientes de caminho referentes as variáveis latentes de primeira ordem. Os resultados apresentados na Tabela 15 são aceitáveis.

Em relação a análise de cargas cruzadas é preciso verificar se a carga de um indicador sobre o construto a que pertence é maior que sua carga nos demais construtos. Conforme APÊNDICE 5 - CARGAS CRUZADAS MODELO A os valores das cargas cruzadas de cada indicador são maiores na sua respectiva variável latente associada do que nas outras variáveis latentes.

A partir desses resultados pode-se destacar que o modelo de mensuração está de certa forma adequado dentro dos critérios de consistência interna, validade convergente e validade discriminante. Os únicos pontos de atenção são referentes 
as variáveis CP_INFRA_TI_5 (A empresa possui tecnologias da informação que permitem a interação entre seus colaboradores, tais como e-mails, ferramentas de instant messaging, vídeo conferência, entre outras) e GC_AQUI_1 (A empresa procura se reunir com seus clientes com 0 objetivo de identificar suas necessidades).

\subsubsection{Resultado Modelo (B)}

O modelo $(B)$ mantém as mesmas características em relação ao modelo $(A)$, porém foi feito a exclusão das variáveis CP_INFRA_TI_5 e GC_AQUI_1. O modelo (B) é apresentado na Figura 24.

Figura 24 - Modelo (B): Diagrama de Caminhos

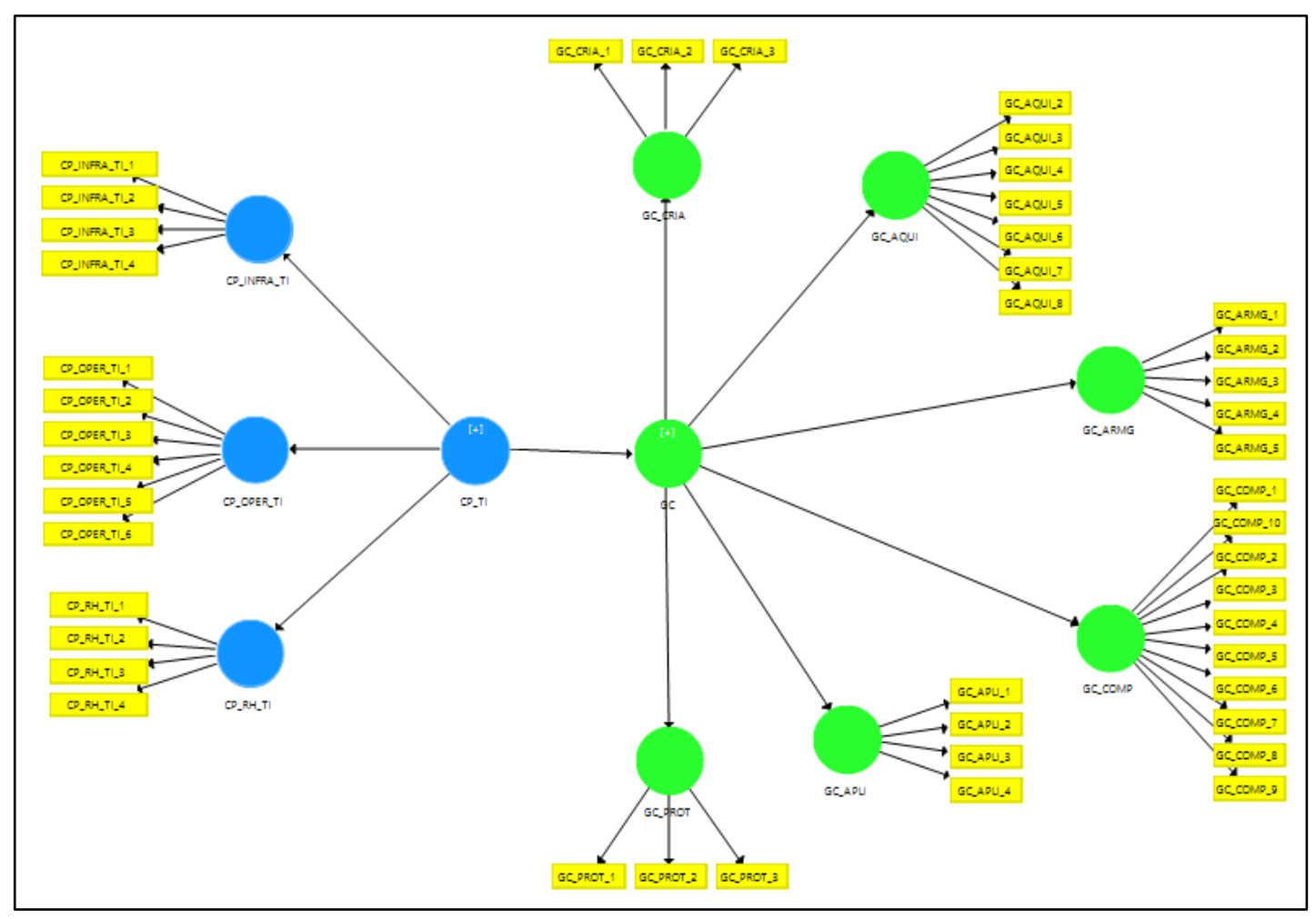

Fonte: Elaborado pelo autor

A Tabela 16 apresenta os valores para as medidas alpha de cronbach's, confiabilidade composta e AVE. Como é possível verificar os valores estão aderentes aos limites desejados. 
Tabela 16 - Modelo (B): Métricas do modelo de mensuração

\begin{tabular}{lccc}
\hline Variável Latente & Alpha de Cronbach's & Confiabilidade composta & AVE \\
\hline CP_INFRA_TI & 0,779 & 0,855 & 0,597 \\
CP_OPER_TI & 0,940 & 0,952 & 0,769 \\
CP_RH_TI & 0,855 & 0,902 & 0,697 \\
CP_TI & 0,903 & 0,919 & 0,629 \\
GC & 0,973 & 0,975 & 0,646 \\
GC_APLI & 0,886 & 0,922 & 0,746 \\
GC_AQUI & 0,929 & 0,943 & 0,702 \\
GC_ARMG & 0,936 & 0,951 & 0,796 \\
GC_COMP & 0,935 & 0,945 & 0,631 \\
GC_CRIA & 0,810 & 0,888 & 0,726 \\
GC_PROT & 0,722 & 0,844 & 0,645 \\
\hline
\end{tabular}

Fonte: Elaborado pelo autor

Com a exclusão do indicador CP_INFRA_TI é possível notar que todos os indicadores associados os construtos de TI estão acima do valor indicado pela literatura de 0,7. A Tabela 17 apresenta os valores para todos os indicadores.

Tabela 17 - Modelo (B): Cargas externas associadas a TI

\begin{tabular}{lcccc}
\hline \multicolumn{1}{c}{ Indicadores } & CP_INFRA_TI & CP_OPER_TI & CP_RH_TI & CP_TI \\
\hline CP_INFRA_TI_1 & 0,790 & & & 0,430 \\
CP_INFRA_TI_2 & 0,752 & & & 0,408 \\
CP_INFRA_TI_3 & 0,829 & & & 0,660 \\
CP_INFRA_TI_4 & 0,716 & & & 0,600 \\
CP_OPER_TI_1 & & 0,868 & & 0,733 \\
CP_OPER_TI_2 & & 0,899 & & 0,770 \\
CP_OPER_TI_3 & & 0,912 & & 0,779 \\
CP_OPER_TI_4 & & 0,880 & & 0,738 \\
CP_OPER_TI_5 & & 0,864 & & 0,745 \\
CP_OPER_TI_6 & & 0,836 & & 0,782 \\
CP_RH_TI_1 & & 0,813 & 0,576 \\
CP_RH_TI_2 & & & 0,864 & 0,705 \\
CP_RH_TI_3 & & & 0,798 & 0,650 \\
CP_RH_TI_4 & & & 0,862 & 0,724 \\
\hline
\end{tabular}

Fonte: Elaborado pelo autor

Analogamente ao que foi indentificado para as variáveis latentes associadas a $\mathrm{Tl}$, para as variáveis latentes associadas a GC todos os indicadores estão acima do 0,7 após a exclusão do indicador GC_AQUI_1. A Tabela 18 apresenta os valores para todos os indicadores. 
Tabela 18 - Modelo (B): Cargas externas associadas a GC

\begin{tabular}{|c|c|c|c|c|c|c|c|}
\hline Indicadores & GC_APLI & GC_AQUI & GC_ARMG & GC_COMP & GC_CRIA & GC_PROT & GC \\
\hline GC_APLI_1 & 0,830 & & & & & & 0,712 \\
\hline GC_APLI_2 & 0,882 & & & & & & 0,797 \\
\hline GC_APLI_3 & 0,903 & & & & & & 0,837 \\
\hline GC_APLI_4 & 0,839 & & & & & & 0,740 \\
\hline GC_AQUI_2 & & 0,798 & & & & & 0,715 \\
\hline GC_AQUI_3 & & 0,824 & & & & & 0,707 \\
\hline GC_AQUI_4 & & 0,830 & & & & & 0,727 \\
\hline GC_AQUI_5 & & 0,879 & & & & & 0,788 \\
\hline GC_AQUI_6 & & 0,887 & & & & & 0,798 \\
\hline GC_AQUI_7 & & 0,822 & & & & & 0,787 \\
\hline GC_AQUI_8 & & 0,821 & & & & & 0,799 \\
\hline GC_ARMG_1 & & & 0,910 & & & & 0,746 \\
\hline GC_ARMG_2 & & & 0,911 & & & & 0,781 \\
\hline GC_ARMG_3 & & & 0,905 & & & & 0,783 \\
\hline GC_ARMG_4 & & & 0,873 & & & & 0,757 \\
\hline GC_ARMG_5 & & & 0,859 & & & & 0,749 \\
\hline GC_COMP_1 & & & & 0,742 & & & 0,702 \\
\hline GC_COMP_10 & & & & 0,757 & & & 0,724 \\
\hline GC_COMP_2 & & & & 0,813 & & & 0,806 \\
\hline GC_COMP_3 & & & & 0,801 & & & 0,770 \\
\hline GC_COMP_4 & & & & 0,842 & & & 0,751 \\
\hline GC_COMP_5 & & & & 0,848 & & & 0,755 \\
\hline GC_COMP_6 & & & & 0,841 & & & 0,746 \\
\hline GC_COMP_7 & & & & 0,772 & & & 0,694 \\
\hline GC_COMP_8 & & & & 0,782 & & & 0,725 \\
\hline GC_COMP_9 & & & & 0,738 & & & 0,687 \\
\hline GC_CRIA_1 & & & & & 0,841 & & 0,703 \\
\hline GC_CRIA_2 & & & & & 0,895 & & 0,770 \\
\hline GC_CRIA_3 & & & & & 0,817 & & 0,720 \\
\hline GC_PROT_1 & & & & & & 0,866 & 0,652 \\
\hline GC_PROT_2 & & & & & & 0,778 & 0,600 \\
\hline GC_PROT_3 & & & & & & 0,761 & 0,624 \\
\hline
\end{tabular}

Fonte: Elaborado pelo autor

Conforme pode-se notar na Tabela 19, sobre o critério de Fornell-Lacker, foi obtido resultados aceitáveis visto que a raiz quadrada das AVEs de cada variável latente de primeira ordem é superior que a sua maior correlação com qualquer outro construto. Além disso, os valores para as variáveis latentes de segunda ordem também estão a um nível aceitável conforme Tabela 20. 
Tabela 19 - Modelo (B): Critério de Fornell-Lacker variáveis de 1 ordem

\begin{tabular}{|c|c|c|c|c|c|c|c|c|c|}
\hline $\begin{array}{l}\text { Variável Latente de } \\
\text { Primeira Ordem }\end{array}$ & CP_INFRA_TI & CP_OPER_TI & CP_RH_TI & GC_APLI & GC_AQUI & GC_ARMG & GC_COMP & GC_CRIA & GC_PROT \\
\hline CP_INFRA_TI & 0,773 & & & & & & & & \\
\hline CP_OPER_TI & 0,381 & 0,877 & & & & & & & \\
\hline CP_RH_TI & 0,567 & 0,462 & 0,835 & & & & & & \\
\hline GC_APLI & 0,280 & 0,540 & 0,500 & 0,864 & & & & & \\
\hline GC_AQUI & 0,347 & 0,607 & 0,519 & 0,793 & 0,838 & & & & \\
\hline GC_ARMG & 0,325 & 0,435 & 0,556 & 0,743 & 0,695 & 0,892 & & & \\
\hline GC_COMP & 0,419 & 0,553 & 0,555 & 0,790 & 0,786 & 0,709 & 0,795 & & \\
\hline GC_CRIA & 0,367 & 0,530 & 0,530 & 0,729 & 0,794 & 0,685 & 0,763 & 0,852 & \\
\hline GC_PROT & 0,254 & 0,421 & 0,500 & 0,661 & 0,630 & 0,730 & 0,677 & 0,610 & 0,803 \\
\hline
\end{tabular}

Fonte: Elaborado pelo autor

Tabela 20 - Modelo (B): Critério de Fornell-Lacker variáveis de 2 ordem

\begin{tabular}{lll}
\hline $\begin{array}{l}\text { Variável Latente de } \\
\text { Segunda Ordem }\end{array}$ & CP_TI & GC \\
\hline CP_TI & 0,793 & \\
GC & 0,684 & 0,804 \\
\hline
\end{tabular}

Fonte: Elaborado pelo autor

No APÊNDICE 6 - CARGAS CRUZADAS MODELO B, é apresetado os valores para as cargas cruzadas que apresenta valores aceitáveis de cada indicador em relação a variável latente a que pertence.

Após a validação dos critérios para avaliação do modelo de mensuração, deve-se iniciar o processo de avaliação do modelo estrutural. Para se realizar essa avaliação é preciso passar pelos seguintes estágios não obrigatoriamente na ordem que serão apresentados.

(1) Avaliação de significância e relevância das relações estruturais do modelo

(2) Avaliação de colinearidade

(3) Avaliação do coeficiente de determinação $R^{2}$

(4) Avaliação do efeito de tamanho $f^{2}$

(5) Avaliação da relevância preditiva $Q^{2}$

A avaliação da significância e relevância das relações estruturais do modelo é feita por meio dos valores de coeficiente de caminho e sua significância estatística, conforme. A Tabela 21 deve ser analisada da seguinte forma:

(a) Se o valor crítico para a estatística T for maior que 2,57 então pode-se aceitar a relação em questão à um nível de significância igual a 1\%;

(b) Se o valor crítico para a estatística T for maior que 1,96 e menor que 2,57 então pode-se aceitar a relação em questão à um nível de significância igual a $5 \%$; 
(c) Se o valor crítico para a estatística $T$ for menor que 1,96 então pode se rejeitar a relação em questão, visto que não atende o nível de significância de $5 \%$;

Tabela 21 - Modelo (B): Coeficientes de caminho

\begin{tabular}{lccr}
\hline \multicolumn{1}{c}{ Relação } & Coeficiente de Caminho & T Statistics (bootstrap) & P Values \\
\hline CP_TI -> CP_INFRA_TI & 0,707 & 17,729 & 0,000 \\
CP_TI -> CP_OPER_TI & 0,865 & 37,834 & 0,000 \\
CP_TI -> CP_RH_TI & 0,799 & 27,452 & 0,000 \\
CP_TI -> GC & 0,684 & 16,208 & 0,000 \\
GC -> GC_APLI & 0,895 & 63,319 & 0,000 \\
GC -> GC_AQUI & 0,909 & 69,185 & 0,000 \\
GC -> GC_ARMG & 0,856 & 41,112 & 0,000 \\
GC -> GC_COMP & 0,928 & 99,085 & 0,000 \\
GC -> GC_CRIA & 0,859 & 51,634 & 0,000 \\
GC -> GC_PROT & 0,780 & 25,394 & 0,000 \\
\hline
\end{tabular}

Fonte: Elaborado pelo autor

Com isso pode-se confirmar a dimensionalidade em relação aos construtos de alto nível (Capacidade de $\mathrm{TI}$ e Gestão do Conhecimento). Todas as relações identificadas no modelo são válidas a um nível de significância de $1 \%$.

As relações identificadas vão ao encontro de estudos similares identificados na literatura como de Pérez-López e Alegre (2011) e Tippins e Sohi (2003), sobre os quais foi identificado uma relação positiva entre a capacidade de $\mathrm{TI}$, composta pelas três dimensões (infraestrutura, operação e recursos humanos) e a gestão do conhecimento. Fato é que os três processos (aquisição, compartilhamento e aplicação) que tiveram um valor de coeficiente de caminho maiores sobre a gestão do conhecimento são os três que já haviam sido estudados na literatura por PérezLopez e Alegre (2011) e Tippins e Sohi (2003). Os outros três procesos (criação, armazenamento e proteção) incluídos no modelo trazem uma abordagem complementar aos modelos dos autores citados, o que indica uma possível contribuição para a literatura ao constatar que existem outros processos que também tem uma associação importante com o construto gestão do conhecimento.

O segundo estágio da análise corresponde a análise de colinearidade, que é feita a partir do fator de inflação da variância (VIF - Variance Infation Factor). Essa análise tem como objetivo validar o quanto uma variável independente varia com outras variáveis independentes que estão relacionadas com essa. Hair (2009) destaca que 
o valor aceitável é o VIF ter um valor menor igual a 5. Conforme Tabela 22 não existe problemas de colinearidade no modelo proposto.

Tabela 22 - Modelo (B): Valores de VIF

\begin{tabular}{lll}
\hline $\begin{array}{c}\text { Variável } \\
\text { Endógena }\end{array}$ & \multicolumn{1}{c}{$\begin{array}{c}\text { Variável } \\
\text { Exógena }\end{array}$} & VIF \\
\hline CP_INFRA_TI & CP_TI & 1,00 \\
CP_OPER_TI & CP_TI & 1,00 \\
CP_RH_TI & CP_TI & 1,00 \\
GC & CP_TI & 1,00 \\
GC_CRIA & GC & 1,00 \\
GC_AQUI & GC & 1,00 \\
GC_ARMG & GC & 1,00 \\
GC_COMP & GC & 1,00 \\
GC_APLI & GC & 1,00 \\
GC_PROT & GC & 1,00 \\
\hline
\end{tabular}

Fonte: Elaborado pelo autor

O terceiro estágio consiste em avaliar o coeficiente de determinação $R^{2}$ que representa a precisão preditiva do modelo proposto, o que indica a variância presente na variável endógena que é explicada pelas variáveis exógenas que estão relacionadas com ela.

Tabela 23 - Modelo (B): Valores de $\mathrm{R}^{2}$

\begin{tabular}{lccl}
\hline $\begin{array}{c}\text { Variável Latente } \\
\text { Endógena }\end{array}$ & $\mathbf{R}^{2}$ & $\mathbf{R}^{2}$ Adjusted & Status \\
\hline CP_INFRA_TI & 0,500 & 0,497 & Moderado \\
CP_OPER_TI & 0,748 & 0,747 & Moderado \\
CP_RH_TI & 0,639 & 0,637 & Moderado \\
GC & 0,468 & 0,465 & Moderado \\
GC_APLI & 0,801 & 0,800 & Substancial \\
GC_AQUI & 0,826 & 0,826 & Substancial \\
GC_ARMG & 0,732 & 0,731 & Moderado \\
GC_COMP & 0,861 & 0,861 & Substancial \\
GC_CRIA & 0,738 & 0,736 & Moderado \\
GC_PROT & 0,608 & 0,606 & Moderado \\
\hline
\end{tabular}

Fonte: Elaborado pelo autor

Segundo Hair (2009) para valores abaixo de 0,25 a precisão preditiva deve ser considerada fraca, para valores entre 0,25 e 0,75 é considerada moderada, e acima de 0,75 é considerada substancial. Então como é possível notar pela Tabela 23, os valores estão a um nível moderado e substancial. Além disso, Hair (2009) destaca que como esse coeficiente pode ser incrementado devido a quantidade maior de 
variáveis exógenas sobre uma variável endógena, o que pode gerar um viés, é preciso também calcular seu valor ajustado, que leva em consideração a quantidade de construtos endógenos em relação ao tamanho da amostra. No caso os valores obtidos foram muito próximos, o que poderia justificar isso seria o tamanho da amostra ser relativamente grande.

A próxima etapa está associada com a análise do efeito do tamanho $\mathrm{f}^{2}$, que mensura a mudança no coeficiente de determinação quando os construtos exógenos em específico são retirados.

Tabela 24 - Modelo (B): Valores de f2

\begin{tabular}{lcl}
\hline \multicolumn{1}{c}{ Relação } & $\mathbf{f}^{2}$ & Status \\
\hline CP_TI -> CP_INFRA_TI & 0,999 & Grande \\
CP_TI ->CP_OPER_TI & 2,976 & Grande \\
CP_TI ->CP_RH_TI & 1,770 & Grande \\
CP_TI -> GC & 0,879 & Grande \\
GC -> GC_APLI & 4,021 & Grande \\
GC -> GC_AQUI & 4,762 & Grande \\
GC -> GC_ARMG & 2,737 & Grande \\
GC -> GC_COMP & 6,204 & Grande \\
GC $->$ GC_CRIA & 2,810 & Grande \\
GC $->$ GC_PROT & 1,552 & Grande \\
\hline
\end{tabular}

Fonte: Elaborado pelo autor

Por fim o último estágio consiste na avaliação da relevância preditiva do modelo com base no critério de Stone-Geisser $\mathrm{Q}^{2}$. O software SmartPLS faz o cálculo dessa variável através do procedimento blindfolding. Hair (2009) destaca que o valor dessa variável deve ser maior que 0 , conforme Tabela 25 essa premissa foi alcançada para todas as variáveis latentes endógenas.

Tabela 25 - Modelo (B): Valores de $\mathrm{Q}^{2}$

\begin{tabular}{lc}
\hline Variáveis Latentes Endógenas & $\mathbf{Q}^{2}$ \\
\hline CP_INFRA_TI & 0,264 \\
CP_OPER_TI & 0,535 \\
CP_RH_TI & 0,413 \\
GC & 0,238 \\
GC_APLI & 0,562 \\
GC_AQUI & 0,540 \\
GC_ARMG & 0,545 \\
GC_COMP & 0,506 \\
GC_CRIA & 0,508 \\
GC_PROT & 0,371 \\
\hline
\end{tabular}

Fonte: Elaborado pelo autor 


\subsubsection{Resultado Modelo (C)}

O do modelo $(C)$ que leva em consideração o fator moderador (orientação da gestão do conhecimento voltada para o conhecimento explícito), conforme Figura 25.

Figura 25 - Modelo (C): Diagrama de Caminhos

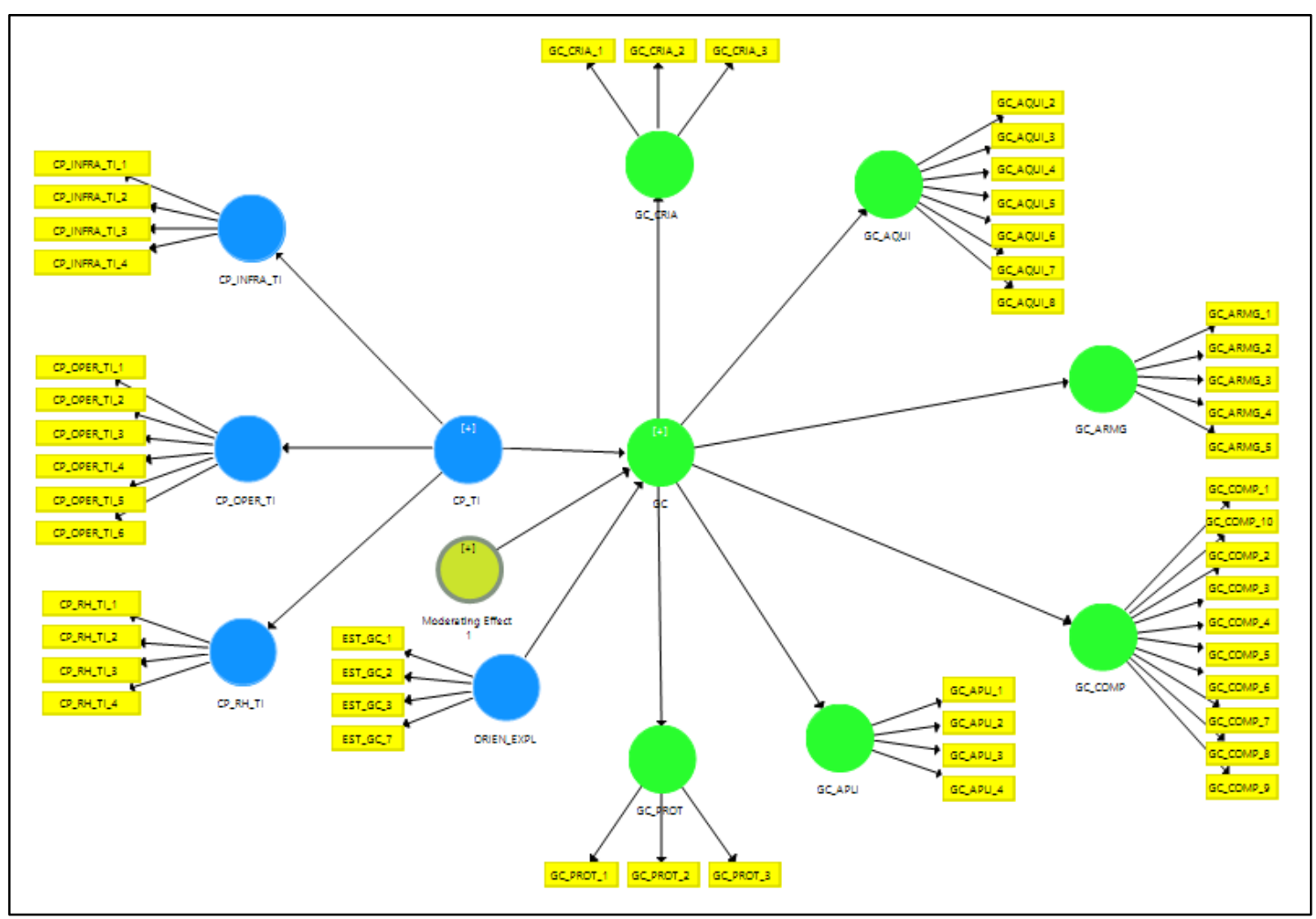

Fonte: Elaborado pelo autor

A Tabela 26 apresenta os valores para as medidas alpha de cronbach's, confiabilidade composta e AVE. Como é possível verificar os valores estão aderentes aos limites desejados. O elemento crucial que precisa ser analisado a partir de agora é a variável latente moderadora (ORIEN_EXPL) e o efeito moderador (MOD_EFCT_1) que foi incluída no modelo, a avaliação do modelo de mensuração das demais variáveis já foram realizadas no momento em que foi avaliado o Modelo (B). 
Tabela 26 - Modelo (C): Métricas do modelo de mensuração

\begin{tabular}{lccc}
\hline Variável Latente & Alpha de Cronbach's & $\begin{array}{c}\text { Confiabilidade } \\
\text { composta }\end{array}$ & AVE \\
\hline CP_INFRA_TI & 0,779 & 0,855 & 0,597 \\
CP_OPER_TI & 0,940 & 0,952 & 0,769 \\
CP_RH_TI & 0,855 & 0,902 & 0,697 \\
CP_TI & 0,903 & 0,919 & 0,629 \\
GC & 0,973 & 0,975 & 0,761 \\
GC_APLI & 0,886 & 0,922 & 0,746 \\
GC_AQUI & 0,929 & 0,943 & 0,702 \\
GC_ARMG & 0,936 & 0,951 & 0,796 \\
GC_COMP & 0,935 & 0,945 & 0,631 \\
GC_CRIA & 0,810 & 0,888 & 0,726 \\
GC_PROT & 0,722 & 0,844 & 0,645 \\
MOD_EFCT_1 & 1,000 & 1,000 & 1,000 \\
ORIEN_EXPL & 0,896 & 0,928 & 0,765 \\
\hline
\end{tabular}

Fonte: Elaborado pelo autor

A Tabela 27 apresenta as cargas externas para os indicadores das variáveis latentes associadas ao construto capacidade de Tecnologia da Informação. Como é possível verificar todos os valores estão acima do valor esperado de 0,7 .

Tabela 27 - Modelo (C): Cargas externas associadas a TI

\begin{tabular}{lcccc}
\hline Indicadores & CP_INFRA_TI & CP_OPER_TI & CP_RH_TI & CP_TI \\
\hline CP_INFRA_TI_1 & 0,790 & & & 0,430 \\
CP_INFRA_TI_2 & 0,752 & & & 0,408 \\
CP_INFRA_TI_3 & 0,829 & & & 0,660 \\
CP_INFRA_TI_4 & 0,716 & & & 0,600 \\
CP_OPER_TI_1 & & 0,868 & & 0,733 \\
CP_OPER_TI_2 & & 0,899 & & 0,770 \\
CP_OPER_TI_3 & & 0,912 & & 0,779 \\
CP_OPER_TI_4 & & 0,880 & & 0,738 \\
CP_OPER_TI_5 & & 0,864 & & 0,745 \\
CP_OPER_TI_6 & & 0,836 & & 0,782 \\
CP_RH_TI_1 & & & 0,813 & 0,576 \\
CP_RH_TI_2 & & & 0,864 & 0,705 \\
CP_RH_TI_3 & & & 0,798 & 0,650 \\
CP_RH_TI_4 & & & 0,862 & 0,724 \\
\hline
\end{tabular}

Fonte: Elaborado pelo autor

Analogamente ao que foi indentificado para as variáveis latentes associadas a $\mathrm{Tl}$, para as variáveis latentes associadas a GC todos os indicadores estão acima do 0,7. A Tabela 28 apresenta os valores para todos os indicadores. Dessa forma pode-se destacar que a validade convergente foi atendida para a nova variável latente moderadora incluída no modelo. 
Tabela 28 - Modelo (C): Cargas externas associadas a GC

\begin{tabular}{|c|c|c|c|c|c|c|c|c|c|}
\hline Indicadores & GC_APLI & GC_AQUI & GC_ARMG & GC_COMP & GC_CRIA & GC_PROT & GC & MOD_EFCT_1 & ORIEN_EXPL \\
\hline GC_APLI_1 & 0,830 & & & & & & 0,712 & & \\
\hline GC_APLI_2 & 0,882 & & & & & & 0,796 & & \\
\hline GC_APLI_3 & 0,903 & & & & & & 0,837 & & \\
\hline GC_APLI_4 & 0,839 & & & & & & 0,739 & & \\
\hline GC_AQUI_2 & & 0,798 & & & & & 0,715 & & \\
\hline GC_AQUI_3 & & 0,824 & & & & & 0,706 & & \\
\hline GC_AQUI_4 & & 0,830 & & & & & 0,726 & & \\
\hline GC_AQUI_5 & & 0,879 & & & & & 0,788 & & \\
\hline GC_AQUI_6 & & 0,887 & & & & & 0,798 & & \\
\hline GC_AQUI_7 & & 0,822 & & & & & 0,787 & & \\
\hline GC_AQUI_8 & & 0,821 & & & & & 0,799 & & \\
\hline GC_ARMG_1 & & & 0,910 & & & & 0,747 & & \\
\hline GC_ARMG_2 & & & 0,911 & & & & 0,781 & & \\
\hline GC_ARMG_3 & & & 0,905 & & & & 0,783 & & \\
\hline GC_ARMG_4 & & & 0,873 & & & & 0,757 & & \\
\hline GC_ARMG_5 & & & 0,859 & & & & 0,750 & & \\
\hline GC_COMP_1 & & & & 0,742 & & & 0,702 & & \\
\hline GC_COMP_10 & & & & 0,757 & & & 0,724 & & \\
\hline GC_COMP_2 & & & & 0,813 & & & 0,806 & & \\
\hline GC_COMP_3 & & & & 0,801 & & & 0,770 & & \\
\hline GC_COMP_4 & & & & 0,842 & & & 0,751 & & \\
\hline GC_COMP_5 & & & & 0,848 & & & 0,755 & & \\
\hline GC_COMP_6 & & & & 0,841 & & & 0,746 & & \\
\hline GC_COMP_7 & & & & 0,772 & & & 0,693 & & \\
\hline GC_COMP_8 & & & & 0,781 & & & 0,725 & & \\
\hline GC_COMP_9 & & & & 0,738 & & & 0,687 & & \\
\hline GC_CRIA_1 & & & & & 0,841 & & 0,703 & & \\
\hline GC_CRIA_2 & & & & & 0,895 & & 0,770 & & \\
\hline GC_CRIA_3 & & & & & 0,817 & & 0,720 & & \\
\hline GC_PROT_1 & & & & & & 0,866 & 0,652 & & \\
\hline GC_PROT_2 & & & & & & 0,778 & 0,601 & & \\
\hline GC_PROT_3 & & & & & & 0,761 & 0,624 & & \\
\hline MOD_EFCT_1 & & & & & & & & 0,959 & \\
\hline EST_GC_1 & & & & & & & & & 0,886 \\
\hline EST_GC_2 & & & & & & & & & 0,918 \\
\hline EST_GC_3 & & & & & & & & & 0,903 \\
\hline EST_GC_7 & & & & & & & & & 0,785 \\
\hline
\end{tabular}

Fonte: Elaborado pelo autor

Conforme pode-se notar na Tabela 29, sobre o critério de Fornell-Lacker, foi obtido resultados aceitáveis visto que a raiz quadrada das AVEs de cada variável latente de primeira ordem é superior que a sua maior correlação com qualquer outro construto.

Tabela 29 - Modelo (C): Critério de Fornell-Lacker variáveis de 1 ordem

\begin{tabular}{|c|c|c|c|c|c|c|c|c|c|c|c|}
\hline $\begin{array}{l}\text { Variável Latente } \\
\text { de Primeira Ordem }\end{array}$ & CP_INFRA_TI & CP_OPER_TI & CP_RH_TI & GC_APLI & GC_AQUI & GC_ARMG & GC_COMP & GC_CRIA & GC_PROT & MOD_EFCT_1 & ORIEN_EXPL \\
\hline CP INFRA TI & 0,773 & & & & & & & & & & \\
\hline CP_OPER_TI & 0,381 & 0,877 & & & & & & & & & \\
\hline CP_RH_TI & 0,567 & 0,462 & 0,835 & & & & & & & & \\
\hline GC_APLI & 0,280 & 0,540 & 0,500 & 0,864 & & & & & & & \\
\hline$G C A Q U I$ & 0,347 & 0,607 & 0,519 & 0,793 & 0,838 & & & & & & \\
\hline GC ARMG & 0,325 & 0,435 & 0,556 & 0,743 & 0,695 & 0,892 & & & & & \\
\hline GC СоMP & 0,419 & 0,553 & 0,555 & 0,790 & 0,786 & 0,709 & 0,795 & & & & \\
\hline GC_CRIA & 0,367 & 0,530 & 0,530 & 0,729 & 0,795 & 0,685 & 0,763 & 0,852 & & & \\
\hline GC_PROT & 0,254 & 0,421 & 0,500 & 0,661 & 0,630 & 0,730 & 0,677 & 0,610 & 0,803 & & \\
\hline MOD_EFCT_1 & $-0,161$ & $-0,250$ & $-0,288$ & $-0,168$ & $-0,141$ & $-0,194$ & $-0,124$ & $-0,097$ & $-0,241$ & 1,000 & \\
\hline ORIEN EXPL & 0,311 & 0,428 & 0,524 & 0,662 & 0,677 & 0,729 & 0,719 & 0,738 & 0,661 & $-0,217$ & 0,875 \\
\hline
\end{tabular}

Fonte: Elaborado pelo autor 
Além disso, os valores para as variáveis latentes de segunda ordem também estão a um nível aceitável conforme Tabela 30.

Tabela 30 - Modelo (C): Critério de Fornell-Lacker variáveis de 2 ordem

\begin{tabular}{lll}
\hline $\begin{array}{l}\text { Variável Latente } \\
\text { de Segunda Ordem }\end{array}$ & CP_TI & GC \\
\hline $\mathrm{CP}_{-} \mathrm{TI}$ & 0,793 & \\
$\mathrm{GC}$ & 0,684 & 0,872 \\
\hline
\end{tabular}

Fonte: Elaborado pelo autor

Os valores das cargas cruzadas estão aceitáveis conformeAPÊNDICE 7 - CARGAS CRUZADAS MODELO C.

Dessa forma pode-se fechar a análise dos critérios que estão associados com a validade discriminante entre as variáveis latentes do modelo de pesquisa em questão.

Após a validação dos critérios para avaliação do modelo de mensuração, será apresentado o processo de avaliação do modelo estrutural. Conforme Tabela 31 quase majoritariamente todas as relações são aceitáveis a um nível de significância de $1 \%$, somente o efeito moderador que ficou com um nível de significância de $5 \%$, o que dentro do modelo de pesquisa é considerável aceitável.

Tabela 31 - Modelo (C): Coeficientes de caminho

\begin{tabular}{lccc}
\hline \multicolumn{1}{c}{ Relação } & Coeficiente de Caminho & T Statistics (bootstrap) & P Values \\
\hline CP_TI -> CP_INFRA_TI & 0,707 & 18,820 & 0,000 \\
CP_TI -> CP_OPER_TI & 0,865 & 38,591 & 0,000 \\
CP_TI -> CP_RH_TI & 0,799 & 29,324 & 0,000 \\
CP_TI -> GC & 0,386 & 8,015 & 0,000 \\
GC -> GC_APLI & 0,895 & 62,044 & 0,000 \\
GC -> GC_AQUI & 0,909 & 72,745 & 0,000 \\
GC -> GC_ARMG & 0,856 & 44,132 & 0,000 \\
GC -> GC_COMP & 0,928 & 98,450 & 0,000 \\
GC -> GC_CRIA & 0,859 & 50,350 & 0,000 \\
GC -> GC_PROT & 0,780 & 25,477 & 0,000 \\
MOD_EFCT_1 -> GC & 0,076 & 1,987 & 0,047 \\
ORIEN_EXPL -> GC & 0,599 & 14,477 & 0,000 \\
\hline
\end{tabular}

Fonte: Elaborado pelo autor

Fica constado o impacto da capacidade composta por três dimensões sobre a gestão do conhecimento que representa os seis processos de conhecimento discutidos no trabalho. Além disso, existe a evidência de que um estilo de gestão do conhecimento voltado para o conhecimento explícito tem um efeito positivo sobre a 
relação entre os construtos capacidade de TI e gestão do conhecimento, visto a relação MOD_EFCT_1 -> GC.

Conforme Tabela 32, não existem problemas de colinearidade no modelo proposto, visto que os valores VIF's são inferiores a 5.

Tabela 32 - Modelo (C): Valores de VIF

\begin{tabular}{llc}
\hline $\begin{array}{c}\text { Variável } \\
\text { Endógena }\end{array}$ & \multicolumn{1}{c}{$\begin{array}{c}\text { Variável } \\
\text { Exógena }\end{array}$} & VIF \\
\hline CP_INFRA_TI & CP_TI & 1 \\
CP_OPER_TI & CP_TI & 1 \\
CP_RH_TI & CP_TI & 1 \\
GC & CP_TI & 1,47 \\
GC_CRIA & GC & 1 \\
GC_AQUI & GC & 1 \\
GC_ARMG & GC & 1 \\
GC_COMP & GC & 1 \\
GC_APLI & GC & 1 \\
GC_PROT & GC & 1 \\
Moderating Effect & & 1,103 \\
1 & GC & 1,405 \\
ORIEN_EXPL & GC & \\
\hline
\end{tabular}

Fonte: Elaborado pelo autor

Sobre o coeficiente de determinação $R^{2}$ é possível notar que seus valores são moderados e substanciais para cada variável latente endógena presente no modelo, conforme Tabela 33.

Tabela 33 - Modelo (C): Valores de $\mathrm{R}^{2}$

\begin{tabular}{lccl}
\hline $\begin{array}{c}\text { Variável Latente } \\
\text { Endógena }\end{array}$ & $\mathbf{R}^{2}$ & $\begin{array}{c}\mathbf{R}^{2} \\
\text { Adjusted }\end{array}$ & Status \\
\hline CP_INFRA_TI & 0,500 & 0,497 & Moderado \\
CP_OPER_TI & 0,748 & 0,747 & Moderado \\
CP_RH_TI & 0,639 & 0,637 & Moderado \\
GC & 0,724 & 0,720 & Moderado \\
GC_APLI & 0,800 & 0,799 & Substancial \\
GC_AQUI & 0,826 & 0,825 & Substancial \\
GC_ARMG & 0,733 & 0,732 & Moderado \\
GC_COMP & 0,861 & 0,860 & Substancial \\
GC_CRIA & 0,738 & 0,737 & Moderado \\
GC_PROT & 0,609 & 0,607 & Moderado \\
\hline
\end{tabular}

Fonte: Elaborado pelo autor

O efeito de tamanho é apresentado na Tabela 34. Como é possível notar, o efeito moderador tem um valor considerado pequeno, porém quando se analisam os 
coeficientes de caminho é possível notar uma relativa queda no valor da relação entre a capacidade de TI e a gestão do conhecimento, o que faz com que não seja interessante descartar esse fator moderador.

Chin et al. (2003) destaca que mesmo que um efeito de interação seja pequeno pode ser significativo dependendo das condições em que ocorre a moderação, se as mudanças de valores das estimativas foram significantes em função da presença de uma variável moderadora, é importante que essas condições sejam consideradas.

Tabela 34 - Modelo (C): Valores de $\mathrm{f}^{2}$

\begin{tabular}{lcc}
\hline \multicolumn{1}{c}{ Relação } & $\mathbf{f}^{2}$ & Status \\
\hline CP_TI -> CP_INFRA_TI & 0,999 & Grande \\
CP_TI -> CP_OPER_TI & 2,975 & Grande \\
CP_TI ->CP_RH_TI & 1,771 & Grande \\
CP_TI -> GC & 0,367 & Grande \\
GC -> GC_APLI & 4,007 & Grande \\
GC -> GC_AQUI & 4,738 & Grande \\
GC -> GC_ARMG & 2,752 & Grande \\
GC -> GC_COMP & 6,196 & Grande \\
GC -> GC_CRIA & 2,815 & Grande \\
GC -> GC_PROT & 1,555 & Grande \\
MOD_EFCT_1 ->GC & 0,017 & Pequeno \\
ORIEN_EXPL -> GC & 0,927 & Grande \\
\hline
\end{tabular}

Fonte: Elaborado pelo autor

Os valores de $Q^{2}$ são superiores a 0 , o que indica uma relevância preditiva do modelo de pesquisa, conforme Tabela 35.

Tabela 35 - Modelo (C): Valores de $Q^{2}$

\begin{tabular}{lc}
\hline Variáveis Latentes Endógenas & $\mathbf{Q}^{\mathbf{2}}$ \\
\hline CP_INFRA_TI & 0,264 \\
CP_OPER_TI & 0,535 \\
CP_RH_TI & 0,413 \\
GC & 0,368 \\
GC_APLI & 0,561 \\
GC_AQUI & 0,540 \\
GC_ARMG & 0,546 \\
GC_COMP & 0,506 \\
GC_CRIA & 0,508 \\
GC_PROT & 0,372 \\
\hline
\end{tabular}

Fonte: Elaborado pelo autor 


\subsubsection{Resultado Modelo (D)}

O modelo (D) que leva em consideração o fator moderador (impacto estratégico da TI no presente), conforme Figura 26.

Figura 26 - Modelo (D): Diagrama de Caminhos

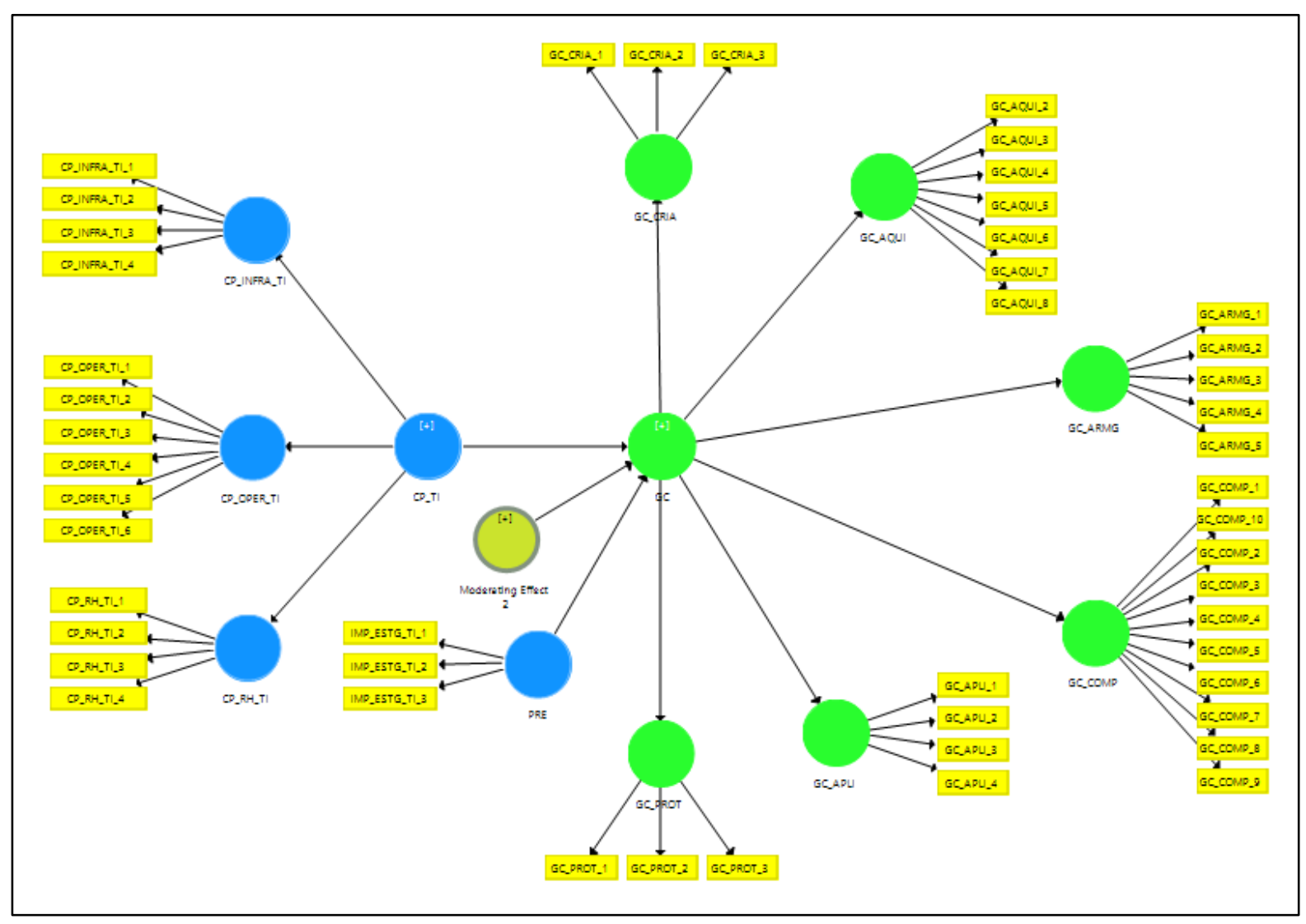

Fonte: Elaborado pelo autor

A Tabela 36 apresenta os valores para as medidas alpha de cronbach's, confiabilidade composta e AVE. Como é possível verificar os valores estão aderentes aos limites desejados. O elemento diferencial que precisa ser analisado é a variável latente moderadora ( $P R E$ ) que foi incluída no modelo e corresponde ao impacto estratégico da $\mathrm{TI}$ no presente. A avaliação do modelo de mensuração das demais variáveis já foram realizadas no momento em que foi avaliado o Modelo (B) e Modelo (C). 
Tabela 36 - Modelo (D): Métricas do modelo de mensuração

\begin{tabular}{lccc}
\hline Variável Latente & Alpha de Cronbach's & Confiabilidade composta & AVE \\
\hline CP_INFRA_TI & 0,779 & 0,855 & 0,597 \\
CP_OPER_TI & 0,940 & 0,952 & 0,769 \\
CP_RH_TI & 0,855 & 0,902 & 0,697 \\
CP_TI & 0,903 & 0,919 & 0,629 \\
GC & 0,973 & 0,975 & 0,761 \\
GC_APLI & 0,886 & 0,922 & 0,746 \\
GC_AQUI & 0,929 & 0,943 & 0,702 \\
GC_ARMG & 0,936 & 0,951 & 0,796 \\
GC_COMP & 0,935 & 0,945 & 0,631 \\
GC_CRIA & 0,810 & 0,888 & 0,726 \\
GC_PROT & 0,722 & 0,844 & 0,645 \\
MOD_EFCT_2 & 1,000 & 1,000 & 1,000 \\
PRE & 0,789 & 0,875 & 0,699 \\
\hline
\end{tabular}

Fonte: Elaborado pelo autor

A Tabela 37 apresenta as cargas externas para os indicadores das variáveis latentes associadas ao construto Tecnologia da Informação. Como é possível verificar todos os valores estão acima do valor esperado de 0,7 . Isso inclui os indicadores que compõem a variável moderadora impacto estratégico da TI no presente.

Tabela 37 - Modelo (D): Cargas externas associadas a TI

\begin{tabular}{|c|c|c|c|c|c|c|}
\hline Indicadores & CP_INFRA_TI & CP_OPER_TI & CP_RH_TI & CP_TI & MOD_EFCT_2 & PRE \\
\hline CP_INFRA_TI_1 & 0,790 & & & 0,430 & & \\
\hline CP_INFRA_TI_2 & 0,752 & & & 0,408 & & \\
\hline CP_INFRA_TI_3 & 0,829 & & & 0,660 & & \\
\hline CP_INFRA_TI_4 & 0,716 & & & 0,600 & & \\
\hline CP_OPER_TI_1 & & 0,868 & & 0,733 & & \\
\hline CP_OPER_TI_2 & & 0,899 & & 0,770 & & \\
\hline CP_OPER_TI_3 & & 0,912 & & 0,779 & & \\
\hline CP_OPER_TI_4 & & 0,880 & & 0,738 & & \\
\hline CP_OPER_TI_5 & & 0,864 & & 0,745 & & \\
\hline CP_OPER_TI_6 & & 0,836 & & 0,782 & & \\
\hline CP_RH_TI_1 & & & 0,813 & 0,576 & & \\
\hline CP_RH_TI_2 & & & 0,864 & 0,705 & & \\
\hline CP_RH_TI_3 & & & 0,798 & 0,650 & & \\
\hline CP_RH_TI_4 & & & 0,862 & 0,724 & & \\
\hline MOD_EFCT_2 & & & & & 0,917 & \\
\hline IMP_ESTG_TI_1 & & & & & & 0,839 \\
\hline IMP_ESTG_TI_2 & & & & & & 0,855 \\
\hline IMP_ESTG_TI_3 & & & & & & 0,815 \\
\hline
\end{tabular}

Fonte: Elaborado pelo autor 
O mesmo pode-se concluir em relação aos indicadores que estão associados com as variáveis latentes associadas da GC, visto que todos estão acima de 0,7. A Tabela 38 apresenta os valores para todos os indicadores. Dessa forma, pode-se destacar que a validade convergente foi atendida para a nova variável latente moderadora incluída no modelo.

Tabela 38 - Modelo (D): Cargas externas associadas a GC

\begin{tabular}{|c|c|c|c|c|c|c|c|}
\hline Indicadores & GC_APLI & GC_AQUI & GC_ARMG & GC_COMP & GC_CRIA & GC_PROT & GC \\
\hline GC_APLI_1 & 0,830 & & & & & & 0,712 \\
\hline GC_APLI_2 & 0,882 & & & & & & 0,796 \\
\hline GC_APLI_3 & 0,903 & & & & & & 0,837 \\
\hline GC_APLI_4 & 0,839 & & & & & & 0,740 \\
\hline GC_AQUI_2 & & 0,798 & & & & & 0,715 \\
\hline GC_AQUI_3 & & 0,825 & & & & & 0,707 \\
\hline GC_AQUI_4 & & 0,830 & & & & & 0,727 \\
\hline GC_AQUI_5 & & 0,879 & & & & & 0,788 \\
\hline GC_AQUI_6 & & 0,887 & & & & & 0,798 \\
\hline GC_AQUI_7 & & 0,822 & & & & & 0,787 \\
\hline GC_AQUI_8 & & 0,821 & & & & & 0,799 \\
\hline GC_ARMG_1 & & & 0,910 & & & & 0,746 \\
\hline GC_ARMG_2 & & & 0,911 & & & & 0,780 \\
\hline GC_ARMG_3 & & & 0,905 & & & & 0,782 \\
\hline GC_ARMG_4 & & & 0,873 & & & & 0,757 \\
\hline GC_ARMG_5 & & & 0,859 & & & & 0,749 \\
\hline GC_COMP_1 & & & & 0,742 & & & 0,703 \\
\hline GC_COMP_10 & & & & 0,757 & & & 0,724 \\
\hline GC_COMP_2 & & & & 0,813 & & & 0,806 \\
\hline GC_COMP_3 & & & & 0,801 & & & 0,770 \\
\hline GC_COMP_4 & & & & 0,842 & & & 0,751 \\
\hline GC_COMP_5 & & & & 0,848 & & & 0,755 \\
\hline GC_COMP_6 & & & & 0,842 & & & 0,746 \\
\hline GC_COMP_7 & & & & 0,772 & & & 0,694 \\
\hline GC_COMP_8 & & & & 0,781 & & & 0,725 \\
\hline GC_COMP_9 & & & & 0,738 & & & 0,687 \\
\hline GC_CRIA_1 & & & & & 0,841 & & 0,703 \\
\hline GC_CRIA_2 & & & & & 0,895 & & 0,770 \\
\hline GC_CRIA_3 & & & & & 0,817 & & 0,720 \\
\hline GC_PROT_1 & & & & & & 0,866 & 0,652 \\
\hline GC_PROT_2 & & & & & & 0,778 & 0,600 \\
\hline GC_PROT_3 & & & & & & 0,761 & 0,624 \\
\hline
\end{tabular}

Fonte: Elaborado pelo autor

Finalizado a validade convergente, será dado início a validade discriminante. Conforme pode-se notar na Tabela 39, sobre o critério de Fornell-Lacker, foi obtido 
resultados aceitáveis visto que a raiz quadrada das AVEs de cada variável latente de primeira ordem é superior que a sua maior correlação com qualquer outro construto.

Tabela 39 - Modelo (D): Critério de Fornell-Lacker variáveis de 1 ordem

\begin{tabular}{|c|c|c|c|c|c|c|c|c|c|c|c|}
\hline $\begin{array}{l}\text { Variável Latente de } \\
\text { Primeira Ordem }\end{array}$ & CP_INFRA_TI & CP_OPER_TI & CP_RH_TI & GC_APLI & GC_AQUI & GC_ARMG & GC_COMP & GC_CRIA & GC_PROT & MOD_EFCT_2 & PRE \\
\hline CP_INFRA_TI & 0,773 & & & & & & & & & & \\
\hline CP_OPER_TI & 0,381 & 0,877 & & & & & & & & & \\
\hline CP_RH_TI & 0,567 & 0,462 & 0,835 & & & & & & & & \\
\hline GC_APLI & 0,280 & 0,540 & 0,500 & 0,864 & & & & & & & \\
\hline GC_AQUI & 0,347 & 0,607 & 0,519 & 0,793 & 0,838 & & & & & & \\
\hline GC_ARMG & 0,325 & 0,435 & 0,556 & 0,743 & 0,695 & 0,892 & & & & & \\
\hline GC_COMP & 0,419 & 0,553 & 0,555 & 0,790 & 0,786 & 0,709 & 0,795 & & & & \\
\hline GC_CRIA & 0,367 & 0,530 & 0,530 & 0,729 & 0,794 & 0,685 & 0,763 & 0,852 & & & \\
\hline GC_PROT & 0,254 & 0,421 & 0,500 & 0,661 & 0,630 & 0,730 & 0,677 & 0,610 & 0,803 & & \\
\hline MOD_EFCT_2 & $-0,170$ & $-0,116$ & $-0,193$ & 0,036 & $-0,034$ & $-0,019$ & 0,037 & $-0,054$ & 0,109 & 1,000 & \\
\hline PRE & 0,323 & 0,276 & 0,296 & 0,213 & 0,226 & 0,169 & 0,230 & 0,190 & 0,138 & $-0,271$ & 0,836 \\
\hline
\end{tabular}

Fonte: Elaborado pelo autor

Além disso, os valores para as variáveis latentes de segunda ordem também estão a um nível aceitável conforme Tabela 40.

Tabela 40 - Modelo (D): Critério de Fornell-Lacker variáveis de 2 ordem

\begin{tabular}{lcc}
\hline $\begin{array}{l}\text { Variável Latente de } \\
\text { Segunda Ordem }\end{array}$ & CP_TI & GC \\
\hline CP_TI & 0,793 & \\
GC & 0,684 & 0,872 \\
\hline
\end{tabular}

Fonte: Elaborado pelo autor

Em relação a análise de cargas cruzadas, pode-se notar que as cargas de um indicador sobre o construto a que pertence são maiores que suas cargas nos demais construtos, conforme APÊNDICE 8 - CARGAS CRUZADAS MODELO D.

Dessa forma, pode-se fechar a análise dos critérios que estão associados com a validade discriminante entre as variáveis latentes do modelo de pesquisa em questão.

Com a conclusão da validação dos critérios para avaliação do modelo de mensuração, será apresentado o processo de avaliação do modelo estrutural. Conforme Tabela 41 quase majoritariamente todas as relações são aceitáveis a um nível de significância de $1 \%$. 
Tabela 41 - Modelo (D): Coeficientes de caminho

\begin{tabular}{lccc}
\hline \multicolumn{1}{c}{ Relação } & Coeficiente de Caminho & T Statistics $(\mid \mathbf{O} /$ STDEV $\mid)$ & P Values \\
\hline CP_TI -> CP_INFRA_TI & 0,707 & 18,974 & 0,000 \\
CP_TI -> CP_OPER_TI & 0,865 & 39,813 & 0,000 \\
CP_TI ->CP_RH_TI & 0,799 & 28,241 & 0,000 \\
CP_TI -> GC & 0,705 & 14,367 & 0,000 \\
GC ->GC_APLI & 0,895 & 64,239 & 0,000 \\
GC ->GC_AQUI & 0,909 & 74,801 & 0,000 \\
GC ->GC_ARMG & 0,856 & 43,312 & 0,000 \\
GC ->GC_COMP & 0,928 & 100,375 & 0,000 \\
GC ->GC_CRIA & 0,859 & 50,698 & 0,000 \\
GC ->GC_PROT & 0,780 & 25,752 & 0,000 \\
MOD_EFCT_2 -> GC & 0,158 & 3,056 & 0,002 \\
PRE ->GC & 0,016 & 0,275 & 0,783 \\
\hline
\end{tabular}

Fonte: Elaborado pelo autor

Ainda fica constado o impacto da capacidade composta por três dimensões sobre a gestão do conhecimento que representa os seis processos de conhecimento discutidos no trabalho. Além disso, existe a evidência de que a necessidade de tecnologias da informação mais confiáveis tem efeito positivo sobre a relação entre os construtos capacidade de TI e gestão do conhecimento, visto a relação MOD_EFCT_2 -> GC.

Conforme Tabela 42 não existe problemas de colinearidade no modelo proposto, visto que os valores VIF's são inferiores que 5 .

Tabela 42 - Modelo (D): Valores de VIF

\begin{tabular}{llc}
\hline Variável Endógena & Variável Exógena & VIF \\
\hline CP_INFRA_TI & CP_TI & 1 \\
CP_OPER_TI & CP_TI & 1 \\
CP_RH_TI & CP_TI & 1 \\
GC & CP_TI & 1,161 \\
GC_CRIA & GC & 1 \\
GC_AQUI & GC & 1 \\
GC_ARMG & GC & 1 \\
GC_COMP & GC & 1 \\
GC_APLI & GC & 1 \\
GC_PROT & GC & 1 \\
MOD_EFCT_2 & GC & 1,090 \\
PRE & GC & 1,210 \\
\hline
\end{tabular}

Fonte: Elaborado pelo autor 
Sobre o coeficiente de determinação $R^{2}$ é possível notar que seus valores são moderados e substanciais para cada variável latente endógena presente no modelo, conforme Tabela 43.

Tabela 43 - Modelo (D): Valores de $\mathrm{R}^{2}$

\begin{tabular}{lccl}
\hline $\begin{array}{c}\text { Variável Latente } \\
\text { Endógena }\end{array}$ & $\mathbf{R}^{2}$ & $\begin{array}{c}\mathbf{R}^{2} \\
\text { Adjusted }\end{array}$ & Status \\
\hline CP_INFRA_TI & 0,500 & 0,497 & Moderado \\
CP_OPER_TI & 0,749 & 0,747 & Moderado \\
CP_RH_TI & 0,639 & 0,637 & Moderado \\
GC & 0,488 & 0,480 & Moderado \\
GC_APLI & 0,801 & 0,800 & Substancial \\
GC_AQUI & 0,827 & 0,826 & Substancial \\
GC_ARMG & 0,732 & 0,731 & Moderado \\
GC_COMP & 0,861 & 0,861 & Substancial \\
GC_CRIA & 0,738 & 0,736 & Moderado \\
GC_PROT & 0,608 & 0,606 & Moderado \\
\hline
\end{tabular}

Fonte: Elaborado pelo autor

O efeito de tamanho é apresentado na Tabela 44. Analogamente ao efeito moderador do Modelo (C), o valor do tamanho do efeito de tamanho é considerado pequeno, porém também houve uma variação sobre a estimativa dos coeficientes de caminho da relação da capacidade de TI com a gestão do conhecimento.

Tabela 44 - Modelo (D): Valores de $\mathrm{f}^{2}$

\begin{tabular}{lcc}
\hline \multicolumn{1}{c}{ Relação } & $\mathbf{f}^{2}$ & Status \\
\hline CP_TI -> CP_INFRA_TI & 0,999 & Grande \\
CP_TI -> CP_OPER_TI & 2,976 & Grande \\
CP_TI -> CP_RH_TI & 1,770 & Grande \\
CP_TI -> GC & 0,836 & Grande \\
GC -> GC_APLI & 4,021 & Grande \\
GC -> GC_AQUI & 4,768 & Grande \\
GC -> GC_ARMG & 2,732 & Grande \\
GC -> GC_COMP & 6,211 & Grande \\
GC -> GC_CRIA & 2,811 & Grande \\
GC -> GC_PROT & 1,550 & Grande \\
MOD_EFCT_2 -> GC & 0,038 & Pequeno \\
PRE -> GC & 0,000 & Pequeno \\
\hline
\end{tabular}

Fonte: Elaborado pelo autor

Os valores de $Q^{2}$ são superiores a 0 , o que indica uma relevância preditiva do modelo de pesquisa, vide Tabela 45. 
Tabela 45 - Modelo (D): Valores de $\mathrm{Q}^{2}$

\begin{tabular}{lc}
\hline Variáveis Latentes Endógenas & $\mathbf{Q}^{2}$ \\
\hline CP_INFRA_TI & 0,264 \\
CP_OPER_TI & 0,535 \\
CP_RH_TI & 0,412 \\
GC & 0,247 \\
GC_APLI & 0,562 \\
GC_AQUI & 0,540 \\
GC_ARMG & 0,545 \\
GC_COMP & 0,506 \\
GC_CRIA & 0,508 \\
GC_PROT & 0,371 \\
\hline
\end{tabular}

Fonte: Elaborado pelo autor

\subsubsection{Resultado Modelo (E)}

O modelo (E) que leva em consideração o fator moderador (impacto estratégico da TI no futuro), conforme Figura 1.

Figura 27 - Modelo (E): Diagrama de Caminhos

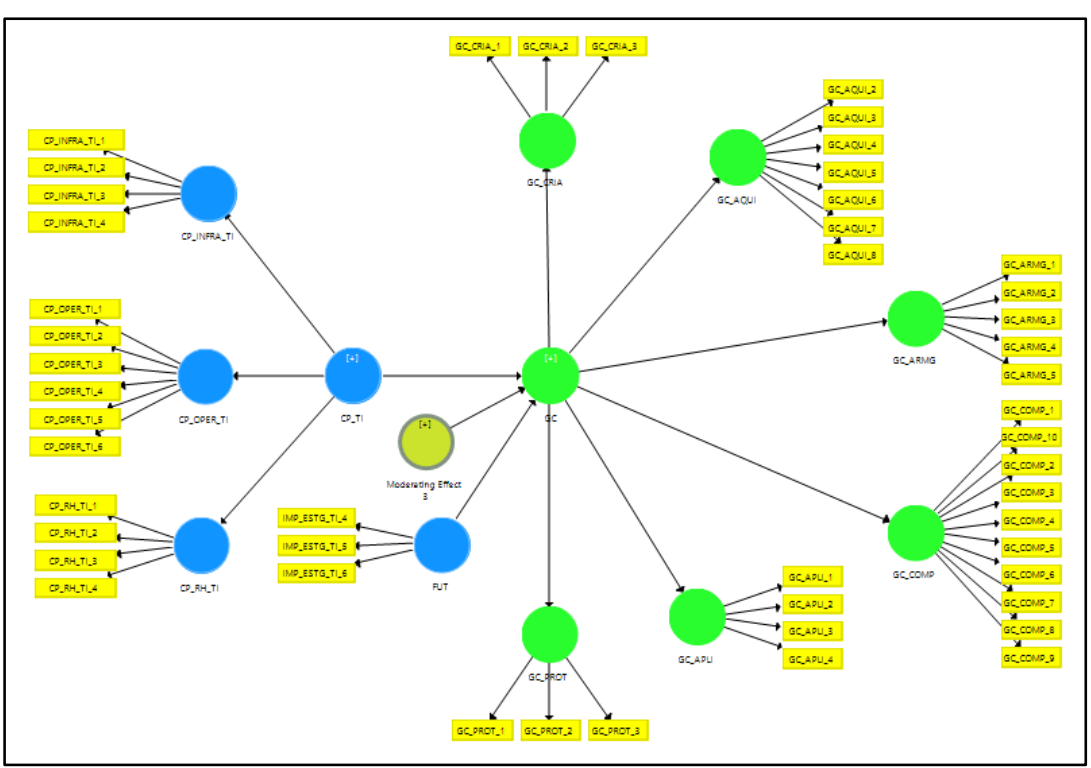

Fonte: Elaborado pelo autor

A Tabela 46 apresenta os valores para as medidas alpha de cronbach's, confiabilidade composta e AVE. Como é possível verificar os valores estão aderentes aos limites desejados. O elemento diferencial que precisa ser analisado é a variável latente moderadora (FUT) que foi incluída no modelo e corresponde ao impacto estratégico da TI no futuro. A avaliação do modelo de mensuração das demais variáveis já foram realizadas no momento em que foi avaliado o Modelo (B), Modelo (C) e modelo (D). 
Tabela 46 - Modelo (E): Métricas do modelo de mensuração

\begin{tabular}{lccc}
\hline Variável Latente & Alpha de Cronbach's & Confiabilidade composta & AVE \\
\hline CP_INFRA_TI & 0,779 & 0,855 & 0,597 \\
CP_OPER_TI & 0,940 & 0,952 & 0,769 \\
CP_RH_TI & 0,855 & 0,902 & 0,697 \\
CP_TI & 0,903 & 0,919 & 0,629 \\
FUT & 0,775 & 0,869 & 0,761 \\
GC & 0,973 & 0,975 & 0,549 \\
GC_APLI & 0,886 & 0,922 & 0,746 \\
GC_AQUI & 0,929 & 0,943 & 0,702 \\
GC_ARMG & 0,936 & 0,951 & 0,796 \\
GC_COMP & 0,935 & 0,945 & 0,631 \\
GC_CRIA & 0,810 & 0,888 & 0,726 \\
GC_PROT & 0,722 & 0,844 & 0,645 \\
MOD_EFCT_3 & 1,000 & 1,000 & 1,000 \\
\hline
\end{tabular}

Fonte: Elaborado pelo autor

A Tabela 47 apresenta as cargas externas para os indicadores das variáveis latentes associadas ao construto Tecnologia da Informação. Como é possível verificar todos os valores estão acima do valor esperado de 0,7 . Isso incluí os indicadores que compõem a variável moderadora impacto estratégico da TI no presente.

Tabela 47 - Modelo (E): Cargas externas associadas a TI

\begin{tabular}{|c|c|c|c|c|c|c|}
\hline Indicadores & CP_INFRA_TI & CP_OPER_TI & CP_RH_TI & CP_TI & MOD_EFCT_3 & FUT \\
\hline CP_INFRA_TI_1 & 0,790 & & & 0,430 & & \\
\hline CP_INFRA_TI_2 & 0,752 & & & 0,408 & & \\
\hline CP_INFRA_TI_3 & 0,829 & & & 0,660 & & \\
\hline CP_INFRA_TI_4 & 0,716 & & & 0,600 & & \\
\hline CP_OPER_TI_1 & & 0,868 & & 0,733 & & \\
\hline CP_OPER_TI_2 & & 0,899 & & 0,770 & & \\
\hline CP_OPER_TI_3 & & 0,912 & & 0,779 & & \\
\hline CP_OPER_TI_4 & & 0,880 & & 0,738 & & \\
\hline CP_OPER_TI_5 & & 0,864 & & 0,745 & & \\
\hline CP_OPER_TI_6 & & 0,836 & & 0,782 & & \\
\hline CP_RH_TI_1 & & & 0,813 & 0,576 & & \\
\hline CP_RH_TI_2 & & & 0,864 & 0,705 & & \\
\hline CP_RH_TI_3 & & & 0,798 & 0,650 & & \\
\hline CP_RH_TI_4 & & & 0,862 & 0,724 & & \\
\hline MOD_EFCT_3 & & & & & 1,157 & \\
\hline IMP_ESTG_TI_4 & & & & & & 0,838 \\
\hline IMP_ESTG_TI_5 & & & & & & 0,784 \\
\hline IMP_ESTG_TI_6 & & & & & & 0,864 \\
\hline
\end{tabular}

Fonte: Elaborado pelo autor 
O mesmo pode-se concluir em relação aos indicadores que estão associadas com as variáveis latentes associadas a GC, visto que todos estão acima de 0,7. A Tabela 48 apresenta os valores para todos os indicadores. Dessa forma pode-se destacar que a validade convergente foi atendida para a nova variável latente moderadora incluída no modelo.

Tabela 48 - Modelo (E): Cargas externas associadas a GC

\begin{tabular}{|c|c|c|c|c|c|c|c|}
\hline Indicadores & GC_APLI & GC_AQUI & GC_ARMG & GC_COMP & GC_CRIA & GC_PROT & GC \\
\hline GC_APLI_1 & 0,830 & & & & & & 0,712 \\
\hline GC_APLI_2 & 0,882 & & & & & & 0,797 \\
\hline GC_APLI_3 & 0,903 & & & & & & 0,837 \\
\hline GC_APLI_4 & 0,839 & & & & & & 0,740 \\
\hline GC_AQUI_2 & & 0,798 & & & & & 0,715 \\
\hline GC_AQUI_3 & & 0,824 & & & & & 0,707 \\
\hline GC_AQUI_4 & & 0,830 & & & & & 0,727 \\
\hline GC_AQUI_5 & & 0,879 & & & & & 0,788 \\
\hline GC_AQUI_6 & & 0,887 & & & & & 0,798 \\
\hline GC_AQUI_7 & & 0,822 & & & & & 0,787 \\
\hline GC_AQUI_8 & & 0,821 & & & & & 0,799 \\
\hline GC_ARMG_1 & & & 0,910 & & & & 0,746 \\
\hline GC_ARMG_2 & & & 0,911 & & & & 0,781 \\
\hline GC_ARMG_3 & & & 0,905 & & & & 0,783 \\
\hline GC_ARMG_4 & & & 0,873 & & & & 0,757 \\
\hline GC_ARMG_5 & & & 0,859 & & & & 0,749 \\
\hline GC_COMP_1 & & & & 0,742 & & & 0,703 \\
\hline GC_COMP_10 & & & & 0,757 & & & 0,724 \\
\hline GC_COMP_2 & & & & 0,813 & & & 0,806 \\
\hline GC_COMP_3 & & & & 0,801 & & & 0,770 \\
\hline GC_COMP_4 & & & & 0,842 & & & 0,751 \\
\hline GC_COMP_5 & & & & 0,848 & & & 0,755 \\
\hline GC_COMP_6 & & & & 0,841 & & & 0,746 \\
\hline GC_COMP_7 & & & & 0,772 & & & 0,694 \\
\hline GC_COMP_8 & & & & 0,781 & & & 0,725 \\
\hline GC_COMP_9 & & & & 0,738 & & & 0,687 \\
\hline GC_CRIA_1 & & & & & 0,841 & & 0,703 \\
\hline GC_CRIA_2 & & & & & 0,895 & & 0,770 \\
\hline GC_CRIA_3 & & & & & 0,817 & & 0,720 \\
\hline GC_PROT_1 & & & & & & 0,866 & 0,652 \\
\hline GC_PROT_2 & & & & & & 0,778 & 0,600 \\
\hline GC_PROT_3 & & & & & & 0,761 & 0,624 \\
\hline
\end{tabular}

Fonte: Elaborado pelo autor

Finalizado a validade convergente, será dado início a validade discriminante. Conforme pode-se notar na Tabela 49, sobre o critério de Fornell-Lacker, foi obtido 
resultados aceitáveis visto que a raiz quadrada das AVEs de cada variável latente de primeira ordem é superior que a sua maior correlação com qualquer outro construto.

Tabela 49 - Modelo (E): Critério de Fornell-Lacker variáveis de 1 ordem

\begin{tabular}{|c|c|c|c|c|c|c|c|c|c|c|c|}
\hline $\begin{array}{l}\text { Variável Latente de } \\
\text { Primeira Ordem }\end{array}$ & CP_INFRA_TI & CP_OPER_TI & CP_RH_TI & FUT & GC_APLI & GC_AQUI & GC_ARMG & GC_COMP & GC_CRIA & GC_PROT & MOD_EFCT_3 \\
\hline $\begin{array}{l}\text { CP_INFRA_TI } \\
\end{array}$ & 0,773 & & & & & & & & & & \\
\hline CP_OPER_TI & 0,381 & 0,877 & & & & & & & & & \\
\hline CP_RH_TI & 0,567 & 0,462 & 0,835 & & & & & & & & \\
\hline FUT & 0,204 & 0,223 & 0,260 & 0,830 & & & & & & & \\
\hline GC_APLI & 0,280 & 0,540 & 0,500 & 0,258 & 0,864 & & & & & & \\
\hline GC_AQUI & 0,347 & 0,607 & 0,519 & 0,205 & 0,793 & 0,838 & & & & & \\
\hline GC_ARMG & 0,325 & 0,435 & 0,556 & 0,227 & 0,743 & 0,695 & 0,892 & & & & \\
\hline GC_COMP & 0,419 & 0,553 & 0,555 & 0,240 & 0,790 & 0,786 & 0,709 & 0,795 & & & \\
\hline GC_CRIA & 0,367 & 0,530 & 0,530 & 0,215 & 0,729 & 0,794 & 0,685 & 0,763 & 0,852 & & \\
\hline GC_PROT & 0,254 & 0,421 & 0,500 & 0,171 & 0,661 & 0,630 & 0,730 & 0,677 & 0,610 & 0,803 & \\
\hline MOD_EFCT_3 & $-0,119$ & $-0,092$ & $-0,189$ & $-0,348$ & $-0,011$ & 0,013 & $-0,001$ & $-0,002$ & $-0,024$ & 0,007 & 1,000 \\
\hline
\end{tabular}

Fonte: Elaborado pelo autor

Além disso, os valores para as variáveis latentes de segunda ordem também estão a um nível aceitável conforme Tabela 50.

Tabela 50 - Modelo (E): Critério de Fornell-Lacker variáveis de 2 ordem

\begin{tabular}{lcc}
\hline $\begin{array}{l}\text { Variável Latente de } \\
\text { Segunda Ordem }\end{array}$ & CP_TI & GC \\
\hline CP_TI & 0,675 & \\
GC & 0,684 & 0,741 \\
\hline
\end{tabular}

Fonte: Elaborado pelo autor

Em relação a análise de cargas cruzadas, pode-se notar que as cargas de um indicador sobre o construto a que pertence são maiores que suas cargas nos demais construtos, conforme APÊNDICE 9 - CARGAS CRUZADAS MODELO E.

Dessa forma pode-se fechar a análise dos critérios que estão associados com a validade discriminante entre as variáveis latentes do modelo de pesquisa em questão.

Com a conclusão da validação dos critérios para avaliação do modelo de mensuração, será apresentado o processo de avaliação do modelo estrutural. Conforme Tabela 51 quase majoritariamente todas as relações são aceitáveis a um nível de significância de 1\%. 
Tabela 51 - Modelo (E): Coeficientes de caminho

\begin{tabular}{lccc}
\hline \multicolumn{1}{c}{ Relação } & Coeficiente de Caminho & T Statistics $(|\mathbf{O} / \mathbf{S T D E V}|)$ & P Values \\
\hline CP_TI ->CP_INFRA_TI & 0,707 & 19,875 & 0,000 \\
CP_TI ->CP_OPER_TI & 0,865 & 38,133 & 0,000 \\
CP_TI ->CP_RH_TI & 0,799 & 29,027 & 0,000 \\
CP_TI -> GC & 0,675 & 15,002 & 0,000 \\
FUT -> GC & 0,110 & 1,917 & 0,056 \\
GC -> GC_APLI & 0,895 & 64,219 & 0,000 \\
GC -> GC_AQUI & 0,909 & 73,050 & 0,000 \\
GC -> GC_ARMG & 0,856 & 41,739 & 0,000 \\
GC -> GC_COMP & 0,928 & 99,507 & 0,000 \\
GC -> GC_CRIA & 0,859 & 50,205 & 0,000 \\
GC -> GC_PROT & 0,780 & 25,268 & 0,000 \\
MOD_EFCT_3 ->GC & 0,123 & 2,584 & 0,010 \\
\hline
\end{tabular}

Fonte: Elaborado pelo autor

Ainda fica constado o impacto da capacidade composta por três dimensões sobre a gestão do conhecimento que representa os seis processos de conhecimento discutidos no trabalho. Além disso, existe a evidência de que a necessidade de tecnologias da informação mais confiáveis tem efeito positivo sobre a relação entre os construtos capacidade de TI e gestão do conhecimento, visto a relação MOD_EFCT_3 -> GC.

Conforme Tabela 52, não existem problemas de colinearidade no modelo proposto, visto que os valores VIF's são inferiores a 5.

Tabela 52 - Modelo (E): Valores de VIF

\begin{tabular}{llc}
\hline Variável Endógena & Variável Exógena & VIF \\
\hline CP_INFRA_TI & CP_TI & 1 \\
CP_OPER_TI & CP_TI & 1 \\
CP_RH_TI & CP_TI & 1 \\
GC & CP_TI & 1,092 \\
GC_CRIA & GC & 1 \\
GC_AQUI & GC & 1 \\
GC_ARMG & GC & 1 \\
GC_COMP & GC & 1 \\
GC_APLI & GC & 1 \\
GC_PROT & GC & 1 \\
MOD_EFCT_3 & GC & 1,142 \\
FUT & GC & 1,212 \\
\hline
\end{tabular}

Fonte: Elaborado pelo autor 
Sobre o coeficiente de determinação R2 é possível notar que seus valores são moderados e substanciais para cada variável latente endógena presente no modelo, conforme Tabela 49.

Tabela 53 - Modelo (E): Valores de $\mathrm{R}^{2}$

\begin{tabular}{lccl}
\hline $\begin{array}{c}\text { Variável Latente } \\
\text { Endógena }\end{array}$ & $\mathbf{R}^{2}$ & $\begin{array}{c}\mathbf{R}^{2} \\
\text { Adjusted }\end{array}$ & Status \\
\hline CP_INFRA_TI & 0,500 & 0,497 & Moderado \\
CP_OPER_TI & 0,748 & 0,747 & Moderado \\
CP_RH_TI & 0,639 & 0,637 & Moderado \\
GC & 0,489 & 0,482 & Moderado \\
GC_APLI & 0,801 & 0,800 & Substancial \\
GC_AQUI & 0,826 & 0,826 & Substancial \\
GC_ARMG & 0,732 & 0,731 & Moderado \\
GC_COMP & 0,861 & 0,861 & Substancial \\
GC_CRIA & 0,738 & 0,736 & Moderado \\
GC_PROT & 0,608 & 0,606 & Moderado \\
\hline
\end{tabular}

Fonte: Elaborado pelo autor

O efeito de tamanho é apresentado na Tabela 54. Analogamente ao efeito moderador do Modelo (C) e Modelo (D), o valor do tamanho do efeito de tamanho é considerado pequeno, porém também houve uma variação sobre a estimativa dos coeficientes de caminho da relação da capacidade de $\mathrm{Tl}$ com a gestão do conhecimento.

Tabela 54 - Modelo (E): Valores de $\mathrm{f}^{2}$

\begin{tabular}{lc}
\hline \multicolumn{1}{c}{ Relação } & $\mathbf{f}^{2}$ \\
\hline CP_TI ->CP_INFRA_TI & 0,999 \\
CP_TI ->CP_OPER_TI & 2,976 \\
CP_TI ->CP_RH_TI & 1,770 \\
CP_TI -> GC & 0,817 \\
FUT -> GC & 0,020 \\
GC -> GC_APLI & 4,024 \\
GC -> GC_AQUI & 4,759 \\
GC -> GC_ARMG & 2,737 \\
GC -> GC_COMP & 6,207 \\
GC -> GC_CRIA & 2,810 \\
GC -> GC_PROT & 1,551 \\
MOD_EFCT_3 -> GC & 0,035 \\
\hline
\end{tabular}

Fonte: Elaborado pelo autor

Os valores de $Q^{2}$ são superiores a 0 , o que indica uma relevância preditiva do modelo de pesquisa, conforme Tabela 55. 
Tabela 55 - Modelo (E): Valores de $\mathrm{Q}^{2}$

\begin{tabular}{lc}
\hline Variáveis Latentes Endógenas & $\mathbf{Q}^{2}$ \\
\hline CP_INFRA_TI & 0,264 \\
CP_OPER_TI & 0,535 \\
CP_RH_TI & 0,413 \\
GC & 0,249 \\
GC_APLI & 0,562 \\
GC_AQUI & 0,540 \\
GC_ARMG & 0,545 \\
GC_COMP & 0,506 \\
GC_CRIA & 0,508 \\
GC_PROT & 0,371 \\
\hline
\end{tabular}

Fonte: Elaborado pelo autor

\subsection{CONCLUSÃO DAS AVALIAÇÕES REALIZADAS}

A avaliação do modelo proposto passou por duas fases a validação do modelo de mensuração, com o objetivo de avaliar a forma como os construtos do estudo foram mensurados, e avaliação do modelo estrutural, para entender as relação entre os construtos estudados.

Em relação ao modelo de mensuração proposto no modelo de pesquisa foi feito a exclusão de dois indicadores CP_INFRA_TI_5 e GC_AQUI_1, visto que eles não apresentaram uma carga externa aceitável em comparação com os demais indicadores dos construtos à que pertencem, o que pode invalidar a validade convergente do modelo, que indica o quanto os indicadores de um construto específico convergem ou compartilham uma elevada proporção de variância comum.

Outro ponto interessante do estudo é que buscou-se apresentar uma evolução dos modelos em relação à inclusão dos fatores moderadores. Esse passo a passo auxilia em uma análise mais completa visto que é possível analisar em um maior detalhe os eventos individuais sobre o modelo de pesquisa.

Pelos resultados identificados é possível comprovar a relação entre o construto capacidade de $\mathrm{Tl}$ e gestão do conhecimento, além disso os fatores moderadores também afetam esse relacionamento, visto que o valor da estatística está dentro do nível de significância de 5\% esperado para validar a relação. 


\subsection{VERIFICAÇÃO DAS HIPÓTESES}

Na seção 2.9 foram apresentados as hipóteses de pesquisa que foram analisadas por meio do modelo de pesquisa elaborado baseado no que foi identificado na literatura a fim de complementar as pesquisas identificadas. O SmartPLS permite aplicar o algoritmo bootstraping para estimar os coeficientes de caminho e o nível de significância para as relações de causalidades que estão associadas com as hipóteses de pesquisa.

Tabela 56 - Validação das hipóteses propostas

\begin{tabular}{lllllll}
\hline Modelo & Caminho & Hipótese & Coeficientes & Estatística t & P-value & Resultado \\
\hline (B) & CP_TI -> GC & Hipótese 1 & 0,684 & 16,208 & $0,000^{* * *}$ & Confirmada \\
(C) & CP_TI -> GC & Hipótese 1 & 0,386 & 8,015 & $0,000^{* * *}$ & Confirmada \\
& MOD_EFCT_1 -> GC & Hipótese 3 & 0,076 & 1,987 & $0,000^{* *}$ & Confirmada \\
(D) & CP_TI -> GC & Hipótese 1 & 0,705 & 14,367 & $0,000^{* * *}$ & Confirmada \\
& MOD_EFCT_2 -> GC & Hipótese 2a & 0,158 & 3,056 & $0,000^{* * *}$ & Confirmada \\
(E) & CP_TI ->GC & Hipótese 1 & 0,675 & 15,002 & $0,000^{* * *}$ & Confirmada \\
& MOD_EFCT_3 -> GC & Hipótese 2b & 0,123 & 2,584 & $0,000^{* * *}$ & Confirmada \\
\hline
\end{tabular}

Nota: ${ }^{* * \star}$ significância de $1 \%$, ${ }^{* \star}$ significância de 5\%. Fonte: Elaborado pelo autor

A partir da análise dos modelos é possível evidenciar que a capacidade de TI composta pelas três dimensões (infraestrutura, operação e recursos humanos) tem um impacto positivo sobre a gestão do conhecimento que representa seis processos de gestão de conhecimento (criação, aquisição, armazenamento, compartilhamento, aplicação e proteção). Além disso, os fatores moderadores estilo de gestão do conhecimento voltado para o conhecimento explícito, impacto estratégico da TI no presente e no futuro têm um impacto estratégico sobre essa relação. 


\section{DISCUSSÃO DOS RESULTADOS}

Este capítulo tem como objetivo apresentar uma discussão teórica dos resultados identificados com o que já foi apresentado na literatura sobre o assunto, por meio de comparações com resultados de outras pesquisas. Busca também apresentar a contribuição teórica do estudo proposto e as implicações práticas. Para finalizar são apresentadas as limitações do estudo realizado, as oportunidades para estudos futuros e as conclusões do estudo em questão.

\subsection{DISCUSSÃO TEÓRICA}

O tema do estudo em questão surgiu a partir do que se identificou na literatura sobre a gestão estratégica das organizações com foco na sobre a teoria da resourcebased view. Wade e Hulland (2004) destacam que a resource-based view da organização como uma teoria robusta que tem sido amplamente aceita em diversos campos de gestão além do campo de gestão de TI. Essa teoria permite entender como determinados recursos que a empresa possui pode afetá-la como um todo no que diz respeito a um melhor desempenho organizacional.

Nesse cenário, os dois recursos envolvidos no estudo foram a tecnologia da informação e o conhecimento, que são dois conceitos estudados em conjunto conforme alguns estudos identificados na literatura como os estudos de Choi e Lee (2003), Tippins e Sohi (2003), Mohamed et al. (2006), Choi et al. (2010) , PérezLopez e Alegre (2012) e Wagner et al. (2014).

O modelo de pesquisa proposto teve como base o modelo estudado por PérezLópez e Alegre (2012). O estudo realizado por esses autores fornece um embassamento empírico no qual a tecnologia da informação facilita a gestão do conhecimento, uma vez que suporta os processos de aquisição, disseminação e uso do conhecimento.

Os autores também identificaram que as competências de TI por si só são insuficientes para gerar e manter uma vantagem competitiva, visto que as empresas precisam de capacidades estratéticas complementares como a gestão do conhecimento para fortalecer o efeito das competências de TI sobre o desempenho organizacional.

Além disso, os resultados apresentados têm implicações importantes para o campo prático, visto que com os resultados obtidos os autores destacam que os gestores 
não deveriam focar somente na alocação de recursos para investimentos em tecnologia da informação, mas sim também levar em consideração o uso dessas tecnologias para suportar os processos de gestão de conhecimento. Isso pode ser feito, por exemplo, por meio do desenvolvimento de políticas claras de criação do conhecimento; da identificação de qual conhecimento é importante e sobre quais circunstâncias deve ser disseminado; da transferência e integração do conhecimento entre os colaboradores, explorando as inter-relações entre os grupos de trabalho; e da elaboração de um mapa de conhecimento.

O estudo realizado corrobora com os fatos identificados por esses autores, visto que é possível notar que as empresas também buscam investir na gestão do conhecimento ao invés de fazer investimentos apenas em recursos TI. Isso é evidenciado pela relação positiva identificada entre a capacidade de Tl e a gestão do conhecimento em algumas empresas, sob a perspectiva dos seus colaboradores.

O fato do efeito moderador impacto estratégico da TI no presente ter um efeito positivo sobre a relação das capacidades de TI sobre a gestão do conhecimento, demonstra o quanto a TI tem um papel fundamental para garantir que o processos de gestão do conhecimento estejam operacionais para a organização.

Os autores Tippins e Sohi (2003) identificaram que a aquisição do conhecimento por meio do aprendizado organizacional pode mediar o efeito das competências de $\mathrm{TI}$ sobre desempenho organizacional. Além disso, reforçam o motivo de algumas empresa não terem grandes benefícios proporcionados por seus investimentos em $\mathrm{TI}$, visto que as empresas que procuram obter vantagem competitiva unicamente pelo desenvolvimento de competências de TI podem não necessariamente ter um desempenho superior. Para que elas consigam obter esse desempenho superior elas deveriam concentrar sua atenção na relação dessas competências com outros processos organizacionais, como o aprendizado organizacional, que está associado com diversos processos de gestão do conhecimento. Só assim as empresas irão conseguir determinar quais os benefícios que são obtidos a partir dos investimentos realizados em $\mathrm{TI}$.

O resultado do estudo corrobora para essa visão, visto que identificou-se que o fator moderador impacto estratégico de $\mathrm{TI}$ no futuro ter um impacto positivo sobre a relação das capacidades de $\mathrm{TI}$ sobre a gestão do conhecimento. Isso indica que a 
aquisição de novos sistemas podem gerar transformações significativas nos processos de gestão do conhecimento.

Esses dois fatores moderadores levados em consideração no modelo se baseiam no grid do impacto estratégico da TI apresentado por Nolan e McFarlan (2005). Esse grid é composto dois eixos que estão atrelados ao impacto da TI no presente e no futuro. O estudo em questão levou esses dois fatores em consideração como possíveis variáveis que poderiam influenciar a relação entre a capacidade de TI e a gestão do conhecimento, o que realmente foi evidenciado vide resultados apresentados em relação ao modelo de pesquisa proposto.

Conforme supracitado no referencial teórico, a importância da TI para organização no presente e/ou no futuro faz com que existam dois estilos de gestão estratégica: a primeira voltada para o lado defensivo, no qual a empresa busca manter as tecnologias operacionais, e a segunda para o lado ofensivo, no qual a empresa busca novas tecnologias visando melhorar seus processos e serviços.

Muitos autores como Nonaka e Takeuchi (1997), Tippins e Sohi (2003), Mohamed et al. (2006), Choi et al. (2010) e Wagner et al. (2014) destacam em seus estudos que as tecnologias da informação tem uma relação positiva sobre alguns processos comuns de gestão do conhecimento, em específico a aquisição, o compartilhamento e aplicação do conhecimento.

Nonaka e Takeuchi (1997) e Tippins e Sohi (2003) descatam que a qualidade do processo de aquisição do conhecimento e os mecanismos de disseminação constituem uma fonte de vantagem competitiva. Já Wagner et al. (2014) concluem que a sociedade está se movimentando para uma sociedade do conhecimento, na qual os ativos de conhecimento de uma empresa têm um grande potencial para determinar sua vantagem competitiva. Os autores identificaram que a TI pode ajudar a organização a gerenciar seus recursos de conhecimento, em específico os autores destacam que o uso de mídias sociais - wikis, blogs, redes sociais, dentre outros proporciona uma variedade de novos comportamentos, que tem influência sobre o processo de criação do conhecimento.

Esse fato é corroborado pelo estudo de Mohamed et al. (2006), no qual é destacado que se a $\mathrm{TI}$ for usada apropriadamente ela pode acelerar as capacidades de compartilhamento do conhecimento. Choi et al. (2010) também evidenciaram 
resultados muito parecidos, os autores identificaram que as tecnologias da informação que são designadas para suportar as práticas de gestão do conhecimento, principalmente no que diz respeito ao processo de compartilhamento e aplicação do conhecimento. Os autores destacam que o compartilhamento do conhecimento por si só não melhora o desempenho do time, uma vez que esse conhecimento deve ser aplicado eficientemente.

O estudo em questão corrobora sobre o fato de que a gestão do conhecimento é composta por essas três dimensões, porém o estudo vai além desse fato ao incluir mais os processos de criação, armazenamento e proteção do conhecimento que são discutidos por outros autores como Nonaka e Takeuchi (1997), Meso e Smith (2000), Alavi e Leidner (2001), Kakabadse et al. (2003), Harlow (2008), Zack et al. (2009) e Joshi et al. (2010). Pelos resultados obtidos é possível notar que as três dimensões incluídas no modelo de pesquisa tem uma força expressiva sobre o construto gestão do conhecimento.

O fator moderador orientação do estilo da gestão do conhecimento explícito baseado nos estudos de Choi e Lee (2003), Stankosky (2005) e Wild e Griggs (2008), também foi um novo elemento incluído no modelo de pesquisa. Na visão de Choi e Lee (2003) um estilo de gestão de conhecimento voltado para um estilo dinâmico é marcado pela integração de um estilo voltado tanto para o conhecimento explícito quanto tácito, e tem um efeito positivo sobre o desempenho organizacional. Porém quando se trata de uma possível relação com as tecnologias de informação, é descatado que as mesmas tem um papel mais importante sobre o conhecimento explícito que é facilmente codificado, consequentemente armazenado, disseminado, utilizado e protegido, o que facilita o uso da TI para sua gestão.

Apesar da forte associação entre tecnologias da informação e o conhecimento explícito, não se pode deixar de destacar que existem um conjunto de tecnologias que podem auxiliar na gestão do conhecimento tácito. Existem tecnologias que permitem que tem uma forte contribuição por meio de uma interação digital entre os colaboradores de uma empresa, como é citado no estudo de Wagner et al. (2014), que destacam a formação de fóruns de discussão (wikis) e redes sociais internas, para faciltar esse processo de interação entre as pessoas, o que é um elemento importante para o compartilhamento e surgimento de novos conhecimentos. 
Conforme apresentado no modelo de pesquisa, o foco do estudo concentrou-se sobre o efeito do estilo de gestão do conhecimento voltado para a gestão do conhecimento explícito, visto a força da sua associação com as tecnologias da informação, pelo que foi constatado nos estudos de Choi e Lee (2003), Stankosky (2005) e Wild e Griggs (2008).

Os resultados do estudo corroboram para esse fato, visto que foi identificado um efeito positivo do estilo do método de gestão do conhecimento orientado para o conhecimento explícito sobre a relação principal do estudo. Outro fato que deve ser destacado é que o construto estilo do método de GC orientado para o conhecimento explícito possui um efeito relevante sobre o construto $\mathrm{GC}$, visto que com a inclusão desse construto a força das capacidades de TI sobre a GC teve uma relação significativa, o que indica que o estilo do método de gestão do conhecimento também impacta a gestão do conhecimento.

Wagner et al. (2014) destacam que o conhecimento é considerado um ativo potencial para as organizações, e a gestão do conhecimento pode ser auxiliada pela TI. Em específico o autor destaca o papel que a $\mathrm{Tl}$ tem em relação ao compartilhamento do conhecimento, que pode estimular o surgimento de novos conhecimentos, assim como também é discutido no estudo de Mohamed et al. (2006) e Choi et al. (2010). Dessa forma é importante que as tecnologias da informação estejam sempre operacionais para que não ocorra uma queda de eficiência sobre esses processos de gestão do conhecimento.

A gestão do conhecimento tem a tecnologia da informação como uma base que sustenta os diversos processos que compõem esse construto, não ficando restrito apenas a aquisição, disseminação e aplicação do conhecimento, mas também a outros processos que foram incluídos no modelo em questão como a criação, armazenamento e proteção de todo o conhecimento que a empresa possui, seja ele explícito ou tácito.

Conforme o modelo apresentado por Alavi e Leidner (2001): as tecnologias de informação associadas como processo de data mining suportam o processo de criação do conhecimento; as tecnologias de informação associadas com banco de dados, repositórios e quadros de avisos suportam o processo de armazenamento e arquisição do conehcimento; as tecnologias de informação associadas com fóruns 
de discussões e diretórios compartilhados suportam o processo de disseminação do conhecimento; por fim as tecnologias de informação voltados para business inteligence e sistemas de workflow permitem aplicar o conhecimento.

No que diz respeito a aplicação do conhecimento, por exemplo, sabe-se que muitas das decisões estratégicas são tomadas com base em algum conhecimento prévio que pode ter sido gerado por meio do uso de TI, o que vai ao encontro do fato de que as empresas devem garantir que seus sistemas permaneçam operacionais para que esse conhecimento possa ser gerado, armazenado, compartilhado e aplicado constantemente para contribuir para manter o processo de tomada de decisão mais eficiente.

Em relação a proteção do conhecimento foi possível notar que ele é um processo que não possui uma força tão grande quanto os demais processos de gestão do conhecimento. Porém esse processo tem uma grande importância para as empresas que deveria ser levado em consideração, uma vez que segundo Zack et al. (2009) esse processo está associado com o fato da empresa reter o capital humano que possui, ou seja, para que não ocorra um êxodo de conhecimento, e também com a questão de segurança em relação ao controle de acessos a determinados conhecimentos que a empresa possui.

No primeiro caso a TI pode auxiliar por meio de uma gestão mais eficiente do conhecimento que cada colaborador possui, atrelado aos seus desejos de desenvolvimento na organização, para que ele se sinta confortável em permanecer na empresa em que está atuando. Já no segundo caso a TI permite que o conhecimento considerado restrito que não pode se tornar público esteja protegido por meio de um controle de acesso a essa informação, ou seja, permite que seja criado níveis para acessar cada tipo de conhecimento que a empresa possui.

Para que a empresa consiga manter uma TI operacional é preciso que ela tenha colaboradores com expertise para estar sempre melhorando as formas de operar as tecnologias existentes, além disso é preciso que dentro do contexto estratégico de longo prazo que a empresa esteja atenta as novas tendências tecnológicas que podem ajudar na gestão do conhecimento mais eficiente. Essa ideia vai ao encontro do que é proposto por Nolan e McFarlan (2005), visto que a empresa deveriam se preocupar em manter os sistemas operacionais, quando se trata de uma posição 
estratégica mais ofensiva, mas elas não necessariamente precisam ficar restritas a esse posicionamento partindo para uma posição mais ofensiva, marcada principalmente pela busca de novas tecnologias que possam ser utilizadas para melhorar os processos asssociados a gestão do conhecimento, por exemplo.

\subsection{CONTRIBUIÇÃO PARA A TEORIA}

Os resultados da análise do modelo de pesquisa corroboraram para resultados que foram identificados por Tippins e Sohi (2003) e Pérez-Lopez e Alegre (2012), nos quais os autores evidenciaram um impacto positivo das capacidades de TI sobre a gestão do conhecimento. Além disso, outros valores ficaram semelhantes no que se refere a importância de cada dimensão da capacidade de TI, nesse caso, o menor valor do coeficiente de caminho ficou com a infraestrutura de $\mathrm{Tl}$, enquanto os maiores coeficiente variam entre a operação da $\mathrm{Tl}$ e o recursos humanos de $\mathrm{TI}$.

Esse fato pode estar relacionado com a questão de que a infraestrutura é um recurso heterogeneamente distribuído pelas organizações, ou seja, é fácil de ser adquirido ou então existem recursos similares que proporcionam um resultado similar. Enquanto, a expertise dos colaboradores e a forma como a organização utiliza a TI são recursos mais dificíeis de serem aquiridos e imitados, o que poderia indicar que essas duas dimensões tem um grau de importância maior.

A relevância dessas três dimensões para a capacidade de $\mathrm{TI}$ da organização, que impacta positivamente a gestão do conhecimento, é uma evidência que reforça a importância que as empresas devem dar para a gestão da tecnologia da informação, visto que a capacidade de TI está associada justamente com a forma como a organização utiliza seus recursos de $\mathrm{Tl}$, no que tange uma infraestrutura de $\mathrm{TI}$ adequada para suportar os processos organizacionais, funcionários com as expertises necessárias para utilizar as tecnologias de informação e capacitados para aplicar boas práticas sobre a operação dos recursos de TI.

Pérez-Lopez e Alegre (2012) destacam que essas três dimensões que representam a capacidade de $\mathrm{TI}$ representam recursos que indicam a habilidade da organização entender e utilizar ferramentas e processos de TI para auxiliar no processo de gestão do conhecimento. Para que a TI seja mais efetiva é preciso que a organização desenvolva políticas claras de geração do conhecimento, identificando qual conhecimento é importante para a empresa e sob quais circunstâncias deve ser 
disseminado; promova a transferência e integração do conhecimento entre os colaboradores, explorando a inter-relação entre grupos de trabalho; e elabore um mapa de conhecimento para auxiliar na localização do conhecimento que a empresa possui em seus colaboradores e sistemas.

Em relação aos construtos que compõem a gestão do conhecimento foi possível notar que os processos de aquisição, compartilhamento e uso do conhecimento que foram estudados pelos autores Tippins e Sohi (2003) e Pérez-Lopez e Alegre (2012), tivem o valor do coeficiente de caminho superiores aos demais processos de gestão de conhecimento incluídos no modelo.

O estudo realizado ajuda a complementar a literatura uma vez que o modelo de pesquisa proposto é mais robusto em alguns contextos, como por exemplo o fato de ter sido levado em consideração três novos processos de gestão do conhecimento (criação, armazenamento e proteção do conhecimento). Esses três novos processos incluídos no modelo complementam a visão sobre a gestão do conhecimento composto pelos processos de aquisição, compartilhamento e uso do conhecimento foco em estudos anteriores, já que eles também são representativos para o construto gestão do conhecimento.

Além disso, o estudo abordou como alguns efeitos moderadores - estilo de gestão do conhecimento voltado para o conhecimento explícito e o impacto estratégico da TI no presente e futuro - podem afetar a relação entre os dois construtos principais do estudo.

Foi identificado que o construto estilo do método de gestão do conhecimento orientado para o conhecimento explícito tem um efeito positivo sobre a gestão do conhecimento, além do seu efeito moderador correspondente ter uma efeito positivo sobre a relação principal do estudo. Dessa forma pode-se destacar que o estilo do método de gestão do conhecimento voltado para o conhecimento explícito tem uma importância sobre os processos de gestão do conhecimento, assim como as capacidades de TI.

Esse fato corrobora para o que foi identificado na revisão da literatura no que tange a questão de que a TI tem um papel importante para a gestão do conhecimento explícito, e complementa a literatura visto que foi identificado que a orientação para o conhecimento explícito também afeta a relação principal foco do estudo, além de 
ter um forte impacto sobre o construto gestão do conhecimento, ou seja, o estilo de gestão do conhecimento também tem um impacto direto sobre a gestão do conhecimento.

Em relação ao construto impacto estratégico da $\mathrm{Tl}$ que teve como base o grid estratégico de Nolan e McFarlan (2005), o estudo trouxe contribuições em duas etapas: a primeira devido ao fato de que foi realizado um estudo preliminar para avaliar os indicadores que são usados para identificar em qual quadrante uma organização pode ser classificada, que permitiu identificar quais questões estão associadas com o impacto estratégico da $\mathrm{Tl}$ no presente e no futuro; e em um segundo momento foi identificado que tanto o impacto estratégico da TI no presente quanto no futuro tem um impacto positivo sobre a relação das capacidades de $\mathrm{TI}$ sobre a gestão do conhecimento.

No caso foi identificado que o impacto estratégico da TI no presente tem um impacto maior na relação das capacidades de $\mathrm{TI}$ sobre a gestão do conhecimento do que o impacto estratégico da TI no futuro. Esse fato sugere que é importante que as empresas mantenham as capacidades de $\mathrm{TI}$ operacionais para suportar os processos de gestão do conhecimento, em contrapartida as organizações devem se preocupar também em identificar novas tecnologias para promover melhorias nos processos organazionais, como é o caso dos dos processos de gestão do conhecimento.

\subsection{IMPLICAÇÕES PRÁTICAS}

Como foi destacado nos resultados, a amostra analisada é bem variada em relação: (1) ao segmento de atuação das empresas; (2) ao porte das empresas; (3) ao departamento de atuação dos colaboradores; (4) ao tempo de casa dos colaboradores.

O uso de tecnologias da informação para apoiar a gestão do conhecimento está presente em organizações de diferentes portes e/ou segmentos de atuação. Além disso, a gestão do conhecimento é um processo que pode ocorrer em diferentes departamentos de uma organização, por meio de processos formais ou informais.

Outro fato interessante é que o estudo considerou a percepção de colaboradores que estavam na organização há pouco tempo até pessoas com um alto tempo de casa. Aqueles que entraram recentemente estão aptos a participar da pesquisa em 
questão visto que eles trazem uma visão inicial de como a empresa lida com a questão do conhecimento, visto que o momento inicial em uma empresa é marcado por diversas iniciativas para contextualizar e passar o conhecimento necessário para o novo colaborador. Enquanto isso aqueles que já tem um maior tempo de casa tem uma percepção mais abrangente de como a tecnologia da informação pode apoiar os processos de conhecimento dentro da organização.

Os resultados do modelo de pesquisa reforçam a importância das empresas garantirem que as tecnologias da informação estejam sempre operacionais para que os processos que dependem das mesmas não sejam impactados. Esse fato vai ao encontro com o que é proposto pelo fator moderador impacto estratégico da TI, no qual é preciso que as organizações tenham tecnologias da informação confiáveis pois a queda dessas tecnologias podem trazer impactos negativos para as empresas.

As três dimensões da capacidade de TI em conjunto são importantes para as organizações visto as diversas facilicidades que podem trazar ganhos de eficiência sobre os processos organizacionais.

Em específico para a gestão do conhecimento foco do estudo, que é composto pelos processos de criação, aquisição, armazenamento, compartilhamento, aplicação e proteção do conhecimento. As capacidades de TI tem uma grande importância para cada processo de gestão do conhecimento citado no estudo.

São inúmeras os tipos de recursos de TI que podem ser aplicadas sobre os processos de gestão do conhecimento, ao longo do estudo foram destacados recursos de $\mathrm{TI}$ associados com business intelligence, customer relationship management, enterprise resource planning, data mining, data bases, data warhouse, groupware, intranet, comunidades virtuais, workflow systems, dentre outros recursos.

Os recursos de TI passam por uma evolução constante, então os gestores não devem ficar em uma zona de conforto com as tecnologias que já possuem, é preciso ficar atento as tendências de mercado para a aquisição de novas tecnologias que podem trazer mais ganhos aos processos de gestão do conhecimento. Esse fato vai ao encontro decom o que é proposto pelo efeito moderador impacto estratégico da TI no futuro, visto que as empresas que novas tecnologias da informação podem 
proporcionar ganhos sobre os processos de gesgão do conhecimento, e consequentemente apoiar uma diferenciação das empresas.

Os gestores também devem se preocupar com o fenômeno de êxodo do conhecimento, para tanto é preciso que exista uma base organizada em relação as skills de seus colaboradores, para sempre saber onde alocá-los com maior assertividade, além de manter um plano para o desenvolvimento do mesmo de acordo com seus planos de desenvolvimento individual.

Um fator importante que os gestores devem levar em consideração quando se aborda da gestão do conhecimento, é o foco em relação a qual estilo de gestão mais efetivo para o ambiente no qual a organização está inserida. Como foi identificado no estudo o estilo de gestão orientado para o conhecimento explícito tem um forte impacto sobre a gestão do conhecimento, o que sugere uma atenção para esse construto. Além disso, quando o estilo de gestão é voltado para o conhecimento explícito ficou constatado que a TI tem um papel importante para os processos de gestão do conhecimento, visto que ficou evidenciado que esse fator moderador tem um impacto positivo sobre a relação das capacidades de TI com a gestão do conhecimento.

\subsection{LIMITAÇÕES E OPORTUNIDADES PARA ESTUDOS FUTUROS}

Quando se aborda a RBV é comum focalizar-se as questões associadas ao impacto dos recursos que a empresa possui e seu uso sobre o desempenho organizacional, por meio de indicadores financeiros ou operacionais. O ponto de partida inicial do estudo foi justamente essa abordagem estratégica, porém como apresentado o modelo de pesquisa do estudo em questão não levou em consideração o construto desempenho organizacional o que deixaria o modelo de pesquisa mais próximo de outros estudos identificados na literatura, como Tippins e Sohi (2003) e Pérez-Lopez e Alegre (2012).

A segunda limitação do estudo se refere ao fato do modelo de pesquisa não levar em consideração um dos eixos que compõem o grid de estilo de gestão do conhecimento apresentado por Choi e Lee (2003) como um fator moderador sobre a relação entre a capacidade de $\mathrm{TI}$ e a gestão do conhecimento, no caso o eixo correspondente ao estilo de gestão do conhecimento voltado para o conhecimento tácito. Uma análise considerando esse fator poderia auxiliar a entender se o estilo de 
gestão do conhecimento afeta a relação das capacidades de TI sobre a gestão do conhecimento.

Na revisão da literatura não foi identificado uma elevada quantidade de estudos que abordam o processo de proteção do conhecimento, que como foi evidenciado tem um papel expressivo também sobre a gestão do conhecimento, e é algo que todas as empresas deveriam se preocupar visto que qualquer tipo de perda de conhecimento pode prejudicar o desempenho da organização.

Outras oportunidades de pesquisas estão relacionadas com o entendimento de como o posicionamento das empresas no grid estratégico de Nolan e McFarlan (2005) afetam a relação das capacidades de TI sobre a gestão do conhecimento, ou então, o posicionamento das empresas no grid de estilo de gestão do conhecimento de Choi e Lee (2003).

\subsection{CONCLUSÃO}

A pesquisa em questão partiu de uma análise bibliométrica sobre a RBV e a capacidade de $\mathrm{TI}$, e sobre os resultados desse estudo foi identificado que o recurso conhecimento é comumente estudado em conjunto com o construto $\mathrm{TI}$ no contexto da RBV. Isso direcionou o foco do estudo no sentido de analisar a relação entre a capacidade de TI e a gestão do conhecimento, porém foi estudado um conjunto maior de processos de gestão do conhecimento, além da inclusão de efeitos moderadores que poderiam afetar a relação da capacidade de TI sobre a gestão do conhecimento.

O foco da pesquisa foi analisar o efeito da capacidade de TI sobre a gestão do conhecimento, além de entender como alguns fatores moderadores poderiam afetar essa relação. No caso as evidências empíricas permitiram identificar que a capacidade de TI tem influência sobre a gestão do conhecimento, e que os fatores moderadores estudados também tem impactos positivos sobre essa relação.

Outro ponto importante de se destacar é que os três novos processos de gestão do conhecimento que foram incluídos no modelo de pesquisa são expressivos, porém os processos que já haviam sido analisados em modelos de pesquisa análogos ao deste trabalho tem uma expressividade maior sobre a gestão do conhecimento.

Em relação ao construto capacidade de TI é importante destacar que as três dimensões são importantes, porém a infraestrutura de TI evidencia ser a de menor 
expressividade, visto que nos resultados dessa pesquisa identificou-se isso e nas pesquisas de Tippins e Sohi (2003) e Pérez-Lopez e Alegre (2012) também foi notado esse fato. 


\section{REFERÊNCIAS}

ACKOFF, R. From Data to Wisdom. Journal of Applied Systems Analysis vol. 16, pp. 3-9, 1989.

ADAMIDES, E.; KARACAPILIDIS, N. Information technology support for the knowledge and social processes of innovation management. Technovation, vol.29, pp. 50-59, 2006.

ADAMS, R.; BESSANT, J.; PHELPS, R. Innovation management measurement: a review. International Journal of Management Reviews, vol. 8, n. 1, pp. 21-47, 2006.

ALAVI, M.; LEIDNER, D. Knowledge management systems: issues, challenges, and benefits. Communication of the Association for Information Systems, vol. 1, 1999.

ALAVI, M.; LEIDNER, D. Review: knowledge management and knowledge management systems: conceptual foundations and research issues. MIS Quaterly, vol. 25, n. 1, pp. 107 - 136, 2001.

ANDERSÉN, J. Strategic resources and firm performance. Management Decision, vol. 49, n. 1, pp. 87 - 98, 2011.

ANDREASI, M.; GAMBARATO, V. Uso de tecnologia da informação como vantagem competitiva nas organizações. Tékhne e Lógos, Botucatu, SP, vol.1, n.2, 2010.

ANDREEVA, T.; KIANTO, A. Does knowledge management really matter? Linking knowledge management practices, competitiveness and economic performance. Journal of Knowledge Management, vol.16, n.4, pp.617-636, 2011.

AJMAL, M.; HELO, P.; KEKÄLE, T. Critical factors for knowledge management in project business. Journal of Knowledge Management, vol. 14, n. 1, pp. 156-168, 2010.

AKUDE, J. Knowledge for development: a literature review and an evolving research agenda. Deutsches Institut für Entwicklungspolitik, 2014.

ANSOFF, H. I.; McDONNELL, E. J. Implantando a administração estratégica. Trad. Antonio Zoratto Sanvicente \& Guilherme Ary Plonsky. São Paulo: Prentice-Hall, 1984.

ARMSTRONG, C.; SHIMIZU, K. A review of approaches to empirical research on the resource-based view of the firm. Journal of Management, vol. 33, n. 6, 2007.

BARNEY, J., Firm Resources and Sustained Competitive Advantage. Journal of Management, vol. 17, n. 1, pp. 99-120, 1991.

BARNEY, J.; HESTERLY, W. Administração estratégica e vantagem competitiva. São Paulo: Pearson Prentice Hall, 2007.

BHARADWAJ, A.; BHARADWAJ, S.; KONSYNSKI, B. Information technology effects on firm performance as measured by Tobin's Q. Management Science, vol. 45, n. 6, 1999.

BHARADWAJ, A. A resource-based perspective on information technology capability and firm performance: an empirical investigation. MIS Quarterly, vol. 24, n. 1, pp. 169-196, 2000. 
BRAGANZA, A. Rethinking the data-information-knowledge hierarchy: towards a case-based model. International Journal of Information Management, vol. 24, pp. 347-356, 2004.

BRYMAN, A. Research methods and organization studies. Unwin Hyman, 1989.

CEPEDA, G.; VERA, D. Dynamic capabilities and operational capabilities: a knowledge management perspective. Journal of Business Research, vol. 60, pp. 426-437, 2007.

CHAKRAVARTY, A.; GREWAL, R.; SAMBAMURTHY, V. Information technology competences, organizational agility, and firm performance: enabling and faciliting roles. Information Systems Research, vol. 24, n. 4, pp. 976-997, 2013.

CHIN, W.; MARCOLIN, B.; NEWSTED, P. A partial least squares latent variable modeling approach for measuring interaction effects: results from Monte Carlo simulation study and an electronic-mail emotion/adotion study. Information System Research, vol. 14, n.2, pp. 187-217, 2003.

$\mathrm{CHOI}, \mathrm{B}$.; LEE, H. An empirical investigation of KM styles and their effect on corporate performance. Information \& Management, vol. 40, pp. 403-417, 2003.

CHUANG, S. A resource-based view perspective on knowledge management capability and competitive advantage: an empirical investigation. Expert Systems with Applications, vol. 27, pp. 459-465, 2004.

CLEMONS, E. Corporate Strategies for information technology: a resourcebased approach. Computer, vol. 24, pp. 23-32, 1991.

COLLIS, D.; MONTGOMERY, C. How do you create and sustain a profitable strategy? Competing on resources. Harvard Business Review, vol. 73, n. 4, pp. 118-128, 1995.

CONNER, K. A historical comparison of the resource-based theory and five schools of thought within industrial organization economics: do we have a new theory of the firm. Journal of Management, pp.121-154, 1991.

CRESWELL, J. Research design: qualitative, quantitative and mixed methods approaches. Thousand Oaks, 2003.

DAVENPORT, T. Ecologia da informação: por que só a tecnologia não basta para o sucesso na era da informação. São Paulo: Futura, 1998.

DEVARAJ, S.; HOHLI, R. Performance impacts of information technology: is actual usage the missing link?. Management Science, vol. 49, n. 3, pp. 273-289, 2003.

EISENHARDT, K.; MARTIN, J. Dynamic Capabilities: what are they? Strategic Management Journal, vol. 21, pp. 1105-1121, 2000.

FARBEY,B.; LAND, F. F.; TARGETT, D. A taxonomy of information systems applications: the benefits evaluation ladder. European Journal of Information Systems, vol.4, n.1, pp.41- 50, 1995.

FORNELL, C., LARCHER, D. Evaluating structural equation models with unobservable variables and measurement error. Journal of Marketing Research, vol. 18, pp. 39-50, 1981. 
FORZA, C. Survey Research in Operations Management: a Process-based Perspective. International Journal of Operations \& Production Management, vol. 22, n. 2, pp. 152-194, 2002.

FURRER, O.; THOMAS, H.; GOUSSEVSKAIA, A. The structure and evolution of strategic management field: A content analysis of 26 years of strategic management research. International Journal of Management Reviews, 2008.

GHAURI, P.; GRONHAUG, K. Research methods in business studies. Prentice Hall, 2010.

GRANT, R. The Resource-Based Theory of Competitive Advantage: Implications for Strategy Formulation. California Management Review, vol. 33, n. 3, pp. 114-135, 1991.

GREINER, M.; BÖHMANN.; KRCMAR, H. A strategy for knowledge management. Journal of Knowledge Management, vol. 11, n. 6, pp. 3-15, 2007.

GUNASEKARAN, A.; PAPADOPOULOS, T.; DUBEY, R.; WAMBA, S.; CHILDE, S.; HAZEN, B.; AKTER, S. Big data and predictive analytics for supply chain and organizational performance. Journal of Business Resarch, vol. 70, pp. 308-317, 2017.

HAIR, J. Análise multivariada de dados. 6 ed. Porto Alegre: Bookman, 2009.

HAIR, J.; RINGLE, C.; SARSTEDT, M. Editorial Partial Least Squares Structural Equation Modeling: rigourous applications, better results and higher acceptance. Long Range Planning, vol. 46, pp. 1-12, 2013.

HAIR, J.; HULT, G.; RINGLE, C.; SARSTED, M. A primer on partial least squares structural equation modeling (PLS-SEM). SAGE Publications, 2014.

HALAWI, L.; McCARTHY, R.; ARONSON, J. Knowledge Management and the competitive strategy of the firm. The Learning Organization, vol. 13, n. 4, pp. 384397, 2006.

HAMEL, G.; PRAHALAD, C. Competindo pelo Futuro. São Paulo: Editora Campus, 1995.

HARLOW, $\mathrm{H}$. The effect of tacit knowledge on firm performance. Journal of Knowledge Management, vol. 12, n. 1, pp. 148-163, 2008.

HELFAT, C.; PETERAF, M. The dynamic resource-based view: capability lifecycles. Strategic Management Journal, vol. 24, n. 10, pp. 997-1010, 2003.

HENSELER, J.; RINGLE, C.; SINKOVICS, R. The Use of Partial Least Squares Path Modeling in International Marketing. Advances in International Marketing, vol.20, pp. 277-320, 2009.

HIDALGO, A.; ALBORS, J. Innovation management techniques and tools: a review from theory and practice. R\&D Management, vol. 38, n. 2, pp. 113-127, 2008.

HOSKISSON, R.; HITT, M.; WAN, W.; YIU, D. Theory and research in strategic management: swings of a pendulum. Journal of Management, vol. 25, n. 3, pp. 417-456, 1999.

HOLSTE, J.; FIELDS, D. Trust and tacit knowledge sharing and use. Journal of Knowledge Management, vol.14, n.1, pp.128-140, 2010. 
JOSHI, K.; CHI, L.; DATTA, A.; HAN, S. Changing the competitive landscape: continuous innovation through IT-enabled knowledge capabilities. Information Systems Research, vol. 21, n. 3, pp. 472-495, 2010.

KAKABADSE, N.; KKABADSE, K.; KOUZMIN, A. Reviewing the knowledge management literature: towards a taxonomy. Journal of Knowledge Management, vol. 7, n. 4, pp. 75-91, 2003.

KING, W.; MARKS JUNIOR, P. Motivating knowledge sharing through a knowledge management system. Omega: The International Journal of Management Science, vol. 36, pp.131-146, 2008.

KISSIMOTO, K. A influência da tecnologia da informação na estratégia da personalização nas empresas brasileiras. Dissertação de mestrado - Escola Politécnica da Universidade de São Paulo. São Paulo, 2011.

KOR, Y. MAHONEY. Edith Penrose's (1959) Contribuitions to the Resourcebased View of Strategic Management. Journal of Management Studies, 2004.

LAKATOS, E.; MARCONI, M. Metodologia Científica. Editora Atlas, 2004.

LAURINDO, F.; SHIMIZU, T.; CARVALHO, M.; RABECHINI JR, R 0 papel da Tecnologia da Informação na estratégia das Organizações. Gestão \& Produção, vol. 8, n. 2, pp. 160-279, 2001.

LAURINDO, F. Tecnologia da Informação: Planejamento e Gestão de Estratégias. Editora Atlas, 2008.

LIMA, M. C. Monografia: a engenharia da produção acadêmica. São Paulo: Saraiva, 2004.

LU, Y.; RAMAMURTHY, K. Understanding the link between information technology capability and organizational agility: an empirical examination. MIS Quaterly, vol. 35, n. 4, pp. 931 - 954, 2011.

MARTENSSON, M. A critical review of knowledge management as a management tool. Journal of Knowledge Management, vol. 4, n. 3, pp. 204-216, 2000.

MARTINS, G. Guia para elaboração de monografias e trabalhos de conclusão de curso. São Paulo: Atlas, 2000.

MATA, F.; FUEREST, W.; BARNEY, J. Information technology and sustained competitive advantage: a resource-based analysis. MIS Quaterly, pp. 487 - 505, 1995.

MARTENSSOM, M. A critical review of knowledge management as a management tool. Journal of Knowledge Management, vol. 4, n. 3, pp. 204-216, 2000.

MAXIMINO, A. Introdução à administração. Editora Atlas, 2008.

MESO, P.; SMITH, R. A resource-based view of organizational knowledge management. Journal of Knowledge Management, vol. 4, n. 3, pp. 224-234, 2000.

MIGUEL, P. Estudo de caso na engenharia de produção: estruturação e recomendações para sua condução. Produção, vol. 17, n. 1, pp. 216-229, 2007.

MIGUEL, P. Metodologia de pesquisa em engenharia de produção e gestão de operações. Editora Campus, 2010. 
MILLER, D.; SHAMSIE, J. The resource-based view of the firm in two environments: the Hollywood film studios from 1936 to 1965. Academy of management Journal, vol. 39, n. 3, pp. 519-543, 1996.

MINTZBERG, H.; AHLSTRAND, B.; LAMPEL, J. Safári de estratégia: um roteiro pela selva do planejamento estratégico. Porto Alegre: Bookman, 2010.

MITHAS, S.; RAMASUBBU, N.; SAMBAMURTHY, V. How information management capability influencies firm performance. MIS Quaterly, vol. 35, n. 1, pp. 237- 256, 2011.

MOHAMED, M.; STANKOSKY, M.; MURRAY, A. Knowledge management and information technology: can they work in perfect harmony?. Journal of Knowledge Management, vol. 10, n. 3, pp. 103-116, 2006.

MUNIZ, J.; TRZESNIAK, P.; BATISTA, E. Um enunciado definitivo para o conceito de gestão do conhecimento: necessidade para o avanço da ciência e para a aplicação eficaz. Associação Nacional de Engenharia de Produção, pp.137145, 2009.

NEWBERT, S. Empirical research on the resource-based view of the firm: an assessment and suggestions for future research. Strategic Management Journal, vol. 28, pp. 121-146, 2007,

NONAKA, I.; TAKEUCHI, H. The knowledge-creating company: how Japanese companies create the dynamics of innovation. Oxford University Press, New York, 1995.

NOKAKA, I.; TAKEUCHI, $H$. Criação de conhecimeno na empresa: como as empresas Japonesas geram a dinâmica da inovação. Rio de Janeiro: Elsevier, 1997.

NOLAN, R.; McFARLAN, F. Information technology and the board of directors. Harvard Business Review, 2005.

OLIVEIRA, F.; GOODMAN, P.; TAN, S. Contribution behaviors in distributed environments. MIS Quarterly, vol. 32, n. 1, pp.23-42, 2008.

PAN, S.; SCARBROUGH, H. A socio-technical view of knowledge-sharing at Buckman laboratories. Journal of Knowledge Management, vol. 2, pp. 55-66, 1998.

PÉREZ-LÒPEZ, S.; ALEGRE, J. Information technology competency, knowledge processes and firm performance. Industrial Management \& Data Systems, vol. 112, n4, pp. 644-662, 2012.

PERSAUD, A. Enhancing synergistic innovative capability in multinational corporations: an empirical investigation. The Journal of Product Innovation Management, vol. 22, pp. 412-429, 2005.

PETERAF, M. The cornerstones of competitive advantage: a resource-based view. Strategic Management Journal, vol. 14, pp. 179-191, 1993.

PORTER, M.; MILLAR, V. How information gives you competitive advantage. Harvard Business Review. vol. 63, pp. 149-174, 1985.

PORTER, Michael E. What is strategy? Harvard Business Review, pp. 61-78, 1996. 
PORTO, G. S.; BRAZ, R. N.; PLONSKI, G. A. O intercâmbio eletrônico de dados EDI e seus impactos organizacionais. Revista FAE, Curitiba, vol.3, n.3, pp.13-29, 2000.

POWELL, T.; DENT-MICALLEF, A. Information technology as competitive advantage: the role of human, business, and technology resources. Strategic Management Journal, vol. 18, n. 5, pp. 375 - 405, 1997.

PRIEM, R.; BUTLER, J. Is the resource-based "view" a useful perspective for strategic management research?. Academy of Management Review, vol. 26, n. 1, pp. 22 - 40, 2001.

RASINSKI, K. Surveys. Encyclopedia of Social Measurement, vol. 3, pp. 733-747, 2005.

RAY, G.; BARNEY, J.; MUHANNA, W. Capabilities, business processes, and competitive advantage: choosing the dependent variable in empirical tests of the resource-based view. Strategic Management Journal, vol. 25, pp. 23-27, 2004.

RAY, G.; MUHANNA, W.; BARNEY, J. Information technology and the performance of the customer service process: a resource-bases analysis. MIS Quaterly, vol. 29, n. 4, pp. 625 - 652, 2005.

REICH, B.; GEMINO, A.; SAUER, C. How knowledge management impacts performance in projects: an empirical study. International Journal of Project Management, vol. 32, pp. 590-602, 2014.

RINGLE, C.; SILVA, D.; BIDO, D. Modelagem de equações estruturais com utilização do SMARTPLS. Revista Brasileira de Marketing, vol. 13, n. 2, 2014.

SANTHANAM, R.; HARTONO, E. Issues inlinking infomation technology capability to firm performance. MIS Quaterly, vol. 27, n. 1, pp. 125 - 153, 2003.

SAUVE, J.; MEDEIROS, E. Avaliação de Impacto de Tecnologias da Informação Emergentes nas Empresas. 1르. ed. Rio de Janeiro: Editora Qualitymark, 2003.

SCHEIN, E. The role of the CEO to the management of change: the case of information technology. Sloan School of Managment Working Paper, USA, 1989.

SEDDON, P. Implications for strategic IS research of the resource-based theory of the firm: A reflection. Journal of Strategic Information Systems, vol. 23, pp. 257269, 2014.

SHAW, M.; SUBRAMANIAM, C., TAN, G., WELGE, M. Knowledge management and data mining for marketing. Decision Support Systems, vol. 31, pp. 127-137, 2001.

SIRMON, D.; HITT, M.; IRELAND, R. Managing firm resources in dynamic environments to create value: looking inside the black box. Management Review, vol. 32, n. 1, pp. 273-292, 2007.

SPENDER, J. Making knowledge the basis of a dynamic theory of the firm. Strategic Management Journal, vol. 17, pp. 45-62, 1996.

STAKE, R. E. Case studies. In: DENZIN, N. K.; LINCOLN, Y. S. (ed.) Handbook of qualitative research. London: Sage, 2000.

STANKOSKY, M. Creating the discipline of knowledge management: the latest in university research. Burlington, USA: Elsevier Butterworth-Heinemann, 2005. 
STOEL, M.; MUHANNA, W. IT capabilities and firm performance: a contingency analysis of the role of industry and IT capability type. Information \& Management, vol. 46, pp. 181 - 189, 2009.

TAKEUSHI, H., NONAKA, I. Gestão do conhecimento. Porto Alegre: Bookman, 2008.

TEECE, D.; PISANO, G.; SHUEN, A. Dynamics capabilities and strategic management. Strategic Management Journal, vol. 18, pp. 509-533, 1997.

TIPPINS, M., SOHI, R. IT competency and firm performance: is organizational learning a missing link?. Strategic Management Journal, vol. 24, pp. 745-761, 2003.

TODOROVIC, M.; PETROVIC, D.; MIHIC M.; OBRADOVIC, V.; BUSHUYEV, S. Project success analysis framework: a knowledge-based approach in project management. International Journal of Project Management, vol. 33, pp. 772-783, 2015.

VASCONCELOS, F.; CYRINO, A. Vantagem competitiva: os modelos teóricos atuais e a convergência entre estratégia e teoria organizacional. Revista de Administração de Empresas, vol. 40, n. 4, 2000.

YIN, R. Estudo de caso: planejamento e métodos. $3^{\underline{a}}$ edição, Bookman, 2005.

WADE, M.; HULLAND, J. Review: the resource-based view and information systems research: review, extension, and suggestions for future research. MIS Quaterly, vol. 28, n. 1, pp. $107-142,2011$.

WAMBA, S.; GUNASEKARAN, A.; PAPADOPOULOS, T.; AKTER, S.; REN, S.; DUBEY, R.; CHILDE, S. Big data analytics and firm performance: Effects of dynamic capabilities. Journal of Business Resarch, vol. 70, pp. 356-365, 2017.

VIVAS, C.; SOBREIRO, P.; CLAUDINO, R. Integrating knowledge management in a business strategy process operationalized using process management approach. Conference: 15th European Conference on Knowledge Management ECKM, 2014

WAGNER, D.; VOLLMAR, G.; WAGNER, H. The impact of information technology on knowledge creation: an affordance approach to social media. Journal of Enterprise Information Management, vol. 27, n. 1, pp.31-44, 2014.

WALDEMAR, P.; PEREIRA, V.; PEREIRA FILHO, H. Pesquisa científica sem tropeços: abordagem sistêmica. São Paulo: Atlas, 2007.

WANG, C.; AHMED, P. Dynamic capabilities: a review and research agenda. International Journal of Management Review, vol. 9, pp. 31-51, 2007.

WANG, Z.; WANG, N.; LIANG, H. Knowledge sharing, intellectual capital and firm performance. Management Decision, vol. 52, n. 2, pp. 230-258, 2014.

WERNERFELT, B. A resource-based view of the firm. Strategic Management Journal, vol. 5, pp. 171-180, 1984.

WILD, R.; GRIGGS, K. A model of information technology opportunities for facilitating the practice of knowledge management. VINE: The Journal of Information and Knowledge Management Systems, vol. 38, n. 4, 2008. 
WU, I.; CHIU, M. Organizational applications of IT innovation and firm's competitive performance: $A$ resource-based view and the innovation diffusion approach. Journal of Engineering and Technology Management, vol. 35, pp. 25-44, 2015.

WU, S.; STRAUB, D.; LIANG, T. How information technology governance mechanisms and strategic aligment influence organizational performance: insights from a matched survey business and IT managers. MIS Quarterly, vol. 39, n. 2, 2015.

ZABLAH, A.; BELLENGER, D.; JOHNSTON, W. An evaluation of divergent perspectives on customer relationship management: towards a common understanding of an emerging phenomenon. Industrial Marketing Management, vol. 33, pp. 475-489, 2004.

ZACK, M.; MCKEEN, J.; SINGH, S. Knowledge management and organizational performance: an exploratory analysis. Journal of Knowledge Management, vol. 13, n. 6, pp. $392-409,2009$.

ZOTT, C. Dynamic capabilities and the emergence of intraindustry differencial firm performance: insights from a simulation study. Strategic Management Journal, vol. 24, pp. 97-125, 2003. 


\section{APÊNDICE 1 - CARTA-CONVITE DA COLETA DE DADOS PRELIMINAR}

Questionário: Projeto de Mestrado - Estilo de gestão do conhecimento e Impacto estratégico da TI

Prezado(a) Senhor(a),

Este levantamento faz parte de uma fase preliminar do projeto de pesquisa de mestrado do Departamento de Engenharia de Produção da Escola Politécnica da USP e tem como objetivo principal validar as variáveis de medição de dois fatores moderadores que serão levados em consideração no modelo de pesquisa: o estilo de gestão do conhecimento e o impacto estratégico das tecnologias da informação.

A sua contribuição é de suma importância para a pesquisa e para a qualidade do trabalho a ser desenvolvido.

São necessários, aproximadamente, 10 minutos para preenchimento do questionário disponível no link a seguir.

https://pt.surveymonkey.com/r/L8WCKGW

Desde já agradecemos sua colaboração e nos comprometemos, caso haja interesse, em enviar o sumário com as conclusões gerais desse levantamento.

Em caso de dúvidas, favor entrar em contato através dos endereços de e-mail indicados a seguir.

Autor: Henrique Takashi Adati Tomomitsu

e-mail: htomomitsu@yahoo.com.br

Currículo: http://lattes.cnpq.br/9754706222974743

Telefone para contato: (11) 99876-3643

Orientador: Renato de Oliveira Moraes

e-mail: remo@usp.br

Currículo: http://lattes.cnpq.br/6265785942463928

Telefone para contato: (11) 5525-8738

Deparamento de Engenharia de Produção - Universidade de São Paulo - http://pro.poli.usp.br/

Av. Professor Almeida Prado, Tr. 2, ํ128, BI. G, $2^{\circ}$ andar - 05508-900, Cid. Universitária - São Paulo - Brasil

Atenciosamente,

Henrique Takashi Adati Tomomitsu 


\section{APÊNDICE 2 - QUESTIONÁRIO PRELIMINAR}

Esse questionário faz parte de um piloto do projeto de pesquisa de mestrado do Departamento de Engenharia de Produção da Escola Politécnica da USP, que tem como objetivo analisar a relação das capacidades de Tecnologia da Informação (TI) com os processos de gestão do conhecimento em diferentes tipos de organizações considerando o grau de importância da TI para a organização assim como seu estilo de gestão do conhecimento.

Ele é uma fase preliminar do projeto de pesquisa e tem como objetivo principal validar as variáveis de medição de dois fatores moderadores que serão levados em consideração no projeto: o estilo de gestão do conhecimento e o impacto estratégico das tecnologias da informação.

Será levado em consideração a perspectiva dos colaboradores das empresas independente do nível hierárquico que eles ocupam.

O tempo médio de resposta desse questionário é de aproximadamente 10 minutos.

Os dados serão apresentados de forma que se torna impossível a identificação da fonte - unidade de pesquisa - empresa.

Henrique Takashi Adati Tomomitsu Possui graduação em Sistemas de Informação pela Universidade de São Paulo (USP) e Engenharia de Produção pela Escola Superior de Engenharia e Gestão (ESEG). E mestrado em andamento em Engenharia de Produção pela USP. Atuação profissional na área de Tecnologia da Informação desde 2013.

Currículo: http://lattes.cnpq.br/9754706222974743

e-mail: htomomitsu@yahoo.com.br

Telefone: (11) 9 9876-3643

Renato de Oliveira Moraes (orientador) Engenheiro de Produção - POLI/USP, Doutor em Administração de Empresas FEA/USP. Professor do Departamento de Engenharia de Produção da Universidade de São Paulo, grupo de pesquisa - Gestão da Tecnologia da Informação.

Currículo: http://lattes.cnpq.br/6265785942463928

PRO: http://pro.poli.usp.br/institucional/corpo-docente/renato-de-oliveira-moraes/

e-mail: remo@usp.br

Telefone: (11) 5525-8738

1. Nome do respondente:

2. E-mail do respondente:

3. Nome da empresa: 


\section{Segmento de atuação:}

( ) indústria ( ) consultoria ( ) varejo ( ) saúde ( ) financeiro ( ) Outro (especifique)

\section{Quantidade de funcionários:}

6. A empresa possui uma área responsável pela gestão da tecnologia da informação?

( ) Não ( ) Sim

7. A empresa possui uma área responsável pela gestão do conhecimento?

( ) Não ( ) Sim

8. Você é colaborador da empresa a quanto tempo?

9. Qual o seu cargo?

10. Você atua em que departamento:

( ) financeiro ( ) $\mathrm{TI}$ ( ) marketing ( ) recursos humanos ( ) Outro (especifique)

Observação para questão 11: A identificação do estilo de cada empresa em relação aos métodos de gestão do conhecimento empregados leva em consideração os níveis de orientação para o âmbito explícito ou tácito. Os autores Choi e Lee (2003) definem a orientação explícita como o grau de codificação e armazenamento de um conhecimento organizacional para acesso e uso fácil por uma pessoa, em contrapartida definem a orientação tácita como o grau de aquisição e compartilhamento de conhecimento organizacional por meio de interações pessoais.

\section{Estilo de gestão do conhecimento}

\begin{tabular}{|l|l|l|l|l|l|}
\hline \multicolumn{1}{|c|}{ Questões } & $\begin{array}{c}\text { Discordo } \\
\text { plenamente }\end{array}$ & $\begin{array}{c}\text { Discordo } \\
\text { parcialmente }\end{array}$ & $\begin{array}{c}\text { Não concordo } \\
\text { nem discordo }\end{array}$ & $\begin{array}{c}\text { Concordo } \\
\text { parcialmente }\end{array}$ & $\begin{array}{c}\text { Concordo } \\
\text { plenamente }\end{array}$ \\
\hline $\begin{array}{l}\text { A empresa possui uma estrutura organizacional que } \\
\text { contribui para uma gestão do conhecimento mais } \\
\text { eficiente. }\end{array}$ & & & & & \\
\hline $\begin{array}{l}\text { A empresa possui uma cultura organizacional que } \\
\text { propicia um melhor compartilhamento do conhecimento } \\
\text { entre seus colaboradores. }\end{array}$ & & & & & \\
\hline $\begin{array}{l}\text { A empresa possui tecnologias da informação que } \\
\text { propiciam um melhor compartilhamento de } \\
\text { conhecimento entre seus colaboradores. }\end{array}$ & & & & & \\
\hline $\begin{array}{l}\text { A empresa mantém o foco sobre a codificação e } \\
\text { reutilização do conhecimento. }\end{array}$ & & & & & \\
\hline $\begin{array}{l}\text { A empresa mantémo foco sobre a aquisição e o } \\
\text { compartilhamento do conhecimento tácito e } \\
\text { experiências interpessoais. }\end{array}$ & & & & & \\
\hline
\end{tabular}


Observação para questão 12: Uma maneira de se classificar uma organização em relação as tecnologias da informação que ela possui é por meio dos impactos que esses recursos podem proporcionar para ela, como é apresentado por Nolan e McFarlan (2005) no "Grid do impacto estratégico da TI", no qual são apresentadas duas abordagens estratégicas em relação a $\mathrm{Tl}$ :

- TI Defensiva: manter os sistemas funcionando é mais importante na $\begin{array}{llll}\text { configuração } & \text { atual da } & \text { empresa }\end{array}$ que competir usando tecnologias emergentes; e

- TI Ofensiva: a visão estratégica de TI está acima ou no mesmo nível da segurança.

Para realizar essa classificação os autores apresentam um modelo que trabalha com dois eixos importantes que são levados em consideração: o grau associado com a necessidade da organização possuir tecnologias confiáveis - com o intuito de que o negócio não pode parar, e caso isso ocorra a empresa corre grandes riscos que podem prejudicar o negócio - e o outro associado com a necessidade da organização possuir novas tecnologias - com o intuito de melhorar seus processos e serviços para atender os seus consumidores da melhor forma possível.

\section{Impacto estratégico da TI}

\begin{tabular}{|l|l|l|l|l|l|}
\hline \multicolumn{1}{|c|}{ Questões } & $\begin{array}{c}\text { Discordo } \\
\text { plenamente }\end{array}$ & $\begin{array}{c}\text { Discordo } \\
\text { parcialmente }\end{array}$ & $\begin{array}{c}\text { Não concordo } \\
\text { nem discordo }\end{array}$ & $\begin{array}{c}\text { Concordo } \\
\text { parcialmente }\end{array}$ & $\begin{array}{c}\text { Concordo } \\
\text { plenamente }\end{array}$ \\
\hline $\begin{array}{l}\text { A queda de um sistema por poucos minutos pode } \\
\text { ocasionar perdas imediatas ao negócio. }\end{array}$ & & & & & \\
\hline $\begin{array}{l}\text { O aumento no tempo de resposta pode ocasionar } \\
\text { consequências graves para usuários internos e externos } \\
\text { a organização. }\end{array}$ & & & & & \\
\hline $\begin{array}{l}\text { A maioria das atividades de negócio essenciais são } \\
\text { online. }\end{array}$ & & & & & \\
\hline $\begin{array}{l}\text { Os sistemas fornecem pouca diferenciação estratégica } \\
\text { ou redução de custos. }\end{array}$ & & & & & \\
\hline $\begin{array}{l}\text { Os sistemas internos são invisíveis para fornecedores e } \\
\text { consumidores. }\end{array}$ & & & & & \\
\hline O trabalho dos sistemas é, principalmente, de apoio. & & & & & \\
\hline $\begin{array}{l}\text { Novas tecnologias da informação propiciam um melhor } \\
\text { processo e transformação nos serviços prestados. }\end{array}$ & & & & & \\
\hline $\begin{array}{l}\text { Novas tecnologias propiciam principalmente uma } \\
\text { redução de custos. }\end{array}$ & & & & & \\
\hline $\begin{array}{l}\text { Novas tecnologias reduzem gaps em relação aos } \\
\text { concorrentes no que diz respeito aos custos, serviços e } \\
\text { processos. }\end{array}$ & & & & & \\
\hline
\end{tabular}

\section{Você deseja receber uma copia dos resultados da pesquisa?}

( ) Não ( ) Sim 


\section{APÊNDICE 3 - CARTA-CONVITE PARA COLETA DE DADOS}

Questionário: Projeto de Mestrado - A relação entre as capacidades de Tecnologia da Informação e a Gestão do Conhecimento

Prezado(a) Senhor(a),

Este levantamento faz parte do meu projeto de pesquisa de mestrado realizado no Departamento de Engenharia de Produção da Escola Politécnica da USP, e tem como objetivo validar a relação entre as capacidades de $\mathrm{TI}$ com a gestão do conhecimento levando em consideração dois fatores moderadores: o estilo de gestão do conhecimento e o impacto estratégico das tecnologias da informação.

A sua contribuição é de suma importância para a pesquisa e para a qualidade do trabalho a ser desenvolvido.

São necessários, aproximadamente, 15 minutos para preenchimento do questionário disponível no link a seguir.

https://pt.surveymonkey.com/r/KTZ6639

Desde já agradecemos sua colaboração e nos comprometemos, caso haja interesse, em enviar o sumário com as conclusões gerais desse levantamento.

Em caso de dúvidas, favor entrar em contato através dos endereços de e-mail indicados a seguir.

Autor: Henrique Takashi Adati Tomomitsu

e-mail: htomomitsu@yahoo.com.br

Currículo: http://lattes.cnpq.br/9754706222974743

Telefone para contato: (11) 99876-3643

Orientador: Renato de Oliveira Moraes

e-mail: remo@usp.br

Currículo: http://lattes.cnpq.br/6265785942463928

Telefone para contato: (11) 5525-8738

Deparamento de Engenharia de Produção - Universidade de São Paulo - http://pro.poli.usp.br/

Av. Professor Almeida Prado, Tr. 2, No 128, BI. G, $2^{\circ}$ andar - 05508-900, Cid. Universitária - São Paulo - Brasil

Atenciosamente, Henrique Takashi Adati Tomomitsu 


\section{APÊNDICE 4 - QUESTIONÁRIO}

Esse questionário faz parte do projeto de pesquisa de mestrado do Departamento de Engenharia de Produção da Escola Politécnica da USP, que tem como objetivo analisar a relação das capacidades de Tecnologia da Informação (TI) com os processos de Gestão do Conhecimento (GC) em diferentes tipos de organizações considerando o grau de importância da TI para a organização assim como seu estilo de gestão do conhecimento.

Será levado em consideração a perspectiva dos colaboradores das empresas independente do nível hierárquico que eles ocupam.

O tempo médio de resposta desse questionário é de aproximadamente 15 minutos.

Os dados serão apresentados de forma que se torna impossível a identificação da fonte - unidade de pesquisa - empresa.

Autor: Henrique Takashi Adati Tomomitsu e-mail: htomomitsu@yahoo.com.br

Currículo: http://lattes.cnpq.br/9754706222974743

Telefone para contato: (11) 99876-3643

Orientador: Renato de Oliveira Moraes e-mail: remo@usp.br

Currículo: http://lattes.cnpq.br/6265785942463928

Telefone para contato: (11) 5525-8738

\section{Dados básicos da empresa (Parte 1 de 5)}

1. Nome do respondente:

2. Sexo do respondente:

3. Idade do respondente:

4. E-mail do respondente:

5. Nome da empresa:

6. Segmento da empresa:

7. Quantidade de funcionários:

8. A empresa possui uma área responsável pela gestão da tecnologia da informação?

9. A empresa possui práticas formais de gestão de conhecimento em seus departamentos/atividades?

10. A quanto tempo você é colaborador da empresa em que trabalha atualmente? 


\section{Qual o seu cargo?}

12. Você atua em que departamento:

13. Você tem interesse de receber uma cópia dos resultados da pesquisas? Se sim, os resultados serão enviados para o e-mail informado anteriormente.

\section{Questões sobre Tecnologias da Informação (Parte 2 de 5)}

As questões abaixo referem-se à importância estratégica dos sistemas de TI para sua empresa. Por favor, avalie as sentenças a seguir desde (1) discordo totalmente até (5) concordo totalmente.

\section{Impacto estratégico da TI}

\begin{tabular}{|l|l|l|l|l|l|}
\hline \multicolumn{1}{|c|}{ Questões } & $\begin{array}{c}\text { Discordo } \\
\text { plenamente }\end{array}$ & $\begin{array}{c}\text { Discordo } \\
\text { parcialmente }\end{array}$ & Indiferente & $\begin{array}{c}\text { Concordo } \\
\text { parcialmente }\end{array}$ & $\begin{array}{c}\text { Concordo } \\
\text { plenamente }\end{array}$ \\
\hline $\begin{array}{l}\text { A queda de um sistema de TI por poucos minutos pode } \\
\text { ocasionar perdas imediatas ao negócio da minha empresa. }\end{array}$ & & & & & \\
\hline $\begin{array}{l}\text { O aumento no tempo de resposta de um sistema de TI pode } \\
\text { ocasionar consequências graves para usuários internos e } \\
\text { externos a organização. }\end{array}$ & & & & & \\
\hline $\begin{array}{l}\text { A maioria das atividades de negócio essenciais da minha } \\
\text { empresa são online. }\end{array}$ & & & & & \\
\hline $\begin{array}{l}\text { Novas tecnologias da informação propiciam um melhor } \\
\text { processo e transformação nos serviços prestados pela minha } \\
\text { empresa. }\end{array}$ & & & & & \\
\hline $\begin{array}{l}\text { Novas tecnologias propiciam principalmente uma redução de } \\
\text { custos. }\end{array}$ & & & & & \\
\hline $\begin{array}{l}\text { Novas tecnologias reduzem gaps em relação aos concorrentes } \\
\text { no que diz respeito aos custos, serviços e processos. }\end{array}$ & & & & & \\
\hline
\end{tabular}

\section{Capacidades de TI (Parte 3 de 5)}

\section{Capacidade de Infraestrutura de TI}

\begin{tabular}{|l|l|l|l|l|l|}
\hline \multicolumn{1}{|c|}{ Questões } & $\begin{array}{c}\text { Discordo } \\
\text { plenamente }\end{array}$ & $\begin{array}{c}\text { Discordo } \\
\text { parcialmente }\end{array}$ & Indiferente & $\begin{array}{c}\text { Concordo } \\
\text { parcialmente }\end{array}$ & $\begin{array}{c}\text { Concordo } \\
\text { plenamente }\end{array}$ \\
\hline $\begin{array}{l}\text { A empresa possui um departamento responsável pela gestão de } \\
\text { tecnologias da informação. }\end{array}$ & & & & & \\
\hline $\begin{array}{l}\text { A empresa possui uma pessoa responsável pela gestão de } \\
\text { tecnologias da informação. }\end{array}$ & & & & & \\
\hline $\begin{array}{l}\text { A empresa reserva um orçamento anual para investir em novas } \\
\text { tecnologias da informação. }\end{array}$ & & & & & \\
\hline $\begin{array}{l}\text { A empresa tem capacidade para criar aplicações customizadas } \\
\text { de softwares para atender necessidades emergentes. }\end{array}$ & & & & & \\
\hline $\begin{array}{l}\text { A empresa possui tecnologias da informação que permitem a } \\
\text { interação entre seus colaboradores, tais como e-mails, } \\
\text { ferramentas de instant messaging, vídeo conferência, entre } \\
\text { outras. }\end{array}$ & & & & & \\
\hline
\end{tabular}

16. Capacidade de Operação de TI 


\begin{tabular}{|l|l|l|l|l|l|}
\hline \multicolumn{1}{|c|}{ Questões } & $\begin{array}{c}\text { Discordo } \\
\text { plenamente }\end{array}$ & $\begin{array}{c}\text { Discordo } \\
\text { parcialmente }\end{array}$ & Indiferente & $\begin{array}{c}\text { Concordo } \\
\text { parcialmente }\end{array}$ & $\begin{array}{c}\text { Concordo } \\
\text { plenamente }\end{array}$ \\
\hline $\begin{array}{l}\text { A empresa coleta informações de mercado por meio de } \\
\text { tecnologias da informação. }\end{array}$ & & & & & \\
\hline $\begin{array}{l}\text { A empresa armazena informações de mercado por meio de } \\
\text { tecnologias da informação. }\end{array}$ & & & & & \\
\hline $\begin{array}{l}\text { A empresa analisa informações de mercado por meio de } \\
\text { tecnologias da informação. }\end{array}$ & & & & & \\
\hline $\begin{array}{l}\text { A empresa toma decisões a partir dos resultados obtidos por } \\
\text { meio de tecnologias da informação. }\end{array}$ & & & & & \\
\hline $\begin{array}{l}\text { A empresa busca rotineiramente utilizar tecnologias da } \\
\text { informação para acessar informações de mercado a partir de } \\
\text { bases de dados externas à organização. }\end{array}$ & & & & & \\
\hline $\begin{array}{l}\text { A empresa possui um conjunto de procedimentos para coletar } \\
\text { informações de mercado a partir de fontes online. }\end{array}$ & & & & & \\
\hline
\end{tabular}

\section{Capacidade de Recursos Humanos de TI}

\begin{tabular}{|l|l|l|l|l|l|}
\hline \multicolumn{1}{|c|}{ Questões } & $\begin{array}{c}\text { Discordo } \\
\text { plenamente }\end{array}$ & $\begin{array}{c}\text { Discordo } \\
\text { parcialmente }\end{array}$ & Indiferente & $\begin{array}{c}\text { Concordo } \\
\text { parcialmente }\end{array}$ & $\begin{array}{c}\text { Concordo } \\
\text { plenamente }\end{array}$ \\
\hline $\begin{array}{l}\text { No geral, os colaboradores da empresa possuem conhecimento } \\
\text { em relação as tecnologias da informação. }\end{array}$ & & & & & \\
\hline $\begin{array}{l}\text { A empresa possui um elevado grau de expertise em tecnologias } \\
\text { da informação. }\end{array}$ & & & & & \\
\hline $\begin{array}{l}\text { A empresa busca realizar treinamentos, para manter seus } \\
\text { colaboradores atualizados em relação as inovações das } \\
\text { tecnologias da informação. }\end{array}$ & & & & & \\
\hline $\begin{array}{l}\text { A empresa possui conhecimento para desenvolver e sustentar } \\
\text { um relacionamento com seus consumidores por meio de } \\
\text { tecnologias da informação. }\end{array}$ & & & & & \\
\hline
\end{tabular}

\section{Questões sobre Estilo de Gestão do Conhecimento (Parte 4 de 5)}

As questões abaixo referem-se ao estilo de gestão do conhecimento presente em sua empresa. Por favor, avalie as sentenças a seguir desde (1) discordo totalmente até (5) concordo totalmente.

O conhecimento no presente estudo deve ser entendido como uma transformação de informações em instruções que podem auxiliar nas tarefas nos níveis estratégico, tático e operacional. Exemplos: know-how de um colaborador, habilidades técnicas de um colaborador, métodos de solução de problemas, processos de análise de dados, entre outros.

18. Estilo de Gestão do Conhecimento 


\begin{tabular}{|c|c|c|c|c|c|}
\hline Questões & $\begin{array}{c}\text { Discordo } \\
\text { plenamente }\end{array}$ & $\begin{array}{c}\text { Discordo } \\
\text { parcialmente }\end{array}$ & Indiferente & $\begin{array}{c}\text { Concordo } \\
\text { parcialmente }\end{array}$ & $\begin{array}{r}\text { Concordo } \\
\text { plenamente }\end{array}$ \\
\hline $\begin{array}{l}\text { O conhecimento (know-how, habilidades técnicas ou métodos } \\
\text { de solução de problemas) é bem documentado na minha } \\
\text { empresa. }\end{array}$ & & & & & \\
\hline $\begin{array}{l}\text { O conhecimento é adquirido facilmente por meio de documentos } \\
\text { formais e manuais na minha empresa. }\end{array}$ & & & & & \\
\hline $\begin{array}{l}\text { Os resultados de projetos e reuniões são documentados na } \\
\text { minha empresa. }\end{array}$ & & & & & \\
\hline $\begin{array}{l}\text { O conhecimento é compartilhado, principalmente, por meios } \\
\text { codificados, como manuais e documentos na minha empresa. }\end{array}$ & & & & & \\
\hline $\begin{array}{l}\text { Meu conhecimento é facilmente adquirido pelos meus pares na } \\
\text { minha empresa. }\end{array}$ & & & & & \\
\hline É fácil obter conselhos de especialistas na minha empresa. & & & & & \\
\hline $\begin{array}{l}\text { Conversas informais são as principais formas usadas para } \\
\text { compartilhar conhecimento na minha empresa. }\end{array}$ & & & & & \\
\hline $\begin{array}{l}\text { O conhecimento é obtido, principalmente, por um processo } \\
\text { individualizado de orientação em minha empresa. }\end{array}$ & & & & & \\
\hline
\end{tabular}

\section{Questões sobre Processos de Gestão do Conhecimento (Parte 4 de 5)}

\section{Criação do Conhecimento}

\begin{tabular}{|l|l|l|l|l|l|}
\hline \multicolumn{1}{|c|}{ Questões } & $\begin{array}{c}\text { Discordo } \\
\text { plenamente }\end{array}$ & $\begin{array}{c}\text { Discordo } \\
\text { parcialmente }\end{array}$ & Indiferente & $\begin{array}{c}\text { Concordo } \\
\text { parcialmente }\end{array}$ & $\begin{array}{c}\text { Concordo } \\
\text { plenamente }\end{array}$ \\
\hline $\begin{array}{l}\text { A empresa possui processos bem definidos para obter } \\
\text { informações do seu ambiente competitivo externo para gerar } \\
\text { conhecimentos para uso interno }\end{array}$ & & & & & \\
\hline $\begin{array}{l}\text { A empresa possui processos bem definidos que permitem um } \\
\text { trabalho de forma bastante interativa entre os seus } \\
\text { colaboradores. }\end{array}$ & & & & & \\
\hline $\begin{array}{l}\text { A empresa incentiva a formação de comunidades de } \\
\text { práticas (grupos de trabalho sobre um determinado assunto) } \\
\text { para desenvolver o conhecimento da organização em um } \\
\text { determinado assunto. }\end{array}$ & & & & & \\
\hline
\end{tabular}

\section{Aquisição do Conhecimento}

\begin{tabular}{|l|l|l|l|l|l|}
\hline \multicolumn{1}{|c|}{ Questões } & $\begin{array}{c}\text { Discordo } \\
\text { plenamente }\end{array}$ & $\begin{array}{c}\text { Discordo } \\
\text { parcialmente }\end{array}$ & Indiferente & $\begin{array}{c}\text { Concordo } \\
\text { parcialmente }\end{array}$ & $\begin{array}{c}\text { Concordo } \\
\text { plenamente }\end{array}$ \\
\hline $\begin{array}{l}\text { A empresa procura se reunir com seus clientes como objetivo } \\
\text { de identificar suas necessidades. }\end{array}$ & & & & & \\
\hline $\begin{array}{l}\text { A empresa tem processos para aquisição do conhecimento } \\
\text { sobre seus fornecedores. }\end{array}$ & & & & & \\
\hline $\begin{array}{l}\text { A empresa tem processos para aquisição do conhecimento } \\
\text { sobre o mercado em que atua. }\end{array}$ & & & & & \\
\hline $\begin{array}{l}\text { A empresa tem processos para gerar novos conhecimentos a } \\
\text { partir do conhecimento existente. }\end{array}$ & & & & & \\
\hline $\begin{array}{l}\text { A empresa tem processos que permitem que sejam capturadas } \\
\text { práticas de sucesso de outras organizações. }\end{array}$ & & & & & \\
\hline $\begin{array}{l}\text { A empresa tem processos para adquirir novos conhecimentos a } \\
\text { partir do conhecimento existente. }\end{array}$ & & & & & \\
\hline $\begin{array}{l}\text { Novas abordagens e ideias sobre o desempenho do trabalho } \\
\text { desenvolvido são discutidas e experimentadas continuamente. }\end{array}$ & & & & & \\
\hline $\begin{array}{l}\text { A empresa tem mecanismos para identificar o conhecimento dos } \\
\text { seus colaboradores. }\end{array}$ & & & & & \\
\hline
\end{tabular}

\section{Armazenamento do Conhecimento}




\begin{tabular}{|c|c|c|c|c|c|}
\hline Questões & $\begin{array}{c}\text { Discordo } \\
\text { plenamente }\end{array}$ & $\begin{array}{c}\text { Discordo } \\
\text { parcialmente }\end{array}$ & Indiferente & $\begin{array}{c}\text { Concordo } \\
\text { parcialmente }\end{array}$ & $\begin{array}{c}\text { Concordo } \\
\text { plenamente }\end{array}$ \\
\hline $\begin{array}{l}\text { A empresa tem mecanismos para armazenar o conhecimento } \\
\text { criado. }\end{array}$ & & & & & \\
\hline $\begin{array}{l}\text { A empresa tem mecanismos para armazenar o conhecimento } \\
\text { adquirido. }\end{array}$ & & & & & \\
\hline $\begin{array}{l}\text { A empresa tem mecanismos para codificar o conhecimento } \mathrm{d} \\
\text { forma que esse possa ser armazenado. }\end{array}$ & & & & & \\
\hline $\begin{array}{l}\text { O conhecimento armazenado pode ser usado por outros } \\
\text { indivíduos, além do originador desse conhecimento. }\end{array}$ & & & & & \\
\hline $\begin{array}{l}\text { A empresa tem mecanismos que permitem a recuperação do } \\
\text { conhecimento de forma eficaze eficiente. }\end{array}$ & & & & & \\
\hline
\end{tabular}

\section{Compartilhamento do Conhecimento}

\begin{tabular}{|c|c|c|c|c|c|}
\hline Questões & $\begin{array}{c}\text { Discordo } \\
\text { plenamente }\end{array}$ & $\begin{array}{c}\text { Discordo } \\
\text { parcialmente }\end{array}$ & Indiferente & $\begin{array}{c}\text { Concordo } \\
\text { parcialmente }\end{array}$ & $\begin{array}{r}\text { Concordo } \\
\text { plenamente }\end{array}$ \\
\hline \multicolumn{6}{|l|}{$\begin{array}{l}\text { Reuniões são periodicamente agendadas para informa todos os } \\
\text { colaboradores sobre as últimas inovações da empresa }\end{array}$} \\
\hline \multicolumn{6}{|l|}{$\begin{array}{l}\text { A empresa tem mecanis mos formais para garantir o } \\
\text { compartilhamento de boas práticas. }\end{array}$} \\
\hline \multicolumn{6}{|l|}{$\begin{array}{l}\text { Existem especialistas que são responsáveis por dis seminar o } \\
\text { conhecimento para o restante da equipe. }\end{array}$} \\
\hline \multicolumn{6}{|l|}{$\begin{array}{l}\text { Existem indivíduos responsáveis por coletar internamente } \\
\text { sugestões dos colaboradores. }\end{array}$} \\
\hline \multicolumn{6}{|l|}{$\begin{array}{l}\text { Existem indivíduos responsáveis por juntar internamente } \\
\text { sugestões dos colaboradores. }\end{array}$} \\
\hline \multicolumn{6}{|l|}{$\begin{array}{l}\text { Existem indivíduos responsáveis por distribuir internamente } \\
\text { sugestões dos colaboradores. }\end{array}$} \\
\hline \multicolumn{6}{|l|}{$\begin{array}{l}\text { A empresa possui mecanismos que permitem que o } \\
\text { conhecimento seja compartilhado entre eventuais subsidárias. }\end{array}$} \\
\hline \multicolumn{6}{|l|}{$\begin{array}{l}\text { A empresa tem mecanis mos para disseminar o conhecimento } \\
\text { com stakeholders externos à organização. }\end{array}$} \\
\hline \multicolumn{6}{|l|}{$\begin{array}{l}\text { A empresa possui mecanismos que facilitam a interação entre } \\
\text { seus colaboradores. }\end{array}$} \\
\hline $\begin{array}{l}\text { A empresa possui mecanismos que facilitam a colaboração entre } \\
\text { seus colaboradores. }\end{array}$ & & & & & \\
\hline
\end{tabular}

\section{Aplicação do Conhecimento}

\begin{tabular}{|l|l|l|l|l|l|}
\hline \multicolumn{1}{|c|}{ Questões } & $\begin{array}{c}\text { Discordo } \\
\text { plenamente }\end{array}$ & $\begin{array}{c}\text { Discordo } \\
\text { parcialmente }\end{array}$ & Indiferente & $\begin{array}{c}\text { Concordo } \\
\text { parcialmente }\end{array}$ & $\begin{array}{c}\text { Concordo } \\
\text { plenamente }\end{array}$ \\
\hline $\begin{array}{l}\text { A empresa possui processos para aplicar o conhecimento } \\
\text { aprendido a partir de experiências nas atividades do dia a dia. }\end{array}$ & & & & & \\
\hline $\begin{array}{l}\text { A empresa facilita o acesso ao conhecimento para aqueles que } \\
\text { precisam dele }\end{array}$ & & & & & \\
\hline $\begin{array}{l}\text { A empresa possui processos para utilizar o conhecimento no } \\
\text { desenvolvimento de novos produtos e/ou serviços. }\end{array}$ & & & & & \\
\hline $\begin{array}{l}\text { A empresa tem capacidade de identificar e aplicar o } \\
\text { conhecimento para mudar as condições de concorrência por } \\
\text { meio de novas capacidades de TI. }\end{array}$ & & & & & \\
\hline
\end{tabular}

\section{Proteção do Conhecimento}

\begin{tabular}{|l|l|l|l|l|l|}
\hline \multicolumn{1}{|c|}{ Questões } & $\begin{array}{c}\text { Discordo } \\
\text { plenamente }\end{array}$ & $\begin{array}{c}\text { Discordo } \\
\text { parcialmente }\end{array}$ & Indiferente & $\begin{array}{c}\text { Concordo } \\
\text { parcialmente }\end{array}$ & $\begin{array}{c}\text { Concordo } \\
\text { plenamente }\end{array}$ \\
\hline $\begin{array}{l}\text { A empresa possui mecanismos para retenção de seus } \\
\text { colaboradores. }\end{array}$ & & & & & \\
\hline $\begin{array}{l}\text { A empresa possui mecanismos para controlar o acesso a bases } \\
\text { de conhecimento. }\end{array}$ & & & & & \\
\hline $\begin{array}{l}\text { A empresa valoriza os seus colaboradores pelo conhecimento } \\
\text { que eles possuem. }\end{array}$ & & & & & \\
\hline
\end{tabular}




\section{APÊNDICE 5 - CARGAS CRUZADAS MODELO A}

\begin{tabular}{|c|c|c|c|c|c|c|c|c|c|c|c|}
\hline Indicadores & CP_INFRA_TI & CP_OPER_TI & CP_RH_TI & CP_TI & GC & GC_APLI & GC_AQUI & GC_ARMG & GC_COMP & GC_CRIA & GC_PROT \\
\hline CP_INFRA_TI_1 & 0,748 & 0,149 & 0,343 & 0,434 & 0,17 & 0,095 & 0,108 & 0,137 & 0,231 & 0,181 & 0,072 \\
\hline CP_INFRA_TI_2 & 0,703 & 0,137 & 0,335 & 0,409 & 0,116 & 0,071 & 0,049 & 0,1 & 0,177 & 0,146 & 0,005 \\
\hline CP_INFRA_TI_3 & 0,813 & 0,413 & 0,514 & 0,664 & 0,436 & 0,336 & 0,404 & 0,312 & 0,453 & 0,406 & 0,324 \\
\hline CP_INFRA_TI_4 & 0,701 & 0,376 & 0,495 & 0,601 & 0,369 & 0,273 & 0,326 & 0,37 & 0,349 & 0,318 & 0,274 \\
\hline CP_INFRA_TI_5 & 0,652 & 0,332 & 0,497 & 0,564 & 0,393 & 0,331 & 0,388 & 0,36 & 0,339 & 0,357 & 0,263 \\
\hline CP_OPER_TI_1 & 0,339 & 0,868 & 0,381 & 0,726 & 0,483 & 0,434 & 0,484 & 0,338 & 0,47 & 0,393 & 0,347 \\
\hline CP_OPER_TI_2 & 0,377 & 0,899 & 0,399 & 0,761 & 0,475 & 0,438 & 0,483 & 0,359 & 0,434 & 0,404 & 0,321 \\
\hline CP_OPER_TI_3 & 0,342 & 0,912 & 0,416 & 0,764 & 0,542 & 0,505 & 0,555 & 0,411 & 0,499 & 0,442 & 0,356 \\
\hline CP_OPER_TI_4 & 0,326 & 0,88 & 0,375 & 0,728 & 0,551 & 0,475 & 0,578 & 0,368 & 0,511 & 0,507 & 0,411 \\
\hline CP_OPER_TI_5 & 0,389 & 0,864 & 0,356 & 0,731 & 0,565 & 0,491 & 0,597 & 0,405 & 0,5 & 0,56 & 0,381 \\
\hline CP_OPER_TI_6 & 0,415 & 0,836 & 0,495 & 0,774 & 0,533 & 0,497 & 0,503 & 0,406 & 0,496 & 0,481 & 0,402 \\
\hline CP_RH_TI_1 & 0,45 & 0,281 & 0,814 & 0,588 & 0,408 & 0,338 & 0,362 & 0,397 & 0,358 & 0,366 & 0,342 \\
\hline CP_RH_TI_2 & 0,573 & 0,392 & 0,863 & 0,703 & 0,421 & 0,332 & 0,329 & 0,425 & 0,396 & 0,397 & 0,354 \\
\hline CP_RH_TI_3 & 0,502 & 0,389 & 0,799 & 0,661 & 0,596 & 0,482 & 0,558 & 0,462 & 0,574 & 0,536 & 0,501 \\
\hline CP_RH_TI_4 & 0,537 & 0,463 & 0,862 & 0,733 & 0,574 & 0,51 & 0,492 & 0,562 & 0,518 & 0,466 & 0,467 \\
\hline GC_APLI_1 & 0,287 & 0,374 & 0,349 & 0,423 & 0,711 & 0,83 & 0,632 & 0,556 & 0,632 & 0,611 & 0,478 \\
\hline GC_APLI_2 & 0,235 & 0,483 & 0,455 & 0,507 & 0,797 & 0,882 & 0,671 & 0,697 & 0,721 & 0,604 & 0,622 \\
\hline GC_APLI_3 & 0,377 & 0,455 & 0,518 & 0,558 & 0,834 & 0,903 & 0,736 & 0,713 & 0,728 & 0,711 & 0,626 \\
\hline GC_APLI_4 & 0,241 & 0,554 & 0,395 & 0,527 & 0,742 & 0,839 & 0,691 & 0,588 & 0,643 & 0,588 & 0,55 \\
\hline GC_AQUI_1 & 0,086 & 0,375 & 0,339 & 0,36 & 0,551 & 0,464 & 0,641 & 0,401 & 0,472 & 0,451 & 0,383 \\
\hline GC_AQUI_2 & 0,299 & 0,515 & 0,409 & 0,528 & 0,722 & 0,641 & 0,812 & 0,5 & 0,637 & 0,644 & 0,441 \\
\hline GC_AQUI_3 & 0,348 & 0,613 & 0,399 & 0,594 & 0,71 & 0,616 & 0,824 & 0,502 & 0,613 & 0,593 & 0,458 \\
\hline GC_AQUI_4 & 0,377 & 0,498 & 0,369 & 0,528 & 0,728 & 0,628 & 0,823 & 0,523 & 0,633 & 0,657 & 0,457 \\
\hline GC_AQUI_5 & 0,373 & 0,458 & 0,429 & 0,526 & 0,787 & 0,677 & 0,863 & 0,619 & 0,668 & 0,711 & 0,518 \\
\hline GC_AQUI_6 & 0,332 & 0,461 & 0,446 & 0,522 & 0,799 & 0,692 & 0,876 & 0,632 & 0,662 & 0,703 & 0,587 \\
\hline GC_AQUI_7 & 0,291 & 0,483 & 0,515 & 0,546 & 0,789 & 0,692 & 0,822 & 0,623 & 0,692 & 0,646 & 0,618 \\
\hline GC_AQUI_8 & 0,356 & 0,544 & 0,472 & 0,584 & 0,8 & 0,697 & 0,819 & 0,655 & 0,697 & 0,697 & 0,594 \\
\hline GC_ARMG_1 & 0,332 & 0,434 & 0,511 & 0,529 & 0,744 & 0,637 & 0,598 & 0,91 & 0,605 & 0,592 & 0,636 \\
\hline GC_ARMG_2 & 0,312 & 0,412 & 0,464 & 0,494 & 0,778 & 0,709 & 0,65 & 0,911 & 0,626 & 0,622 & 0,631 \\
\hline GC_ARMG_3 & 0,397 & 0,394 & 0,534 & 0,534 & 0,781 & 0,66 & 0,645 & 0,905 & 0,657 & 0,633 & 0,646 \\
\hline GC_ARMG_4 & 0,339 & 0,365 & 0,513 & 0,492 & 0,756 & 0,673 & 0,591 & 0,873 & 0,649 & 0,575 & 0,669 \\
\hline GC_ARMG_5 & 0,302 & 0,334 & 0,46 & 0,446 & 0,748 & 0,631 & 0,602 & 0,859 & 0,623 & 0,634 & 0,676 \\
\hline GC_COMP_1 & 0,332 & 0,437 & 0,459 & 0,512 & 0,703 & 0,607 & 0,645 & 0,49 & 0,742 & 0,593 & 0,503 \\
\hline GC_COMP_2 & 0,308 & 0,426 & 0,496 & 0,512 & 0,807 & 0,73 & 0,692 & 0,643 & 0,813 & 0,699 & 0,602 \\
\hline GC_COMP_3 & 0,35 & 0,398 & 0,495 & 0,509 & 0,77 & 0,653 & 0,658 & 0,627 & 0,801 & 0,628 & 0,58 \\
\hline GC_COMP_4 & 0,414 & 0,443 & 0,406 & 0,521 & 0,75 & 0,575 & 0,639 & 0,554 & 0,842 & 0,667 & 0,512 \\
\hline GC_COMP_5 & 0,362 & 0,493 & 0,399 & 0,531 & 0,754 & 0,612 & 0,649 & 0,541 & 0,848 & 0,63 & 0,519 \\
\hline GC_COMP_6 & 0,309 & 0,449 & 0,401 & 0,491 & 0,744 & 0,638 & 0,631 & 0,513 & 0,841 & 0,639 & 0,491 \\
\hline GC_COMP_7 & 0,421 & 0,392 & 0,414 & 0,497 & 0,69 & 0,606 & 0,558 & 0,524 & 0,772 & 0,546 & 0,489 \\
\hline GC_COMP_8 & 0,352 & 0,468 & 0,411 & 0,518 & 0,725 & 0,626 & 0,61 & 0,569 & 0,781 & 0,549 & 0,55 \\
\hline GC_COMP_9 & 0,403 & 0,431 & 0,471 & 0,535 & 0,685 & 0,596 & 0,551 & 0,557 & 0,738 & 0,521 & 0,547 \\
\hline GC_COMP_10 & 0,34 & 0,46 & 0,459 & 0,527 & 0,724 & 0,625 & 0,595 & 0,6 & 0,757 & 0,573 & 0,584 \\
\hline GC_CRIA_1 & 0,336 & 0,494 & 0,401 & 0,524 & 0,702 & 0,608 & 0,661 & 0,541 & 0,601 & 0,841 & 0,536 \\
\hline GC_CRIA_2 & 0,314 & 0,423 & 0,464 & 0,501 & 0,77 & 0,65 & 0,701 & 0,632 & 0,688 & 0,895 & 0,53 \\
\hline GC_CRIA_3 & 0,407 & 0,44 & 0,488 & 0,547 & 0,719 & 0,604 & 0,659 & 0,576 & 0,658 & 0,817 & 0,492 \\
\hline GC_PROT_1 & 0,277 & 0,345 & 0,405 & 0,424 & 0,649 & 0,534 & 0,549 & 0,6 & 0,551 & 0,506 & 0,865 \\
\hline GC_PROT_2 & 0,285 & 0,271 & 0,436 & 0,396 & 0,597 & 0,518 & 0,425 & 0,613 & 0,515 & 0,507 & 0,777 \\
\hline GC_PROT_3 & 0,136 & 0,396 & 0,365 & 0,396 & 0,627 & 0,54 & 0,538 & 0,546 & 0,564 & 0,456 & 0,763 \\
\hline
\end{tabular}




\section{APÊNDICE 6 - CARGAS CRUZADAS MODELO B}

\begin{tabular}{|c|c|c|c|c|c|c|c|c|c|c|c|}
\hline Indicadores & CP_INFRA_TI & CP_OPER_TI & CP_RH_TI & CP_TI & GC & GC_APLI & GC_AQUI & GC_ARMG & GC_COMP & GC_CRIA & GC_PROT \\
\hline CP_INFRA_TI_1 & 0,790 & 0,149 & 0,344 & 0,430 & 0,176 & 0,095 & 0,131 & 0,137 & 0,231 & 0,181 & 0,073 \\
\hline CP_INFRA_TI_2 & 0,752 & 0,137 & 0,335 & 0,408 & 0,123 & 0,071 & 0,072 & 0,100 & 0,177 & 0,146 & 0,006 \\
\hline CP_INFRA_TI_3 & 0,829 & 0,413 & 0,514 & 0,660 & 0,440 & 0,336 & 0,421 & 0,312 & 0,453 & 0,406 & 0,324 \\
\hline CP_INFRA_TI_4 & 0,716 & 0,376 & 0,495 & 0,600 & 0,371 & 0,273 & 0,332 & 0,370 & 0,349 & 0,318 & 0,275 \\
\hline CP_OPER_TI_1 & 0,297 & 0,868 & 0,381 & 0,733 & 0,481 & 0,434 & 0,481 & 0,338 & 0,470 & 0,393 & 0,346 \\
\hline CP_OPER_TI_2 & 0,338 & 0,899 & 0,399 & 0,770 & 0,473 & 0,438 & 0,480 & 0,359 & 0,434 & 0,404 & 0,321 \\
\hline CP_OPER_TI_3 & 0,318 & 0,912 & 0,416 & 0,779 & 0,540 & 0,505 & 0,550 & 0,411 & 0,499 & 0,442 & 0,356 \\
\hline CP_OPER_TI_4 & 0,290 & 0,880 & 0,375 & 0,738 & 0,548 & 0,475 & 0,573 & 0,368 & 0,511 & 0,507 & 0,411 \\
\hline CP_OPER_TI_5 & 0,376 & 0,864 & 0,357 & 0,745 & 0,564 & 0,491 & 0,598 & 0,405 & 0,500 & 0,560 & 0,381 \\
\hline CP_OPER_TI_6 & 0,382 & 0,836 & 0,496 & 0,782 & 0,535 & 0,497 & 0,511 & 0,406 & 0,496 & 0,481 & 0,402 \\
\hline CP_RH_TI_1 & 0,394 & 0,281 & 0,813 & 0,576 & 0,406 & 0,338 & 0,356 & 0,397 & 0,358 & 0,366 & 0,342 \\
\hline CP_RH_TI_2 & 0,564 & 0,392 & 0,864 & 0,705 & 0,422 & 0,332 & 0,332 & 0,425 & 0,396 & 0,397 & 0,354 \\
\hline CP_RH_TI_3 & 0,445 & 0,389 & 0,798 & 0,650 & 0,593 & 0,483 & 0,548 & 0,462 & 0,574 & 0,536 & 0,501 \\
\hline CP_RH_TI_4 & 0,478 & 0,462 & 0,862 & 0,724 & 0,574 & 0,510 & 0,494 & 0,562 & 0,518 & 0,466 & 0,467 \\
\hline GC_APLI_1 & 0,264 & 0,374 & 0,348 & 0,423 & 0,712 & 0,830 & 0,636 & 0,556 & 0,632 & 0,611 & 0,478 \\
\hline GC_APLI_2 & 0,183 & 0,483 & 0,455 & 0,505 & 0,797 & 0,882 & 0,668 & 0,697 & 0,721 & 0,604 & 0,621 \\
\hline GC_APLI_3 & 0,332 & 0,455 & 0,518 & 0,553 & 0,837 & 0,903 & 0,746 & 0,713 & 0,728 & 0,711 & 0,626 \\
\hline GC_APLI_4 & 0,184 & 0,554 & 0,395 & 0,525 & 0,740 & 0,839 & 0,687 & 0,588 & 0,643 & 0,588 & 0,550 \\
\hline GC_AQUI_2 & 0,260 & 0,516 & 0,409 & 0,528 & 0,715 & 0,641 & 0,798 & 0,500 & 0,637 & 0,644 & 0,441 \\
\hline GC_AQUI_3 & 0,304 & 0,613 & 0,399 & 0,593 & 0,707 & 0,616 & 0,824 & 0,502 & 0,613 & 0,593 & 0,458 \\
\hline GC_AQUI_4 & 0,312 & 0,498 & 0,369 & 0,517 & 0,727 & 0,628 & 0,830 & 0,523 & 0,633 & 0,657 & 0,457 \\
\hline GC_AQUI_5 & 0,329 & 0,458 & 0,428 & 0,521 & 0,788 & 0,677 & 0,879 & 0,619 & 0,668 & 0,711 & 0,518 \\
\hline GC_AQUI_6 & 0,282 & 0,461 & 0,446 & 0,516 & 0,798 & 0,692 & 0,887 & 0,632 & 0,662 & 0,703 & 0,586 \\
\hline GC_AQUI_7 & 0,231 & 0,483 & 0,515 & 0,541 & 0,787 & 0,692 & 0,822 & 0,623 & 0,692 & 0,646 & 0,618 \\
\hline GC_AQUI_8 & 0,316 & 0,544 & 0,472 & 0,583 & 0,799 & 0,697 & 0,821 & 0,655 & 0,697 & 0,697 & 0,594 \\
\hline GC_ARMG_1 & 0,281 & 0,434 & 0,511 & 0,523 & 0,746 & 0,637 & 0,602 & 0,910 & 0,605 & 0,592 & 0,636 \\
\hline GC_ARMG_2 & 0,266 & 0,412 & 0,464 & 0,489 & 0,781 & 0,709 & 0,657 & 0,911 & 0,626 & 0,622 & 0,631 \\
\hline GC_ARMG_3 & 0,354 & 0,394 & 0,534 & 0,528 & 0,783 & 0,660 & 0,646 & 0,905 & 0,657 & 0,633 & 0,646 \\
\hline GC_ARMG_4 & 0,291 & 0,365 & 0,512 & 0,485 & 0,757 & 0,673 & 0,590 & 0,873 & 0,649 & 0,575 & 0,669 \\
\hline GC_ARMG_5 & 0,257 & 0,335 & 0,459 & 0,439 & 0,749 & 0,631 & 0,601 & 0,859 & 0,623 & 0,634 & 0,676 \\
\hline GC_COMP_1 & 0,309 & 0,437 & 0,459 & 0,514 & 0,702 & 0,607 & 0,642 & 0,490 & 0,742 & 0,593 & 0,503 \\
\hline GC_COMP_10 & 0,272 & 0,460 & 0,458 & 0,517 & 0,724 & 0,625 & 0,593 & 0,600 & 0,757 & 0,573 & 0,583 \\
\hline GC_COMP_2 & 0,264 & 0,426 & 0,495 & 0,509 & 0,806 & 0,730 & 0,685 & 0,643 & 0,813 & 0,699 & 0,602 \\
\hline GC_COMP_3 & 0,329 & 0,398 & 0,495 & 0,510 & 0,770 & 0,653 & 0,655 & 0,627 & 0,801 & 0,628 & 0,580 \\
\hline GC_COMP_4 & 0,399 & 0,443 & 0,406 & 0,522 & 0,751 & 0,576 & 0,640 & 0,554 & 0,842 & 0,667 & 0,511 \\
\hline GC_COMP_5 & 0,372 & 0,493 & 0,399 & 0,542 & 0,755 & 0,612 & 0,651 & 0,541 & 0,848 & 0,630 & 0,519 \\
\hline GC_COMP_6 & 0,316 & 0,449 & 0,401 & 0,501 & 0,746 & 0,638 & 0,634 & 0,513 & 0,841 & 0,639 & 0,490 \\
\hline GC_COMP_7 & 0,406 & 0,392 & 0,414 & 0,496 & 0,694 & 0,606 & 0,567 & 0,524 & 0,772 & 0,546 & 0,489 \\
\hline GC_COMP_8 & 0,331 & 0,468 & 0,411 & 0,520 & 0,725 & 0,626 & 0,611 & 0,569 & 0,782 & 0,549 & 0,550 \\
\hline GC_COMP_9 & 0,338 & 0,431 & 0,471 & 0,522 & 0,687 & 0,596 & 0,554 & 0,557 & 0,738 & 0,521 & 0,547 \\
\hline GC_CRIA_1 & 0,312 & 0,494 & 0,401 & 0,526 & 0,703 & 0,608 & 0,666 & 0,541 & 0,601 & 0,841 & 0,536 \\
\hline GC_CRIA_2 & 0,257 & 0,423 & 0,464 & 0,494 & 0,770 & 0,650 & 0,703 & 0,632 & 0,688 & 0,895 & 0,530 \\
\hline GC_CRIA_3 & 0,375 & 0,440 & 0,487 & 0,544 & 0,720 & 0,604 & 0,660 & 0,576 & 0,658 & 0,817 & 0,493 \\
\hline GC_PROT_1 & 0,259 & 0,345 & 0,405 & 0,425 & 0,652 & 0,534 & 0,558 & 0,600 & 0,551 & 0,506 & 0,866 \\
\hline GC_PROT_2 & 0,288 & 0,271 & 0,436 & 0,401 & 0,600 & 0,518 & 0,428 & 0,613 & 0,515 & 0,507 & 0,778 \\
\hline GC_PROT_3 & 0,066 & 0,396 & 0,364 & 0,388 & 0,624 & 0,540 & 0,526 & 0,546 & 0,564 & 0,456 & 0,761 \\
\hline
\end{tabular}




\section{APÊNDICE 7 - CARGAS CRUZADAS MODELO C}

\begin{tabular}{|c|c|c|c|c|c|c|c|c|c|c|c|c|c|}
\hline Indicadores & CP_INFRA_TI & CP_OPER_TI & CP_RH_TI & CP_TI & GC & GC_APLI & GC_AQUI & GC_ARMG & GC_COMP & GC_CRIA & GC_PROT & MOD_EFCT_1 & ORIEN_EXPL \\
\hline CP_INFRA_TI_1 & 0,790 & 0,149 & 0,344 & 0,430 & 0,176 & 0,095 & 0,131 & 0,137 & 0,231 & 0,181 & 0,073 & $-0,047$ & 0,111 \\
\hline CP_INFRA_TI_2 & 0,752 & 0,137 & 0,335 & 0,408 & 0,123 & 0,071 & 0,072 & 0,100 & 0,177 & 0,146 & 0,006 & $-0,134$ & 0,120 \\
\hline CP_INFRA_TI_3 & 0,829 & 0,413 & 0,514 & 0,660 & 0,440 & 0,336 & 0,421 & 0,312 & 0,453 & 0,406 & 0,324 & $-0,209$ & 0,361 \\
\hline CP_INFRA_TI_4 & 0,716 & 0,376 & 0,495 & 0,600 & 0,371 & 0,273 & 0,332 & 0,370 & 0,349 & 0,318 & 0,275 & $-0,081$ & 0,282 \\
\hline CP_OPER_TI_1 & 0,297 & 0,868 & 0,381 & 0,733 & 0,481 & 0,434 & 0,481 & 0,338 & 0,470 & 0,393 & 0,346 & $-0,223$ & 0,312 \\
\hline CP_OPER_TI_2 & 0,338 & 0,899 & 0,399 & 0,770 & 0,473 & 0,438 & 0,480 & 0,359 & 0,434 & 0,404 & 0,321 & $-0,231$ & 0,359 \\
\hline CP_OPER_TI_3 & 0,318 & 0,912 & 0,416 & 0,779 & 0,539 & 0,505 & 0,550 & 0,411 & 0,499 & 0,442 & 0,356 & $-0,249$ & 0,375 \\
\hline CP_OPER_TI_4 & 0,290 & 0,880 & 0,375 & 0,738 & 0,548 & 0,475 & 0,573 & 0,368 & 0,511 & 0,507 & 0,411 & $-0,221$ & 0,382 \\
\hline CP_OPER_TI_5 & 0,376 & 0,864 & 0,357 & 0,745 & 0,564 & 0,491 & 0,598 & 0,405 & 0,500 & 0,560 & 0,381 & $-0,135$ & 0,439 \\
\hline CP_OPER_TI_6 & 0,382 & 0,836 & 0,496 & 0,782 & 0,535 & 0,496 & 0,511 & 0,406 & 0,496 & 0,481 & 0,402 & $-0,252$ & 0,386 \\
\hline CP_RH_TI_1 & 0,394 & 0,281 & 0,813 & 0,576 & 0,407 & 0,338 & 0,356 & 0,397 & 0,358 & 0,366 & 0,342 & $-0,232$ & 0,390 \\
\hline CP_RH_TI_2 & 0,564 & 0,392 & 0,864 & 0,705 & 0,423 & 0,332 & 0,332 & 0,425 & 0,396 & 0,397 & 0,354 & $-0,238$ & 0,357 \\
\hline CP_RH_TI_3 & 0,445 & 0,389 & 0,798 & 0,650 & 0,593 & 0,483 & 0,548 & 0,462 & 0,574 & 0,536 & 0,501 & $-0,194$ & 0,557 \\
\hline CP_RH_TI_4 & 0,478 & 0,462 & 0,862 & 0,724 & 0,574 & 0,510 & 0,494 & 0,562 & 0,518 & 0,466 & 0,467 & $-0,295$ & 0,451 \\
\hline MOD_EFCT_1 & $-0,161$ & $-0,250$ & $-0,288$ & $-0,298$ & $-0,172$ & $-0,168$ & $-0,141$ & $-0,194$ & $-0,124$ & $-0,097$ & $-0,241$ & 1,000 & $-0,217$ \\
\hline EST_GC_1 & 0,242 & 0,410 & 0,461 & 0,480 & 0,713 & 0,593 & 0,630 & 0,669 & 0,640 & 0,647 & 0,595 & $-0,221$ & 0,886 \\
\hline EST_GC_2 & 0,248 & 0,380 & 0,456 & 0,463 & 0,706 & 0,611 & 0,579 & 0,647 & 0,652 & 0,659 & 0,615 & $-0,195$ & 0,918 \\
\hline EST_GC_3 & 0,325 & 0,360 & 0,537 & 0,502 & 0,722 & 0,608 & 0,626 & 0,682 & 0,647 & 0,666 & 0,599 & $-0,187$ & 0,903 \\
\hline EST_GC_7 & 0,274 & 0,347 & 0,369 & 0,418 & 0,614 & 0,498 & 0,528 & 0,544 & 0,573 & 0,611 & 0,495 & $-0,152$ & 0,785 \\
\hline GC_APLI_1 & 0,264 & 0,374 & 0,348 & 0,423 & 0,712 & 0,830 & 0,636 & 0,556 & 0,632 & 0,611 & 0,478 & $-0,083$ & 0,528 \\
\hline GC_APLI_2 & 0,183 & 0,483 & 0,455 & 0,505 & 0,796 & 0,882 & 0,668 & 0,697 & 0,721 & 0,604 & 0,621 & $-0,172$ & 0,625 \\
\hline GC_APLI_3 & 0,332 & 0,455 & 0,518 & 0,553 & 0,837 & 0,903 & 0,746 & 0,713 & 0,728 & 0,711 & 0,626 & $-0,171$ & 0,662 \\
\hline GC_APLI_4 & 0,184 & 0,554 & 0,395 & 0,525 & 0,739 & 0,839 & 0,687 & 0,588 & 0,643 & 0,588 & 0,550 & $-0,148$ & 0,460 \\
\hline GC_AQUI_2 & 0,260 & 0,516 & 0,409 & 0,528 & 0,715 & 0,641 & 0,798 & 0,500 & 0,637 & 0,644 & 0,441 & $-0,106$ & 0,545 \\
\hline GC_AQUI_3 & 0,304 & 0,613 & 0,399 & 0,593 & 0,706 & 0,616 & 0,824 & 0,502 & 0,613 & 0,593 & 0,458 & $-0,131$ & 0,475 \\
\hline GC_AQUI_4 & 0,312 & 0,498 & 0,369 & 0,517 & 0,726 & 0,628 & 0,830 & 0,523 & 0,633 & 0,657 & 0,457 & $-0,041$ & 0,500 \\
\hline GC_AQUI_5 & 0,329 & 0,458 & 0,428 & 0,521 & 0,788 & 0,677 & 0,879 & 0,619 & 0,668 & 0,711 & 0,518 & $-0,049$ & 0,620 \\
\hline GC_AQUI_6 & 0,282 & 0,461 & 0,446 & 0,516 & 0,798 & 0,692 & 0,887 & 0,632 & 0,662 & 0,703 & 0,586 & $-0,157$ & 0,643 \\
\hline GC_AQUI_7 & 0,231 & 0,483 & 0,515 & 0,541 & 0,787 & 0,692 & 0,822 & 0,623 & 0,692 & 0,646 & 0,618 & $-0,192$ & 0,572 \\
\hline GC_AQUI_8 & 0,316 & 0,544 & 0,472 & 0,583 & 0,799 & 0,697 & 0,821 & 0,655 & 0,697 & 0,697 & 0,594 & $-0,145$ & 0,600 \\
\hline GC_ARMG_1 & 0,281 & 0,434 & 0,511 & 0,523 & 0,747 & 0,637 & 0,602 & 0,910 & 0,605 & 0,592 & 0,636 & $-0,201$ & 0,651 \\
\hline GC_ARMG_2 & 0,266 & 0,412 & 0,464 & 0,489 & 0,781 & 0,709 & 0,657 & 0,911 & 0,626 & 0,622 & 0,631 & $-0,174$ & 0,669 \\
\hline GC_ARMG_3 & 0,354 & 0,394 & 0,534 & 0,528 & 0,783 & 0,660 & 0,647 & 0,905 & 0,657 & 0,633 & 0,646 & $-0,175$ & 0,664 \\
\hline GC_ARMG_4 & 0,291 & 0,365 & 0,512 & 0,485 & 0,757 & 0,673 & 0,590 & 0,873 & 0,649 & 0,575 & 0,669 & $-0,168$ & 0,620 \\
\hline GC_ARMG_5 & 0,257 & 0,335 & 0,459 & 0,439 & 0,750 & 0,631 & 0,601 & 0,859 & 0,623 & 0,634 & 0,676 & $-0,146$ & 0,647 \\
\hline GC_COMP_1 & 0,309 & 0,437 & 0,459 & 0,514 & 0,702 & 0,607 & 0,642 & 0,490 & 0,742 & 0,593 & 0,503 & $-0,154$ & 0,567 \\
\hline GC_COMP_10 & 0,272 & 0,460 & 0,458 & 0,517 & 0,724 & 0,625 & 0,593 & 0,600 & 0,757 & 0,573 & 0,583 & $-0,182$ & 0,549 \\
\hline GC_COMP_2 & 0,264 & 0,426 & 0,495 & 0,509 & 0,806 & 0,730 & 0,685 & 0,643 & 0,813 & 0,699 & 0,602 & $-0,117$ & 0,672 \\
\hline GC_COMP_3 & 0,329 & 0,398 & 0,495 & 0,510 & 0,770 & 0,653 & 0,655 & 0,627 & 0,801 & 0,628 & 0,580 & $-0,176$ & 0,615 \\
\hline GC_COMP_4 & 0,399 & 0,443 & 0,406 & 0,522 & 0,751 & 0,576 & 0,640 & 0,554 & 0,842 & 0,667 & 0,511 & $-0,088$ & 0,602 \\
\hline GC_COMP_5 & 0,372 & 0,493 & 0,399 & 0,542 & 0,755 & 0,612 & 0,651 & 0,541 & 0,848 & 0,630 & 0,519 & $-0,049$ & 0,578 \\
\hline GC_COMP_6 & 0,316 & 0,449 & 0,401 & 0,501 & 0,746 & 0,638 & 0,634 & 0,513 & 0,841 & 0,639 & 0,490 & $-0,030$ & 0,555 \\
\hline GC_COMP_7 & 0,406 & 0,392 & 0,414 & 0,496 & 0,693 & 0,606 & 0,567 & 0,524 & 0,772 & 0,546 & 0,489 & $-0,016$ & 0,527 \\
\hline GC_COMP_8 & 0,331 & 0,468 & 0,411 & 0,520 & 0,725 & 0,626 & 0,611 & 0,569 & 0,781 & 0,549 & 0,550 & $-0,029$ & 0,523 \\
\hline GC_COMP_9 & 0,338 & 0,431 & 0,471 & 0,522 & 0,687 & 0,596 & 0,554 & 0,557 & 0,738 & 0,521 & 0,547 & $-0,143$ & 0,505 \\
\hline GC_CRIA_1 & 0,312 & 0,494 & 0,401 & 0,526 & 0,703 & 0,608 & 0,666 & 0,541 & 0,601 & 0,841 & 0,536 & $-0,080$ & 0,581 \\
\hline GC_CRIA_2 & 0,257 & 0,423 & 0,464 & 0,494 & 0,770 & 0,650 & 0,703 & 0,632 & 0,688 & 0,895 & 0,530 & $-0,090$ & 0,709 \\
\hline GC_CRIA_3 & 0,375 & 0,440 & 0,487 & 0,544 & 0,720 & 0,604 & 0,660 & 0,576 & 0,658 & 0,817 & 0,493 & $-0,079$ & 0,591 \\
\hline GC_PROT_1 & 0,259 & 0,345 & 0,405 & 0,425 & 0,652 & 0,534 & 0,558 & 0,600 & 0,551 & 0,506 & 0,866 & $-0,180$ & 0,550 \\
\hline GC_PROT_2 & 0,288 & 0,271 & 0,436 & 0,401 & 0,601 & 0,518 & 0,428 & 0,613 & 0,515 & 0,507 & 0,778 & $-0,132$ & 0,522 \\
\hline GC_PROT_3 & 0,066 & 0,396 & 0,364 & 0,388 & 0,624 & 0,540 & 0,526 & 0,546 & 0,564 & 0,456 & 0,761 & $-0,268$ & 0,518 \\
\hline
\end{tabular}




\section{APÊNDICE 8 - CARGAS CRUZADAS MODELO D}

\begin{tabular}{|c|c|c|c|c|c|c|c|c|c|c|c|c|c|}
\hline Cross Loadings & CP_INFRA_TI & CP_OPER_TI & CP_RH_TI & CP_TI & GC & GC_APLI & GC_AQUI & GC_ARMG & GC_COMP & GC_CRIA & GC_PROT & MOD_EFCT_2 & PRE \\
\hline CP_INFRA_TI_1 & 0,790 & 0,149 & 0,344 & 0,430 & 0,176 & 0,095 & 0,131 & 0,137 & 0,231 & 0,181 & 0,073 & $-0,190$ & 0,343 \\
\hline CP_INFRA_TI_2 & 0,752 & 0,137 & 0,335 & 0,408 & 0,123 & 0,071 & 0,072 & 0,100 & 0,177 & 0,146 & 0,006 & $-0,199$ & 0,211 \\
\hline CP_INFRA_TI_3 & 0,829 & 0,413 & 0,514 & 0,660 & 0,440 & 0,336 & 0,421 & 0,312 & 0,453 & 0,406 & 0,324 & $-0,095$ & 0,198 \\
\hline CP_INFRA_TI_4 & 0,716 & 0,376 & 0,495 & 0,600 & 0,371 & 0,273 & 0,332 & 0,370 & 0,349 & 0,318 & 0,275 & $-0,083$ & 0,266 \\
\hline CP_OPER_TI_1 & 0,297 & 0,868 & 0,381 & 0,733 & 0,481 & 0,434 & 0,481 & 0,338 & 0,470 & 0,393 & 0,346 & $-0,114$ & 0,232 \\
\hline CP_OPER_TI_2 & 0,338 & 0,899 & 0,399 & 0,770 & 0,473 & 0,438 & 0,480 & 0,359 & 0,434 & 0,404 & 0,321 & $-0,142$ & 0,255 \\
\hline CP_OPER_TI_3 & 0,318 & 0,912 & 0,416 & 0,779 & 0,540 & 0,505 & 0,550 & 0,411 & 0,499 & 0,442 & 0,356 & $-0,129$ & 0,287 \\
\hline CP_OPER_TI_4 & 0,290 & 0,880 & 0,375 & 0,738 & 0,548 & 0,475 & 0,573 & 0,368 & 0,511 & 0,507 & 0,411 & $-0,038$ & 0,220 \\
\hline CP_OPER_TI_5 & 0,376 & 0,864 & 0,357 & 0,745 & 0,564 & 0,491 & 0,598 & 0,405 & 0,500 & 0,560 & 0,381 & $-0,075$ & 0,206 \\
\hline CP_OPER_TI_6 & 0,382 & 0,836 & 0,496 & 0,782 & 0,535 & 0,497 & 0,511 & 0,406 & 0,496 & 0,481 & 0,402 & $-0,112$ & 0,249 \\
\hline CP_RH_TI_1 & 0,394 & 0,281 & 0,813 & 0,576 & 0,406 & 0,338 & 0,356 & 0,397 & 0,358 & 0,366 & 0,342 & $-0,162$ & 0,175 \\
\hline CP_RH_TI_2 & 0,564 & 0,392 & 0,864 & 0,705 & 0,422 & 0,332 & 0,332 & 0,425 & 0,396 & 0,397 & 0,354 & $-0,196$ & 0,281 \\
\hline CP_RH_TI_3 & 0,445 & 0,389 & 0,798 & 0,650 & 0,593 & 0,483 & 0,548 & 0,462 & 0,574 & 0,536 & 0,501 & $-0,176$ & 0,295 \\
\hline CP_RH_TI_4 & 0,478 & 0,462 & 0,862 & 0,724 & 0,574 & 0,510 & 0,494 & 0,562 & 0,518 & 0,466 & 0,467 & $-0,113$ & 0,231 \\
\hline MOD_EFCT_2 & $-0,170$ & $-0,116$ & $-0,193$ & $-0,186$ & 0,009 & 0,036 & $-0,034$ & $-0,019$ & 0,037 & $-0,054$ & 0,109 & 1,000 & $-0,271$ \\
\hline GC_APLI_1 & 0,264 & 0,374 & 0,348 & 0,423 & 0,712 & 0,830 & 0,636 & 0,556 & 0,632 & 0,611 & 0,478 & 0,074 & 0,130 \\
\hline GC_APLI_2 & 0,183 & 0,483 & 0,455 & 0,505 & 0,796 & 0,882 & 0,668 & 0,697 & 0,721 & 0,604 & 0,621 & 0,090 & 0,127 \\
\hline GC_APLI_3 & 0,332 & 0,455 & 0,518 & 0,553 & 0,837 & 0,903 & 0,746 & 0,713 & 0,728 & 0,711 & 0,626 & $-0,052$ & 0,254 \\
\hline GC_APLI_4 & 0,184 & 0,554 & 0,395 & 0,525 & 0,740 & 0,839 & 0,687 & 0,588 & 0,643 & 0,588 & 0,550 & 0,021 & 0,219 \\
\hline GC_AQUI_2 & 0,260 & 0,516 & 0,409 & 0,528 & 0,715 & 0,641 & 0,798 & 0,500 & 0,637 & 0,644 & 0,441 & $-0,007$ & 0,225 \\
\hline GC_AQUI_3 & 0,304 & 0,613 & 0,399 & 0,593 & 0,707 & 0,616 & 0,825 & 0,502 & 0,613 & 0,593 & 0,458 & $-0,078$ & 0,191 \\
\hline GC_AQUI_4 & 0,312 & 0,498 & 0,369 & 0,517 & 0,727 & 0,628 & 0,830 & 0,523 & 0,633 & 0,657 & 0,457 & $-0,023$ & 0,271 \\
\hline GC_AQUI_5 & 0,329 & 0,458 & 0,428 & 0,521 & 0,788 & 0,677 & 0,879 & 0,619 & 0,668 & 0,711 & 0,518 & $-0,010$ & 0,184 \\
\hline GC_AQUI_6 & 0,282 & 0,461 & 0,446 & 0,516 & 0,798 & 0,692 & 0,887 & 0,632 & 0,662 & 0,703 & 0,586 & $-0,066$ & 0,161 \\
\hline GC_AQUI_7 & 0,231 & 0,483 & 0,515 & 0,541 & 0,787 & 0,692 & 0,822 & 0,623 & 0,692 & 0,646 & 0,618 & 0,005 & 0,156 \\
\hline GC_AQUI_8 & 0,316 & 0,544 & 0,472 & 0,583 & 0,799 & 0,697 & 0,821 & 0,655 & 0,697 & 0,697 & 0,594 & $-0,023$ & 0,149 \\
\hline GC_ARMG_1 & 0,281 & 0,434 & 0,511 & 0,523 & 0,746 & 0,637 & 0,602 & 0,910 & 0,604 & 0,592 & 0,636 & $-0,006$ & 0,138 \\
\hline GC_ARMG_2 & 0,266 & 0,412 & 0,464 & 0,489 & 0,780 & 0,709 & 0,657 & 0,911 & 0,626 & 0,622 & 0,631 & $-0,013$ & 0,118 \\
\hline GC_ARMG_3 & 0,354 & 0,394 & 0,534 & 0,528 & 0,782 & 0,660 & 0,646 & 0,905 & 0,657 & 0,633 & 0,646 & $-0,021$ & 0,143 \\
\hline GC_ARMG_4 & 0,291 & 0,365 & 0,512 & 0,485 & 0,757 & 0,673 & 0,590 & 0,873 & 0,649 & 0,575 & 0,669 & $-0,034$ & 0,231 \\
\hline GC_ARMG_5 & 0,257 & 0,335 & 0,459 & 0,439 & 0,749 & 0,631 & 0,601 & 0,859 & 0,623 & 0,634 & 0,676 & $-0,010$ & 0,122 \\
\hline GC_COMP_1 & 0,309 & 0,437 & 0,459 & 0,514 & 0,703 & 0,607 & 0,642 & 0,490 & 0,742 & 0,593 & 0,503 & $-0,067$ & 0,243 \\
\hline GC_COMP_2 & 0,264 & 0,426 & 0,495 & 0,509 & 0,806 & 0,730 & 0,685 & 0,643 & 0,813 & 0,699 & 0,602 & 0,058 & 0,164 \\
\hline GC_COMP_3 & 0,329 & 0,398 & 0,495 & 0,510 & 0,770 & 0,653 & 0,655 & 0,627 & 0,801 & 0,628 & 0,580 & $-0,023$ & 0,213 \\
\hline GC_COMP_4 & 0,399 & 0,443 & 0,406 & 0,522 & 0,751 & 0,576 & 0,640 & 0,554 & 0,842 & 0,667 & 0,511 & $-0,018$ & 0,238 \\
\hline GC_COMP_5 & 0,372 & 0,493 & 0,399 & 0,542 & 0,755 & 0,612 & 0,651 & 0,541 & 0,848 & 0,630 & 0,519 & 0,017 & 0,203 \\
\hline GC_COMP_6 & 0,316 & 0,449 & 0,401 & 0,501 & 0,746 & 0,638 & 0,634 & 0,513 & 0,842 & 0,639 & 0,490 & 0,009 & 0,209 \\
\hline GC_COMP_7 & 0,406 & 0,392 & 0,414 & 0,496 & 0,694 & 0,606 & 0,567 & 0,524 & 0,772 & 0,546 & 0,489 & 0,099 & 0,124 \\
\hline GC_COMP_8 & 0,331 & 0,468 & 0,411 & 0,520 & 0,725 & 0,626 & 0,611 & 0,569 & 0,781 & 0,549 & 0,550 & 0,113 & 0,105 \\
\hline GC_COMP_9 & 0,338 & 0,431 & 0,471 & 0,522 & 0,687 & 0,596 & 0,554 & 0,557 & 0,738 & 0,521 & 0,547 & 0,040 & 0,179 \\
\hline GC_COMP_10 & 0,272 & 0,460 & 0,458 & 0,517 & 0,724 & 0,625 & 0,593 & 0,600 & 0,757 & 0,573 & 0,583 & 0,073 & 0,145 \\
\hline GC_CRIA_1 & 0,312 & 0,494 & 0,401 & 0,526 & 0,703 & 0,608 & 0,666 & 0,541 & 0,601 & 0,841 & 0,536 & $-0,034$ & 0,213 \\
\hline GC_CRIA_2 & 0,257 & 0,423 & 0,464 & 0,494 & 0,770 & 0,650 & 0,703 & 0,632 & 0,688 & 0,895 & 0,530 & $-0,068$ & 0,115 \\
\hline GC_CRIA_3 & 0,375 & 0,440 & 0,487 & 0,544 & 0,720 & 0,604 & 0,660 & 0,576 & 0,658 & 0,817 & 0,493 & $-0,034$ & 0,162 \\
\hline GC_PROT_1 & 0,259 & 0,345 & 0,405 & 0,425 & 0,652 & 0,534 & 0,558 & 0,600 & 0,551 & 0,506 & 0,866 & 0,080 & 0,133 \\
\hline GC_PROT_2 & 0,288 & 0,271 & 0,436 & 0,401 & 0,600 & 0,518 & 0,428 & 0,613 & 0,515 & 0,507 & 0,778 & 0,125 & 0,104 \\
\hline GC_PROT_3 & 0,066 & 0,396 & 0,364 & 0,388 & 0,624 & 0,540 & 0,526 & 0,546 & 0,564 & 0,456 & 0,761 & 0,058 & 0,094 \\
\hline IMP_ESTG_TI_1 & 0,321 & 0,216 & 0,208 & 0,292 & 0,157 & 0,128 & 0,144 & 0,126 & 0,157 & 0,128 & 0,125 & $-0,229$ & 0,839 \\
\hline IMP_ESTG_TI_2 & 0,335 & 0,222 & 0,284 & 0,327 & 0,182 & 0,167 & 0,161 & 0,165 & 0,174 & 0,160 & 0,101 & $-0,287$ & 0,855 \\
\hline IMP_ESTG_TI_3 & 0,181 & 0,247 & 0,244 & 0,286 & 0,226 & 0,220 & 0,242 & 0,132 & 0,230 & 0,178 & 0,120 & $-0,176$ & 0,815 \\
\hline
\end{tabular}




\section{APÊNDICE 9 - CARGAS CRUZADAS MODELO E}

\begin{tabular}{|c|c|c|c|c|c|c|c|c|c|c|c|c|c|}
\hline Indicadores & CP_INFRA_TI & CP_OPER_TI & CP_RH_TI & CP_TI & GC & GC_APLI & GC_AQUI & GC_ARMG & GC_COMP & GC_CRIA & GC_PROT & MOD_EFCT_3 & FUT \\
\hline CP_INFRA_TI_1 & 0,79 & 0,149 & 0,344 & 0,43 & 0,176 & 0,095 & 0,131 & 0,137 & 0,231 & 0,181 & 0,073 & $-0,162$ & 0,21 \\
\hline CP_INFRA_TI_2 & 0,752 & 0,137 & 0,335 & 0,408 & 0,123 & 0,071 & 0,072 & 0,1 & 0,177 & 0,146 & 0,006 & $-0,187$ & 0,175 \\
\hline CP_INFRA_TI_3 & 0,829 & 0,413 & 0,514 & 0,66 & 0,44 & 0,336 & 0,421 & 0,312 & 0,453 & 0,406 & 0,324 & $-0,06$ & 0,155 \\
\hline CP_INFRA_TI_4 & 0,716 & 0,376 & 0,495 & 0,6 & 0,371 & 0,273 & 0,332 & 0,37 & 0,349 & 0,318 & 0,275 & $-0,012$ & 0,112 \\
\hline CP_OPER_TI_1 & 0,297 & 0,868 & 0,381 & 0,733 & 0,481 & 0,434 & 0,481 & 0,338 & 0,47 & 0,393 & 0,346 & $-0,134$ & 0,18 \\
\hline CP_OPER_TI_2 & 0,338 & 0,899 & 0,399 & 0,77 & 0,473 & 0,438 & 0,48 & 0,359 & 0,434 & 0,404 & 0,321 & $-0,149$ & 0,205 \\
\hline CP_OPER_TI_3 & 0,318 & 0,912 & 0,416 & 0,779 & 0,539 & 0,505 & 0,55 & 0,411 & 0,499 & 0,442 & 0,356 & $-0,088$ & 0,212 \\
\hline CP_OPER_TI_4 & 0,29 & 0,88 & 0,375 & 0,738 & 0,548 & 0,475 & 0,573 & 0,368 & 0,511 & 0,507 & 0,411 & $-0,009$ & 0,138 \\
\hline CP_OPER_TI_5 & 0,376 & 0,864 & 0,357 & 0,745 & 0,564 & 0,491 & 0,598 & 0,405 & 0,5 & 0,56 & 0,381 & $-0,016$ & 0,197 \\
\hline CP_OPER_TI_6 & 0,382 & 0,836 & 0,496 & 0,782 & 0,535 & 0,497 & 0,511 & 0,406 & 0,496 & 0,481 & 0,402 & $-0,083$ & 0,237 \\
\hline CP_RH_TI_1 & 0,394 & 0,281 & 0,813 & 0,576 & 0,406 & 0,338 & 0,356 & 0,397 & 0,358 & 0,366 & 0,342 & $-0,157$ & 0,157 \\
\hline CP_RH_TI_2 & 0,564 & 0,392 & 0,864 & 0,705 & 0,422 & 0,332 & 0,332 & 0,425 & 0,396 & 0,397 & 0,354 & $-0,149$ & 0,187 \\
\hline CP_RH_TI_3 & 0,445 & 0,389 & 0,798 & 0,65 & 0,593 & 0,483 & 0,548 & 0,462 & 0,574 & 0,536 & 0,501 & $-0,169$ & 0,309 \\
\hline CP_RH_TI_4 & 0,478 & 0,462 & 0,862 & 0,724 & 0,574 & 0,51 & 0,494 & 0,562 & 0,518 & 0,466 & 0,467 & $-0,156$ & 0,211 \\
\hline MOD_EFCT_3 & $-0,119$ & $-0,092$ & $-0,189$ & $-0,156$ & $-0,001$ & $-0,011$ & 0,013 & $-0,001$ & $-0,002$ & $-0,024$ & 0,007 & 1 & $-0,348$ \\
\hline GC_APLI_1 & 0,264 & 0,374 & 0,348 & 0,423 & 0,712 & 0,83 & 0,636 & 0,556 & 0,632 & 0,611 & 0,478 & 0,003 & 0,219 \\
\hline GC_APLI_2 & 0,183 & 0,483 & 0,455 & 0,505 & 0,797 & 0,882 & 0,668 & 0,697 & 0,721 & 0,604 & 0,621 & 0,023 & 0,179 \\
\hline GC_APLI_3 & 0,332 & 0,455 & 0,518 & 0,553 & 0,837 & 0,903 & 0,746 & 0,713 & 0,728 & 0,711 & 0,626 & $-0,058$ & 0,276 \\
\hline GC_APLI_4 & 0,184 & 0,554 & 0,395 & 0,525 & 0,74 & 0,839 & 0,687 & 0,588 & 0,643 & 0,588 & 0,55 & $-0,002$ & 0,214 \\
\hline GC_AQUI_2 & 0,26 & 0,516 & 0,409 & 0,528 & 0,715 & 0,641 & 0,798 & 0,5 & 0,637 & 0,644 & 0,441 & $-0,006$ & 0,155 \\
\hline GC_AQUI_3 & 0,304 & 0,613 & 0,399 & 0,593 & 0,707 & 0,616 & 0,824 & 0,502 & 0,613 & 0,593 & 0,458 & 0,044 & 0,141 \\
\hline GC_AQUI_4 & 0,312 & 0,498 & 0,369 & 0,517 & 0,727 & 0,628 & 0,83 & 0,523 & 0,633 & 0,657 & 0,457 & 0,062 & 0,173 \\
\hline GC_AQUI_5 & 0,329 & 0,458 & 0,428 & 0,521 & 0,788 & 0,677 & 0,879 & 0,619 & 0,668 & 0,711 & 0,518 & 0,094 & 0,149 \\
\hline GC_AQUI_6 & 0,282 & 0,461 & 0,446 & 0,516 & 0,798 & 0,692 & 0,887 & 0,632 & 0,662 & 0,703 & 0,586 & $-0,031$ & 0,158 \\
\hline GC_AQUI_7 & 0,231 & 0,483 & 0,515 & 0,541 & 0,787 & 0,692 & 0,822 & 0,623 & 0,692 & 0,646 & 0,618 & $-0,071$ & 0,175 \\
\hline GC_AQUI_8 & 0,316 & 0,544 & 0,472 & 0,583 & 0,799 & 0,697 & 0,821 & 0,655 & 0,697 & 0,697 & 0,594 & $-0,01$ & 0,244 \\
\hline GC_ARMG_1 & 0,281 & 0,434 & 0,511 & 0,523 & 0,746 & 0,637 & 0,602 & 0,91 & 0,604 & 0,592 & 0,636 & 0,016 & 0,161 \\
\hline GC_ARMG_2 & 0,266 & 0,412 & 0,464 & 0,489 & 0,781 & 0,709 & 0,657 & 0,911 & 0,626 & 0,622 & 0,631 & 0,018 & 0,209 \\
\hline GC_ARMG_3 & 0,354 & 0,394 & 0,534 & 0,528 & 0,783 & 0,66 & 0,646 & 0,905 & 0,657 & 0,633 & 0,646 & 0,021 & 0,177 \\
\hline GC_ARMG_4 & 0,291 & 0,365 & 0,512 & 0,485 & 0,757 & 0,673 & 0,59 & 0,873 & 0,649 & 0,575 & 0,669 & $-0,035$ & 0,273 \\
\hline GC_ARMG_5 & 0,257 & 0,335 & 0,459 & 0,439 & 0,749 & 0,631 & 0,601 & 0,859 & 0,623 & 0,634 & 0,676 & $-0,024$ & 0,19 \\
\hline GC_COMP_1 & 0,309 & 0,437 & 0,459 & 0,514 & 0,703 & 0,607 & 0,642 & 0,49 & 0,742 & 0,593 & 0,503 & $-0,039$ & 0,286 \\
\hline GC_COMP_10 & 0,272 & 0,46 & 0,458 & 0,517 & 0,724 & 0,625 & 0,593 & 0,6 & 0,757 & 0,573 & 0,583 & $-0,075$ & 0,172 \\
\hline GC_COMP_2 & 0,264 & 0,426 & 0,495 & 0,509 & 0,806 & 0,73 & 0,685 & 0,643 & 0,813 & 0,699 & 0,602 & 0,033 & 0,225 \\
\hline GC_COMP_3 & 0,329 & 0,398 & 0,495 & 0,51 & 0,77 & 0,653 & 0,655 & 0,627 & 0,801 & 0,628 & 0,58 & $-0,013$ & 0,178 \\
\hline GC_COMP_4 & 0,399 & 0,443 & 0,406 & 0,522 & 0,751 & 0,576 & 0,64 & 0,554 & 0,842 & 0,667 & 0,511 & $-0,033$ & 0,194 \\
\hline GC_COMP_5 & 0,372 & 0,493 & 0,399 & 0,542 & 0,755 & 0,612 & 0,651 & 0,541 & 0,848 & 0,63 & 0,519 & 0,032 & 0,199 \\
\hline GC_COMP_6 & 0,316 & 0,449 & 0,401 & 0,501 & 0,746 & 0,638 & 0,634 & 0,513 & 0,841 & 0,639 & 0,49 & 0,004 & 0,231 \\
\hline GC_COMP_7 & 0,406 & 0,392 & 0,414 & 0,496 & 0,694 & 0,606 & 0,567 & 0,524 & 0,772 & 0,546 & 0,489 & 0,053 & 0,109 \\
\hline GC_COMP_8 & 0,331 & 0,468 & 0,411 & 0,52 & 0,725 & 0,626 & 0,611 & 0,569 & 0,781 & 0,549 & 0,55 & 0,087 & 0,133 \\
\hline GC_COMP_9 & 0,338 & 0,431 & 0,471 & 0,522 & 0,687 & 0,596 & 0,554 & 0,557 & 0,738 & 0,521 & 0,547 & $-0,071$ & 0,174 \\
\hline GC_CRIA_1 & 0,312 & 0,494 & 0,401 & 0,526 & 0,703 & 0,608 & 0,666 & 0,541 & 0,601 & 0,841 & 0,536 & $-0,023$ & 0,179 \\
\hline GC_CRIA_2 & 0,257 & 0,423 & 0,464 & 0,494 & 0,77 & 0,65 & 0,703 & 0,632 & 0,688 & 0,895 & 0,53 & 0,01 & 0,187 \\
\hline GC_CRIA_3 & 0,375 & 0,44 & 0,487 & 0,544 & 0,72 & 0,604 & 0,66 & 0,576 & 0,658 & 0,817 & 0,493 & $-0,05$ & 0,183 \\
\hline GC_PROT_1 & 0,259 & 0,345 & 0,405 & 0,425 & 0,652 & 0,534 & 0,558 & 0,6 & 0,551 & 0,506 & 0,866 & 0,019 & 0,164 \\
\hline GC_PROT_2 & 0,288 & 0,271 & 0,436 & 0,401 & 0,6 & 0,518 & 0,428 & 0,613 & 0,515 & 0,507 & 0,778 & 0,106 & 0,137 \\
\hline GC_PROT_3 & 0,066 & 0,396 & 0,364 & 0,388 & 0,624 & 0,54 & 0,526 & 0,546 & 0,564 & 0,456 & 0,761 & $-0,104$ & 0,11 \\
\hline IMP_ESTG_TI_4 & 0,244 & 0,194 & 0,334 & 0,306 & 0,221 & 0,232 & 0,197 & 0,22 & 0,192 & 0,161 & 0,14 & $-0,454$ & 0,838 \\
\hline IMP_ESTG_TI_5 & 0,073 & 0,136 & 0,11 & 0,142 & 0,167 & 0,138 & 0,146 & 0,167 & 0,152 & 0,183 & 0,079 & $-0,151$ & 0,784 \\
\hline IMP_ESTG_TI_6 & 0,17 & 0,213 & 0,181 & 0,24 & 0,232 & 0,254 & 0,163 & 0,175 & 0,242 & 0,193 & 0,191 & $-0,233$ & 0,864 \\
\hline
\end{tabular}

